\title{
Structural Interactions of Hydrogen with Bulk Amorphous Microstructures in Metallic Systems: Understanding the Role of Partial Crystallinity on Permeation and Embrittlement
}

K. Brinkman

E. Fox

P. Korinko

May 2010

Materials Science and Technology Directorate Savannah River National Laboratory Aiken, SC 29808

This document was prepared in conjunction with work accomplished under Contract No. DE-AC09-08SR22470 with the U.S. Department of Energy.

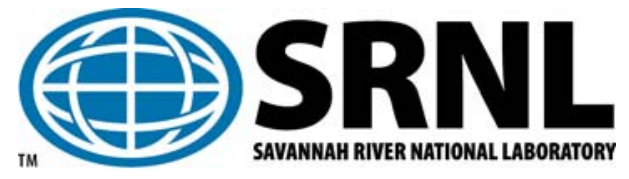


SRNS-STI-2008-00133

Revision 1

\section{DISCLAIMER}

This work was prepared under an agreement with and funded by the U.S. Government. Neither the U.S. Government or its employees, nor any of its contractors, subcontractors or their employees, makes any express or implied: 1 . warranty or assumes any legal liability for the accuracy, completeness, or for the use or results of such use of any information, product, or process disclosed; or 2. representation that such use or results of such use would not infringe privately owned rights; or 3. endorsement or recommendation of any specifically identified commercial product, process, or service. Any views and opinions of authors expressed in this work do not necessarily state or reflect those of the United States Government, or its contractors, or subcontractors.

This document was prepared in conjunction with work accomplished under Contract No. DE-AC09-08SR22470 with the U.S. Department of Energy. 
Keywords: membrane, hydrogen, separation membrane

Retention: permanent

\section{Structural Interactions of Hydrogen with Bulk Amorphous Microstructures in Metallic Systems: Understanding the Role of Partial Crystallinity on Permeation and Embrittlement}

K. Brinkman

E. Fox

P. Korinko

May 2010

Materials Science and Technology Directorate Savannah River National Laboratory Aiken, SC 29808

This document was prepared in conjunction with work accomplished under Contract No. DE-AC09-08SR22470 with the U.S. Department of Energy. 


\section{EXECUTIVE SUMMARY}

This report details experiments on the hydrogen permeation behavior of partially crystalline bulk metallic glasses sponsored by Laboratory Directed Research and Development, Plant Directed Research and Development and EERE-DOE programs focused on the production and delivery of hydrogen. A major focus area of metallic glasses is their use as hydrogen separation membranes to replace the high cost of palladium alloy membranes. An obstacle to their large scale employment in membrane separations processes is the unknown crystallization/devitrification behavior at elevated temperaratures and times and subsequent impact on material properties including hydrogen permeation. This project sought to address this fundamental research need by examining the crystallization behavior both structurally as well as the impact on gas transport in these materials.

The permeation of hydrogen through metallic membranes is a multi-function process involving adsorption, dissociation, diffusion, and recombination and desorption. Two of the inherent materials properties that play a critical role in these processes are the solubility and diffusivity of hydrogen in the material. Though the long range structure is "disordered" in amorphous materials, diffusion has been thought to occur through interstitial mechanisms similar to crystalline materials. The solubility however, should be enhanced in amorphous materials due to the greater density of defects and distribution of sorption sites which can be occupied by hydrogen over a wide range of potential energies. For materials which are partially crystalline one of the critical factors determing the diffusivity, solubility and ultimately the permeability is the role the secondary crystalline phase play in the composite structure. It has also been shown that the nature of the crystalline phase depends on the gas environment of crystallization or hydrogen content of the material. In order to systematically study the impact of partial crystallinity in these materials, a variety of metallic glass alloys were procured from commercial sources to obtain five $\mathrm{Fe}, \mathrm{Ni}, \mathrm{Co}$ and $\mathrm{Zr}$ based metallic glasses. These samples were subjected to Differential Scanning Calorimetry (DSC) as a function of temperature under different gas compositions in order to quantify phase transition temperature and energies. X-ray diffraction analysis was also performed as a function of temperature and gas compositon. Finally, hydrogen permeation properties were measured in two measurement modes i) in-situ where crystallization took place during gas phase hydrogen permeation at elevated temperatures and ii) ex-situ where pre-crystallized sample's hydrogen permeation properties were measured and compared with the as-received amorphous materials at ambient temperature using an electrochemical method.

The temperatures, energy release and structure of crystalline phases as a function of temperature and gas composition were identified by DSC and XRD for the five Bulk Metallic Glass (BMG) materials. The 2826 alloy was chosen for further kinetic studies due to avalibility of literature data on kinetic crystallization parameters for comparision. Kinetic rate parameters were obtained from DSC experiments and Avrami kinetic expressions were used to compare experimental crystallization kinetics with literature. The baseline permeation properties using evaluated using both electrochemical method and gas phase permeation methods. Values for electrochemical flux were $3 \times 10^{-11} \mathrm{~mol} / \mathrm{m} \mathrm{s}$ for 2826 alloy measured at $25^{\circ} \mathrm{C}$ and $-1 \mathrm{~mA} / \mathrm{cm}^{2}$ charging current compared to $3 \times 10^{-9} \mathrm{~mol} / \mathrm{m} \mathrm{s}$ for a pure Pd metal standard. 2826 samples crystallized at $430^{\circ} \mathrm{C}$ for 1 minute were measured for comparison resulting in flux values of $2.6 \times 10^{-12} \mathrm{~mol} / \mathrm{m} \mathrm{s}$. Diffusivity values for the amorphous and crystalline samples determined from hydrogen current transients were comparable and the reduction in permeation is thus attributed to reduced hydrogen solubility in the crystalline phase. Experiments looking at "in-situ" crystallization were inconclusive due to scatter in the hydrogen flux data represented by the pressure versus time plot. 


\section{TABLE OF CONTENTS}

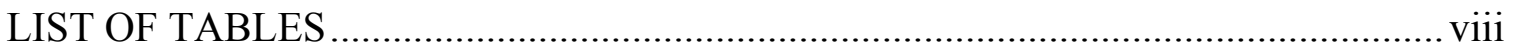

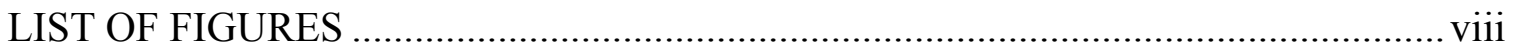

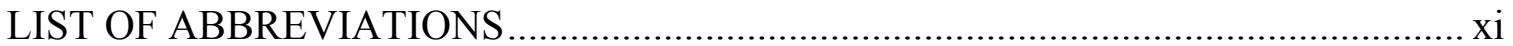

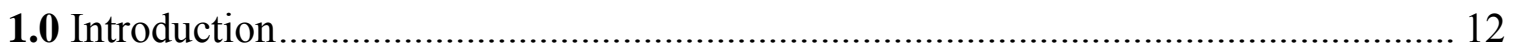

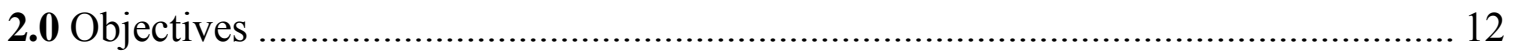

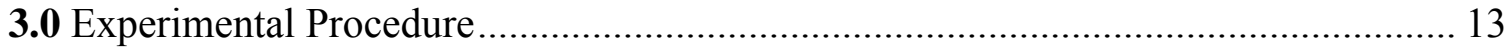

3.1 Selection of Metallic Glass Compositions............................................................ 13

3.2 Partial Crystallization of Metallic Glass Samples ................................................... 13

3.3 Property Measurements ......................................................................................... 14

3.3.1 XPS (X-ray Photoelectron Spectroscopy) ………………………………...... 14

3.3.2 X-Ray Diffraction Analysis ........................................................................... 14

3.3.3 Differential Scanning Calorimetry (DSC)..................................................... 15

3.3.4 Electrochemical Hydrogen Permeation............................................................ 15

3.3.5 Gas Phase Hydrogen Permeation ............................................................... 16

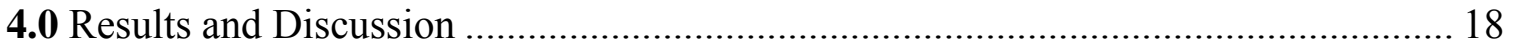

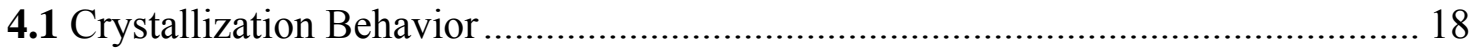

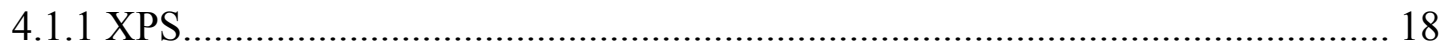

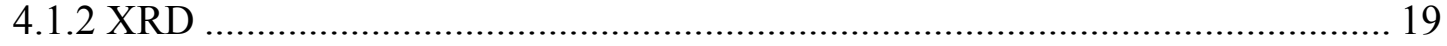

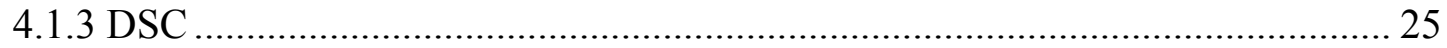

4.2 Hydrogen Flux Measurement ........................................................................... 31

4.2.1 Electrochemical Permeation........................................................................... 31

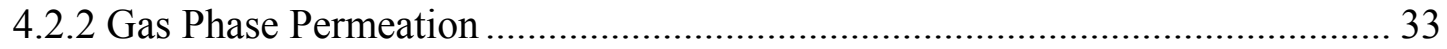

4.2.3 Ex-situ crystallized samples: Electrochemical characterization ....................... 34

4.2.4 In-Situ crystallization: Gas Permeation Rig................................................... 35

4.3 Discussion \& Literature comparison ................................................................. 36

5.0 Fundamental Influence of Materials Chemistry ...................................................... 38

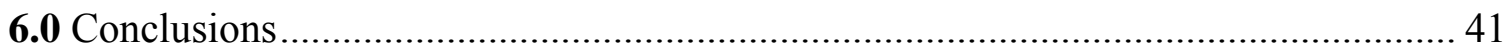

7.0 Suggestions for Future Work/Path Forward ............................................................. 41

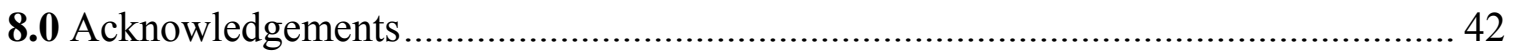

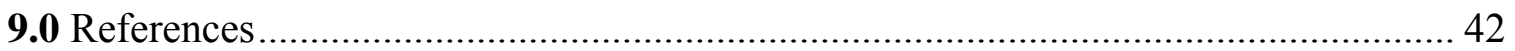




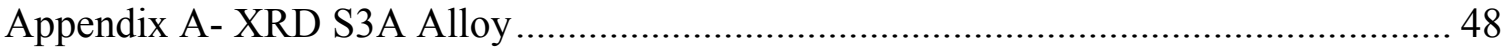

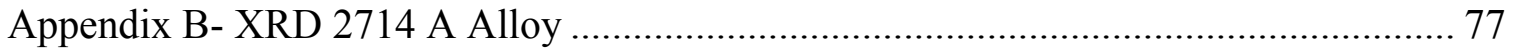

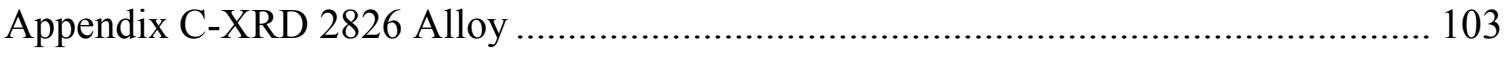

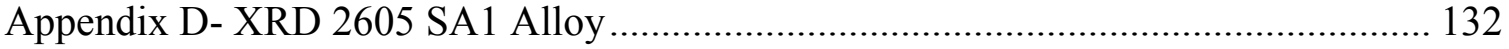




\section{LIST OF TABLES}

Table 1 Alloy composition investigated, purchased from Metglas company Inc.. ..................... 19

Table 2 Comparison of metallic glass surface oxide to candidate materials............................... 19

Table 3 Comparison of $\mathrm{O} / \mathrm{Fe}$ ratio of metallic glass surface oxide …....................................... 19

Table 4 Summary of identified phases for S3A Metallic Glass crystallization experiments ........ 20

Table 5 Percent Crystallinity S3A alloy as a Function of Temperature and Atmosphere............. 20

Table 6 Summary of identified phases for 2714A Metallic Glass crystallization experiments .... 21

Table 7 Percent Crystallinity 2714A alloy as a Function of Temperature and Atmosphere ........ 21

Table 8 Summary of identified phases for 2826 Metallic Glass crystallization experiments ....... 22

Table 9 Percent crystallinity $2714 \mathrm{~A}$ alloy as a function of temperature and atmosphere ............ 23

Table 10 Percent crystallinity as a function of time (0 to 3-hr) at $400{ }^{\circ} \mathrm{C}$ in $\mathrm{He}$.......................... 23

Table 11 Summary of identified phases for 2605 SA1 Metallic Glass crystallization experiment 23

Table 12 Percent crystallinity 2605 SA1 alloy as a function of temperature and atmosphere ...... 24

Table 13 Summary of identified phases for Zr (Howmet Inc.) Metallic Glass crystallization

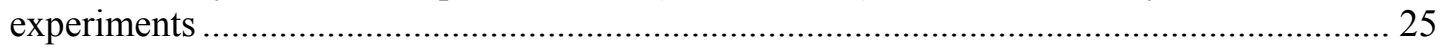

Table 14 DSC determined crystallization temperatures and compositions ................................. 26

Table 15 Permeation data comparison between electrochemical techniques and gas phase

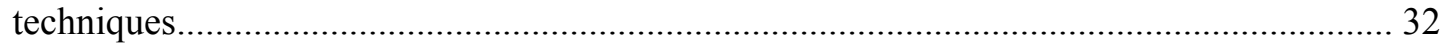

Table 16 Amorphous vs. Crystalline 2826 Alloy Electrochemical Permeability (P mol/m s), Diffusivity $(\mathrm{D} \mathrm{m} / \mathrm{s})$, and Solubility $\left(\mathrm{S} \mathrm{mol} / \mathrm{m}^{3}\right)$.

\section{LIST OF FIGURES}

Figure 1 Temperature versus time traces for vacuum heating metglas alloy samples followed by Argon quenching in order to achieve partial crystallization a) $430^{\circ} \mathrm{C} 1$ minute, b) $400^{\circ} \mathrm{C} 1$ minute, c) $400^{\circ} \mathrm{C}$ for 1 hour

Figure 2 X-ray diffraction (XRD) of as-received amorhous 2826 metglass material and samples after annealing a) $400^{\circ} \mathrm{C}$ for $1 \mathrm{~min}$ and 1 hour, b) $430^{\circ} \mathrm{C}$ for 1 minute showing increased level of crystallinity

Figure 3 Profile fitting the amorphous portion in the $400{ }^{\circ} \mathrm{C}$ in $\mathrm{He}$ scan. The remaining area is the crystalline content. 
Figure 4 Hydrogen flux of Pd membrane ( 25 microns) at $470^{\circ} \mathrm{C}$ with hydrogen supplied to feed side at steady state and time resolved decrease in flux when argon is supplied to feed side. 17

Figure 5 Pressure (torr) versus time saturation plot for Fe, $\mathrm{Co}$ and $\mathrm{Zr}$ based Alloys. The slope of the pressure versus time plot is proportional to the hydrogen flux through the membrane $\mathrm{dP} / \mathrm{dt}(\mathrm{mol} / \mathrm{s})$, flux in $\mathrm{mol} / \mathrm{m}^{2} \mathrm{sPa}^{1 / 2}$ calculated via equation 3 .

Figure 6 X-ray Photoelectron Spectra (XPS) for surface of 2826 metallic glass. Spectra were taken using $\mathrm{Mg} \mathrm{Ka}(h \mathrm{n}=1253.6 \mathrm{eV})$ x-rays and corrected for charging using the $\mathrm{C} 1 \mathrm{~s}$ adventitous carbon as $284.6 \mathrm{eV}$. Pass energy is $160 \mathrm{eV}$. *These peaks are examined at higher resolution in Figure 7.

Figure 7 X-ray Photoelectron Spectra (XPS) for Fe 2p and O 1s regions of surface of metallic glass. Peak maxima are labeled. Spectra were taken of the as received shiny side of the metallic glass using $\mathrm{Mg} \mathrm{Ka}(h \mathrm{n}=1253.6 \mathrm{eV})$ x-rays and charge corrected using $\mathrm{C} 1 \mathrm{~s}$ adventitous carbon as $284.6 \mathrm{eV}$. Pass energy is $40 \mathrm{eV}$

Figure $8 \mathrm{X}$-ray fluorescence scan of the $\mathrm{Zr}$ metallic glass (Howmet Inc.)

Figure 9 Differential scanning calorimetry (DSC) performed on metglass alloys at $10^{\circ} \mathrm{C} / \mathrm{min}$ under Argon atmosphere $30 \mathrm{sccm}$ from $25^{\circ} \mathrm{C}$ to $590^{\circ} \mathrm{C}$ on a) $2714 \mathrm{~A}$, b) $2605 \mathrm{~S} 3 \mathrm{~A}$, c) 2826 , d) 2605SA1

Figure 10 DSC scan of 2826 alloy at $10^{\circ} \mathrm{C} / \mathrm{min}$ under Argon gas and $96 \%$ argon $/ 4 \%$ hydrogen gas mixture. Transition T1 to crystalline phase FeNi (argon $421^{\circ} \mathrm{C} \Delta \mathrm{H}=28.7 \mathrm{~J} / \mathrm{g}$ : $\operatorname{argon} / \mathrm{H}_{2} \mathrm{mix}$ $422^{\circ} \mathrm{C} \Delta \mathrm{H}=26.3 \mathrm{~J} / \mathrm{g}$ ); Transition $\mathrm{T} 2$ crystaline phase $\mathrm{Fe}_{11.5} \mathrm{Ni}_{11.5} \mathrm{~B}_{6}\left(\operatorname{argon} 549^{\circ} \mathrm{C} \Delta \mathrm{H}=30.3\right.$ $\mathrm{J} / \mathrm{g}: \operatorname{argon} / \mathrm{H}_{2} \operatorname{mix} 549^{\circ} \mathrm{C} \Delta \mathrm{H}=36.2 \mathrm{~J} / \mathrm{g}$ ).

Figure $11 \mathrm{DSC}$ of 2826 metglass alloy in argon at 5,10 and $20^{\circ} \mathrm{C} /$ minute heating rate showing an upward shift in peak crystallization temperataure wth increasing heating rate.

Figure 12 Activation energy determination for 2826 alloy crystallization: plot of $1 / \mathrm{T}$ versus $\ln \left(\mathrm{C} / \mathrm{T}^{2}\right) .355 \mathrm{~kJ} / \mathrm{mol}$ compares well with literature for comparable compositions (350 $\mathrm{kJ} / \mathrm{mol}$ ) [30].

Figure 13 Fraction crystallized from experimentally determined parameters and equations 5, 6. Isothermal DSC crystallization data at $400^{\circ} \mathrm{C}$ included for comparison.

Figure 14 Time to $1 / 2$ fraction of crystallization at a given temperature from equations $5 \& 6$ as compared to literature data from Morris [30].

Figure 15 Current proportional to hydrogen flux at the anode versus time for a) 2605S3A and b) 2826 alloy with charging sequence of $-7,-1$ and $-0.1 \mathrm{~mA} / \mathrm{cm}^{2}$.

Figure 16 Nernst equation applied to charging conditions of $\left(-1 \mathrm{~mA} / \mathrm{cm}^{2}\right)$ where $-200 \mathrm{mV}$ was applied to the membrane on one side resulting in an effective pressure differential driving force $\Delta \mathrm{P}^{1 / 2}$ of $31 \mathrm{~Pa}^{1 / 2} ; 2826$ flux of $3 \times 10^{-11} \mathrm{~mol} / \mathrm{ms}$ is converted to $9.7 \mathrm{X} 10^{-13} \mathrm{~mol} / \mathrm{m} \mathrm{s} \mathrm{Pa}^{1 / 2}$

Figure 172826 amorphous material hydrogen permeation transient used with equation 9 in order to calculate diffusivity $\mathrm{D}=2.5 \times 10^{-11} \mathrm{~m}^{2} / \mathrm{s}\left(\mathrm{Pd}\right.$ metal at $\left.25^{\circ} \mathrm{C} 3.3 \times 10^{-11} \mathrm{~m}^{2} / \mathrm{s}\right)[34]$ 
Figure 18 Pressure in the dynamic hydrogen gas permeation measurement conducted at 350,380 and $400^{\circ} \mathrm{C}$ as a function of time.

Figure 19 Current versus time for amorphous 2826 sample and sample crystallized at $430^{\circ} \mathrm{C}$ for 1 minute under charging condition of $-7 \mathrm{~mA} / \mathrm{cm}^{2}$ showing a near order of magnitude decrease in the hydrogen flux current with increasing crystallinity of the membrane.

Figure $20 \mathrm{XRD}$ pattern of amorphous 2826 alloy and sample annealed to $430^{\circ} \mathrm{C}$ for 1 minute in vacuum, followed by argon quenching. $\mathrm{Fe}_{0.5} \mathrm{Ni}_{0.5} \mathrm{FCC}$ alloy ordered tetragonal superlattice with $\mathrm{a}=2.53 \mathrm{~A}, \mathrm{c}=3.58 \mathrm{~A}$

Figure 21 a) Dynamic gas flux measurement of 2826 alloy at $400^{\circ} \mathrm{C}$ as a function of time b) XRD spectra at $400 \mathrm{oC}$ as a function of time. 36

Figure 22 Nanoscale crystalline precipitates inside of an amorphous matrix[36].

Figure 23 Hydrogen flux (X $\left.10^{-7} \mathrm{~mol} / \mathrm{m}^{2} \mathrm{~s}\right)$ for 25 micron thick metglass ribbons of 2826 used in this study versus $\mathrm{Fe}_{40} \mathrm{Ni}_{38} \mathrm{Mo}_{4} \mathrm{~B}_{18}$ composition used by Dos Santos[33]. Plot displays same order of magnitude maximum hydrogen flux but orders of magnitude difference in the time to maximum flux proportional to hydrogen diffusivity $D\left(\mathrm{~m}^{2} / \mathrm{s}\right)$ and solubility $S\left(\mathrm{~mol} / \mathrm{m}^{3}\right)$ in the material.

Figure 24 DTA of a) LM110 and b) LM110a Zr based metglass materials

Figure 25 XRD of LM100 and LM100a material.

Figure 26 Hydrogen permeation (via gas permeation with GC detection) versus time of LM100 and LM100a alloy as compared to Pd standard. 
SRNS-STI-2008-00133

Revision 1

\section{LIST OF ABBREVIATIONS}

SRNL Savannah River National Laboratory

SRS

Savannah River Site

XRD

X-ray Diffraction

$\mathrm{BMG}$

Bulk Metallic Glass

XPS

X-ray Photoelectron Spectroscopy

DSC

Differential Scanning Calorimetry 


\subsection{Introduction}

The development of metallic glasses in bulk form has led to a resurgence of interest into the utilization of these materials for a variety of applications. A potentially exciting application for these bulk metallic glass (BMG) materials is their use as composite membranes to replace high cost $\mathrm{Pd} / \mathrm{Pd}$-alloy membranes for enhanced gas separation processes. One of the major drawbacks to the industrial use of $\mathrm{Pd} / \mathrm{Pd}$-alloy membranes is that during cycling above and below a critical temperature an irreversible change takes place in the palladium lattice structure which can result in significant damage to the membrane. Furthermore, the cost associated with Pd-based membranes is a potential detractor for their continued use and BMG alloys offer a potentially attractive alternative. Several BMG alloys have been shown to possess high permeation rates, comparable to those measured for pure Pd metal. In addition, high strength and toughness when either in-situ or ex-situ second phase dispersoids are present. Both of these properties- high permeation and high strength/toughness potentially make these materials attractive for gas separation membranes that could resist hydrogen "embrittlement". However, a fundamental understanding of the relationship between partially crystalline "structure"/devitrification and permeation/embrittlement in these BMG materials is required in order to determine the operating window for separation membranes and provide additional input to the material synthesis community for improved alloy design. This project aims to fill the knowledge gap regarding the impact of crystallization on the permeation properties of metallic glass materials.

\subsection{Objectives}

The objectives of this study are to i) determine the crystallization behavior in different gas environments of $\mathrm{Fe}$ and $\mathrm{Zr}$ based commercially available bulk metallic glass and ii) quantify the effects of partial crystallinity on the hydrogen permeation properties of these metallic glass membranes. 


\subsection{Experimental Procedure}

\subsection{Selection of Metallic Glass Compositions}

Metallic glass samples with a nominal thickness of 25 microns in 2 inch wide ribbons were purchased from commercial sources (MetGlas Inc., Conway SC) with the compositions given in Table 1.

Table 1. Alloy composition investigated, purchased from Metglas company Inc.

\begin{tabular}{||c|c|c|c|c|c|c|c||}
\hline Alloy & Fe & B & Cr & Mo & Co & Ni & Si \\
\hline 2605S3A & $85-95 \%$ & $1-5 \%$ & $1-5 \%$ & $0 \%$ & $0 \%$ & $0 \%$ & $1-5 \%$ \\
\hline 2714A & $7-13 \%$ & $1-5 \%$ & $0 \%$ & $0 \%$ & $75-90 \%$ & $1-5 \%$ & $7-13 \%$ \\
\hline 2826 & $40-50$ & $1-5 \%$ & $0 \%$ & $5-10 \%$ & $0.3 \%$ & $40-50 \%$ & $0 \%$ \\
\hline 2605SA1 & $85-95 \%$ & $1-5 \%$ & $0 \%$ & $0 \%$ & $0.2 \%$ & $0.2 \%$ & $5-10 \%$ \\
\hline Zr Alloy & proprietary & & & & & & \\
\hline
\end{tabular}

\subsection{Partial Crystallization of Metallic Glass Samples}

Metglass ribbon samples were heated under vacuum to elevated temperatures for various times and quenched under argon to achieve different degrees of partial crystallinity. Figure 1 displays the temperature versus time traces for the 2826 alloy heated to temperatures near $400^{\circ} \mathrm{C}$ for various times. The X-ray diffraction determined crystallinity of these samples is shown in figure 2 as compared to the as-received amorphous material.

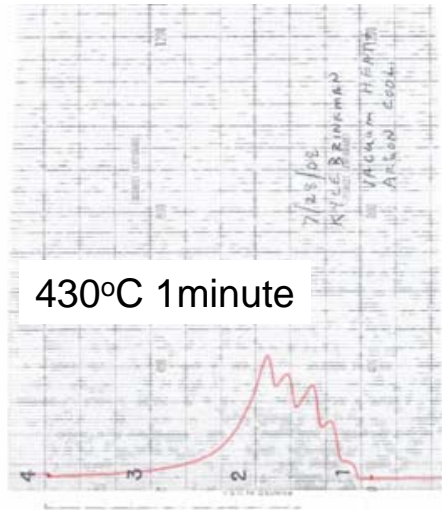

a)

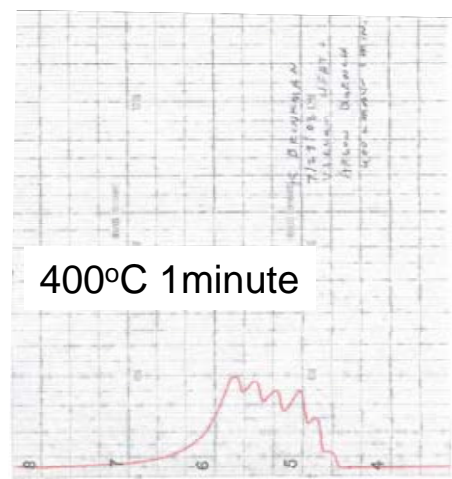

b)

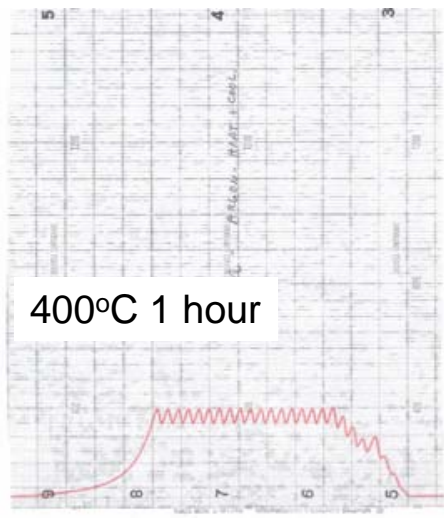

c)

Figure 1. Temperature versus time traces for vacuum heating metglas alloy samples followed by Argon quenching in order to achieve partial crystallization a) $430^{\circ} \mathrm{C} 1$ minute, b) $400^{\circ} \mathrm{C} 1$ minute, c) $400^{\circ} \mathrm{C}$ for 1 hour 


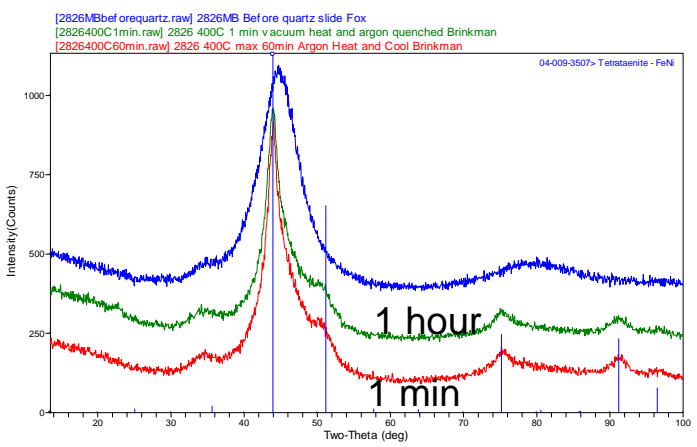

a)

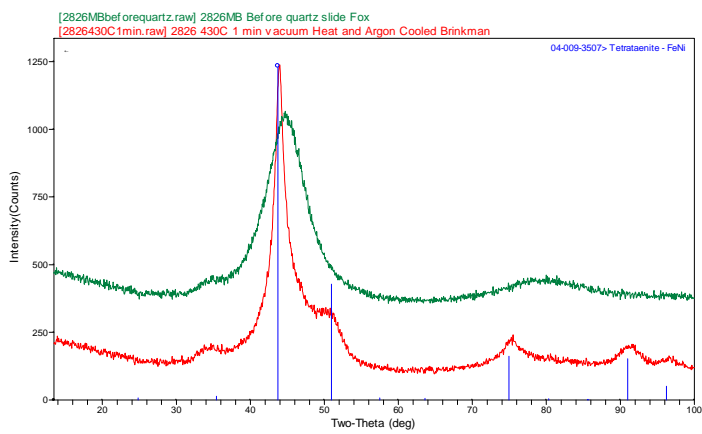

b)

Figure 2. X-ray diffraction (XRD) of as-received amorhous 2826 metglass material and samples after annealing a) $400^{\circ} \mathrm{C}$ for $1 \mathrm{~min}$ and 1 hour, b) $430^{\circ} \mathrm{C}$ for 1 minute showing increased level of crystallinity

\subsection{Property Measurements}

This section provides a general discussion of the methods used to characterize the materials, perform X-ray diffraction (XRD) analyses, determine the crystallization behavior via Differential Scanning Calorimetry (DSC), and measure the hydrogen permeation properties.

\subsubsection{X-ray Photoelectron Spectroscop) (XPS)}

$\mathrm{X}$-ray photoelectron spectroscopy (XPS) is a surface analysis technique that uses incident X-rays and emitted electrons to determine the elemental composition and electronic state of elements in the surface (typically top $10 \mathrm{~nm}$ ) of the material. Spectra were taken of the as-received shiny side of the metallic glass using $\mathrm{Mg} \mathrm{Ka}(h \mathrm{n}=1253.6 \mathrm{eV})$ x-rays and charge corrected using $\mathrm{C} 1 \mathrm{~s}$ adventitous carbon as $284.6 \mathrm{eV}$ using a pass energy of $40 \mathrm{eV}$.

\subsubsection{X-Ray Diffraction Analysis (XRD)}

Representative samples of the as-purchased metallic glass ribbons were submitted to SRNL Analytical Development for XRD analysis. Samples were initially characterized from 10 to 90 degrees two theta on X-ray diffraction data (XRD) were collected on a theta-theta PANalytical X'Pert Pro X-ray diffractometer using an Anton Paar HTK 1200 high temperature attachment. Samples which were intentionally crystallized were characterized by XRD to determine the degree of crystallinity. In addition, in-situ XRD was performed on the samples from 25 to $600^{\circ} \mathrm{C}$ using a high temperature stage with flowing $\mathrm{He}$, Air and $\mathrm{He} 96 \%, \mathrm{H}_{2} 4 \%$ gas mixtures in order to examine phase transformation behavior. The degree of crystallintity was estimated incorporating several assumptions:

1) The initial metallic glass is amorphous, i.e., it doesn't have any crystallinity.

2) The full width half $\max (\mathrm{FWHM})$ of the amorphous component is constant. This is normally the case.

The percent crystallinity was determined in all three atmospheres from 350 to $710^{\circ} \mathrm{C}$ and in isothermal scans in $\mathrm{He}$ at $400^{\circ} \mathrm{C}$. The metallic glasses were typically amorphous below 300 $350^{\circ} \mathrm{C}$. The amorphous "hump" in the $25^{\circ} \mathrm{C}$ HTXRD scans were profile fitted using the pseudovoight (combination Gaussian and Lorentzian) function in the Jade software to determine their full width half maximum (FWHM). The FWHM for the amorphous reflection in the apparently non-crystalline scans up to $\sim 300^{\circ} \mathrm{C}\left(\mathrm{H}_{2} / \mathrm{He}\right.$ and air $)$ or $350^{\circ} \mathrm{C}(\mathrm{He})$ was also measured 
and had the same relative value as the $25^{\circ} \mathrm{C}$ run. This confirms that devitrification had not started. Using this FWHM, the integrated area for the amorphous component in the remaining crystalline scans was determined. The percent crystallinity was calculated using the simple relationship:

$\%$ crys $=100 *($ total peak area - amorphous area $) /$ total peak area

An example of this amorphous fraction fitting process is shown in Figure 3. Because of the uncertainty in measuring the integrated areas, the estimated error for the $\%$ crystallinity determination is $\pm 10 \%$.

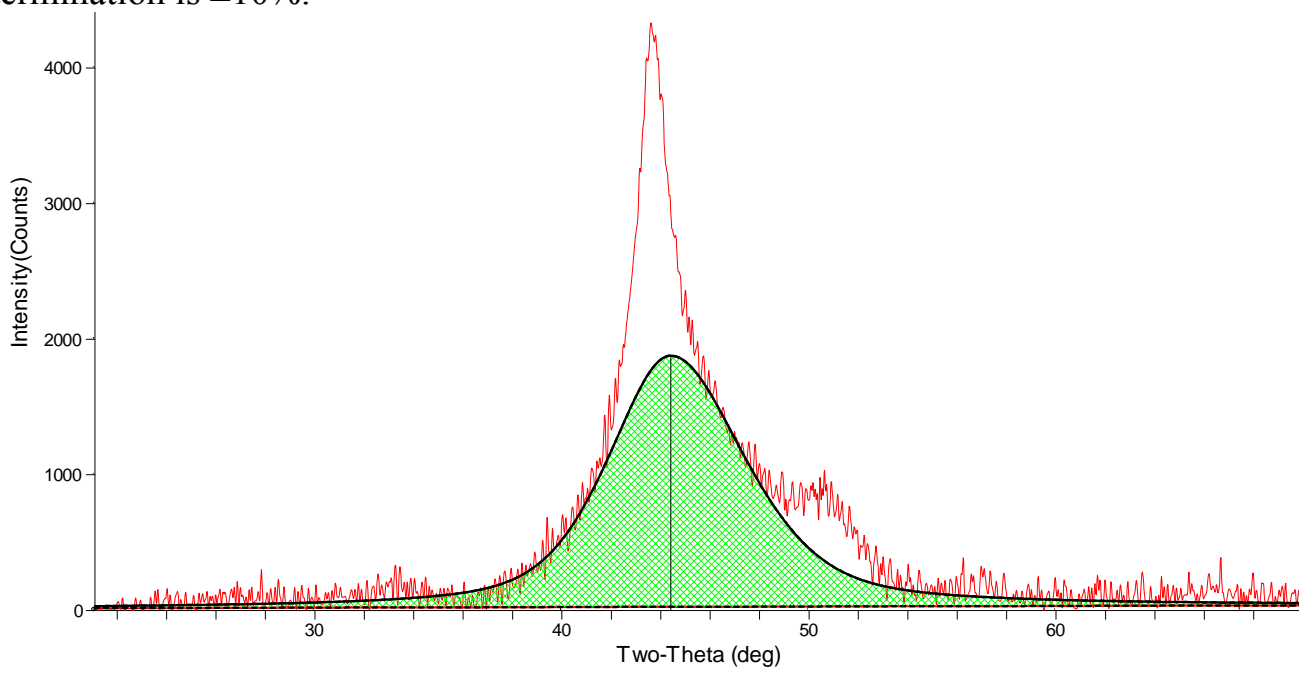

Figure 3. Profile fitting the amorphous portion in the $400{ }^{\circ} \mathrm{C}$ in He scan. The remaining area is the crystalline content.

\subsubsection{Differential Scanning Calorimetry (DSC)}

To examine the temperature and energy released upon crystallization, differential scanning calorimetry was used. A 910 model TA Instruments DSC was used to evaluate crystallization temperatures at scan rates of $10^{\circ} \mathrm{C} / \mathrm{min}$ from $25^{\circ} \mathrm{C}$ up to $590^{\circ} \mathrm{C}$ (up to $1000^{\circ} \mathrm{C}$ with differential thermal analysis or DTA attachment) in argon and argon $96 \%-\mathrm{H}_{2} 4 \%$ gas flowing at $30 \mathrm{sccm}$. The instrument was calibrated using an indium standard and the nominal metallic glass sample mass was $\sim 8 \mathrm{mg}$.

\subsubsection{Electrochemical Hydrogen Permeation}

The ambient temperature hydrogen gas permeation properties were investigated using an electrochemical hydrogen permeation setup based on the ASTM G148-7 [1,2]. A 0.1M NaOH solution was used with platinum counter electrodes and standard calomel reference electrodes (SCE). Cathode charging currents were varied from $-0.1 \mathrm{~mA} / \mathrm{cm}^{2}$ to $-7 \mathrm{~mA} / \mathrm{cm}^{2}$ with anode detection potential fixed at $200 \mathrm{mV}$ (SCE). The area available for permeation was $3.12 \mathrm{~cm}^{2}$. After establishing a stable baseline, the initiation of cathode charging leads to an increase in the anode current which is proportional to the hydrogen flux $\left(\mathrm{mol} / \mathrm{m}^{2} \mathrm{~s}\right)$ through the membrane described in equation 1 .

$$
J S S=\frac{J / A}{F}
$$


Where Jss $=$ steady state flux $\mathrm{mol} / \mathrm{m}^{2} \mathrm{~s}, \mathrm{~J}=$ steady state current $(\mathrm{A}), \mathrm{A}=$ permeation area $\left(\mathrm{m}^{2}\right)$, $\mathrm{F}=$ Faraday's constant $9.6 \times 10^{4} \mathrm{C} / \mathrm{mol}$.

The hydrogen permeation rate $\left(\mathrm{mol} / \mathrm{m}^{*} \mathrm{~s}\right)$ is obtained by the product of Jss with the sample thickness as described in equation 2 .

$$
P=J_{S S} * L
$$

where $\mathrm{P}=$ hydrogen permeation rate $(\mathrm{mol} / \mathrm{m} * \mathrm{~s}), \mathrm{L}=$ sample thickness $25 \times 10^{-6} \mathrm{~m}(25 \mu \mathrm{m})$.

\subsubsection{Gas Phase Hydrogen Permeation}

The flux and permeability of a material of a given membrane material are readily determined experimentally and the following section describes two methods of membrane characterization currently employed at SRNL i) gas permeation in vacuum system and ii) flow through system with GC detection.

\subsubsection{1_Gas permeation in vacuum system}

Permeation test samples are typically sealed by compressing them between two VCR fittings which are then connected to a standard 2.12" CF flange and helium leak tested to confirm leakage flow lower than $1 \times 10^{-7} \mathrm{std} \mathrm{cc} / \mathrm{second}$ at 1atmosphere pressure. Measurement of the steady state permeation flux are conducted under sub-atmospheric pressures (400 to 700 Torr) but at values typically used at the Savannah River Site for hydrogen isotope purification. The slope of the saturation data in Torr/s can be converted into $\mathrm{mol} \mathrm{H}_{2} / \mathrm{s}$ via the ideal gas equation $\mathrm{PV}=\mathrm{nRT}$ with the known expansion volume of the system. The flux $\mathrm{J}$ is then given by equation 3 .

$\mathrm{J}=\mathrm{K} /\left(\mathrm{A} * \mathrm{P}^{1 / 2}\right)$

Where $\mathrm{J}=$ hydrogen flux $\left(\mathrm{mol} / \mathrm{m}^{2} \mathrm{~s} \mathrm{~Pa}^{1 / 2}\right), \mathrm{K}=$ slope $\mathrm{dP} / \mathrm{dt}$ in $(\mathrm{mol} / \mathrm{s}), \mathrm{A}=$ permeation area $\left(\mathrm{m}^{2}\right)$, $\mathrm{P}=$ feed pressure in pascals $(\mathrm{Pa})$. Figure 5 displays the permeation rates in terms of pressure rise of metallic glass samples evaluated by this method.

\subsubsection{Flow through system with GC detection}

An additional membrane permeation apparatus consisting of gas flow controls supplying a mixture (hydrogen, argon, plus contaminant of interest) to the feed side and $100 \%$ argon to the permeate side at atmospheric pressure on both sides of the membrane. The hydrogen content and quality in the permeate side is quantified with gas chromatography using a molecular sieve $5 \mathrm{~A}^{\circ}$ column and a thermal conductivity detector. The hydrogen flux $\mathrm{J}$, is calculated from the percentage of hydrogen present in the argon sweep.

$\mathrm{J}=\left(\mathrm{F} * \% \mathrm{H}_{2} / 100\right) /\left(\mathrm{R} * \mathrm{~T} * \mathrm{~A} * \mathrm{P}^{1 / 2}\right)$

Where $\mathrm{J}$ is the molar flux of hydrogen $\mathrm{mol} / \mathrm{m}^{2} \mathrm{~s} \mathrm{~Pa}^{1 / 2}, \mathrm{~F}$ is the flow rate $(\mathrm{L} / \mathrm{s})$ of argon sweep gas, $\mathrm{R}$ is the gas constant, $\mathrm{T}$ is the gas temperature, $\mathrm{A}$ is the membrane area $\left(\mathrm{m}^{2}\right)$ and $\mathrm{P}^{1 / 2}$ is the square root of the hydrogen pressure difference between feed and permeate membrane sides. Both of these techniques allow for membrane performance to be evaluated with gas phase contaminants present. Figure 4 shows the hydrogen flux from Pd membrane determined using the flow through 
membrane reactor with GC detection depicting flux values on the order of $4 \times 10^{-9} \mathrm{~mol} / \mathrm{m} \mathrm{s} \mathrm{Pa}^{1 / 2}$ which compares well with standard literature values [3].

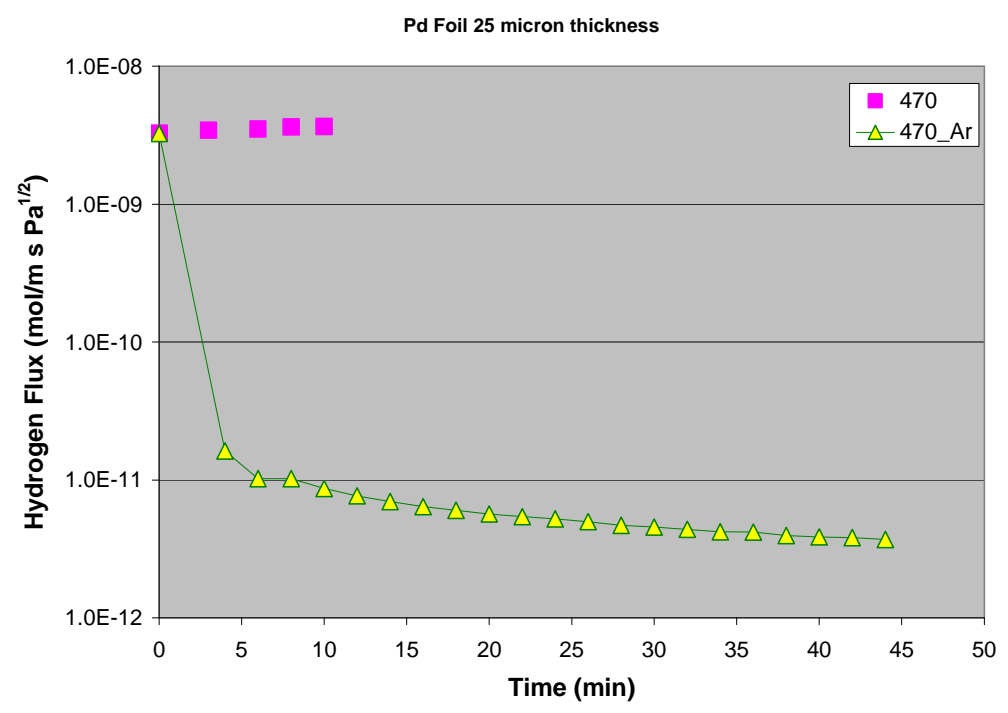

Figure 4. Hydrogen flux of Pd membrane ( 25 microns) at $470^{\circ} \mathrm{C}$ with hydrogen supplied to feed side at steady state and time resolved decrease in flux when argon is supplied to feed side.

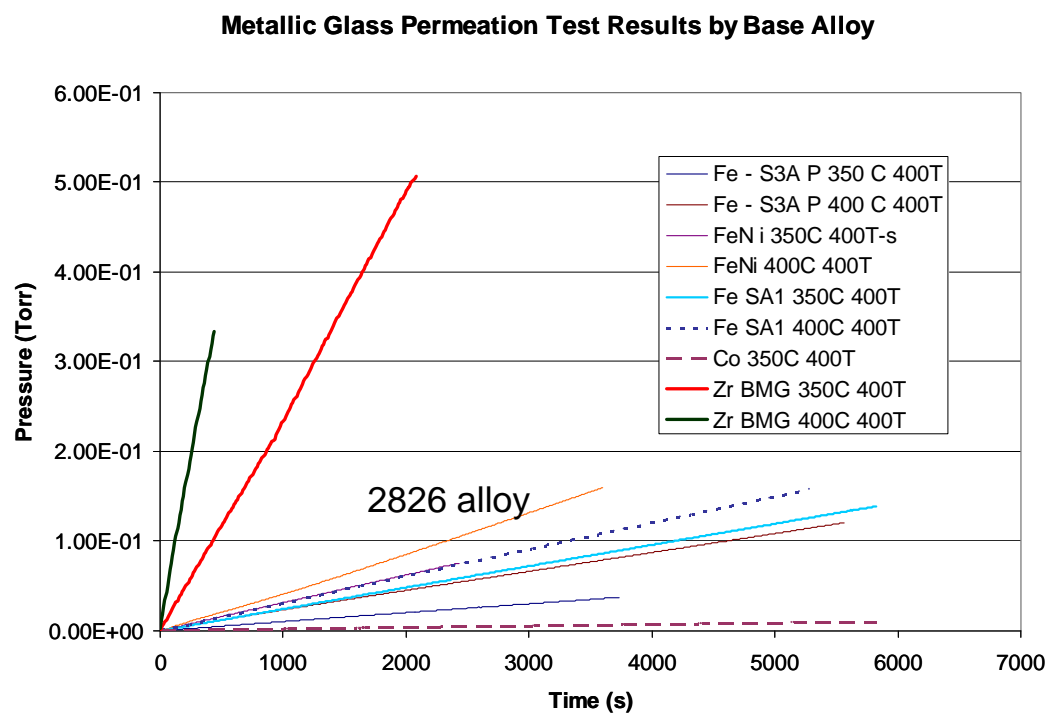

Figure 5. Pressure (torr) versus time saturation plot for Fe, Co and Zr based Alloys. The slope of the pressure versus time plot is proportional to the hydrogen flux through the membrane $\mathrm{dP} / \mathrm{dt}(\mathrm{mol} / \mathrm{s})$, flux in $\mathrm{mol} / \mathrm{m}^{2} \mathrm{sPa}^{1 / 2}$ calculated via equation 3 . 


\subsection{Results and Discussion}

\subsection{Crystallization Behavior}

The crystallization behavior of metallic glass alloys was studied by $\mathrm{x}$-ray diffraction and calorimetric techniques under different gas environments (argon, air, argon/hydrogen mixtures) in order to examine the effects of possible hydride phase formation (hydrogen gas mixtures) and oxidation behavior. Exposure to oxygen or oxygen partial pressures, a possible contaminant during membrane operations could lead to oxide phase formation with subsequent negative impact on both flux performance and mechanical properties of separation membranes.

\subsubsection{XPS}

X-ray photoelectron spectroscopy (XPS) was performed on as-received 2826 alloy metglass samples in order to investigate the prescence of surface oxide layers possibly formed during the melt-spin fabrication process. Figure 6 presents a "survey" scan of the 2826 as-received alloy. Peak maxima are labeled indicating the element and atomic orbital, except for Auger transitions, which are indicated with the element and the Auger transition (three capital letters). Elements identified are oxygen $(\mathrm{O})$, carbon $(\mathrm{C})$, and iron $(\mathrm{Fe})$. A higher resolution scan of the Fe peaks is displayed in figure 7.

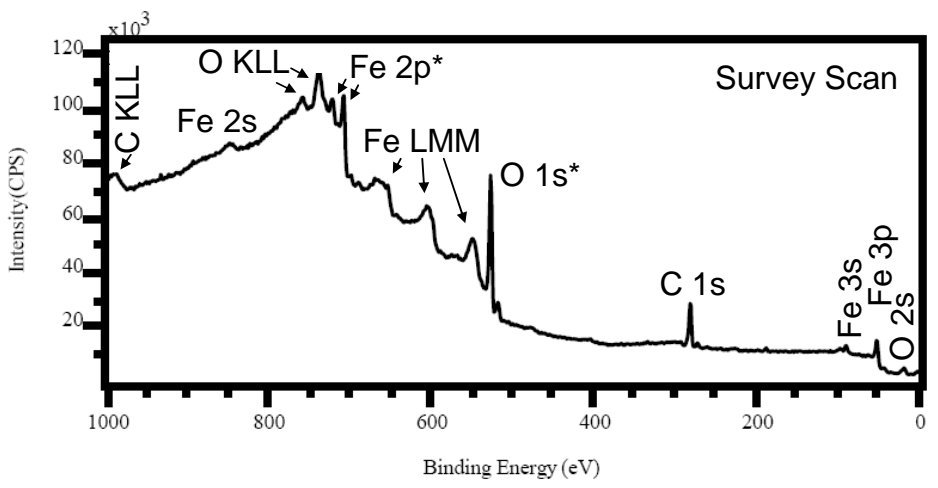

Figure 6. X-ray Photoelectron Spectra (XPS) for surface of 2826 metallic glass. Spectra were taken using $\mathrm{Mg} \mathrm{Ka}(h \mathrm{~h}=1253.6 \mathrm{eV}) \mathrm{x}$-rays and corrected for charging using the $\mathrm{C} 1 \mathrm{~s}$ adventitous carbon as $284.6 \mathrm{eV}$. Pass energy is $160 \mathrm{eV}$. *These peaks are examined at higher resolution in Figure 8.
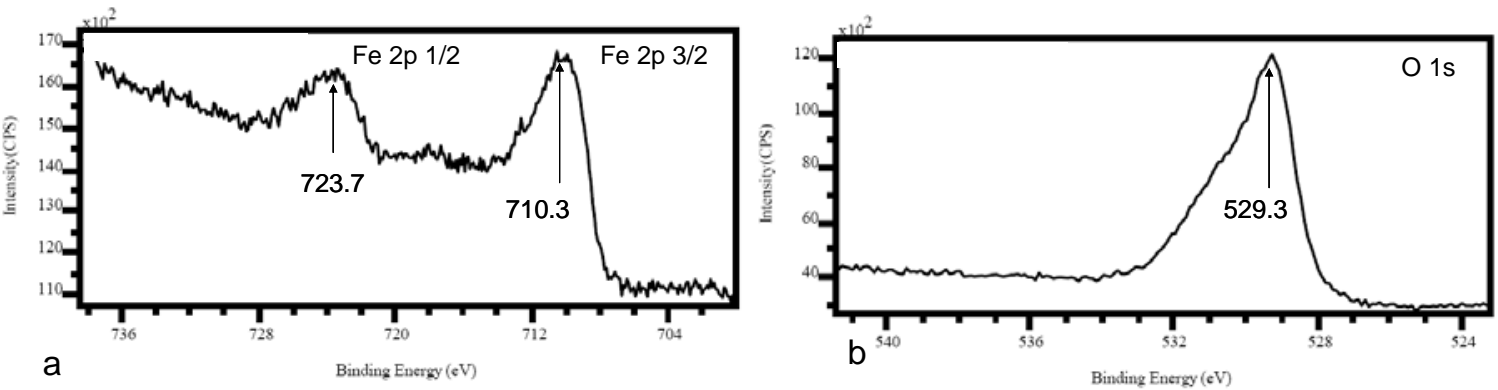

Figure 7. X-ray Photoelectron Spectra (XPS) for Fe 2p and $O$ 1s regions of surface of metallic glass. Peak maxima are labeled. Spectra were taken of the as received shiny side of the metallic glass using $\mathrm{Mg} \mathrm{Ka}(\mathrm{hn}=1253.6 \mathrm{eV}) \mathrm{x}$-rays and charge corrected using $\mathrm{C} 1 \mathrm{~s}$ adventitous carbon as $284.6 \mathrm{eV}$. Pass energy is $40 \mathrm{eV}$ 
A comparison of metallic glass surface oxide layer to candidate oxide materials of interest is shown in table 2. The best matches are a thin film of $\mathrm{Fe}_{2} \mathrm{O}_{3}$ on $\mathrm{FeO}\left(\mathrm{Fe}_{2} \mathrm{O}_{3} / \mathrm{FeO}\right)$ - which is simply $\mathrm{Fe}_{2} \mathrm{O}_{3}$, and gamma- $\mathrm{Fe}_{2} \mathrm{O}_{3}$ - an alotrope of $\mathrm{Fe}_{2} \mathrm{O}_{3}$.

Table 2 Comparison of metallic glass surface oxide to candidate materials.

\begin{tabular}{|c|c|c|c|c||}
\hline Material & $\begin{array}{c}\text { Fe 2p } \\
\mathbf{3 / 2}\end{array}$ & Fe 2p 1/2 & O 1s & Ref \\
\hline $\mathbf{F e}$ & 707 & 720 & N/A & {$[4]$} \\
\hline Fe2O3/FeO & 710.1 & 724 & 529.6 & {$[5]$} \\
\hline$\gamma$ Fe2O3 & 710.2 & 724.1 & 529.6 & {$[6]$} \\
\hline $\begin{array}{c}\text { Metallic } \\
\text { Glass oxide }\end{array}$ & 710.3 & 723.7 & 529.3 & $\begin{array}{c}\text { This } \\
\text { work }\end{array}$ \\
\hline $\boldsymbol{\alpha}$ FeOOH & 710.7 & 724.7 & 529.7 & {$[7]$} \\
\hline Fe3O4 & 711 & 723.8 & 530.3 & {$[8]$} \\
\hline
\end{tabular}

Table 3 compares the $\mathrm{O} / \mathrm{Fe}$ ratio of the metallic glass oxide surface (with adsorbed water subtracted from the oxygen peak) to candidate materials. As is seen in the table, $\mathrm{Fe}_{2} \mathrm{O}_{3}$ and $\mathrm{Fe}_{3} \mathrm{O}_{4}$ are the closest matches. In combination with the data summarized in Table 1, it appears clear that the iron oxide on the metallic glass is $\mathrm{Fe}_{2} \mathrm{O}_{3}$. This result is consistent with the free energy of formation of the oxides.

\section{Table 3 Comparison of $\mathrm{O} / \mathrm{Fe}$ ratio of metallic glass surface oxide}

\begin{tabular}{|l|r|}
\hline Material & O/Fe ratio \\
\hline Fe & 0 \\
\hline FeO & 1 \\
\hline Fe3O4 & 1.3 \\
\hline Metallic Glass oxide & 1.4 \\
\hline Fe2O3 & 1.5 \\
\hline FeOOH & 2 \\
\hline
\end{tabular}

\subsubsection{XRD}

High temperature x-ray diffraction (HTXRD) using air, helium, and 4\% hydrogen / 96\% helium atmospheres was used to determine the crystalline phases that are formed as a function of temperature from 25 to $710^{\circ} \mathrm{C}$. The following summarizes the relavent information obtained from XRD experiments for the S3a, 2714A, 2826, 2605 SA1, Howmet Proprietary Zr metallic glass materials. Additional information is available in technical memos detailing experiments for each individual material as well as XRD spectra included in the appendix of this report.

\section{$\underline{\mathrm{S} 3 \mathrm{~A}}$}

Detailed issues related to XRD measurements of S3A metallic glass material are detailed in the technical memo SRNL-L400-2008-00016 [9]. The S3A intermediate and final products with their calibrated temperature ranges in $\mathrm{He}, 4 \%-\mathrm{He} / 96 \%-\mathrm{Ar}$, and air are summarized in Table 4 . The binary $\mathrm{Fe} / \mathrm{Cr}$ alloy, $\mathrm{Fe}_{0.97} \mathrm{Cr}_{0.03}[10]$, is the first phase to appear at 350 or $450{ }^{\circ} \mathrm{C}$ in $\mathrm{SA} 3$ glass under all three gases. This composition is consistent with the initial glass chemistry, which is 
approximately $95 / 5 \mathrm{Fe} / \mathrm{Cr}$. In contrast to $2826 \mathrm{MB}$, the devitrification process clearly initiates at a lower temperature in air in SA3. The $\mathrm{Fe} / \mathrm{Cr}$ alloy persisted under all atmospheres to $710{ }^{\circ} \mathrm{C}$ - the end of the temperature ramp.

The second phase, $\mathrm{Fe}_{2} \mathrm{~B}$ [11], forms at 400 (air) or $500{ }^{\circ} \mathrm{C}\left(\mathrm{He}\right.$ and $\mathrm{H}_{2} / \mathrm{He}$ ) immediately after $\mathrm{Fe} / \mathrm{Cr}$ alloy crystallization and is stable up to $710^{\circ} \mathrm{C}$. Orthorhombic $\mathrm{Fe}_{3} \mathrm{~B}$ [12] crystallizes next in the sequence at 500 (air) or $550{ }^{\circ} \mathrm{C}\left(\mathrm{He}\right.$ and $\left.\mathrm{H}_{2} / \mathrm{He}\right)$. This is a metstable phase that disappears before end of the run. Both of these iron borides probably contain a few atomic $\% \mathrm{Cr}$ at the glass stoichiometric ratio. Guperite [13], $\mathrm{Fe}_{3} \mathrm{Si}$, could also be forming at this temperature, but its main reflection coincides with one of the strong $\mathrm{Fe}_{3} \mathrm{~B}$ peaks. The final boride, $\mathrm{Fe}_{23} \mathrm{~B}_{6}$ [14] was found only in the $\mathrm{He}$ and $\mathrm{H}_{2} / \mathrm{He}$ runs at $650^{\circ} \mathrm{C}$. In air, the oxidation of iron to hematite $\left(\mathrm{Fe}_{2} \mathrm{O}_{3}\right)$ is the dominant reaction at this temperature, precluding $\mathrm{Fe}_{23} \mathrm{~B}_{6}$ formation. There is a large shift in the $\mathrm{Fe}_{23} \mathrm{~B}_{6}$ lattice parameters indicating that there is solid solution substitution in this compound possibility $\mathrm{Cr}$ for $\mathrm{Fe}$ or $\mathrm{Si}$ for B.

Table 4. Summary of identified phases for S3A Metallic Glass crystallization experiments

a) Orthorhombic $\mathrm{Fe}_{3} \mathrm{~B}$ equivalent of the Jade matched phase, $\mathrm{B}_{0.7} \mathrm{Fe}_{3} \mathrm{C}_{0.3}$.

b) Formed during the cool down cycle as air infiltrated the detector. The gas cylinders had been valved off to conserve gas.

\begin{tabular}{|c|c|c|c|c|}
\hline Compound & Formula & $\begin{array}{c}5 \% / \min \text { in } \mathrm{He} \\
\left({ }^{\circ} \mathrm{C}\right)\end{array}$ & $\begin{array}{l}5 \% / \min \text { in } 4 \% \\
\mathrm{H}_{2} \text { in } \mathrm{He}\left({ }^{\circ} \mathrm{C}\right)\end{array}$ & $\begin{array}{c}5 \% / \mathrm{min} \text { in } \\
\text { Air }\left({ }^{\circ} \mathrm{C}\right)\end{array}$ \\
\hline Iron Chromium & $\mathrm{Fe}_{0.97} \mathrm{Cr}_{0.03}$ & $450-710$ & $450-710$ & $350-710$ \\
\hline Iron Boron & $\mathrm{Fe}_{2} \mathrm{~B}$ & $500-710$ & $500-710$ & $400-710$ \\
\hline Iron Boron $^{\mathrm{a}}$ & $\mathrm{Fe}_{3} \mathrm{~B}$ & $550-650$ & $550-650$ & $500-550$ \\
\hline Boron Iron & $\mathrm{Fe}_{23} \mathrm{~B}_{6}$ & $650-710$ & $650-710$ & \\
\hline Hematite & $\mathrm{Fe}_{2} \mathrm{O}_{3}$ & & & $500-710$ \\
\hline Sassolite ${ }^{\mathrm{b}}$ & $\mathrm{H}_{3} \mathrm{BO}_{3}$ & Residue only & Residue only & Residue only \\
\hline
\end{tabular}

Table 5. Percent Crystallinity S3A alloy as a Function of Temperature and Atmosphere

\begin{tabular}{|c|c|c|c|c|c|c|c|c|}
\hline Atmosphere & $350^{\circ} \mathrm{C}$ & $400^{\circ} \mathrm{C}$ & $450^{\circ} \mathrm{C}$ & $500^{\circ} \mathrm{C}$ & $550^{\circ} \mathrm{C}$ & $600^{\circ} \mathrm{C}$ & $650^{\circ} \mathrm{C}$ & $710^{\circ} \mathrm{C}$ \\
\hline He & & & 26 & 100 & 100 & 100 & 100 & 100 \\
\hline $4 \% \mathrm{H}_{2}$ in $\mathrm{He}$ & & & 29 & 100 & 100 & 100 & 100 & 100 \\
\hline Air & 16 & 57 & 100 & 100 & 100 & 100 & 100 & 100 \\
\hline
\end{tabular}

2714A

Detailed issues related to XRD measurements of 2714A metallic glass material are detailed in the technical memo SRNL-L400-2008-00040 [15]. The 2714 intermediate and final products with their calibrated temperature ranges in $\mathrm{He}, 4 \%-\mathrm{He} / 96 \%-\mathrm{Ar}$, and air are summarized in Table 6. 
Table 6. Summary of identified phases for 2714A Metallic Glass crystallization experiments

a) Face-Centered Cubic (FCC) cobalt.

b) Hexagonal cobalt.

c) Formed during the cool down cycle as air infiltrated into the camera. The gas cylinders had been valved off to conserve gas.

\begin{tabular}{|c|c|c|c|c|}
\hline Compound & Formula & $\begin{array}{c}5^{\circ} / \mathrm{min} \text { in } \\
\text { He }\left({ }^{\circ} \mathrm{C}\right)\end{array}$ & $\begin{array}{l}5 \% / \mathrm{min} \text { in } 4 \% \\
\mathrm{H}_{2} \text { in } \mathrm{He}\left({ }^{\circ} \mathrm{C}\right)\end{array}$ & $\begin{array}{l}5^{\circ} / \mathrm{min} \text { in } \\
\operatorname{Air}\left({ }^{\circ} \mathrm{C}\right)\end{array}$ \\
\hline$\alpha-$ Cobalt $^{\mathrm{a}}$ & Co & $500-710$ & $500-710$ & $400-710$ \\
\hline Cobalt Boron & $\mathrm{Co}_{2} \mathrm{~B}$ & $500-710$ & $500-710$ & $350-710$ \\
\hline Cobalt Silicon & $\mathrm{Co}_{2} \mathrm{Si}$ & $500-710$ & $500-710$ & $400-650$ \\
\hline Iron Nickel Boron & $\mathrm{Fe}_{4.5} \mathrm{Ni}_{18.5} \mathrm{~B}_{6}$ & $500-710$ & $500-710$ & 450 \\
\hline$\varepsilon$-Cobalt ${ }^{\mathrm{b}}$ & Co & & & 400 \\
\hline Cobalt Boron (?) & $\mathrm{Co}_{3} \mathrm{~B}_{2}$ & $500-550$ & $500-550$ & \\
\hline Iron Nickel Silicide & $\left(\mathrm{Fe}, \mathrm{Ni}_{22} \mathrm{Si}_{7}\right.$ & $550-600$ & $550-600$ & 450 \\
\hline Iron Boron & $\mathrm{Fe}_{23} \mathrm{~B}_{6}$ & $550-600$ & 600 & \\
\hline Iron Borate & $\mathrm{Fe}\left(\mathrm{BO}_{2}\right)_{2}$ & & & $600-710$ \\
\hline Sassolite $^{\mathrm{c}}$ & $\mathrm{H}_{3} \mathrm{BO}_{3}$ & & & 710 \\
\hline
\end{tabular}

The first four crystalline phases to appear during the 2714 metallic glass heat treatment are $\alpha$-Co [16], $\mathrm{Co}_{2} \mathrm{~B}$ [17], $\mathrm{Co}_{2} \mathrm{Si}$ [18], and $\mathrm{Fe}_{4.5} \mathrm{Ni}_{18.5} \mathrm{~B}_{6}$ [19]. The temperature at which they arise are the same in the $\mathrm{He}$ and $\mathrm{H}_{2} / \mathrm{He}$ atmospheres (simultaneously at $500{ }^{\circ} \mathrm{C}$ ), but are lower in air (from 350 to $450{ }^{\circ} \mathrm{C}$ ). This trend for a lower crystallization temperature in air follows what was observed for the iron based metallic glasses. These phases persist in $\mathrm{He}$ and $\mathrm{H}_{2} / \mathrm{He}$ to $710{ }^{\circ} \mathrm{C}$ - the end of the temperature ramp. In air however, $\mathrm{Co}_{2} \mathrm{Si}$ and $\mathrm{Fe}_{4.5} \mathrm{Ni}_{18.5} \mathrm{~B}_{6}$ disappear at $650^{\circ} \mathrm{C}$ and $450^{\circ} \mathrm{C}$, respectively, while $\alpha-\mathrm{Co}$ and $\mathrm{Co}_{2} \mathrm{~B}$ survive to $710^{\circ} \mathrm{C}$. Pure cobalt undergoes an allotropic transformation from $\varepsilon-\mathrm{Co}$ (hexagonal) to $\alpha-\mathrm{Co}(\mathrm{FCC})$ at $422^{\circ} \mathrm{C}$ [20]. This transition temperature changes with the alloying element; for instance Ni will decrease the temperature, while Si will increase it. In $\mathrm{He}$ or $\mathrm{He} / \mathrm{H}_{2}$, the initial crystallization of $500^{\circ} \mathrm{C}$ is above the cobalt phase transition temperature, so only $\alpha$-Co is seen. In contrast in air, the glass devitrification temperature $\left(350^{\circ} \mathrm{C}\right)$ is low enough to detect $\varepsilon$-Co [21]. The next metastable phase, $\mathrm{Co}_{3} \mathrm{~B}_{2}$ [22], forms at $500^{\circ} \mathrm{C}(\mathrm{He})$ and $550^{\circ} \mathrm{C}\left(\mathrm{H}_{2} / \mathrm{He}\right)$, but both disappear by $600^{\circ} \mathrm{C}$. Another silicide, $(\mathrm{Fe}, \mathrm{Ni})_{22} \mathrm{Si}_{7}$ [23], is next in the crystallization sequence growing in at $550^{\circ} \mathrm{C}\left(\mathrm{He}\right.$ and $\mathrm{H}_{2} / \mathrm{He}$ ) or $450^{\circ} \mathrm{C}$ (air). It also disappears before the end of the run. The final boride, $\mathrm{Fe}_{23} \mathrm{~B}_{6}[14]$, was found only in the $\mathrm{He}$ and $\mathrm{H}_{2} / \mathrm{He}$ runs at $550-600^{\circ} \mathrm{C}$ and $600^{\circ} \mathrm{C}$ respectively. Finally, iron borides started to oxidize in air forming $\mathrm{Fe}\left(\mathrm{BO}_{2}\right)_{2}$ at $600^{\circ} \mathrm{C}$. Cobalt oxidation was not detected. Again, this is related to the difference in the free energy of formation for the transition metal oxides.

Table 7. Percent Crystallinity 2714A alloy as a Function of Temperature and Atmosphere

\begin{tabular}{|c|c|c|c|c|c|c|c|c|}
\hline Atmosphere & $350^{\circ} \mathrm{C}$ & $400{ }^{\circ} \mathrm{C}$ & $450{ }^{\circ} \mathrm{C}$ & $500{ }^{\circ} \mathrm{C}$ & $550^{\circ} \mathrm{C}$ & $600{ }^{\circ} \mathrm{C}$ & $650^{\circ} \mathrm{C}$ & $710^{\circ} \mathrm{C}$ \\
\hline He & & & $7(?)$ & 100 & 100 & 100 & 100 & 100 \\
\hline $4 \% \mathrm{H}_{2}$ in $\mathrm{He}$ & & & & 100 & 100 & 100 & 100 & 100 \\
\hline Air & 13 & 30 & 100 & 100 & 100 & 100 & 100 & 100 \\
\hline
\end{tabular}


Detailed issues related to XRD measurements of 2826 metallic glass material are detailed in the technical memo SRNL-L400-2008-00015 [24]. The 2826MB intermediate and final products with their calibrated temperature ranges in $\mathrm{He}, 4 \%-\mathrm{He} / 96 \%-\mathrm{Ar}$, and air are summarized in Table 8 .

\section{Table 8. Summary of identified phases for 2826 Metallic Glass crystallization experiments}

a) $\mathrm{FeBO}_{3}$ could be present at $710{ }^{\circ} \mathrm{C}$ in air. Its presence would be masked by the large hematite peaks.

b) $\mathrm{Fe}_{2} \mathrm{Mo}_{3} \mathrm{O}_{8}$ was found only in the HTXRD residues at concentrations, which are too low to detect on the high temperature stage. It is assumed that it develops above $500{ }^{\circ} \mathrm{C}$.

c) Formed during the cool down cycle as air infiltrated the camera. The gas cylinders had been valved off to conserve gas.

\begin{tabular}{|c|c|c|c|c|}
\hline Compound & Formula & $\begin{array}{l}5 \% / \min \text { in } \\
\text { He }\left({ }^{\circ} \mathrm{C}\right) \\
\end{array}$ & $\begin{array}{l}5 \% \text { min in } 4 \% \\
\mathrm{H}_{2} \text { in } \mathrm{He}\left({ }^{\circ} \mathrm{C}\right) \\
\end{array}$ & $\begin{array}{l}5 \% \text { min in } \\
\text { Air }\left({ }^{\circ} \mathrm{C}\right) \\
\end{array}$ \\
\hline Tetrataenite & $\mathrm{FeNi}$ & $400-710$ & $350-710$ & $350-650$ \\
\hline Boron Iron Nickel & $\mathrm{Fe}_{11.5} \mathrm{Ni}_{11 . .5} \mathrm{~B}_{6}$ & $500-710$ & $500-710$ & $450-550$ \\
\hline Boron Iron Molybdenum & $\mathrm{Mo}_{2} \mathrm{FeB}_{2}$ & $?-710$ & $?-710$ & \\
\hline Iron Oxide Borate & $\mathrm{Fe}_{2} \mathrm{O}\left(\mathrm{BO}_{3}\right)$ & & & $450-710$ \\
\hline Iron Borate & $\mathrm{Fe}\left(\mathrm{BO}_{3}\right)$ & & & $500-710 ?^{\mathrm{a}}$ \\
\hline Molybdenum Iron Oxide & $\mathrm{Mo}_{3} \mathrm{Fe}_{3} \mathrm{O}$ & & & $500-710$ \\
\hline Hematite & $\mathrm{Fe}_{2} \mathrm{O}_{3}$ & & & $650-710$ \\
\hline Nickel & $\mathrm{Ni}$ & & & $?-710$ \\
\hline Kamiokitei & $\mathrm{Fe}_{2} \mathrm{Mo}_{3} \mathrm{O}_{8}$ & & & $?-710^{\mathrm{b}}$ \\
\hline Sassolite ${ }^{\mathrm{c}}$ & $\mathrm{B}(\mathrm{OH})_{3}$ & Residue only & Residue only & \\
\hline $\begin{array}{l}\text { Isostructural variation of } \\
\text { Pinakiolte }^{c}\end{array}$ & $(\mathrm{Mg}, \mathrm{Mn})_{2} \mathrm{Mn}\left(\mathrm{BO}_{3}\right)_{2}$ & Residue only & & \\
\hline
\end{tabular}

The equimolar binary $\mathrm{Fe} / \mathrm{Ni}$ alloy, tetrataenite[25], is the first crystalline phase to appear at 350 or $400^{\circ} \mathrm{C}$ in $2826 \mathrm{MB}$ heated in all three gases. This composition is consistent with the initial glass chemistry, which is approximately 50:50 Fe/Ni. Since spectra were only acquired in $50^{\circ} \mathrm{C}$ intervals, it's difficult to state that there is any real difference in the devitrification onset temperature for the different atmospheres. This alloy persisted under inert or reducing conditions to $710^{\circ} \mathrm{C}$ - the end of the temperature ramp. In contrast, in air iron is gradually removed preferentially through oxidation from the glass to form iron borates and hematite, leaving only $\mathrm{Ni}$ metal in the residue. This is expected since the free energy of formation for iron oxides is more negative than for NiO. At higher temperatures $\mathrm{Ni}$ was not detected in the XRD patterns, since it was obscured by the thick oxide coatings and was only identified in the pulverized HTXRD residue.

The second phase, $\mathrm{Fe}_{11.5} \mathrm{Ni}_{11.5} \mathrm{~B}_{6}$ [26], forms at 450 or $500^{\circ} \mathrm{C}$ immediately after tetrataenite crystallization and is stable in $\mathrm{He}$ and $\mathrm{H}_{2} / \mathrm{He}$ up to $710^{\circ} \mathrm{C}$. In air it survives only to $550^{\circ} \mathrm{C}$, after which it is completely oxidized to iron oxide borate and iron borate. There is another possibility for these XRD reflections, an isotructural molybdenum containing phase, $(\mathrm{Fe}, \mathrm{Ni}, \mathrm{Mo})_{23} \mathrm{~B}_{6}$ [27], which is indistinguishable by XRD from $\mathrm{Fe}_{11.5} \mathrm{Ni}_{11.5} \mathrm{~B}_{6}$. The stoichiomety of the "true" boride phase is probably similar to the $\mathrm{Fe}, \mathrm{Ni}$, and, Mo molar ratio in the initial glass. The final nonoxide, $\mathrm{Mo}_{2} \mathrm{FeB}_{2}$ [28] or possibly $\mathrm{Mo}_{2} \mathrm{FeB}_{4}$ [29], was found only in the HTXRD residues at concentrations, which are too low to detect on the high temperature stage for reasons previously described. It was assumed that it develops above $500^{\circ} \mathrm{C}$. 
Table 9. Percent crystallinity 2714A alloy as a function of temperature and atmosphere

\begin{tabular}{|c|c|c|c|c|c|c|c|c|}
\hline \hline Atmosphere & $\mathbf{3 5 0}{ }^{\circ} \mathbf{C}$ & $\mathbf{4 0 0}^{\circ} \mathbf{C}$ & $\mathbf{4 5 0}^{\circ} \mathbf{C}$ & $\mathbf{5 0 0}^{\circ} \mathbf{C}$ & $\mathbf{5 5 0}{ }^{\circ} \mathbf{C}$ & $\mathbf{6 0 0}^{\circ} \mathbf{C}$ & $\mathbf{6 5 0}^{\circ} \mathbf{C}$ & $\mathbf{7 1 0}^{\circ} \mathbf{C}$ \\
\hline \hline He & & & & & & & & \\
\hline $\mathbf{4 \%} \mathbf{H}_{2}$ in $\mathbf{H e}$ & 16 & 30 & 47 & 77 & 79 & 81 & 80 & 80 \\
\hline Air & 28 & 43 & 75 & 80 & 100 & 100 & 100 & 100 \\
\hline \hline
\end{tabular}

Table 10. Percent crystallinity as a function of time ( $(0$ to 3 -hr $)$ at $400^{\circ} \mathrm{C}$ in $\mathrm{He}$.

\begin{tabular}{|c|c|c|c|}
\hline Run \# & $\begin{array}{c}\% \\
\text { Crystallinity } \\
\end{array}$ & Run \# & $\begin{array}{c}\% \\
\text { Crystallinity } \\
\end{array}$ \\
\hline 1 & 17 & 10 & 25 \\
\hline 2 & 19 & 11 & 24 \\
\hline 3 & 19 & 12 & 25 \\
\hline 4 & 20 & 13 & 26 \\
\hline 5 & 21 & 14 & 25 \\
\hline 6 & 22 & 15 & 26 \\
\hline 7 & 22 & 16 & 26 \\
\hline 8 & 23 & 17 & 28 \\
\hline 9 & 23 & 18 & 27 \\
\hline
\end{tabular}

\section{SA1}

Detailed issues related to XRD measurements of 2714A metallic glass material are reported in the technical memo SRNL-L400-2008-00017[30]. The 2605 SA1 intermediate and final products with their calibrated temperature ranges in $\mathrm{He}, 4 \%-\mathrm{He} / 96 \%-\mathrm{Ar}$, and air are summarized in Table 11.

\section{Table 11. Summary of identified phases for 2605 SA1 Metallic Glass crystallization experiments}

a) Orthorhombic $\mathrm{Fe}_{3} \mathrm{~B}$ equivalent of the Jade matched phase, $\mathrm{B}_{0.7} \mathrm{Fe}_{3} \mathrm{C}_{0.3}$.

\begin{tabular}{|c|c|c|c|c|}
\hline Compound & Formula & $\begin{array}{c}5^{\circ} / \mathrm{min} \text { in } \\
\text { He }\left({ }^{\circ} \mathrm{C}\right)\end{array}$ & $\begin{array}{l}5^{\circ} / \mathrm{min} \text { in } 4 \% \\
\mathrm{H}_{2} \text { in } \mathrm{He}\left({ }^{\circ} \mathrm{C}\right) \\
\end{array}$ & $\begin{array}{c}5^{\circ} / \mathrm{min} \text { in } \\
\text { Air }\left({ }^{\circ} \mathrm{C}\right)\end{array}$ \\
\hline $\mathrm{BCC} \mathrm{Fe}$ & $\mathrm{Fe}$ & $450-500$ & $400-450$ & $350-710$ \\
\hline Iron Silicon (?) & $\mathrm{Fe}_{5} \mathrm{Si}_{3}$ & 450 & - & - \\
\hline Iron Boride & $\mathrm{Fe}_{2} \mathrm{~B}$ & $450-710$ & $500-710$ & $450-710$ \\
\hline PC Alloy, $\mathrm{a}=2.88-\AA$ & $\mathrm{Fe}, \mathrm{x}$ & $550-710$ & $500-710$ & - \\
\hline BCC Alloy, a=3.19- $\AA$ (?) & $?$ & $550-710$ & $500-710$ & $500-550$ \\
\hline Iron Boride ${ }^{a}$ & $\mathrm{Fe}_{3} \mathrm{~B}$ & - & - & $450-710$ \\
\hline Guperiite & $\mathrm{FeSi}$ & - & Residue Only & - \\
\hline Cobalt Oxide & $\mathrm{CoO}$ & - & - & $600-710$ \\
\hline Hematite & $\mathrm{Fe}_{2} \mathrm{O}_{3}$ & - & - & $450-710$ \\
\hline
\end{tabular}

Body centered cubic (BCC) iron [31], possibly alloyed with a low concentration of Co and/or $\mathrm{Ni}$, is the first phase to appear from 350 to $450{ }^{\circ} \mathrm{C}$ in $\mathrm{S} 1 \mathrm{~A}$ glass under all three gases. This composition is consistent with the initial glass transition metal chemistry, which is nominally $90 \% \mathrm{Fe}$, see Table 1. As for the S3A metallic glass, the devitrification process clearly initiates at a lower temperature in air in SA1. At $500{ }^{\circ} \mathrm{C}\left(\mathrm{H}_{2} / \mathrm{He}\right)$ or $550{ }^{\circ} \mathrm{C}(\mathrm{He})$, iron transformed from a $\mathrm{BCC}$ phase to a primitive cubic phase with $\mathrm{a}=2.88 \AA$, as evidenced by the in-growth of the (100) reflection at $31^{\circ} 2 \Theta$. BCC iron persisted in air to $710{ }^{\circ} \mathrm{C}$ - the end of the temperature ramp without the formation of the primitive cubic phase. In air the minor elements, particularly $\mathrm{Si}$ 
which has the most negative $\Delta \mathrm{G}$ of all the elements in the glass, are probably oxidized before they can be fully incorporated into the new alloy structure. Since Si is more abundant in SA1 as compared to S3A, and no major iron silicide was identified in the SA1 high temperature residue, it is assumed that the addition of Si is transforming the SA1 alloy structure.

The second phase, $\mathrm{Fe}_{2} \mathrm{~B}$ [11], forms at $500\left(\mathrm{H}_{2} / \mathrm{He}\right)$ or $450^{\circ} \mathrm{C}$ (He and air) immediately after iron crystallization and is stable up to $710^{\circ} \mathrm{C}$. An iron silicide [32], $\mathrm{Fe}_{5} \mathrm{Si}_{3}$, was observed only at $450^{\circ} \mathrm{C}$ in He. This short-lived metastable phase may be forming in the other two gases and is simply not detected because of the $50^{\circ} \mathrm{C}$ sampling frequency.

Orthorhombic $\mathrm{Fe}_{3} \mathrm{~B}$ [12] crystallizes next in the sequence only in air at $500^{\circ} \mathrm{C}$. In contrast to $\mathrm{S} 3 \mathrm{~A}$, this boride was stable and was found in the HTXRD residue. Both of these iron borides probably contain a few atomic \% $\mathrm{Co}$ or $\mathrm{Ni}$ at the glass stoichiometric ratio. Guperite [13], $\mathrm{Fe}_{3} \mathrm{Si}$, could also be forming at this temperature, but its main reflection coincides with one of the strong $\mathrm{Fe}_{3} \mathrm{~B}$ peaks. In air, the oxidation of iron to hematite $\left(\mathrm{Fe}_{2} \mathrm{O}_{3}\right)$ is the dominant reaction starting at $450^{\circ} \mathrm{C}$ followed by $\mathrm{CoO}$ formation at $600^{\circ} \mathrm{C}$, as would be expected from their free energies of formation $(-419 \mathrm{~kJ}$ and $-354 \mathrm{~kJ}$, respectively at $800 \mathrm{~K})$. No bunsenite $(\mathrm{NiO})$ was detected $(-331 \mathrm{~kJ}$ at $800 \mathrm{~K})$. The iron oxide layer could be protective (non-permeable) preventing $\mathrm{Ni}$ oxidation at higher temperature, similar to the chromium oxide layer on austenitic stainless steels. There was one extraneous peak at $\sim 40^{\circ} 2 \Theta$ that may correspond to a BCC phase, $a=3.19-\AA$. There were no phases in the ICDD database with SA1 restricted chemistry that had a major reflection at this angle.

Table 12. Percent crystallinity 2605 SA1 alloy as a function of temperature and atmosphere

\begin{tabular}{|c|c|c|c|c|c|c|c|c|}
\hline Atmosphere & $350^{\circ} \mathrm{C}$ & $400^{\circ} \mathrm{C}$ & $450^{\circ} \mathrm{C}$ & $500^{\circ} \mathrm{C}$ & $550^{\circ} \mathrm{C}$ & $600^{\circ} \mathrm{C}$ & $650^{\circ} \mathrm{C}$ & $710^{\circ} \mathrm{C}$ \\
\hline He & & & 52 & 100 & 100 & 100 & 100 & 100 \\
\hline $4 \% \mathrm{H}_{2}$ in $\mathrm{He}$ & & 20 & 90 & 100 & 100 & 100 & 100 & 100 \\
\hline Air & 12 & 79 & 100 & 100 & 100 & 100 & 100 & 100 \\
\hline
\end{tabular}

\section{Zr alloy (Howmet)}

The exact composition for the $\mathrm{Zr}$ metallic glass sample is proprietary, but the major elements in this sample as determined by $\mathrm{x}$-ray fluorescence analysis are $\mathrm{Zr}, \mathrm{Cu}, \mathrm{Ni}, \mathrm{Nb}$, Ta, and $\mathrm{Y}$ (See Figure 9). 


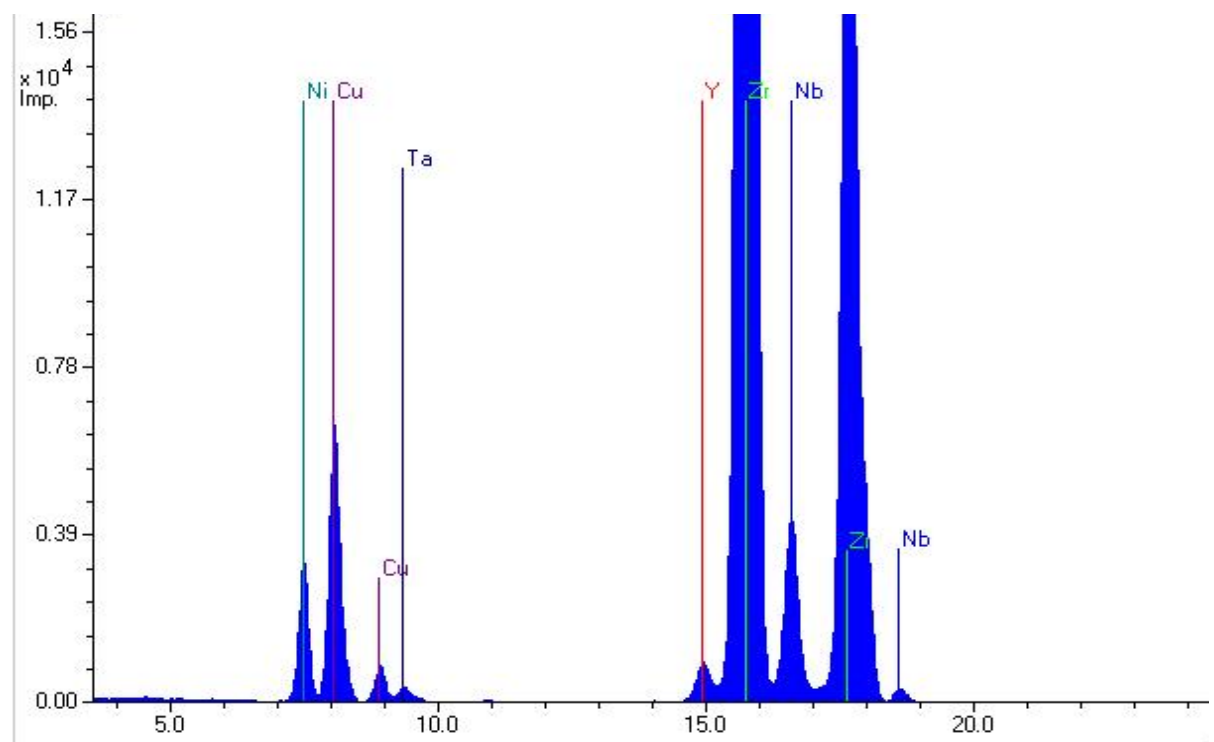

Figure 8. X-ray fluorescence scan of the Zr metallic glass (Howmet Inc.)

Table 3 Summary of identified phases for $\mathrm{Zr}$ (Howmet Inc.) Metallic Glass crystallization experiments

a) The $\mathrm{Y}_{2} \mathrm{O}_{3}$ peak maybe obscured by the background form the other phases from 600 to $710^{\circ} \mathrm{C}$.

b) The $\mathrm{Y}_{2} \mathrm{O}_{3}$ peak is obscured by $\mathrm{ZrO}_{2}$ from 350 to $710{ }^{\circ} \mathrm{C}$

\begin{tabular}{|c|c|c|c|}
\hline Compound & Formula & $\begin{array}{l}5 \% / \mathrm{min} \text { in } 4 \% \\
\mathrm{H}_{2} \text { in } \mathrm{He}\left({ }^{\circ} \mathrm{C}\right)\end{array}$ & $\begin{array}{c}5 \% \text { min in } \\
\text { Air }\left({ }^{\circ} \mathrm{C}\right)\end{array}$ \\
\hline Yttrium Oxide & $\mathrm{Y}_{2} \mathrm{O}_{3}$ & $25-550^{\mathrm{a}}$ & $\begin{array}{l}25-710^{\mathrm{b}} \\
\text { Residue }\end{array}$ \\
\hline Zirconium Niobium Oxide & $\mathrm{Zr}_{6} \mathrm{Nb}_{2} \mathrm{O}_{17}$ & 400-710, Residue & $300-710$ \\
\hline Zirconium & $\mathrm{Zr}$ & 400 & \\
\hline Baddeleyite & $\mathrm{ZrO}_{2}$ & 450-710, Residue & $350-710$ \\
\hline Zirconium Nickel & $\mathrm{Zr}_{2} \mathrm{Ni}$ & $500-550$ & $\mathrm{x}$ \\
\hline Zirconium Nickel & $\mathrm{Zr}_{9} \mathrm{Ni}_{11}$ & 550-710, Residue & $\mathrm{x}$ \\
\hline Bunsenite? & $\mathrm{NiO}$ & $550-710$ & $\mathrm{x}$ \\
\hline Tenorite & $\mathrm{CuO}$ & 600-710, Residue & $\mathrm{x}$ \\
\hline Zirconium Copper? & $\mathrm{ZrCu}$ & $\begin{array}{l}500,600-710 \\
\text { Residue }\end{array}$ & $\mathrm{x}$ \\
\hline Copper Nickel Oxide & $\left(\mathrm{Cu}_{0.2} \mathrm{Ni}_{0.8}\right) \mathrm{O}$ & & $\begin{array}{c}450-710 \\
\text { Metal Core } \\
\text { after heating }\end{array}$ \\
\hline
\end{tabular}

\subsubsection{DSC}

Differential scanning calorimetry is a technique used to quantify the heat flow between a sample and reference specimen at a given temperature. The results obtainable from these tests are the energy released during structural changes and crystallization temperatures. In addition, performing the scans under different gas enviorments may elucidate different phase formation pathways and sequences with corresponding differences in the amount of energy release. Scans performed at different heating rates leads to a shift in exothermic peak of crystallization which can be used to determine the kinetics of crystallization via the Flynn/Wall/Ozawa methods outlined in ASTM E698-05 [33, 34]. Figure 9 shows the baseline DSC measurements on the as 
received metallic glass alloys under an argon atmosphere at $10^{\circ} \mathrm{C} / \mathrm{min}$ heating rate. Figure compares the effect of gas composition on the phase transformation behavior for 2826 alloy using argon and argon/hydrogen mixtures. Table 14 summarizes the salient features of the DSC data including phase transition temperature, as a function of alloy composition.
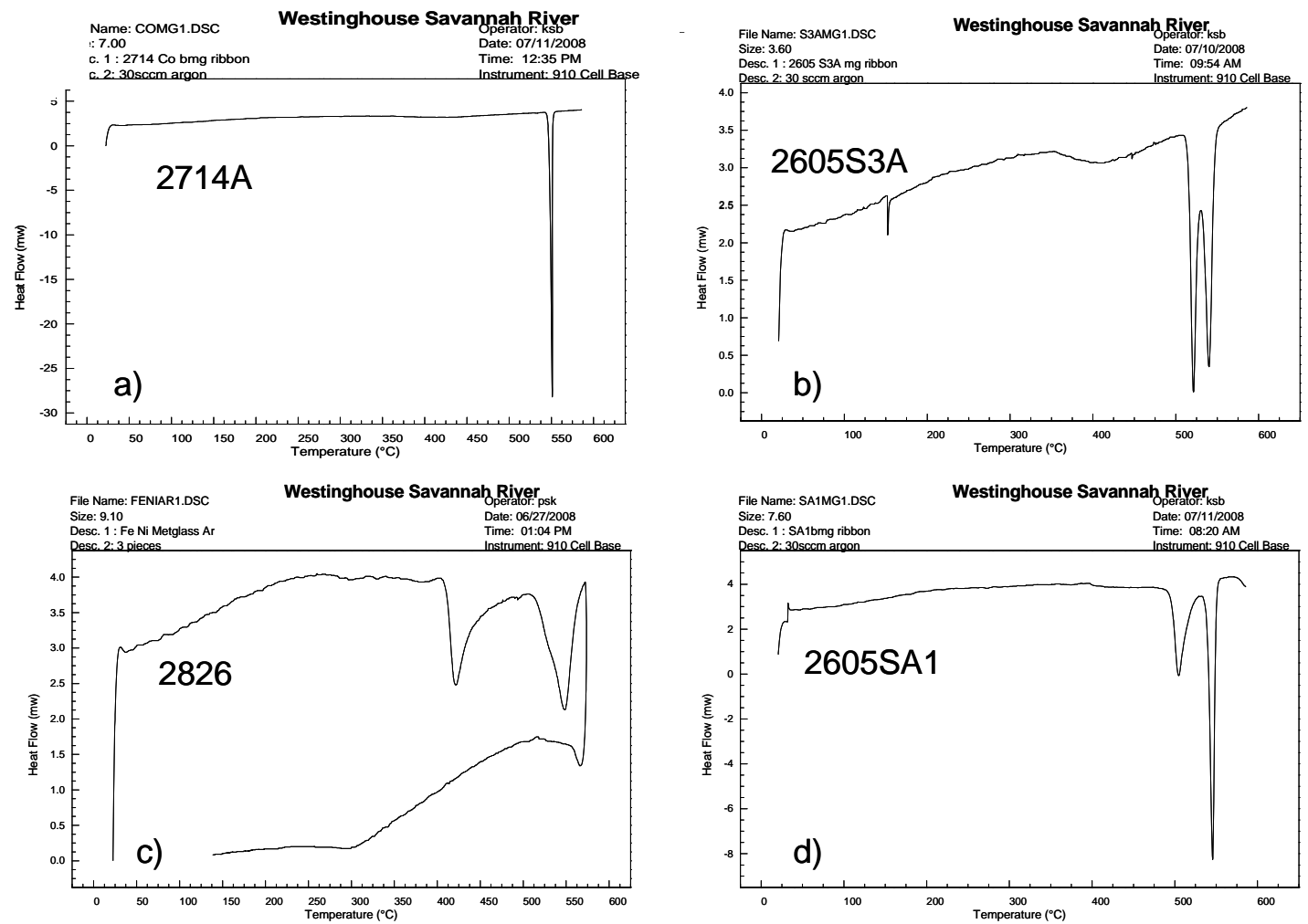

Figure 9. Differential scanning calorimetry (DSC) performed on metglass alloys at $10^{\circ} \mathrm{C} / \mathrm{min}$ under Argon atmosphere $30 \mathrm{sccm}$ from $25^{\circ} \mathrm{C}$ to $590^{\circ} \mathrm{C}$ on a) $2714 \mathrm{~A}$, b) $2605 \mathrm{~S} 3 \mathrm{~A}$, c) 2826, d) 2605SA1

Table 14. DSC determined crystallization temperatures and compositions

\begin{tabular}{|c|c|c|c|c|c|c|c|c||}
\hline \hline Alloy & $\begin{array}{c}\mathbf{T}_{\mathbf{1}} \mathbf{C r y s t} \\
{ }^{\mathbf{0}} \mathbf{C}\end{array}$ & $\mathbf{F e}$ & $\mathbf{B}$ & $\mathbf{C r}$ & $\mathbf{M o}$ & $\mathbf{C o}$ & $\mathbf{N i}$ & Si \\
\hline 2605S3A & 521 & $85-95 \%$ & $1-5 \%$ & $1-5 \%$ & $0 \%$ & $0 \%$ & $0 \%$ & $1-5 \%$ \\
\hline 2714A & 551 & $7-13 \%$ & $1-5 \%$ & $0 \%$ & $0 \%$ & $75-90 \%$ & $1-5 \%$ & $7-13 \%$ \\
\hline 2826 & 421 & $40-50$ & $1-5 \%$ & $0 \%$ & $5-10 \%$ & $0.3 \%$ & $40-50 \%$ & $0 \%$ \\
\hline 2605SA1 & 504 & $85-95 \%$ & $1-5 \%$ & $0 \%$ & $0 \%$ & $0.2 \%$ & $0.2 \%$ & $5-10 \%$ \\
\hline Zr Alloy & $\mathbf{4 7 1}$ & Proprietary & & & & & & \\
\hline
\end{tabular}




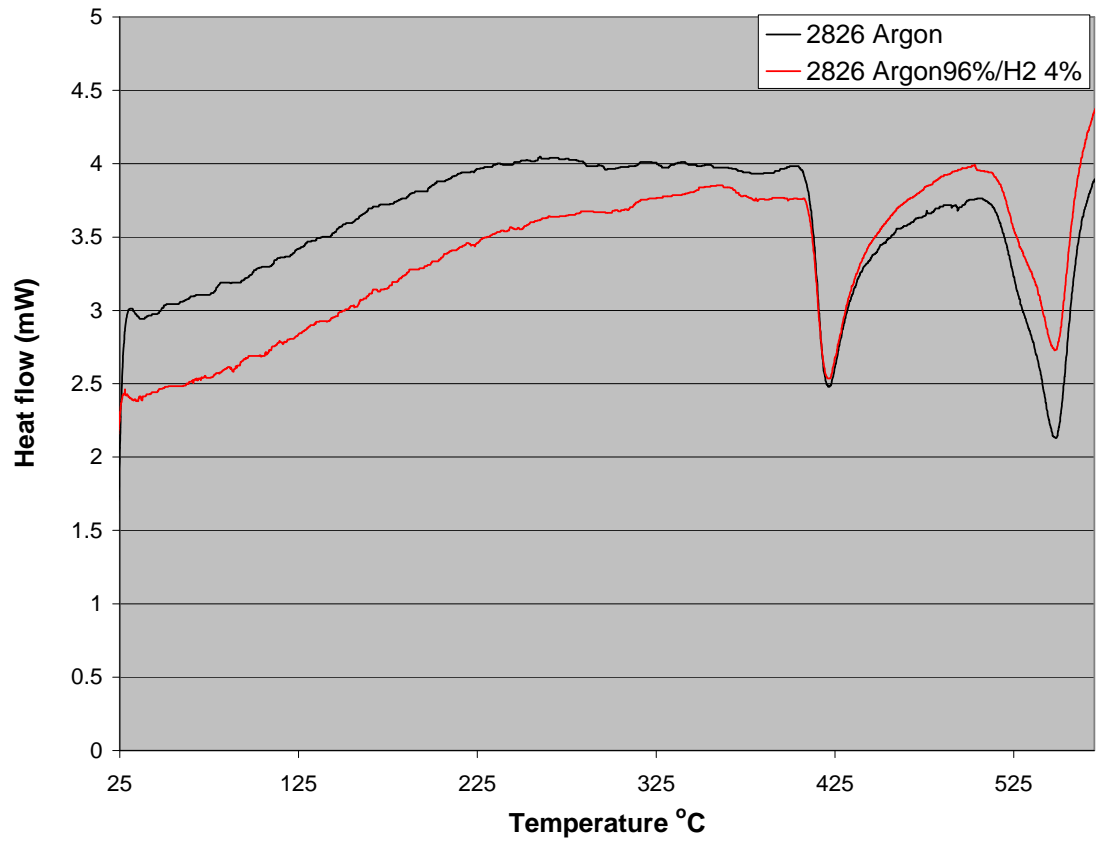

Figure 10. DSC scan of 2826 alloy at $10^{\circ} \mathrm{C} / \mathrm{min}$ under Argon gas and $96 \%$ argon $/ 4 \%$ hydrogen gas mixture. Transition $\mathrm{T} 1$ to crystalline phase $\mathrm{FeNi}\left(\operatorname{argon} 421^{\circ} \mathrm{C} \Delta \mathrm{H}=28.7 \mathrm{~J} / \mathrm{g}\right.$ : $\operatorname{argon} / \mathrm{H}_{2}$ mix $422^{\circ} \mathrm{C} \Delta \mathrm{H}=26.3 \mathrm{~J} / \mathrm{g}$ ); Transition $\mathrm{T} 2$ crystaline phase $\mathrm{Fe}_{11.5} \mathrm{Ni}_{11.5} \mathrm{~B}_{6}$ (argon $\left.549^{\circ} \mathrm{C} \Delta \mathrm{H}=30.3 \mathrm{~J} / \mathrm{g}: \operatorname{argon} / \mathrm{H}_{2} \mathrm{mix} 549^{\circ} \mathrm{C} \Delta \mathrm{H}=36.2 \mathrm{~J} / \mathrm{g}\right)$. 


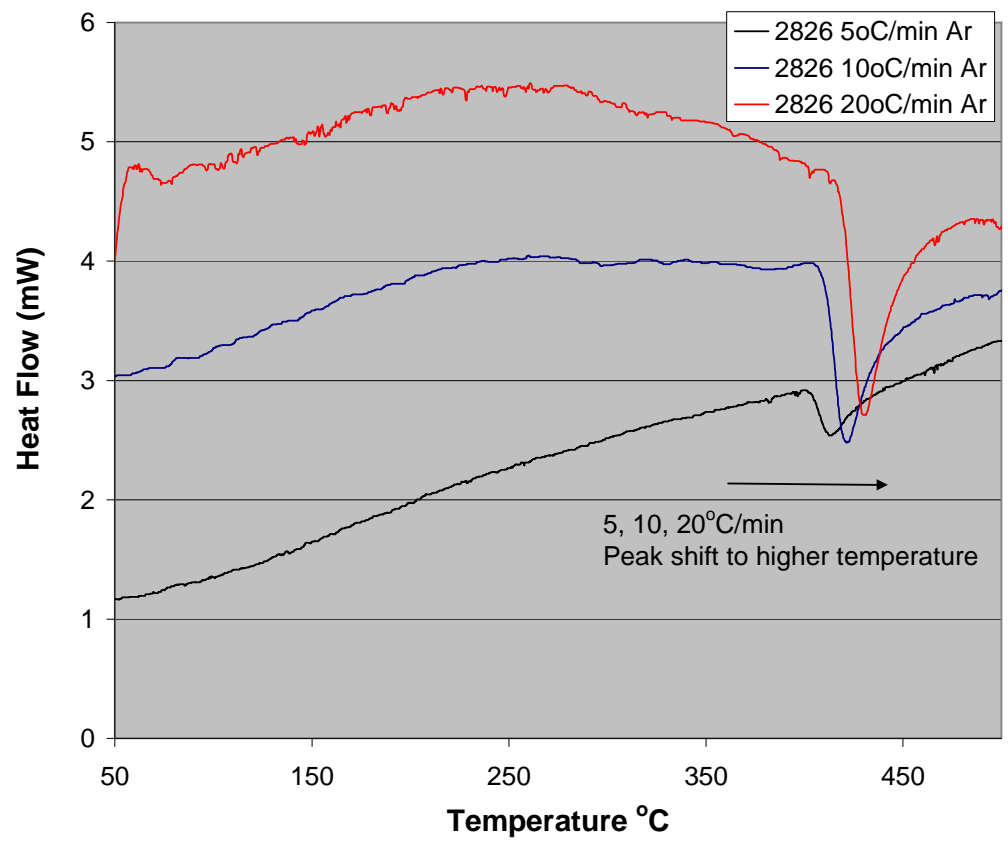

Figure 11. DSC of 2826 metglass alloy in argon at 5,10 and $20^{\circ} \mathrm{C} /$ minute heating rate showing an upward shift in peak crystallization temperataure wth increasing heating rate.

The crystallization kinetics of a respective material may be determined from the peak temperature shift of the crystallization exotherm taken at different heating rates. Figure 11 shows the raw data from DSC scans taken of the 2826 alloy under argon atmosphere at 5, 10 and $20^{\circ} \mathrm{C} / \mathrm{min}$.

The shift of the crystallization peak may be used with equation 4 to obtain an activation energy and pre-exponential factor described as:

$\ln \left(\frac{C}{T p^{2}}\right)=-\frac{E}{k T p}+A$

where $\mathrm{C}=$ heating rate ${ }^{\circ} \mathrm{C} /$ minute, $\mathrm{Tp}=$ peak crystallization temperature, $\mathrm{E}=$ activation energy $(\mathrm{J} / \mathrm{mol}), \mathrm{k}=$ boltzman constant and $\mathrm{A}=$ pre-exponential factor [33, 34]. From equation 4 , a plot of $\ln \left(\mathrm{C} / \mathrm{Tp}^{2}\right)$ versut $1 / \mathrm{Tp}$ gives a slope equal to $-\mathrm{E} / \mathrm{k}$ and the pre-exponential factor A. A plot of the data for the 2826 alloy is shown in figure 13 to determine the activation energy of $355 \mathrm{~kJ} / \mathrm{mol}$ and a pre-exponential factor of $1.9 \times 10^{22}$ The value of activation energy determined from DSC measurements agrees well with literature values of the activation energy $(350 \mathrm{~kJ} / \mathrm{mol})$ determined from microscopy studies used to determine the nucleation and growth rate as a function of temperature in 2826 metglass alloys [35]. 


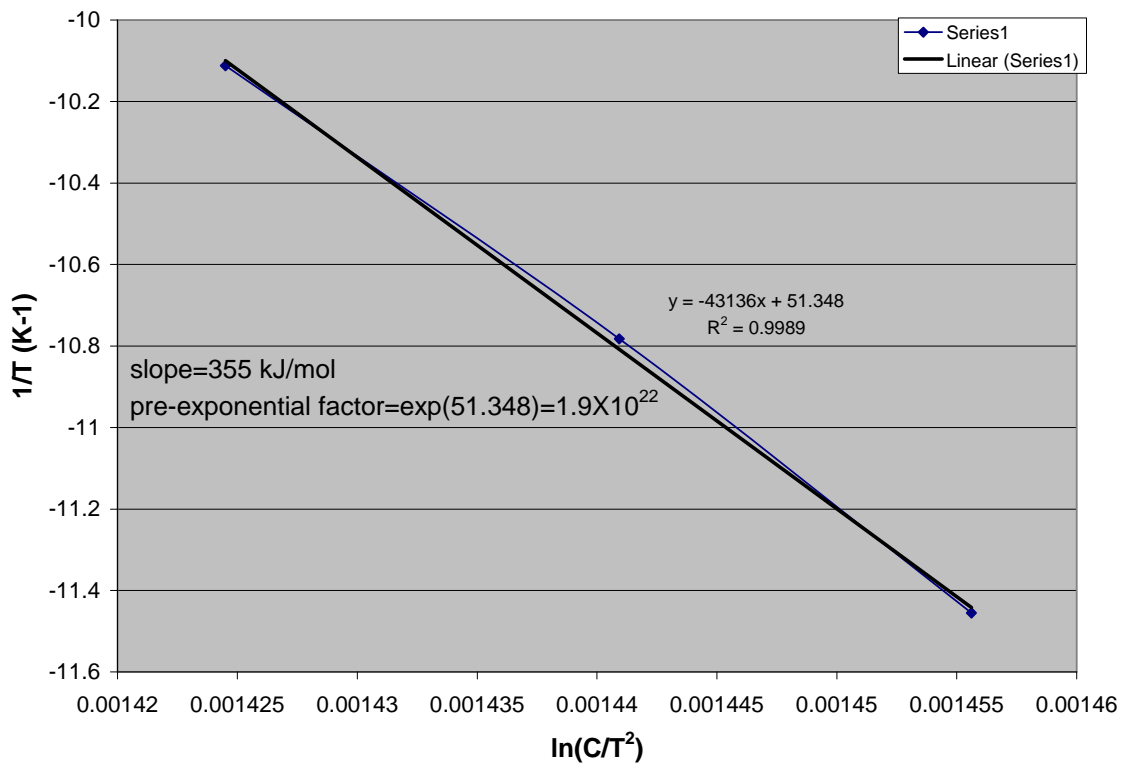

Figure 12 Activation energy determination for 2826 alloy crystallization: plot of 1/T versus $\ln \left(\mathrm{C} / \mathrm{T}^{2}\right) .355 \mathrm{~kJ} / \mathrm{mol}$ compares well with literature for comparable compositions (350 $\mathbf{k J} / \mathbf{m o l})[35]$.

Using the parameters from equation 4 and assuming an arrehenius reation rate is appropriate for the description of the rate constant as a function of temperature equation 6 is obtained.

$$
k=A \exp \left(\frac{-E}{R T}\right)
$$

Previous studies have shown than metallic glass specimens can be well described by JohnsonMehl-Avrami kinetic expressions such as:

$\mathrm{X}(\mathrm{t})=1-\exp \left(-\mathrm{kt}^{\mathrm{n}}\right)$

Where $\mathrm{x}(\mathrm{t})$ is the fraction transformed at time $\mathrm{t}, \mathrm{n}$ is an exponent experimentally determined which reflects the nucleation rate taken to be 3.5 in this case from literature [36], $\mathrm{k}$ is the rate constant determined at temperature $\mathrm{T}$ from equation 6.

Using equation 6 and 7, the crystallization fraction of the material can be determined as a function of time at various temperatures. A plot of this behavior for the 2826 metglass alloy is shown in Figure 13 for temperatures of 380,400 and $420^{\circ} \mathrm{C}$. Included in the plot is the experimental data for isothermal crystallization behavior of the 2826 alloy determined by DSC. The material was heated at $10^{\circ} \mathrm{C} / \mathrm{min}$ up to $380^{\circ} \mathrm{C}$ and slowly ramped to $400^{\circ} \mathrm{C}$ at $2^{\circ} \mathrm{C} / \mathrm{min}$ and held for 3 hours. The heat flow was corrected for thermal lag [33]by using an aluminum sample with the same mass as the 2826 metglass alloy. The area under the crystallization peak at time $t$ was divided by the total area under the crystallization peak in order to determine $x(t)$. 
SRNS-STI-2008-00133

Revision 1

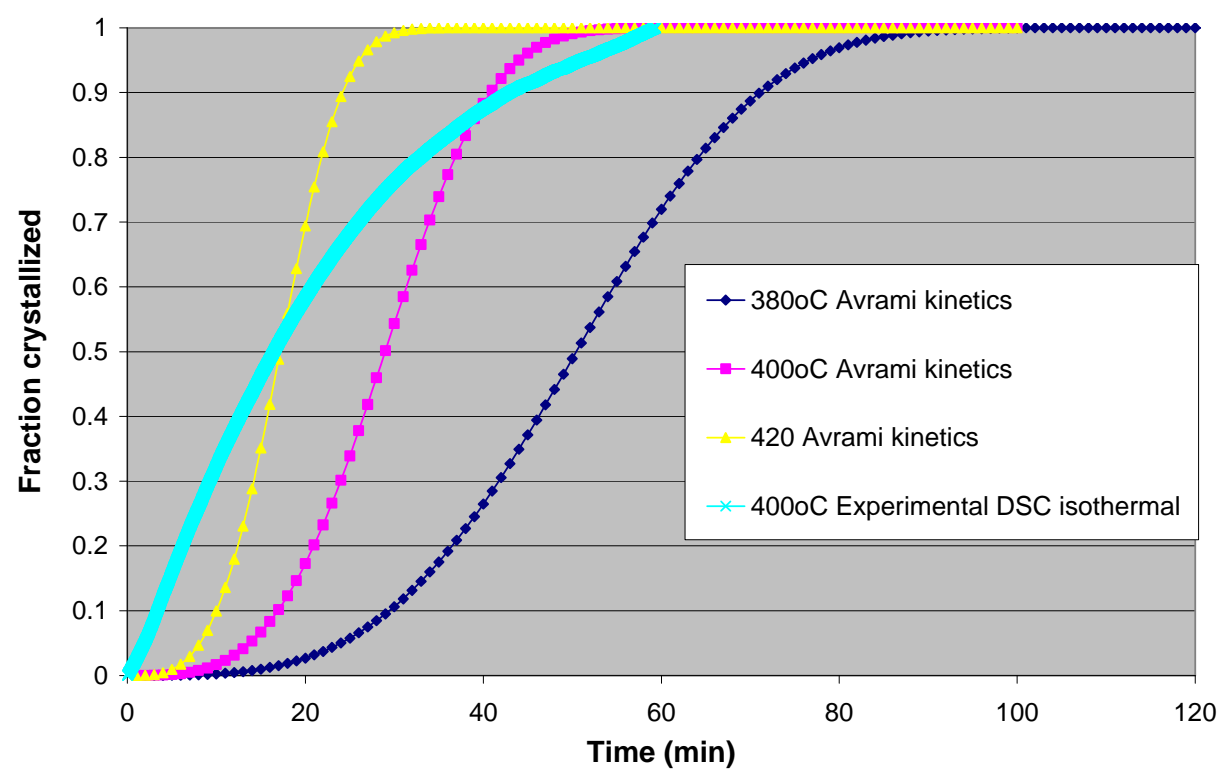

Figure 13. Fraction crystallized from experimentally determined parameters and equations 6, 7. Isothermal DSC crystallization data at $400^{\circ} \mathrm{C}$ included for comparison.

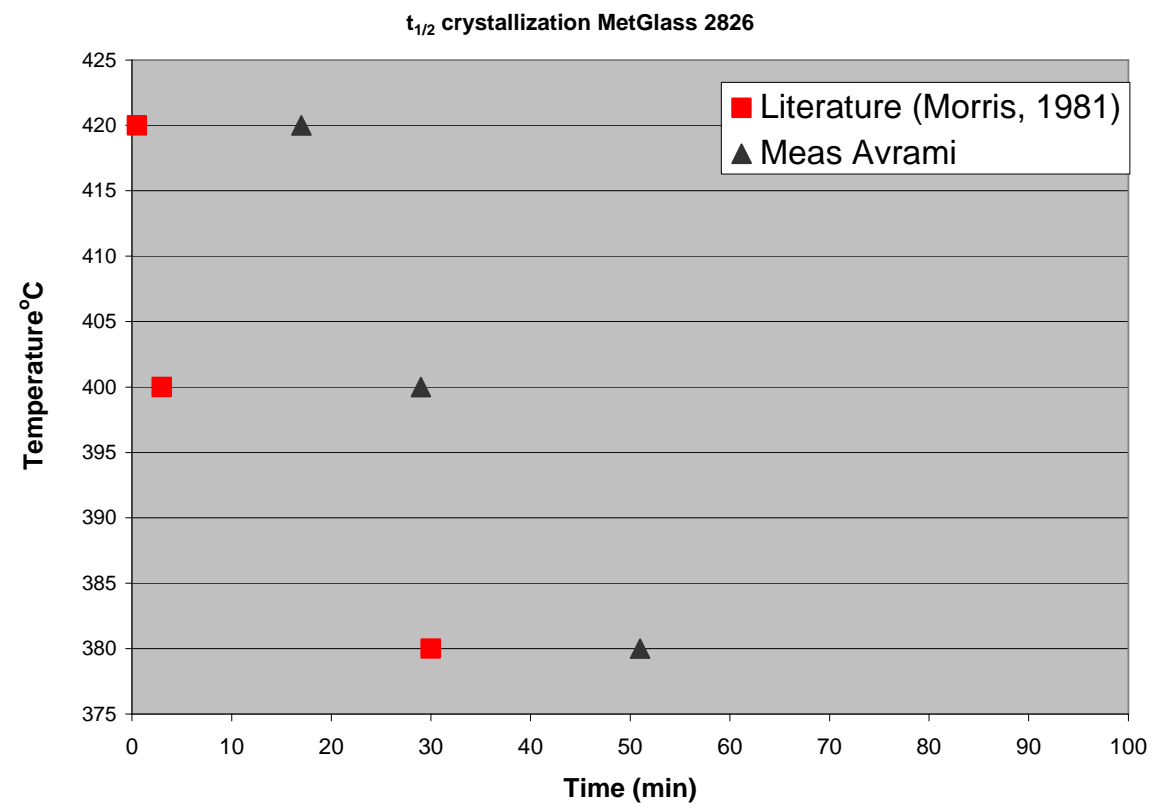

Figure 14. Time to $1 / 2$ fraction of crystallization at a given temperature from equations 6 \& 7as compared to literature data from Morris [35]. 
As seen in Figure 14, kinetic expressions from equation 6 and 7 predict that crystallization is complete at $400^{\circ} \mathrm{C}$ after approximately 50 minutes which agrees well with the experimentally determined isothermal DSC behavior showing completion after 60 minutes. The deviation from experimental isothermal DSC and Avrami kinetics at the beginning of crystallization may be due to the uncertaintly in baseline correction/thermal lag adjustments in the isothermal DSC data. In addition, some of the shape shifting may also do to the fact that experimentally we do not have isothermal exposure. The sample is heated to temperature then held, so that there may be some initial crystallization which is followed by steady state transformation. The deviation in the crystallization half life as compared to literature data from Morris depicted in Figure 14Figure may be due to compositional differences ( $5 \%$ or greater variation in the elemental composition in purchased samples) as well as the thicker (greater than 50 microns) samples used in the previous study impacting crystallization measurements. The relative form of the time versus temperature crystallization behavior is retained in our experiments as compared to literature from Morris [35].

\subsection{Hydrogen Flux Measurement}

In this section, the hydrogen flux measurements through metglass samples are presented and compared for electrochemical permeation and gas permeation measurements.

\subsubsection{Electrochemical Permeation}

The baseline electrochemical measurements for amorphous alloys are presented in this section:

\subsubsection{Baseline Measurements}

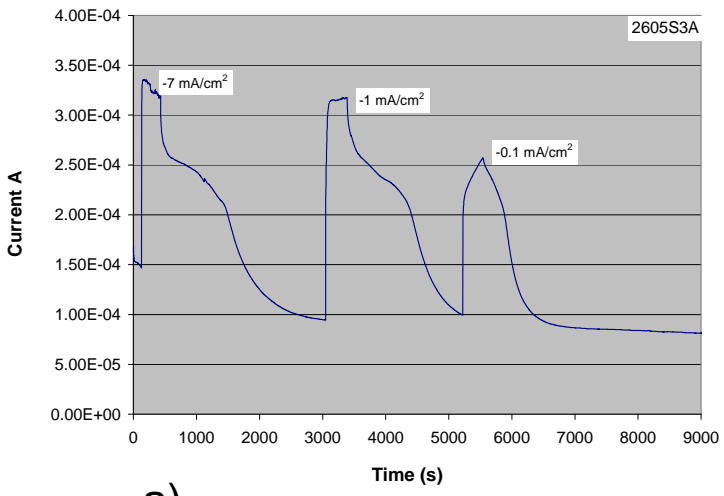

a)

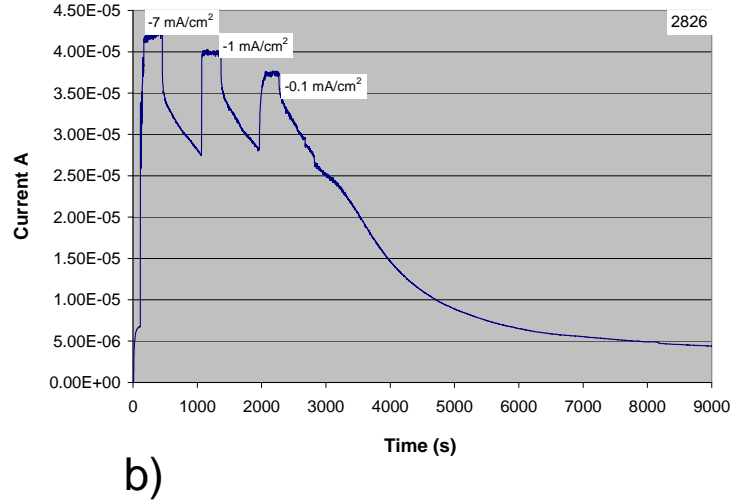

b)

Figure 15. Current proportional to hydrogen flux at the anode versus time for a) 2605S3A and b) 2826 alloy with charging sequence of $-7,-1$ and $-0.1 \mathrm{~mA} / \mathrm{cm}^{2}$.

Metglass samples of 2714A (Co based) and 2605SA1 did not show current peaks indicating hydrogen flux even after extended charging times (excess of 48 hours). The flux of 2714A was also barely detectable at elevated temperatures in the gas phase system indicating the low hydrogen flux performace of this composition. The 2605SA1 showed appreciable levels of flux on the gas phase system at elevated temperature and visual examination of the electrochemical tested samples revealed rust and a self passivation behavior that is thought responsible for the undetectable room temperature flux via electrochemical means. The current measured and displayed in Figure was converted into flux and permeation rate via equation 1 and 2 resulting in values of $2 \times 10^{-10} \mathrm{~mol} \mathrm{H}_{2} / \mathrm{ms}$ for 2605 and $3 \times 10^{-11} \mathrm{~mol} \mathrm{H}_{2} / \mathrm{ms}$ for 2826 alloys measured at $25^{\circ} \mathrm{C}$ and $-1 \mathrm{~mA} / \mathrm{cm}^{2}$ charging conditions as compared to $3 \mathrm{X}^{-9} 0^{-9} \mathrm{~mol} \mathrm{H}_{2} / \mathrm{ms}$ for Pd metal standard 
under the same conditions. Dos Santos has reported flux values on the order of $1 \times 10^{-8} \mathrm{~mol} / \mathrm{m} \mathrm{s}$ for 150 micron $\mathrm{Pd}_{80} \mathrm{Ru}_{20}$ alloy under similar charging conditions [37].

\subsubsection{Nernst Equation relation to Pressure/Gas Phase measurements}

Electrochemical permeation rates are quoted in $\mathrm{mol} / \mathrm{m} \mathrm{s}$ at given charging conditions, while gas phase measurements are quoted as $\mathrm{mol} / \mathrm{m} \mathrm{s} \mathrm{Pa}{ }^{1 / 2}$. In order to compare electrochemical measurments with gas phase measurements we need a link between the electromotive force used for $\mathrm{H}_{2}$ generation and the hydrogen pressure which is given by the Nernst equation:

$E=\frac{R T}{2 F} \ln \frac{p H 2 I}{p H 2 I I}$

where $\mathrm{E}=$ electromotive force in volts $(\mathrm{V}), \mathrm{R}$ is gas constant $8.314 \mathrm{~J} / \mathrm{molK}, \mathrm{F}$ is Faraday's constant $9.64 \times 10^{4} \mathrm{C} / \mathrm{mol}, \mathrm{pH}_{2}$ are the partial pressure of hydrogen on side I and side II of the membrane. Since the hydrogen diffusing through the membrane is oxidized on side II resulting in the current measured for hydrogen flux, the value of hydrogen partial pressure is very low. For this estimation we assume that the value is $1 \times 10^{-9}$ bar (or $\left.0.0001 \mathrm{~Pa}\right)$. A comparison of the electrochemical and gas phase measurements in the same units are presented in Table 15. Permeation data comparison between electrochemical techniques and gas phase techniques.

Nernst

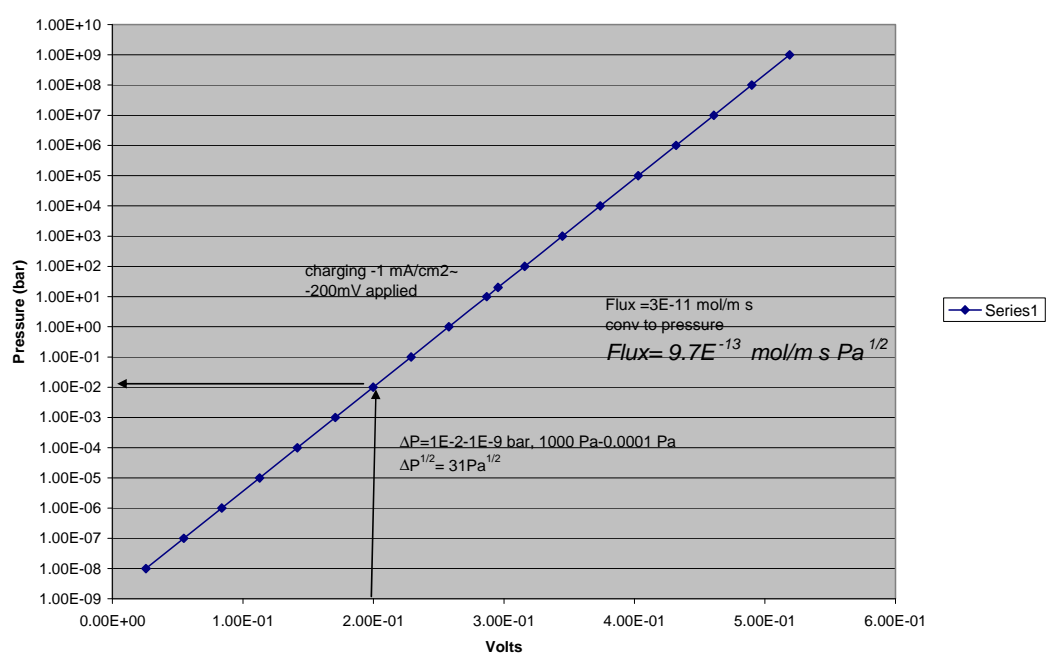

Figure 16. Nernst equation applied to charging conditions of $\left(-1 \mathrm{~mA} / \mathrm{cm}^{2}\right)$ where $-200 \mathrm{mV}$ was applied to the membrane on one side resulting in an effective pressure differential driving force $\Delta P^{1 / 2}$ of $31 \mathrm{~Pa}^{1 / 2} ; 2826$ flux of $3 \times 10^{-11} \mathrm{~mol} / \mathrm{ms}$ is converted to $9.7 \times 10^{-13} \mathrm{~mol} / \mathrm{m}$ $\mathrm{sPa}^{1 / 2}$

Table 15. Permeation data comparison between electrochemical techniques and gas phase techniques

\begin{tabular}{|c|c|c|c|}
\hline Alloy & $\begin{array}{c}\text { Electrochemical } \\
\text { Permeability } \\
\left(\mathrm{mol} \mathrm{H}_{2} / \mathrm{m} \mathrm{s}\right) \\
\end{array}$ & $\begin{array}{c}\text { Electrochemical } \\
\text { Permeability } \\
\left(\mathrm{mol} \mathrm{H}_{2} / \mathrm{m} \mathrm{s} \mathrm{Pa}^{1 / 2}\right) \\
\end{array}$ & $\begin{array}{c}\text { Gas Phase Permeability } \\
400^{\circ} \mathrm{C} 700 \text { Torr } \\
\left(\mathrm{mol} \mathrm{H}_{2} / \mathrm{m} \mathrm{s} \mathrm{Pa}^{1 / 2}\right) \\
\end{array}$ \\
\hline Pd & $3.5 \times 10^{-9}$ & $1 \times 10^{-10}$ & $2.8 \times 10^{-8}[38]$ \\
\hline 2605S3A & $2 \times 10^{-10}$ & $6 \times 10^{-12}$ & $2.5 \times 10^{-9}$ \\
\hline $\begin{array}{c}2826 \\
\text { amorphous }\end{array}$ & $3 \times 10^{-11}$ & $1 \times 10^{-12}$ & $5.3 \times 10^{-9}$ \\
\hline $\begin{array}{c}2826 \\
\text { crystalline }\end{array}$ & $2.6 \times 10^{-12}$ & $8 \times 10^{-14}$ & $\mathrm{x}$ \\
\hline
\end{tabular}




\subsubsection{Diffusivity and Solubility Determination}

The transient current due to hydrogen flux through the membrane can be used to calculate the diffusivity $\mathrm{D}\left(\mathrm{m}^{2} / \mathrm{s}\right)$ of hydrogen in the material via equation 9 [39].

$\frac{J(t)}{J_{S S}}=1+2 \sum_{n=1}^{\infty}(-1)^{n} \exp \left(-n^{2} \pi^{2} \frac{D^{*} t}{L^{2}}\right)$

where $J(t)$ is the flux at time $t$, Jss is the steady state flux, $\mathrm{n}$ is the number of iterations, $\pi$ is a constant, $\mathrm{D}$ is the Diffusivity and $\mathrm{L}$ is the membrane thickness. A plot of $\mathrm{J}(\mathrm{t}) / \mathrm{Jss}-1$ versus $\mathrm{t}$ for a truncated series with $n=1,2,3$ was used along with a Levenberg-Marquardt algorithm in order to find the best fit value for the diffusivity.

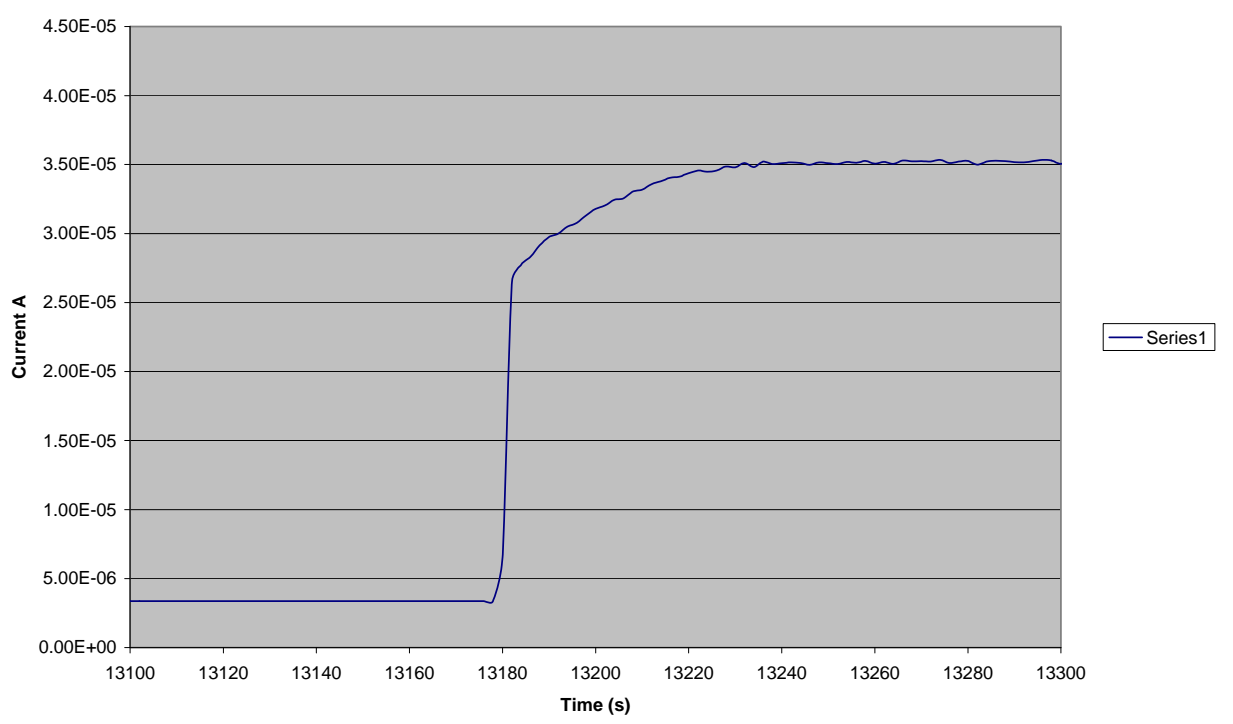

Figure 17. 2826 amorphous material hydrogen permeation transient used with equation 9 in order to calculate diffusivity $\mathrm{D}=2.5 \times 10^{-11} \mathrm{~m}^{2} / \mathrm{s}$ (Pd metal at $25^{\circ} \mathrm{C} 3.3 \times 10^{-11} \mathrm{~m}^{2} / \mathrm{s}$ ) [40]

Using equation 9 on the current transient of 2826 alloy shown in Figure 17 results in a diffusivity value $\mathrm{D}=2.5 \times 10^{-11} \mathrm{~m}^{2} / \mathrm{s}$, the same order of magnitude as pure $\mathrm{Pd}$ metal at $25^{\circ} \mathrm{C}$ [40]. The solubility $\mathrm{S}\left(\mathrm{mol} / \mathrm{m}^{3}\right)$ is then obtained by dividing the permeation rate $(\mathrm{mol} / \mathrm{m} \mathrm{s})$ by the diffusivity $\left(\mathrm{m}^{2} / \mathrm{s}\right)$ resulting in $1.18 \mathrm{~mol} / \mathrm{m}^{3}$ for amorphous 2826 metglass alloy or roughly 1 hydrogen atom associated with 1 metal atom in the material; crystalline materials such as $\mathrm{TiH}_{2}$ and $\mathrm{HfH}_{2}$ have $\mathrm{H} / \mathrm{M}$ ratios greater than 1 at $27^{\circ} \mathrm{C}[41]$.

\subsubsection{Gas Phase Permeation}

This section provides a description of "dynamic" measurement technique used for the in-situ crystallization/permeation measurments. Figure 19 shows a plot of measured total pressure and hydrogen partial pressure versus time and temperature for a 2826 metglass alloy. In the dynamic measurement configuration the backside of the membrane is always being pumped down to turbomolecular pump pressure so that the actual hydrogen flux is proportional to both the pump speed and concentration/partial pressure presented in Figure 18. Nevertheless, for a relative value of hydrogen permeation in the same sample under different crystallization conditions determined 
by measurement temperature the hydrogen partial pressure is a measure of the hydrogen flux. The hydrogen flux is seen to increase with increasing temperature as expected.

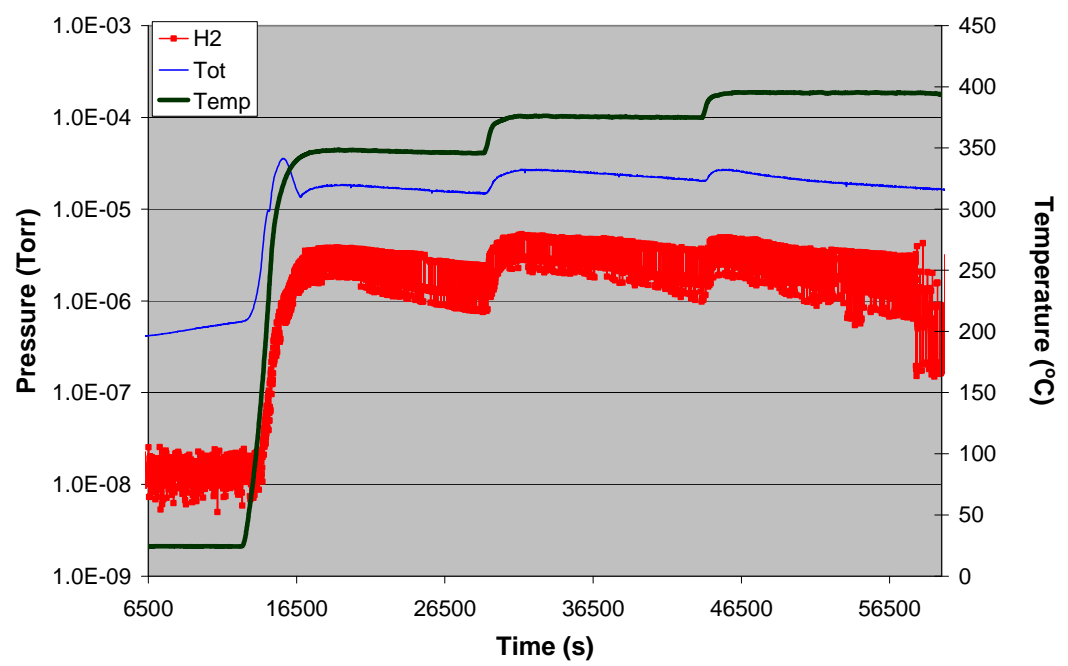

Figure 18. Pressure in the dynamic hydrogen gas permeation measurement conducted at 350,380 and $400^{\circ} \mathrm{C}$ as a function of time.

\subsubsection{Ex-situ crystallized samples: Electrochemical characterization}

In addition to time dependant measurements at or near crystallization temperatures, samples were annealed to elevated temperatures, characterized in terms of crystalline nature and then measured

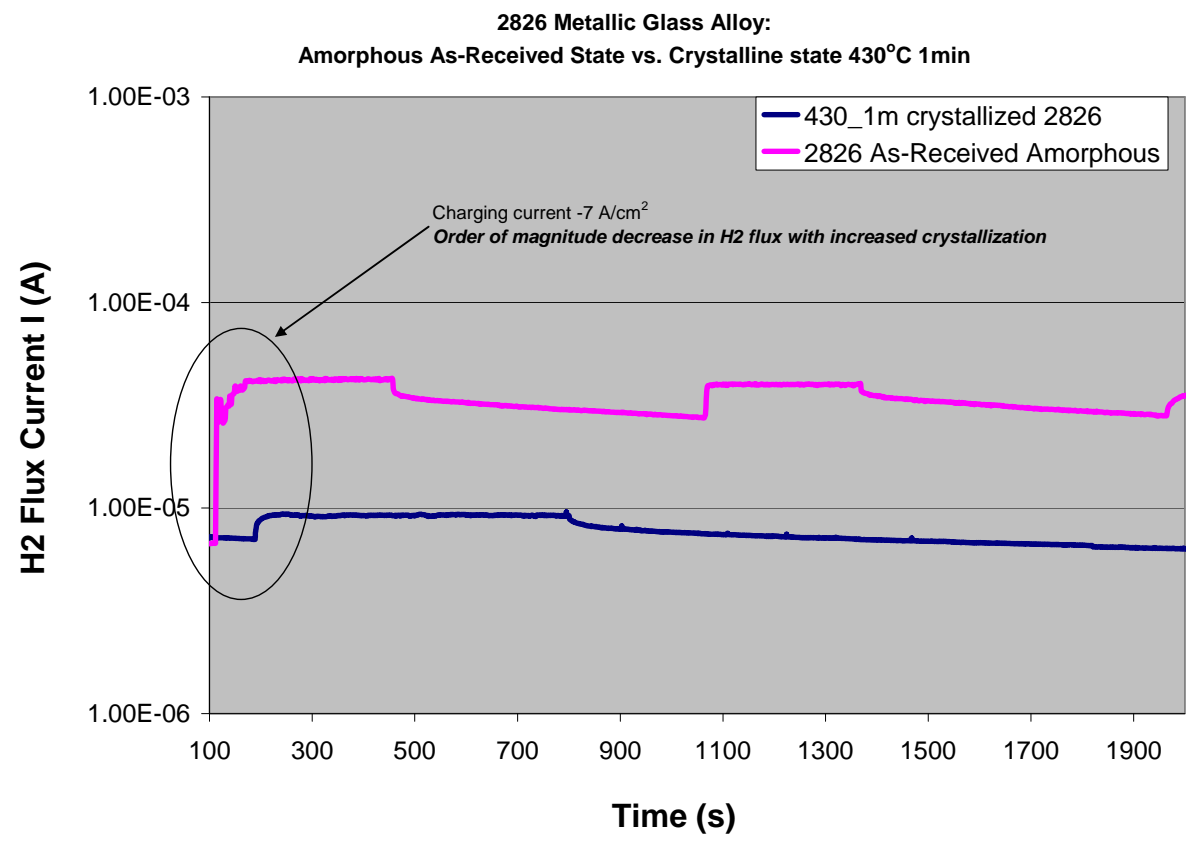

Figure 19. Current versus time for amorphous 2826 sample and sample crystallized at $430^{\circ} \mathrm{C}$ for 1 minute under charging condition of $-7 \mathrm{~mA} / \mathrm{cm}^{2}$ showing a near order of 
magnitude decrease in the hydrogen flux current with increasing crystallinity of the membrane.

at ambient temperatures in the electrochemical permeation setup. Figure 19 shows the current proportional to the hydrogen flux versus time for an amorphous 2826 and crystalline sample annealed to $430^{\circ} \mathrm{C}$ for 1 minute showing the near order of magnitude decrease in the current with increasing crystallintity of the membrane. The XRD patterns of the amorphous and crystalline materials are shown in Figure 20 for reference.

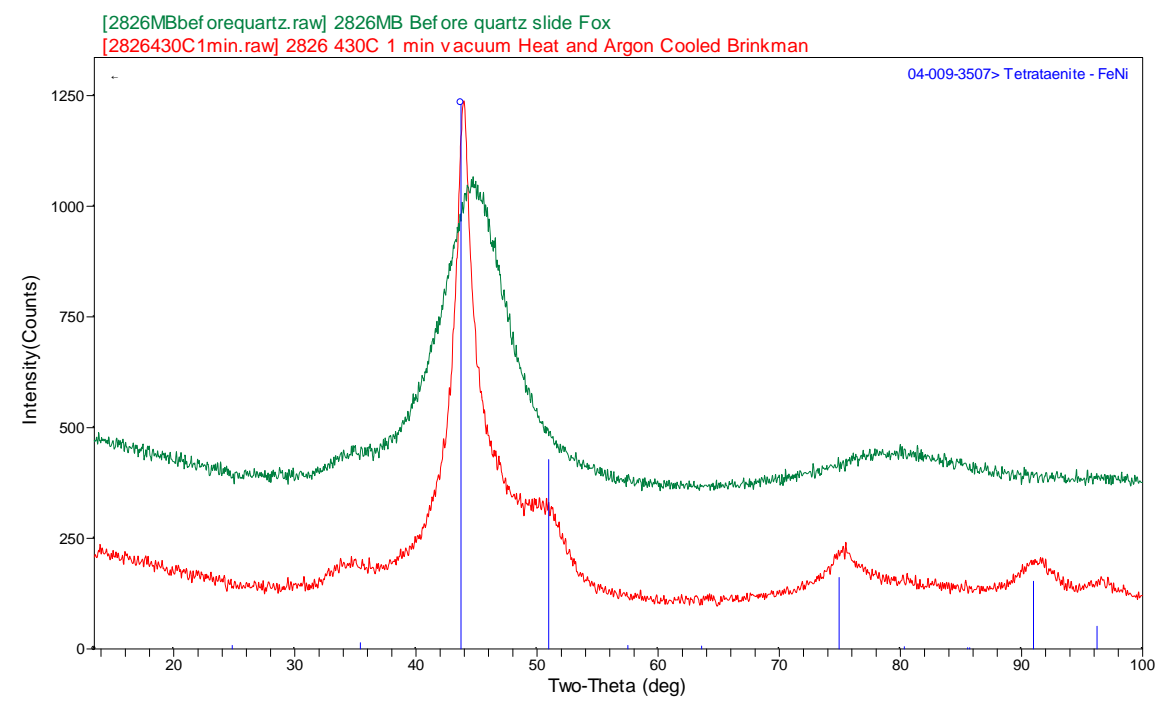

Figure 20. XRD pattern of amorphous 2826 alloy and sample annealed to $430^{\circ} \mathrm{C}$ for 1 minute in vacuum, followed by argon quenching. $\mathrm{Fe}_{0.5} \mathrm{Ni}_{0.5} \mathrm{FCC}$ alloy ordered tetragonal superlattice with $a=2.53 \mathrm{~A}, \mathrm{c}=3.58 \mathrm{~A}$

\subsubsection{In-Situ crystallization: Gas Permeation Rig}

A close up of the dynamic permeation measurement displaying pressure versus time at $400^{\circ} \mathrm{C}$ is shown in Figure 21a. Inspection of the figure reveals i) a decrease in the flux with time at $400^{\circ} \mathrm{C}$ as well as ii) a change in the slope of the pressure versus time relation which is proportional to the hydrogen flux. Figure $21 \mathrm{~b}$ shows the XRD spectra versus time at $400^{\circ} \mathrm{C}$ in a He inert atmosphere. Amorphous versus crystalline content determined from XRD spectra at $400^{\circ} \mathrm{C}$ indicted that the crystalline content increased from $17 \%$ after 10 minutes to approximately $28 \%$ after 3 hours at $400^{\circ} \mathrm{C}$. Kinetic estimates from DSC experiments indicate that the reaction should be complete after approximately 1 hour. However, XRD data show the crystalline content is only $22 \%$ after 1 hour, and slowly increases to $28 \%$ after 3 hours time where it remains stable. This behavior can be explained by an "in-complete" phase transformation which consists of stable crystalline phases inside an amorphous matrix which is graphically depicted in figure 23 and has been observed in FeNi metallic glass doped with Co [42]. Further work involving TEM analysis of partially crystalline materials after permeation measurements are required to confirm this hypothesis for 2826 alloy materials studied in this report. This hypothesis would explain the ensemble of structure/property relations observed in the in-situ permeation experiments consisting of: i) quick crystallization of a small fraction of the material leading to both crystalline content measured in $\mathrm{XRD}$ and a reduction in hydrogen flux in permeation experiments, ii) small changes in crystalline content after the first hour leading to small changes in the XRD crystalline patterns and no measurable difference in hydrogen permeation with time up to 3 hours at $400^{\circ} \mathrm{C}$ in hydrogen 
environments. The fact that the material retains significant amount of amorphous content after 3 hours at $400^{\circ} \mathrm{C}$ is reflected in both the XRD patterns (amorphous hump), as well the observed permeation which would be lower by an order of magnitude in fully crystalline specimens (see figure 20) and reference [43].

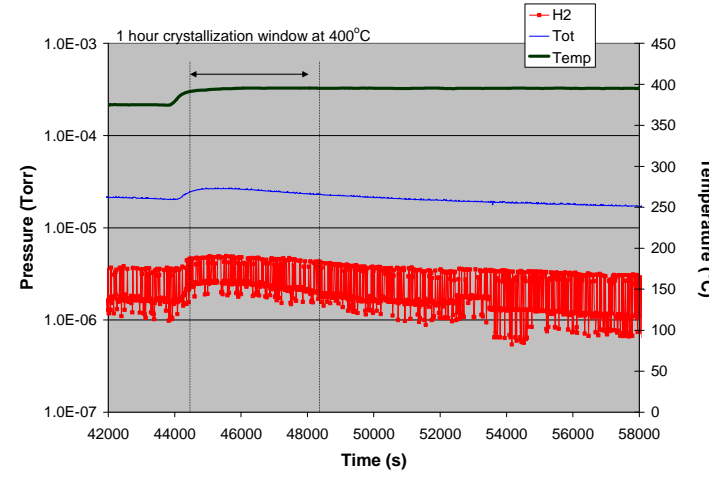

a)

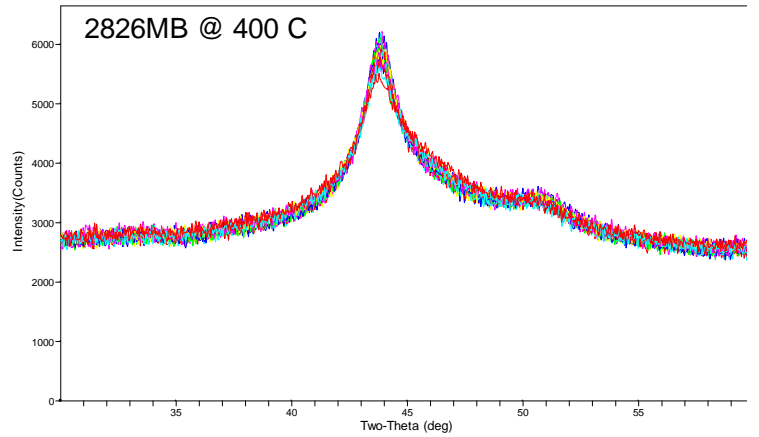

b)

Figure 21. a) Dynamic gas flux measurement of 2826 alloy at $400^{\circ} \mathrm{C}$ as a function of time b) $\mathrm{XRD}$ spectra at $400^{\circ} \mathrm{C}$ as a function of time.

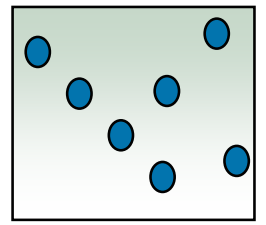

Figure 22. Nanoscale crystalline precipitates inside of an amorphous matrix [42].

\subsection{Discussion \& Literature Comparison}

Presently, the authors are aware of only one recent publication regarding the impact of partial crystallization on the hydrogen permeation properties of amorphous glass in the $\mathrm{Zr}_{65} \mathrm{Al}_{7.5} \mathrm{Ni}_{10} \mathrm{Cu}_{12.5} \mathrm{Pd}_{5}$ phase by Yamaura [44]. This material composition forms an icosahedral (i-phase) which precipatetes and co-exists within the glass matrix. Yamaura found that the crystallization pathway for this material differed in argon versus hydrogen atmosphere. The argon atmosphere crystallization was preceded by a supercooled liquid region showing an endothermic glass transition temperature. Samples heated under hydrogen crystallized at much lower temperatures without this glassy endotherm. Permeation properties as a function of time showed constant flux performance in the amorphous region and steady decrease in the flux when crystallization temperatures were approached. A near order of magnitude decrease from $10^{-8}$ $\mathrm{mol} / \mathrm{m} \mathrm{s} \mathrm{Pa}{ }^{1 / 2}$ to $10^{-9} \mathrm{~mol} / \mathrm{m} \mathrm{s} \mathrm{Pa}{ }^{1 / 2}$ was observed for amorphous and crystalline material respectively at $330^{\circ} \mathrm{C}$.

Dos Santos published numerous papers on the electrochemical hydrogen permeation technique. A comparison of our results on $2826 \mathrm{Fe}_{40-50} \mathrm{Ni}_{40-50} \mathrm{Mo}_{5-10} \mathrm{~B}_{1-5}$ composition compared to Dos Santos $\mathrm{Fe}_{40} \mathrm{Ni}_{38} \mathrm{Mo}_{4} \mathrm{~B}_{18}$ compostion shown in Figure 24 reflects the similar level of maximum hydrogen flux under charging conditions, but drastically different time dependence and hence diffusivity and solubility values [39]. The calculated diffusivity values were $5 \times 10^{-14} \mathrm{~m}^{2} / \mathrm{s}$ from Dos Santos $\mathrm{Fe}_{40} \mathrm{Ni}_{38} \mathrm{Mo}_{4} \mathrm{~B}_{18}$ phase compared to $2.5 \times 10^{-11} \mathrm{~m}^{2} / \mathrm{s}$ from the $2826 \mathrm{Fe}_{40-50} \mathrm{Ni}_{40-50} \mathrm{Mo}_{5-10} \mathrm{~B}_{1-5}$ composition used in this study. Dos Santos used various electrochemical techniques in order to 
tailor the hydrogen concentration profiles through the membrane and observed hydride formation, with significant lower diffusivities $10^{-15} \mathrm{~m}^{2} / \mathrm{s}$ in the hydride phase. An equation representing the permeation through composite materials (amorphous and hydride) was used along the the diffusivities of each phase to estimate the thickness of the hydride layer (18 microns) which was estimated to occupy a majority of the 25 micron thickness. No hydride phases were observed via $\mathrm{XRD}$ in the present work after measurement. Table 16 summarizes the difference in permeability, diffusivity and solubility of the 2826 amorphous and crystalline alloy examined in this work.

Table 16. Amorphous vs. Crystalline 2826 Alloy Electrochemical Permeability (P mol/m s), Diffusivity (D $\left.\mathrm{m}^{2} / \mathrm{s}\right)$, and Solubility $\left(\mathrm{S} \mathrm{mol} / \mathrm{m}^{3}\right)$

\begin{tabular}{|c|c|c|c|}
\hline Alloy & $\begin{array}{c}\mathbf{P} \\
\text { Electrochemical } \\
\text { Permeability } \\
\left(\mathrm{mol} \mathrm{H}_{2} / \mathbf{m ~ s}\right) \\
\end{array}$ & $\begin{array}{c}\text { D } \\
\text { Diffusivity } \\
\left(\mathrm{m}^{2} / \mathbf{s}\right) \\
\end{array}$ & $\begin{array}{c}\mathrm{S} \\
\text { Solubility } \\
\left(\mathrm{mol} / \mathrm{m}^{3}\right) \\
\end{array}$ \\
\hline $\begin{array}{c}2826 \\
\text { amorphous } \\
\end{array}$ & $3 \times 10^{-11}$ & $2.5 \times 10^{-11}$ & 1.18 \\
\hline $\begin{array}{c}2826 \\
\text { crystalline }\end{array}$ & $2.6 \times 10^{-12}$ & $5.8 \times 10^{-11}$ & 0.045 \\
\hline
\end{tabular}

An explanation the large discrepancy between the present work and the work of Dos Santos is the presence of a native oxide layer on the surface due to processing/cooling of the metglass ribbons and the fact that no hydride phases (with lower diffusivity of hydrogen) were observed in the 2826 specimens in this work as compared to slightly different compositions utilized by Dos Santos. In our work, we noticed that using the as-received samples and charging at an elevated current of $-7 \mathrm{~mA} / \mathrm{cm}^{2}(-2000 \mathrm{mV} \mathrm{SCE})$ there was no observable flux even after extended measurement times exceeding 24 hours. Polishing the surface of the sample with fine 1000 or greater grit paper before measurement resulted in immediate measurable hydrogen current. This further suggests the role of an oxide blocking layer on the surface of as-received specimens. Surface sensitive techniques such as XPS were used to identify the presence of an oxide layer on the surface before polishing and measurement. An additional item for consideration is to take a look at the fundamental properties of likely oxides in this system namely $\mathrm{Fe}_{2} \mathrm{O}_{3}$, NiO and $\mathrm{B}_{2} \mathrm{O}_{3}$ and their impact on the hydrogen permeation properties. There are two likely scenarios: i) is that the oxide is stable under the measurement conditions and the hydrogen diffusivity in the oxide is extremely low at ambient temperatures leading to the observed blocking of the hydrogen flux, ii) is that the oxides will be reduced under the measurement conditions and the kinetics of the reduction reaction will replace the effective "diffusivity" of the oxide layer and determine the breakthrough time of hydrogen in the material. 


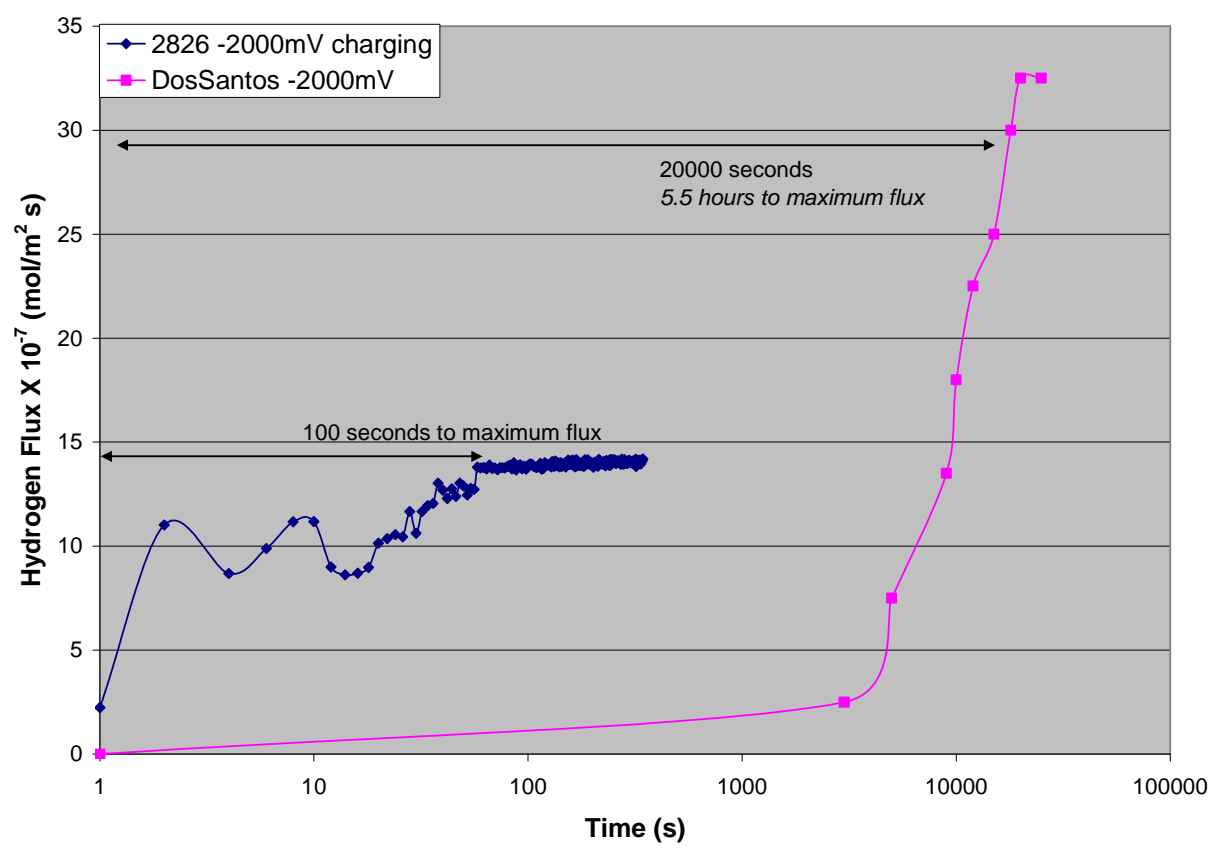

Figure 23. Hydrogen flux $\left(X 10^{-7} \mathrm{~mol} / \mathrm{m}^{2} \mathrm{~s}\right)$ for 25 micron thick metglass ribbons of 2826 used in this study versus $\mathrm{Fe}_{40} \mathrm{Ni}_{38} \mathrm{Mo}_{4} \mathrm{~B}_{18}$ composition used by Dos Santos [39]. Plot displays same order of magnitude maximum hydrogen flux but orders of magnitude difference in the time to maximum flux proportional to hydrogen diffusivity $D\left(\mathrm{~m}^{2} / \mathrm{s}\right)$ and solubility $S$ $\left(\mathrm{mol} / \mathrm{m}^{3}\right)$ in the material.

\subsection{Fundamental Influence of Materials Chemistry}

Additional work on metallic glass materials conducted at SRNL focused on the fundamental influence of materials chemistry on the structure and permeation flux of membrane materials.

Several Zirconium based BMG alloys have been shown to possess high permeation rates--Zr-Al$\mathrm{Co}-\mathrm{Ni}-\mathrm{Cu}$ alloy $=1.13 \times 10^{-8}\left(\mathrm{~mol} /\left(\mathrm{m} \mathrm{s} \mathrm{Pa}^{1 / 2}\right)\right.$ which is comparable to permeation rates measured for pure Pd metal--and high elastic toughness [45]. Both of these properties-high permeation and high elastic toughness-- potentially make these materials attractive for gas separation membranes that could resist the hydrogen "embrittlement". However, a fundamental understanding of the relationship between their amorphous "structure" and diffusion/solubility of hydrogen in these BMG materials is required if their potential as replacement membrane materials will ever be realized. This portion of work aimed to elucidate the impact of changes in chemistry (Zr content in $\mathrm{Zr}$-Al-Co glasses) [46] on the local structure with and without hydrogen incorporation. Using the methods developed by Miracle [47], models were used to predict the structure of the alloys at various compositions and hydrogen loading. Zirconium is a strong hydride former, and the low energy hydrogen in tetrahedral enhances the hydrogen solubility. However, the permeation of hydrogen through the material is a product of the solubility and diffusivity; if the hydrogen is strongly attracted tetrahedral zirconium spaces the crystallization of $\mathrm{ZrH}_{2}$ may occur reducing the hydrogen diffusivity in the composite material. Ternary compositions of $\mathrm{Zr}$ based metallic

ú

ú ú

ú \lrcorner ú

ú

ú ú

ú

ú 
We selected two Zr based BMG Alloys, LM 100 (55 Zr 25 Co 20 Al) and LM 110a (60 Zr 27 Co $13 \mathrm{Al}$ ) as our model systems. The $\mathrm{Zr}$ based BMGs exhibit unique properties and are being studied by other researchers as well. A methodology developed by Miracle was implemented to generate possible structures for the bulk metallic glasses of interest. These structures were subsequently optimized using Density Functional Theory with the most stable unit cell for each BMG composition yielding a bulk density that closely matched the experimental results. Unfortunately, molecular dynamics simulations using these unit cells and additional hydrogen atoms were unable to be run long enough to generate reliable estimates for the rate of diffusion or permeation of hydrogen through the BMGs at the temperatures of interest. Collaborations with other researchers in this topical area were initiated and other research at SRNL may result in these properties being determined at a later date in a different manner using the potential energy surface maps and binding energy density of states that we have also calculated. The alloys were characterized using x-ray diffraction and showed that the LM110 was amorphous while the LM110a had a crystalline component.

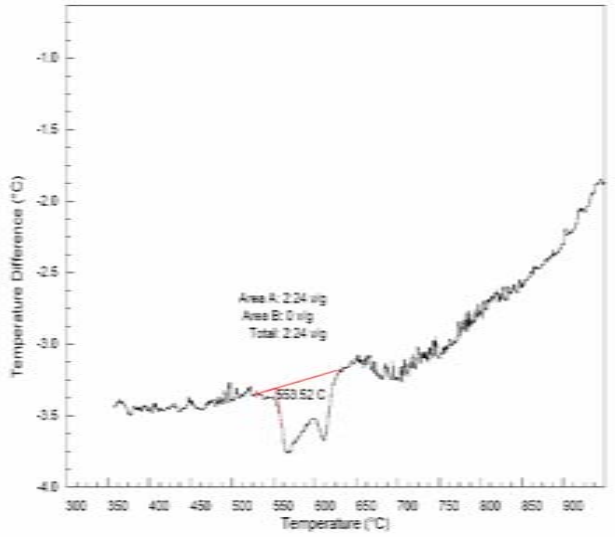

a)

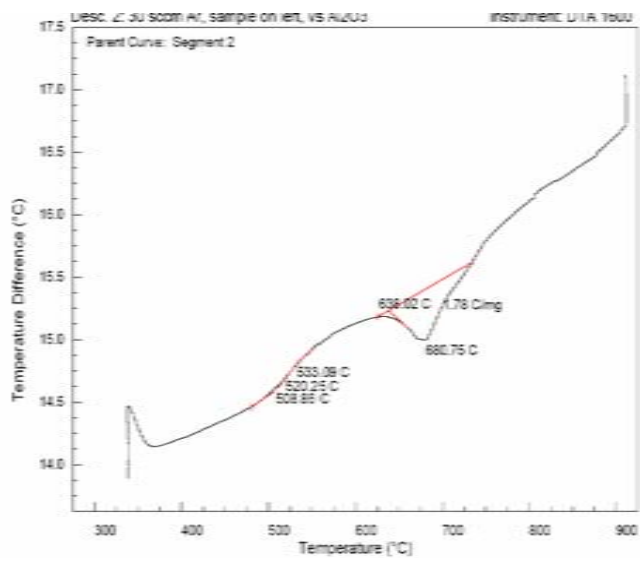

b)

\section{Figure 24. DTA of a) LM110 and b) LM110a Zr based metglass materials}

The degree of crystallinity was not quantified, but its presence was noted. Further characterization included determining the nominal glass transition and crystallization temperatures using DTA and shown in figure 25. The glass transition and crystallization temperatures were $520^{\circ} \mathrm{C}$ and $638^{\circ} \mathrm{C}$ for $\mathrm{LM} 110 \mathrm{a}$, respectively, while the glass transition temperature was not obvious for the LM110 and the crystallization temperature appears to be $553^{\circ} \mathrm{C}$. The measured permeation rates are shown in figure 27 and indicate that the hydrogen flux was within two orders of magnitude of the baseline Pd-based material. During the permeation testing, a reduction in flux with time was observed that was associated with surface oxidation and possible crystallization. XRD analysis before and after permeation testing is shown in figure 26. Post test XRD revealed a surface oxide and partial crystallinity. Due to the oxide layer blocking hydrogen access to the bulk of the material, direct comparisons of the hydrogen flux versus $\mathrm{Zr}$ concentration are difficult and no strong conclusions can be drawn at this time. 
SRNS-STI-2008-00133

Revision 1
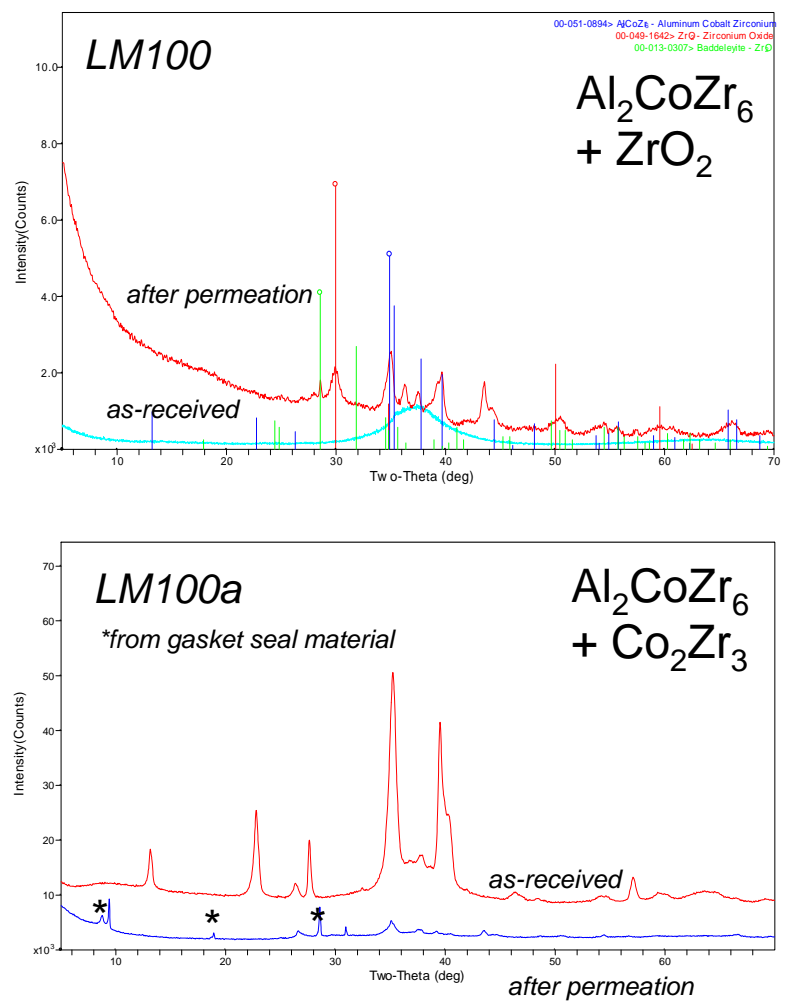

Figure 25. XRD of LM100 and LM100a material.

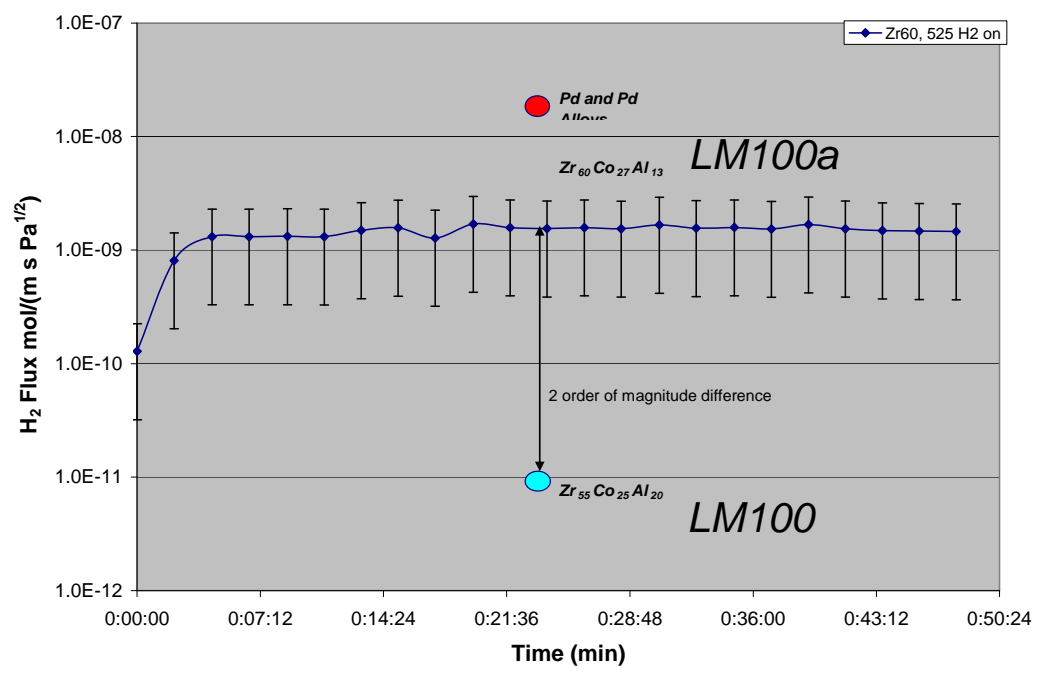

Figure 26. Hydrogen permeation (via gas permeation with GC detection) versus time of LM100 and LM100a alloy as compared to Pd standard. 


\subsection{Conclusions}

The objective of this study was to experimentally measure the properties and performance of metglass membranes in both the amorphous and crystalline state to examine the impact of partial crystallinity on membrane performance. The following items were achieved

- Crystallization temperature, energy released and phase composition/structure identity under argon, air and hydrogen gas environments were obtained.

- Kinetic crystallization parameters based on Avrami equation were obtained for the 2826 alloy and compared with literature

- Baseline permeation properties of the amorphous alloys were characterized by i) electrochemical permeation and ii) gas phase permeation

- The effect of crystallization on the permeation was studied i) ex-situ by annealing samples before measurement and ii) in-situ by measuring gas phase hydrogen permeation during crystallization.

- Ex-situ studies revealed that the hydrogen permeation was reduced in crystalline samples by an order of magnitude from $3 \times 10^{-11}\left(\mathrm{~mol} \mathrm{H}_{2} / \mathrm{m} \mathrm{s}\right)$ to $2.6 \times 10^{-12}\left(\mathrm{~mol} \mathrm{H}_{2} / \mathrm{m} \mathrm{s}\right)$ in 2826 alloys due to reduced solubility of hydrogen in the crystalline phase

- In-situ studies on the 2826 alloy revealed a drop in permeation at $400^{\circ} \mathrm{C}$ during the first hour (with crystalline content by XRD increasing from 0 to $17 \%$ ), followed by stabilization of the flux and crystalline content $(27 \%)$ over a 3 hour period. Permeation and XRD analysis suggest a crystalline phase co-exists in an amorphous matrix.

\subsection{Suggestions for Future Work/Path Forward}

There were significant difficulties encountered while measuring the electrochemical flux of samples crystallized at elevated temperatures due to their brittle nature. It is recommended that future work focus on elevated temperature "in-situ" gas phase measurements. Larger flux area would improve the $\mathrm{dP} / \mathrm{dt}$ sensivitity perhaps allowing detailed discrimination of the changes in flux behavior accompanying structural changes. Also, there are two functional relation differences between amorphous and crystalline material that should be explored:

1) Pressure dependence: flux is proportional to $\Delta \mathrm{P} 1 / 2$ in crystalline membranes and $\Delta \mathrm{P}^{\mathrm{n}}$ in amorphous

2) Temperature dependence: activation energies for hydrogen flux are different in the amorphous and crystalline states

A full characterization of the $\mathrm{P}$ and $\mathrm{T}$ dependence of hydrogen flux in amorphous and crystalline "zones" of metglass materials can be used to predict behavior in "crossover" transition regions from amorphous to crystalline and to predict the impact on membrane performance. In addition, contaminant effects are of prime importance in membrane separation literature. The dominant mechanism is proposed to be stable phase formation between contaminant (sulfur for instance) and metal component of membranes which blocks hydrogen diffusion. Since metallic glass materials are amorphous, the ability to form a stable blocking layer should be limited and they should be more resistant to gas phase contaminant effects than conventional metal alloy membranes like $\mathrm{Pd} / \mathrm{Pd}$ alloys. Experimental studies on these effects are warranted. 


\subsection{Acknowledgements}

Dr. H. Ajo is gratefully acknowledged for XPS work on surface oxide layers of metallic glass specimens. D. Missimer and Dr. A. Jurgensen are acknowledged for their work on high temperature XRD analysis of amorphous to crystalline phase transformations in metallic glass materials. Structural modeling using DFT was performed by Dr. Stephen Garrison and his insight into structure property relations is acknowledged. 


\subsection{References}

1. ASTM G148-97 Standard Practice for Evaluation of Hydrogen Uptake, Permeation, and Transport in Metals by an Electrochemical Technique.

2. Adams, T.M. and J. Mickalonis, Hydrogen permeability of multiphase V-Ti-Ni metallic membranes. Materials Letters, 2007. 61(3): p. 817-820.

3. Phair, J. and R. Donelson, Developments and Design of Novel (Non-Palladium-Based) Metal Membranes for Hydrogen Separation. Ind. Eng. Chem. Res., 2006. 45: p. 5657.

4. Mansour, A. and R. Brizzolara, Iron XPS Spectra from the Physical Electronics Model 5400 Spectrometer. Surface Science Spectra, 1997. 4: p. 175.

5. Mansour, A. and R. Brizzolara, Characterization of the Surface of FeO Powder by XPS. Surface Science Spectra, 1998. 4: p. 345.

6. Mansour, A. and R. Brizzolara, Characterization of the Surface of gamma-Fe2O3 Powder by XPS. Surface Science Spectra, 1998. 4: p. 351.

7. Mansour, A. and R. Brizzolara, Characterization of the Surface of alpha FeOOH Powder by XPS. Surface Science Spectra, 1998. 4: p. 357.

8. Anderson, J., M. Kuhn, and U. Diebold, Epitaxially Grown Fe3O4 Thin Films: An XPS Study. Surface Science Spectra, 1998. 4: p. 266.

9. Missimer, D., A. Jurgensen, and R. Rutherford, High Temperature X-ray Diffraction Analysis of S3A Metallic Glass in Air, He, and 4\% H2 /96\% He. SRNL-L400-200800016, October 2008.

10. Abrahamson, E. and S. Lopata, The Lattice Parameters and Solubility Limits of Alpha Iron as Affected by Some Binary Transition-Element Additions. Trans. Met. Soc. AIME, 1966. 236: p. 76.

11. Buschow, K., D. Mooij, and H. Van Noort, The Fe-rich Isothermal Section of Nd-Fe-B at $900{ }^{\circ} \mathrm{C}$. Philips J. Res, 1985. 40: p. 227.

12. Thimmappa, B., et al., Amorphous Alloy Thin Films from Molecular Precursors. Evidence of Structure and Stoichiometry from Crystallization and Effects of Precursor Ligand Structure on Stoichiometry. Chem. Mater., 1991. 3: p. 1148.

13. Hubbard, C., Private Communication, ORNL, 1993.

14. Khan, Y. and H. Wibbeke, Formation of the $\tau$-Phase in Fe-B Alloys. Z. Metallkd., 1991. 82: p. 703.

15. Missimer, D., A. Jurgensen, and R. Rutherford, High Temperature X-ray Diffraction Analysis of 2714A Metallic Glass in Air, He, and 4\% H2 196\% He. SRNL-L4000-200800040, February, 2009.

16. Swanson, H., M. Morris, and E. Evans, Natl. Bur. Stand. (U.S.) Monogr., 1966. 25(4): p. 10.

17. Makovicky, E., E. Sotofte, and S. Karup-Moller, The Crystal Structure of Cu2.31TeSO.32 - a Condensed Cluster Compound. Ark. Kemi, Mineral Geo., 1933. 11A: p. 5.

18. Landrum, G., et al., The TiNiSi Family of Compounds: Structure and Bonding. Inorg. Chem., , 1998. 37: p. 5754.

19. Ayel, Inorg. Chem., , 1967. 264: p. 1756.

20. Aldinger, F. and S. Jonsson, The Phase Diagram. Beryllium-Cobalt. Z. Metallkd., 1977. 68: p. 363 .

21. Okamoto, H., Phase Diagrams for Binary Alloys. ASM International, 2000.

22. Guo-Hua, T. and C. Wan-Rong, An X-ray diffraction Study of the Crystallization Characteristics of Amorphous Co-B Ribbons. Mater. Sci. Eng, 1988. 97: p. 329.

23. Yedneral, A., Phys. Met. Metall., 1982(53): p. 111. 
24. Missimer, D., A. Jurgensen, and R. Rutherford, High Temperature X-ray Diffraction Analysis of 2826 Metallic Glass in Air, He, and 4\% H2 196\% He. SRNL-L400-200800015, October, 2008.

25. Tagai, T., H. Takeda, and T. Fukuda, Superstructure of Tetrataenite from the Saint Severin Meteorite. Z. Kristallogr., 1995. 210: p. 14.

26. Khan, Y., Crystallization Behaviour of the Melt-Quenched (Fel-yNiy)3B Alloys. Z. Metallkd., 1983. 74: p. 385.

27. Kamzeeva, E., N. Khatanova, and G. Zhdanov, Sov. Phys. Crystallogr. (Engl. Transl.\}, 1984. 29: p. 338.

28. Rieger, W., H. Nowotny, and F. Benesovsky, Die Kristallstruktur von Mo2FeB2 - Kurze Mitteilung. Monatsh. Chem, 1964. 95: p. 1502.

29. Haschke, H., H. Nowotny, and F. Benesovsky, Investigations of the three component systems: $(\mathrm{Mo}, \mathrm{W})-(\mathrm{Fe}, \mathrm{Co}, \mathrm{Ni})-\mathrm{B}$. Monatsh. Chem., 1966. 97: p. 1459.

30. Missimer, D., A. Jurgensen, and R. Rutherford, High Temperature X-ray Diffraction Analysis of 2605 SA1Metallic Glass in Air, He, and 4\% H2 196\% He. SRNL-L400-200800017, November, 2008.

31. Swanson, H., Natl. Bur. Stand. (U.S.), Circ., 1955. 539 IV: p. 3.

32. Aronsson, B., An Investigation of the Fe5Si3-FeSi Region of the Mn-Fe-Si and some Related Systems. Acta Chem. Scand., 1958. 12: p. 308.

33. ASTM E-698-05 Standard Test Method for Arrhenius Kinetic Constants for Thermally Unstable Materials Using Differential Scanning Calorimetry and the Flynn/Wall/Ozawa Method.

34. Aoki, K., Amorphous phase formation by hydrogen absorption. Materials Science and Engineering a-Structural Materials Properties Microstructure and Processing, 2001. 304: p. 45-53.

35. Morris, D.G., Crystallization of the Metglas-2826 Amorphous Alloy. Acta Metallurgica, 1981. 29(7): p. 1213-1220.

36. Greer, A.L., Crystallization Kinetics of Fe80b20 Glass. Acta Metallurgica, 1982. 30(1): p. 171-192.

37. dos Santos, D.S., S. Miraglia, and D. Fruchart, Effects of cathodic charging on hydrogen permeation in a Pd80Rh20 alloy. Journal of Alloys and Compounds, 2004. 383(1-2): p. 213-218.

38. Ockwig, N.W. and T.M. Nenoff, Membranes for hydrogen separation. Chemical Reviews, 2007. 107(10): p. 4078-4110.

39. dos Santos, D.S. and P.E.V. de Miranda, The use of electrochemical hydrogen permeation techniques to detect hydride phase separation in amorphous metallic alloys. Journal of Non-Crystalline Solids, 1998. 234: p. 133-139.

40. $\quad$ Alfeld G., V.J., Hydrogen in Metals I., Springer-Verlag, New York. 1978.

41. Dolan, M.D., et al., Composition and operation of hydrogen-selective amorphous alloy membranes. Journal of Membrane Science, 2006. 285(1-2): p. 30-55.

42. Li, H.F. and R.V. Ramanujan, Crystallization behavior of the cobalt based metallic glass Co65Si15B14Fe4Ni2. Materials Science and Engineering a-Structural Materials Properties Microstructure and Processing, 2004. 375: p. 1087-1091.

43. Hao, S.Q. and D.S. Sholl, Using first-principles calculations to accelerate materials discovery for hydrogen purification membranes by modeling amorphous metals. Energy \& Environmental Science, 2008. 1(1): p. 175-183.

44. Yamaura, S.I., et al., Hydrogen permeation of the Zr65Al7.5Ni10Cu12.5Pd5 alloy in three different microstructures. Journal of Membrane Science, 2007. 291(1-2): p. 126130. 
SRNS-STI-2008-00133

Revision 1

45. Shimpo, Y., et al., Hydrogen permeation characteristics of melt-spun

Zr60Al15Co2.5Ni7.5Cu15 glassy alloy membrane. Journal of Alloys and Compounds, 2004. 372(1-2): p. 197-200.

46. Wang, Y.M., et al., Composition optimization of the Al-Co-Zr bulk metallic glasses. Scripta Materialia, 2004. 50(6): p. 829-833.

47. Miracle, D.B., The efficient cluster packing model - An atomic structural model for metallic glasses. Acta Materialia, 2006. 54(16): p. 4317-4336. 


\author{
Distribution: \\ P. Korinko, 773-A \\ E. Fox, 773-41A \\ T. Adams, 773-41A \\ K. Brinkman, 773-41A \\ N. Iyer, 773-41A \\ D. Missimer, 773-A \\ S. Garrison, 773-42A \\ G. Morgan, 999-2W
}


SRNS-STI-2008-00133

Revision 1 
SRNS-STI-2008-00133

Revision 1

Appendix A- XRD S3A Alloy 


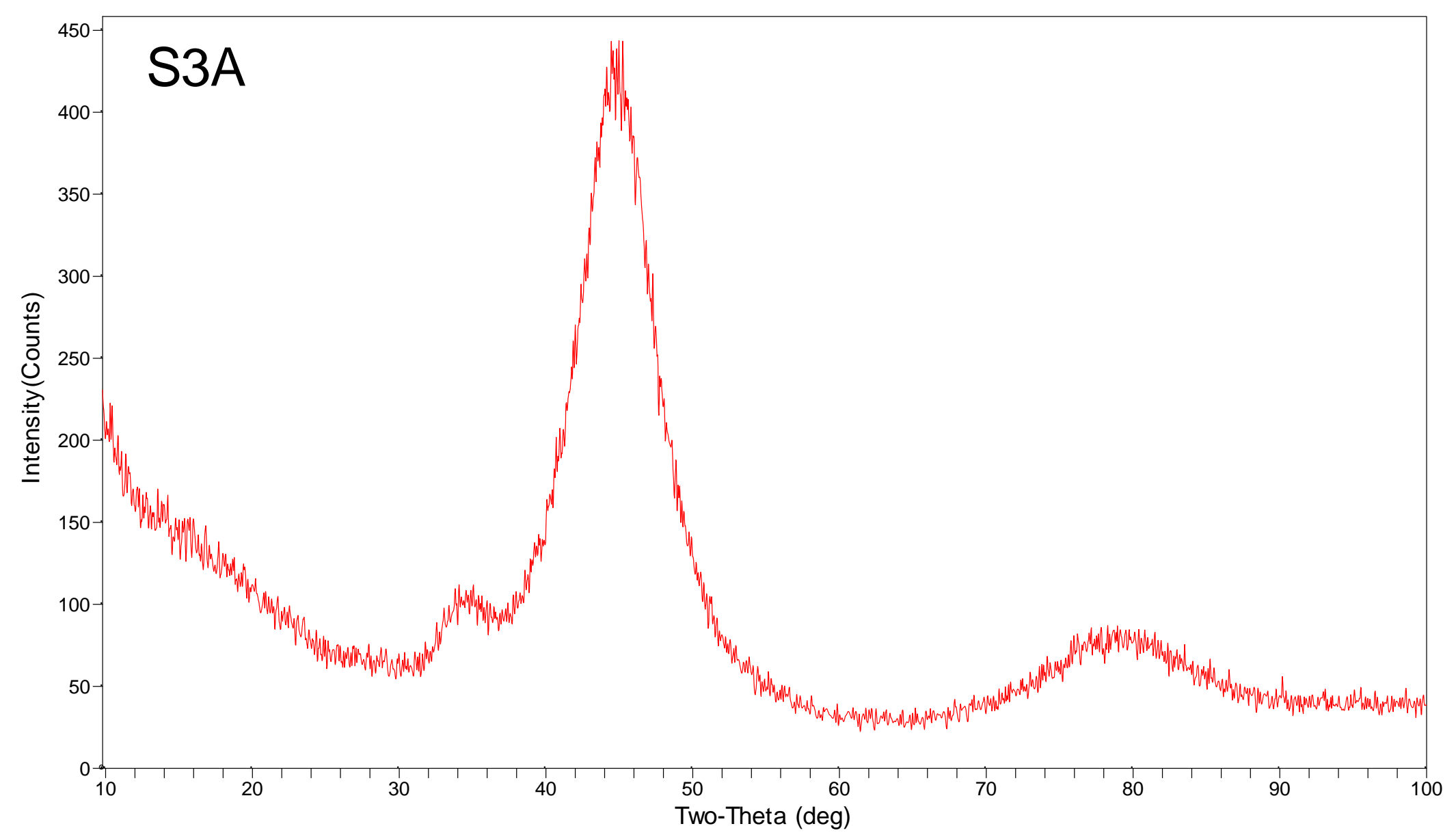

Figure 3. XRD scan of S3A at 25 


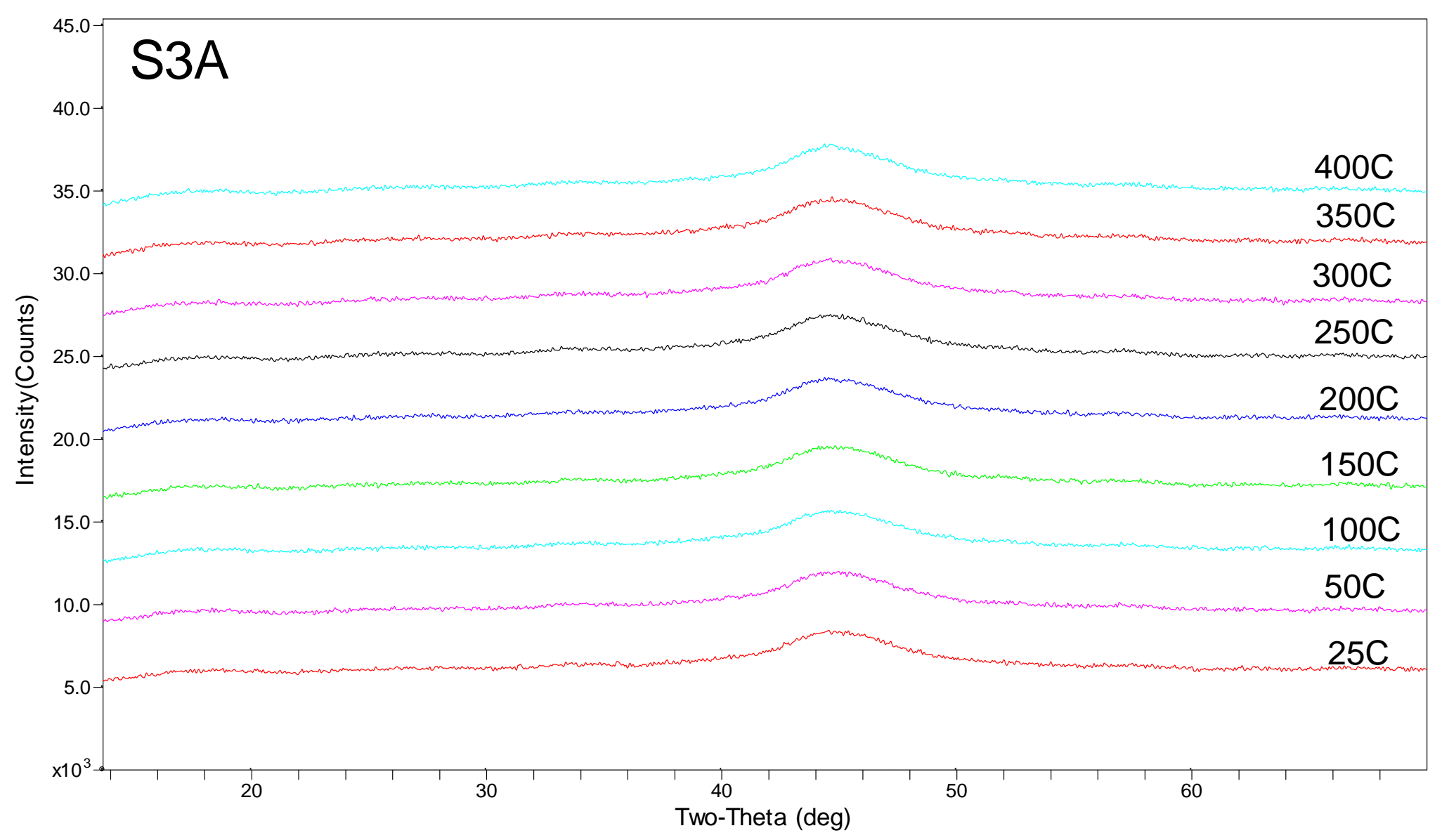

Figure 4. HTXRD scans of S3A from 25 to $400^{\circ} \mathrm{C}$ in He. 


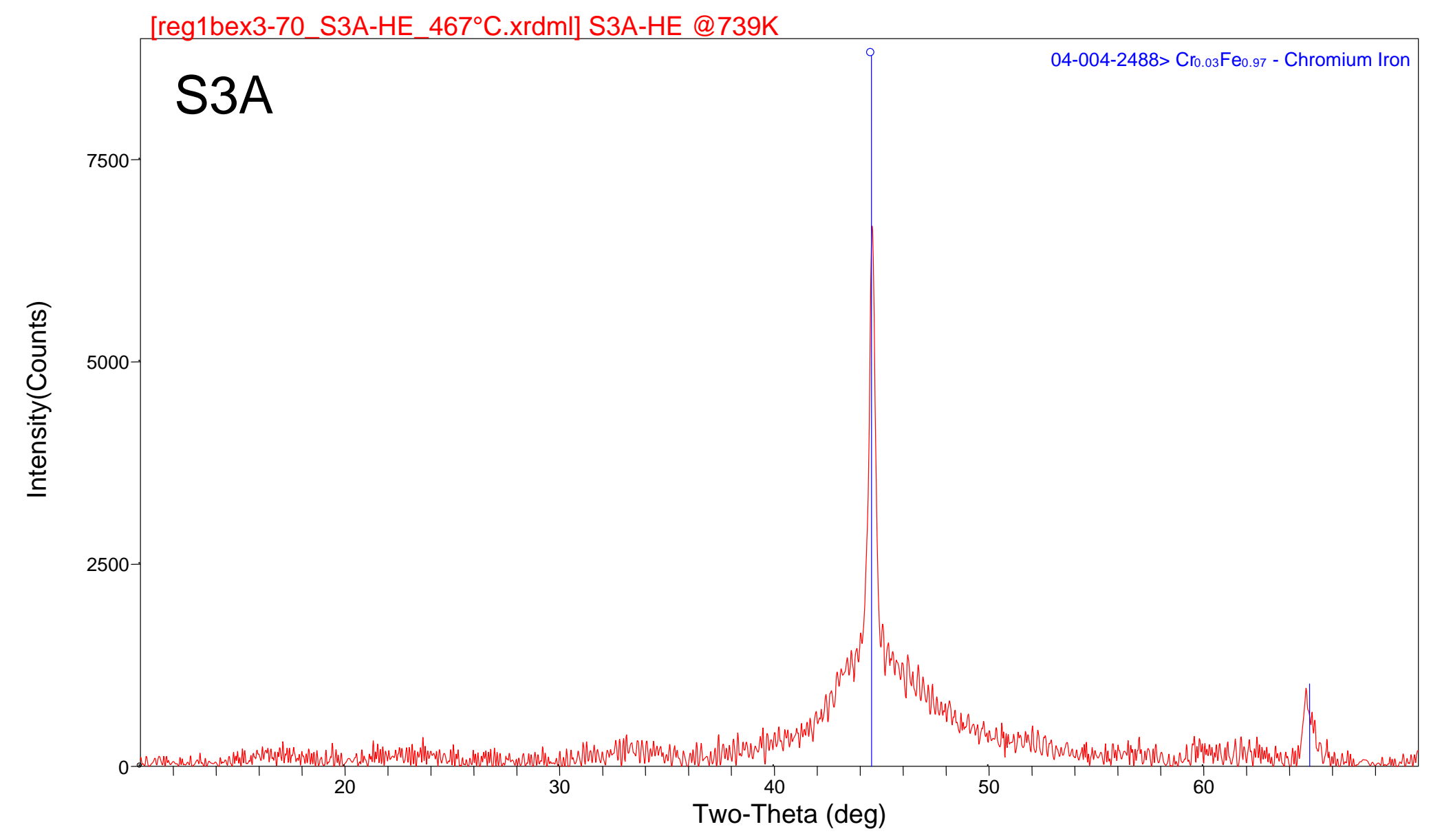

Figure 5. HTXRD scan of S3A at $450^{\circ} \mathrm{C}$ in He. 


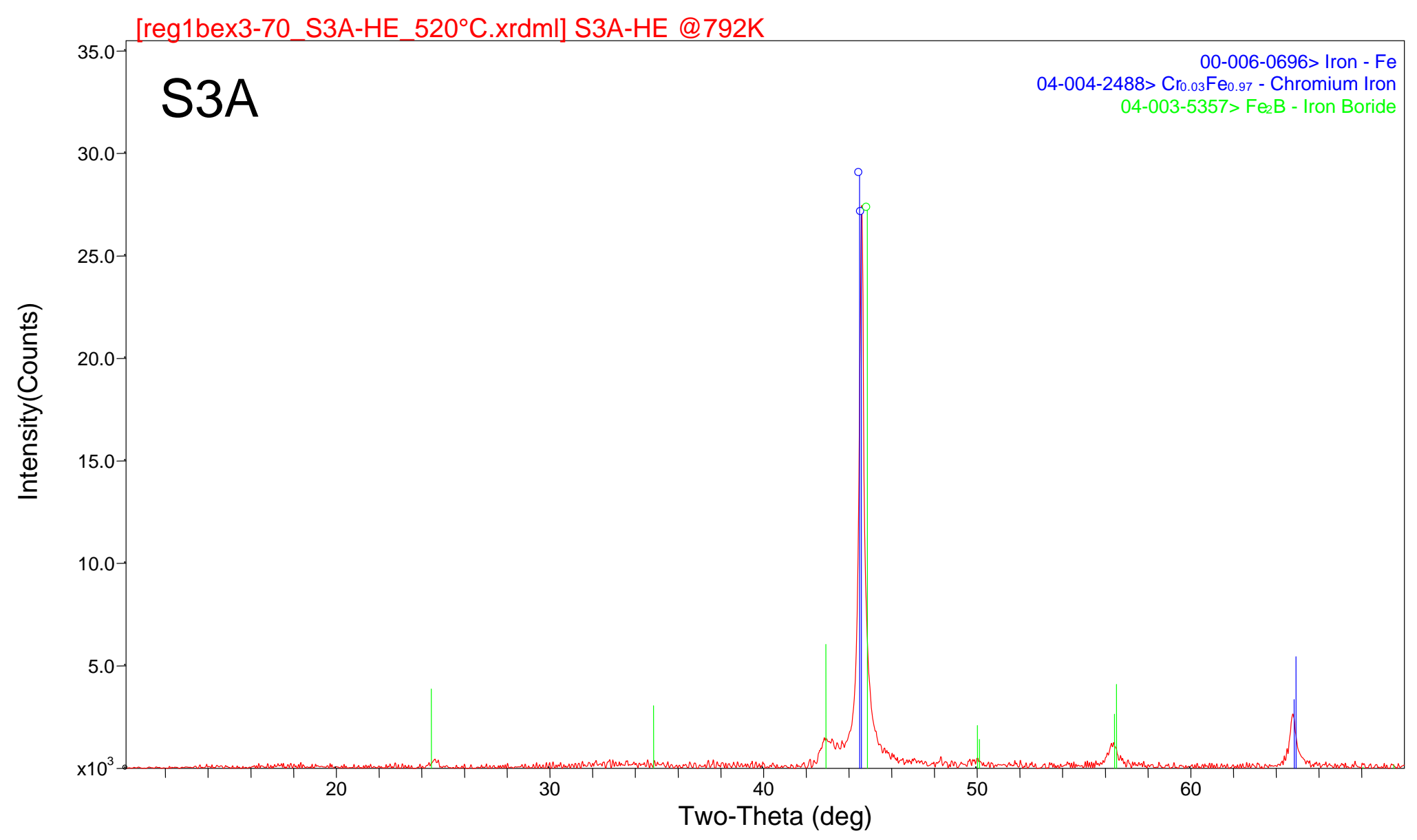

Figure 6. HTXRD scan of $\mathrm{S} 3 \mathrm{~A}$ at $500^{\circ} \mathrm{C}$ in $\mathrm{He}$. 


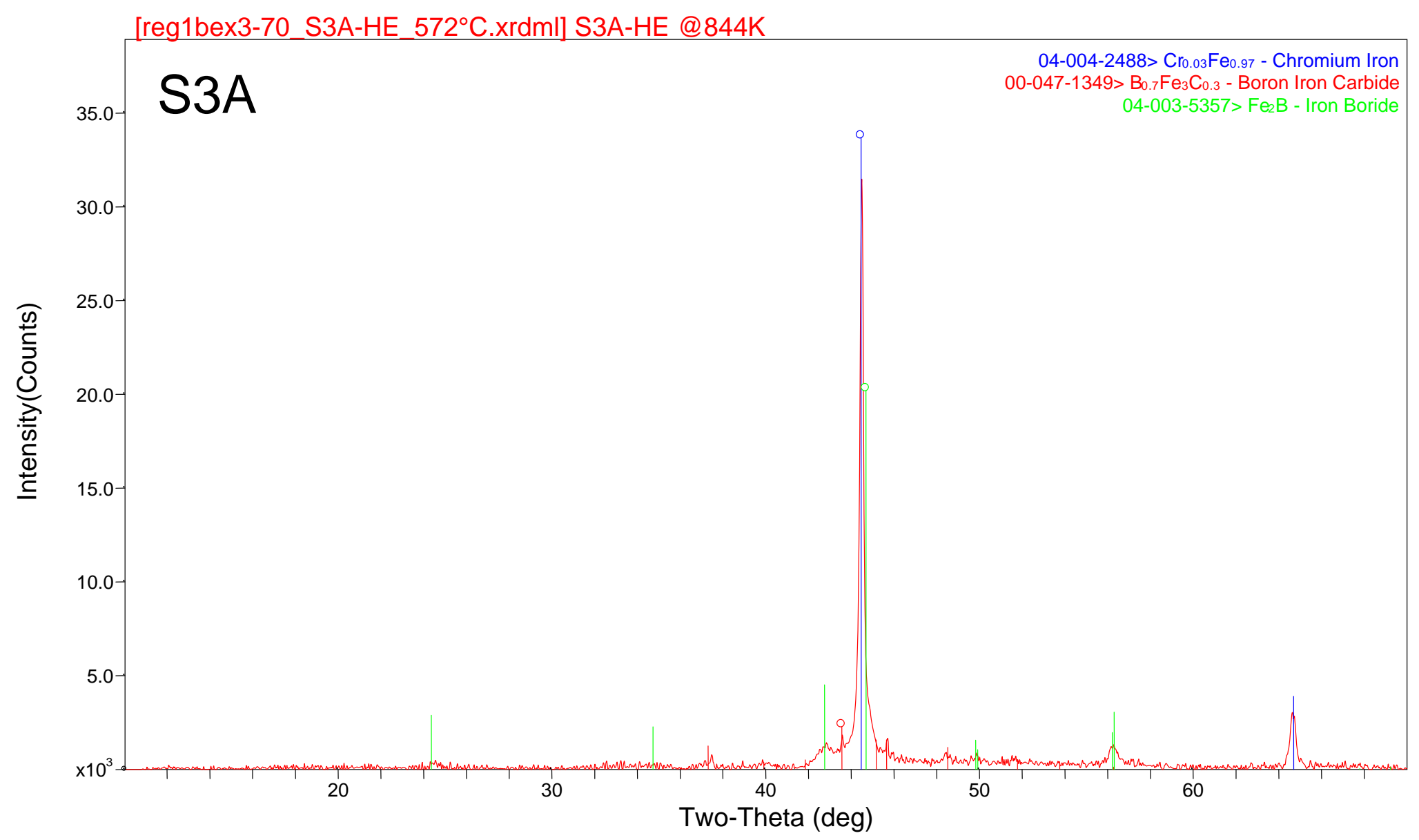

Figure 7. HTXRD scan of $\mathrm{S} 3 \mathrm{~A}$ at $550^{\circ} \mathrm{C}$ in $\mathrm{He}$. 


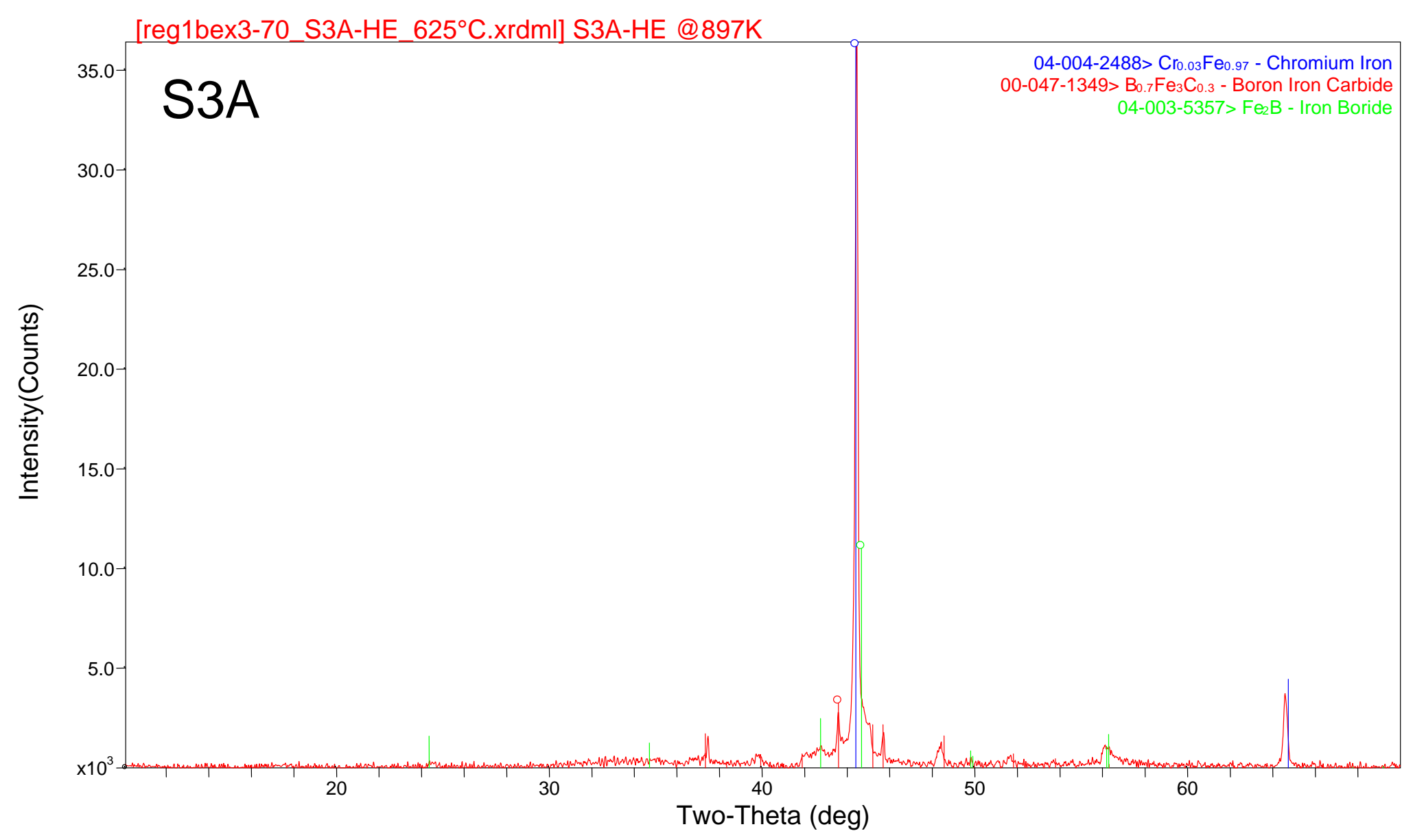

Figure 8. HTXRD scan of S3A at $600^{\circ} \mathrm{C}$ in $\mathrm{He}$. 


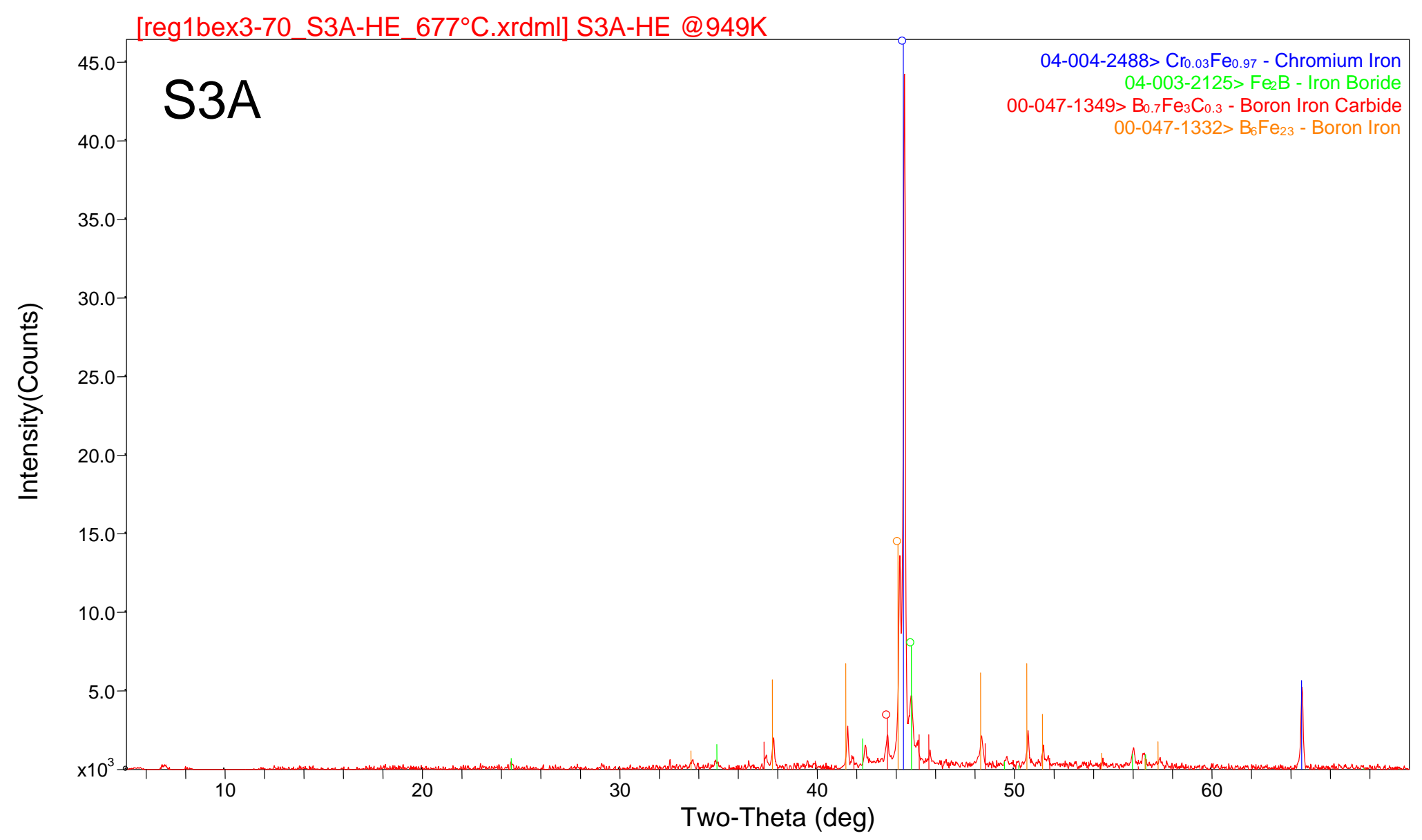

Figure 9. HTXRD scan of S3A at $650^{\circ} \mathrm{C}$ in He. 


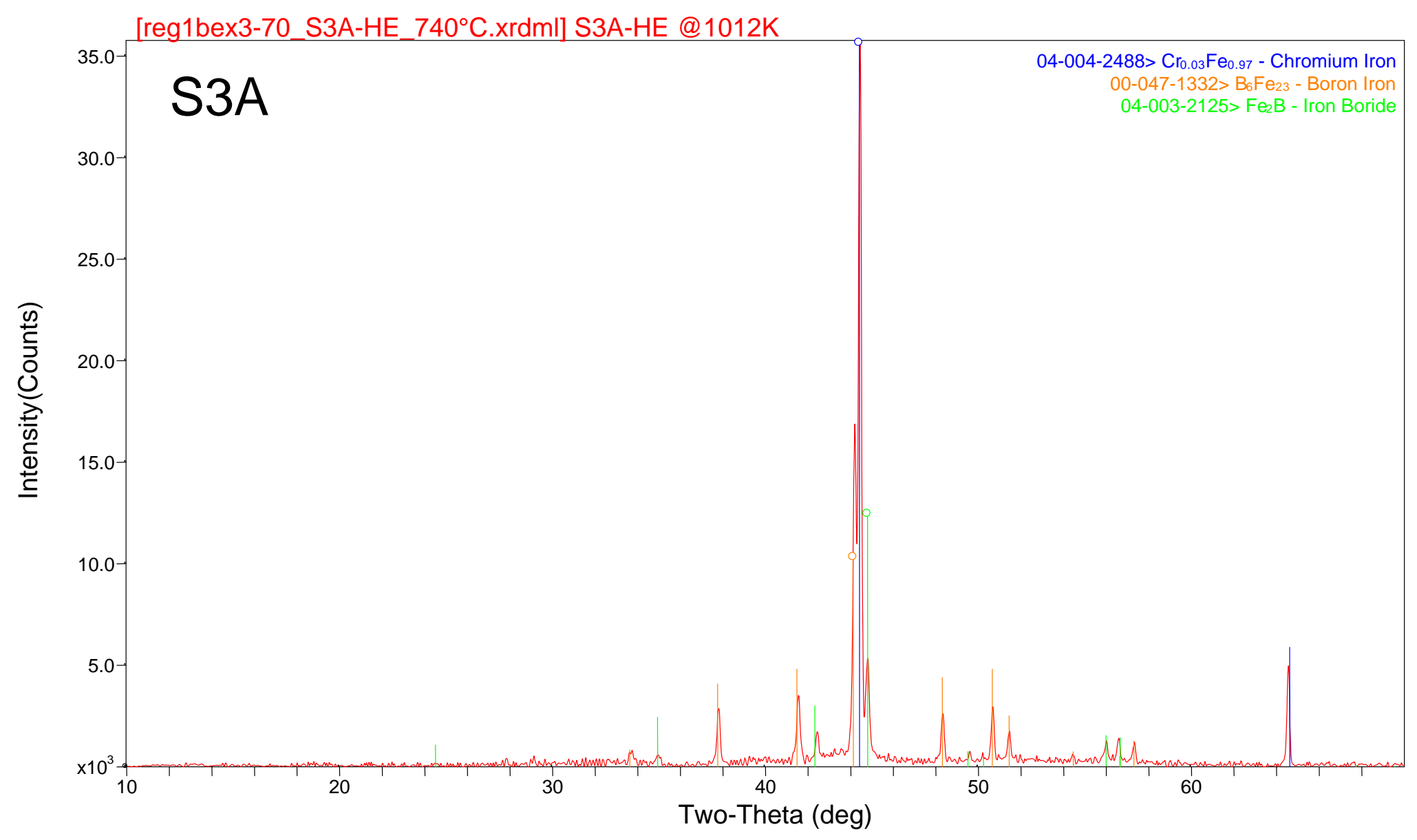

Figure 10. HTXRD scan of S3A at $710^{\circ} \mathrm{C}$ in $\mathrm{He}$. 


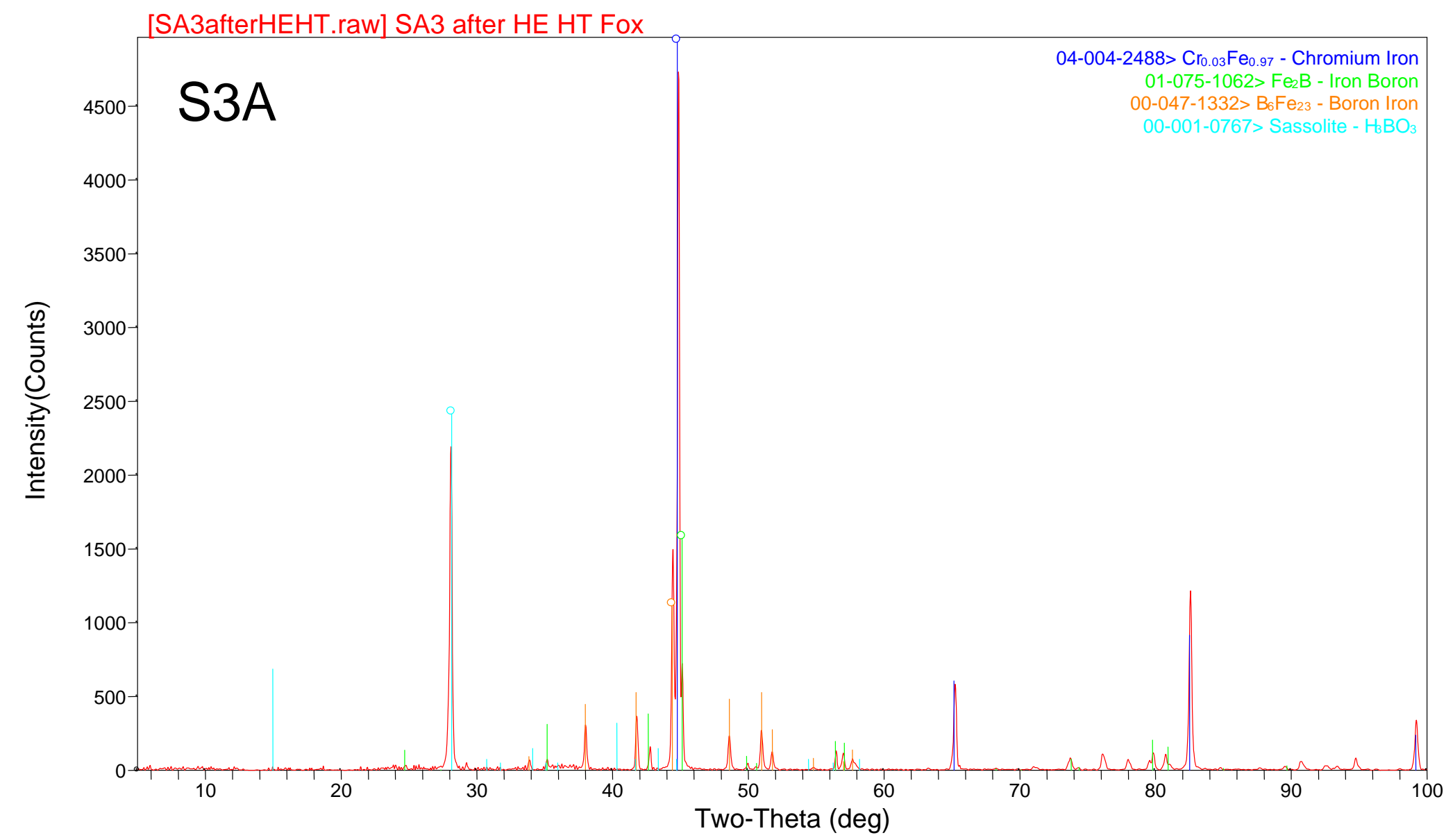

Figure 11. XRD scan of S3A HTXRD residue in He. 


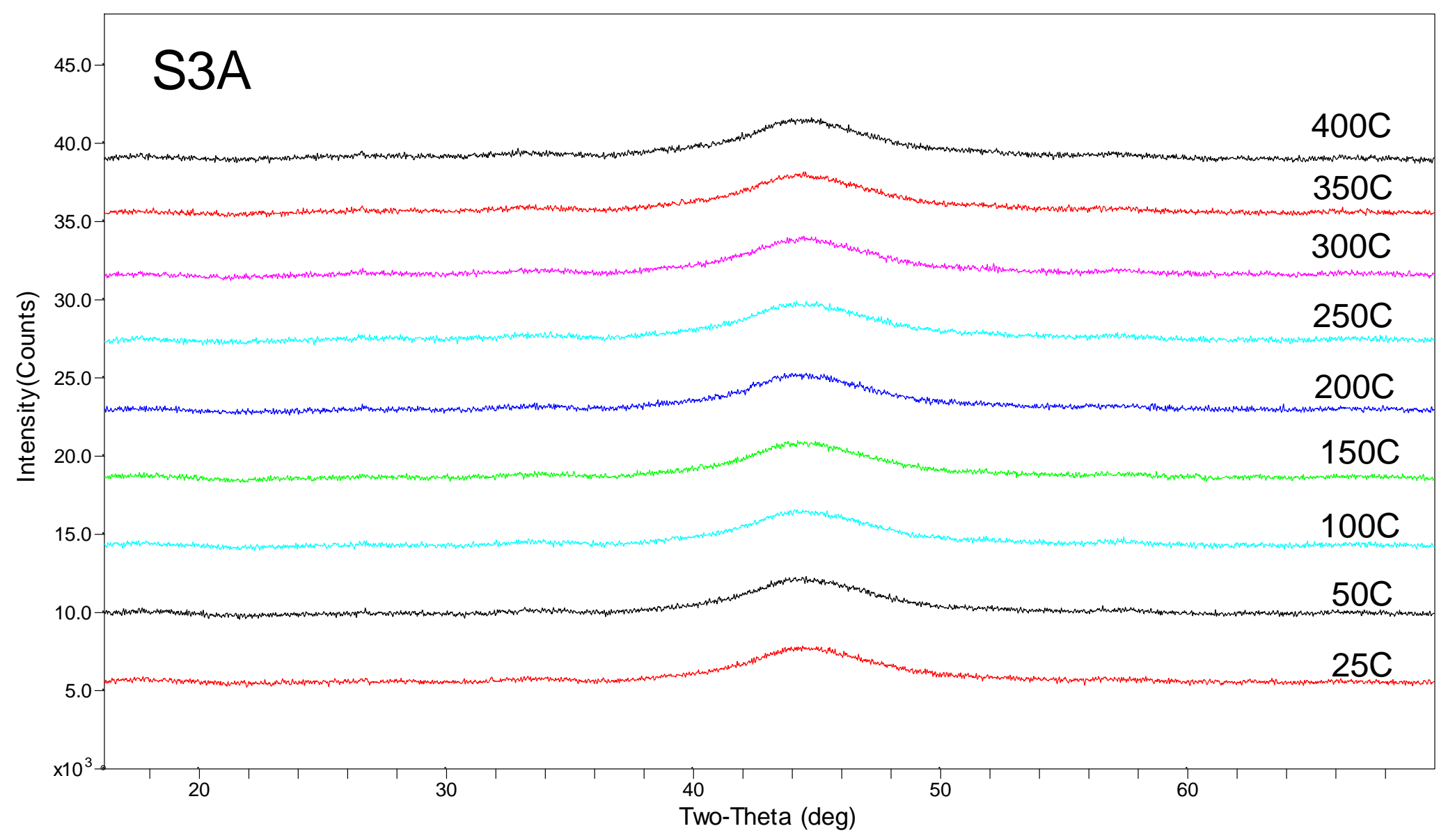

Figure 12. HTXRD scans of S3A from 25 to $400^{\circ} \mathrm{C}$ in $4 \%-\mathrm{H}_{2} / 96 \%-\mathrm{He}$. 


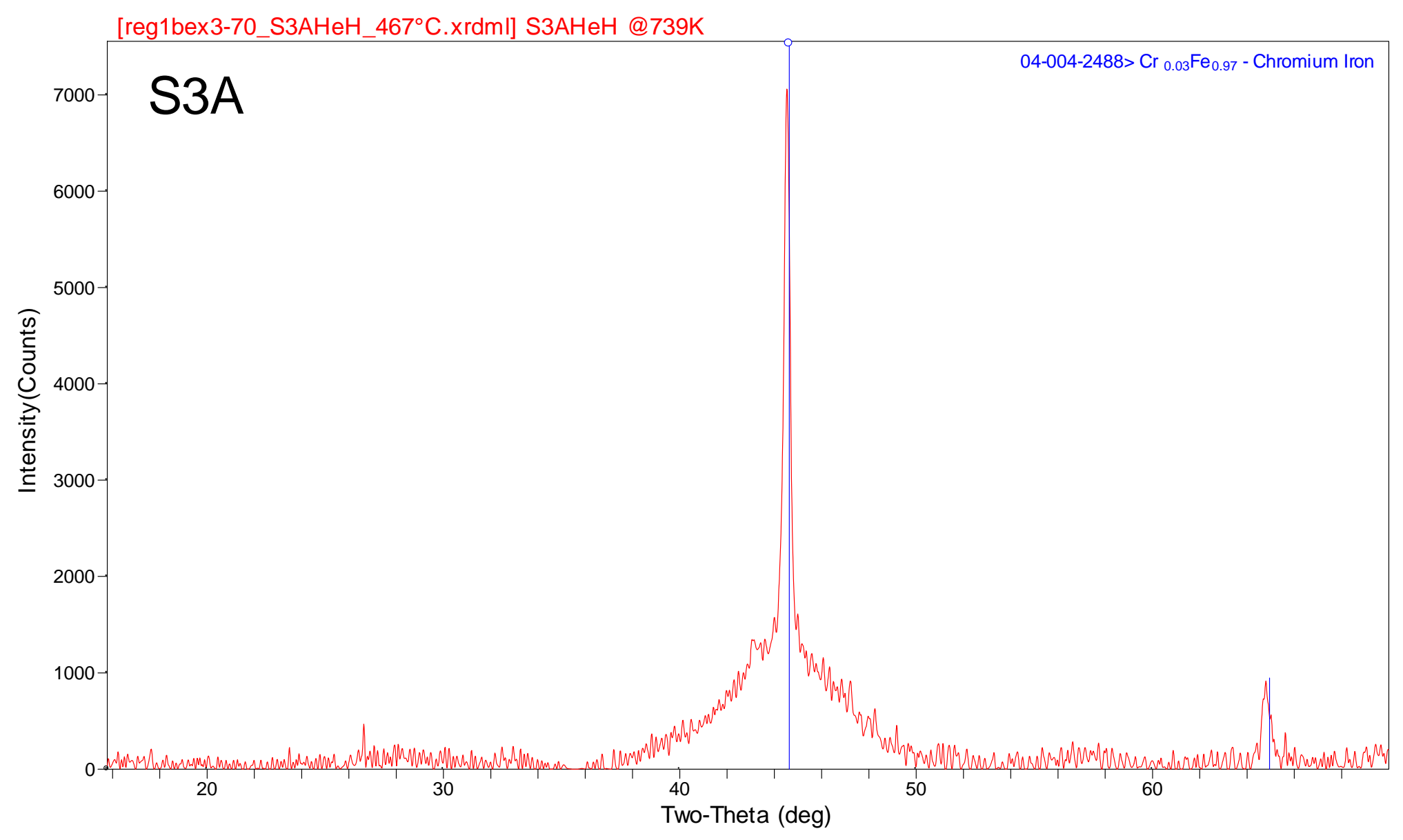

Figure 13. HTXRD scan of $\mathrm{S} 3 \mathrm{~A}$ at $450^{\circ} \mathrm{C}$ in $4 \%-\mathrm{H}_{2} / 96 \%-\mathrm{He}$. 


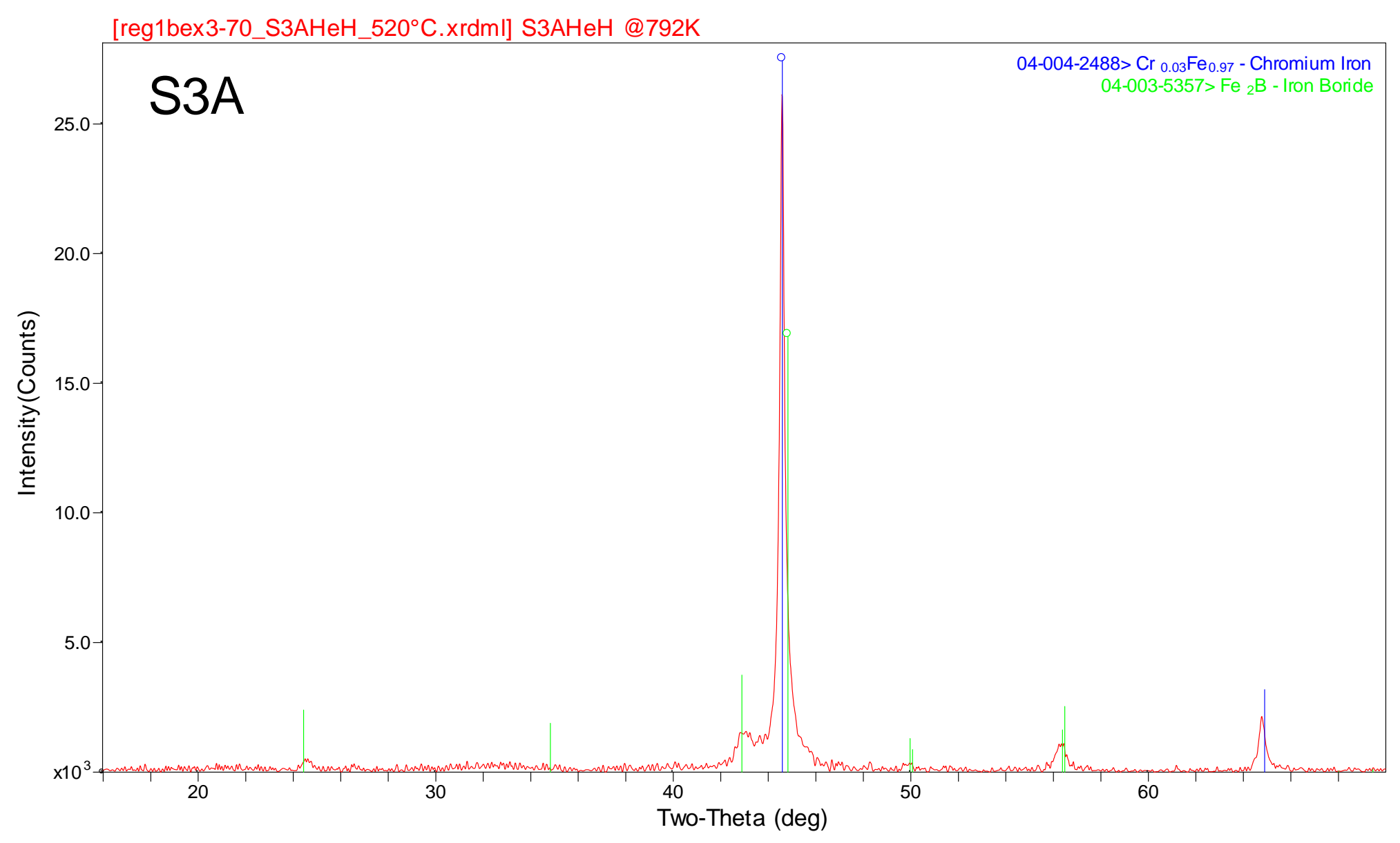

Figure 14. HTXRD scan of S3A at $500^{\circ} \mathrm{C}$ in $4 \%-\mathrm{H}_{2} / 96 \%-\mathrm{He}$. 


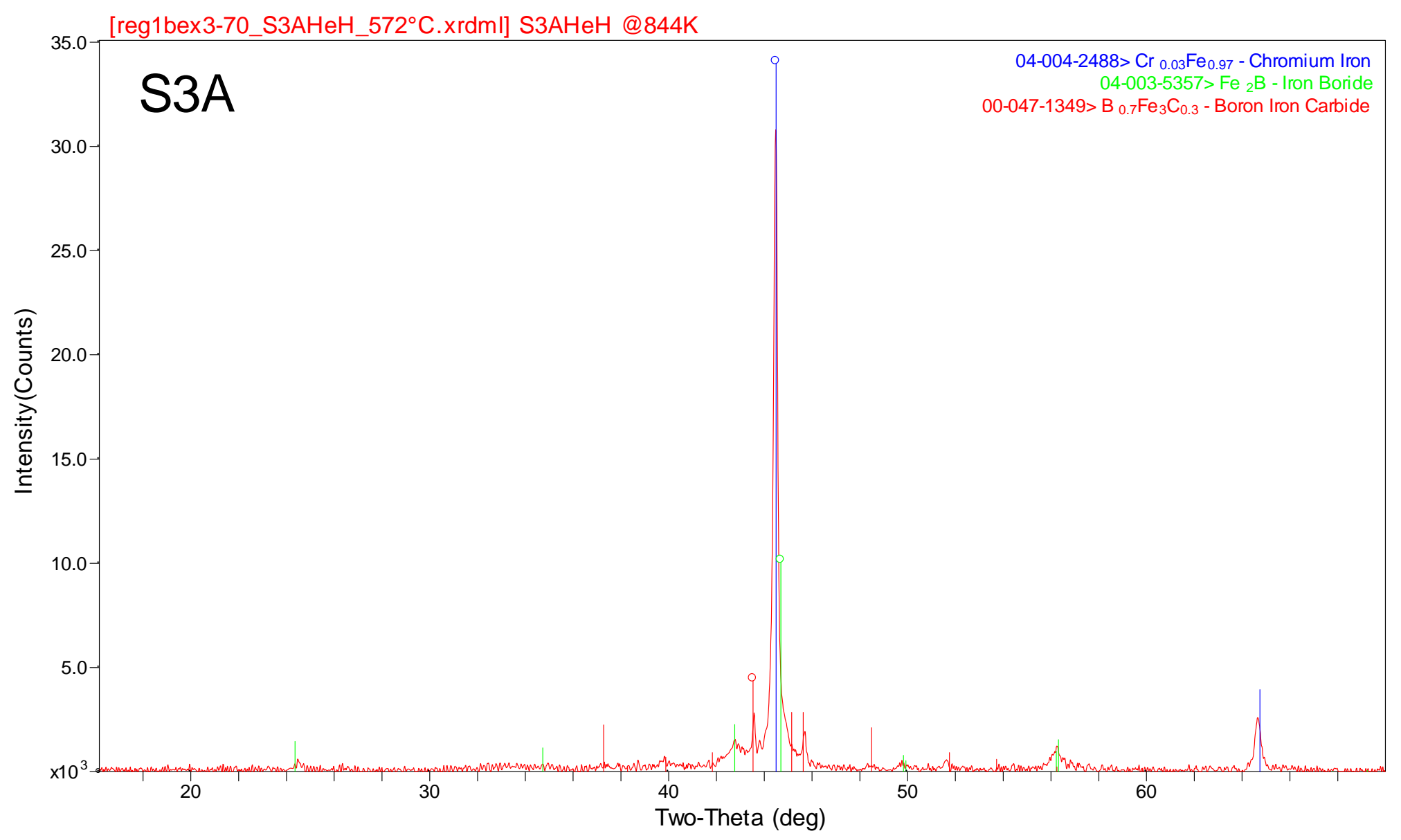

Figure 15. HTXRD scan of S3A at $550^{\circ} \mathrm{C}$ in $4 \%-\mathrm{H}_{2} / 96 \%-\mathrm{He}$. 


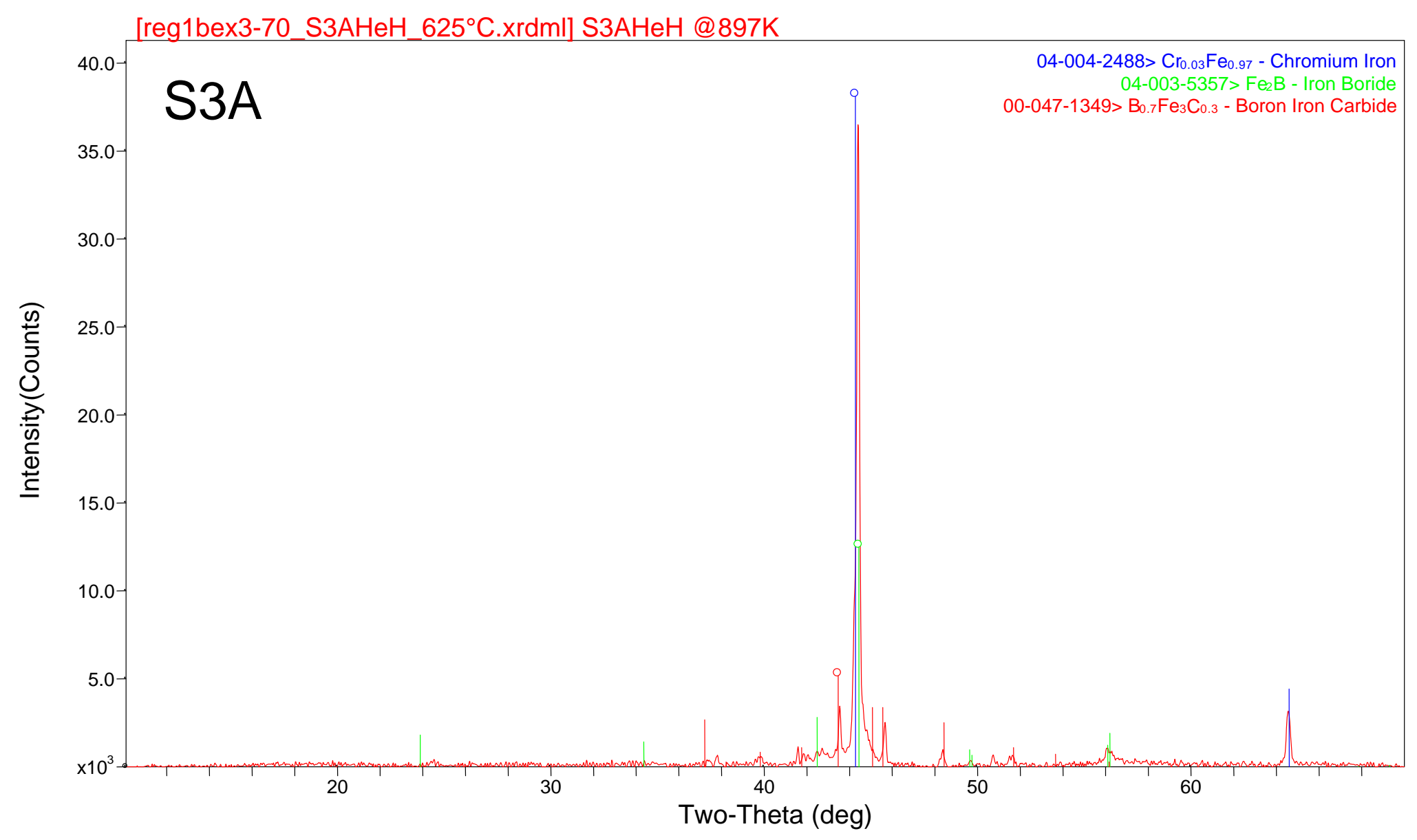

Figure 16. HTXRD scan of S3A at $600^{\circ} \mathrm{C}$ in $4 \%-\mathrm{H}_{2} / 96 \%-\mathrm{He}$. 


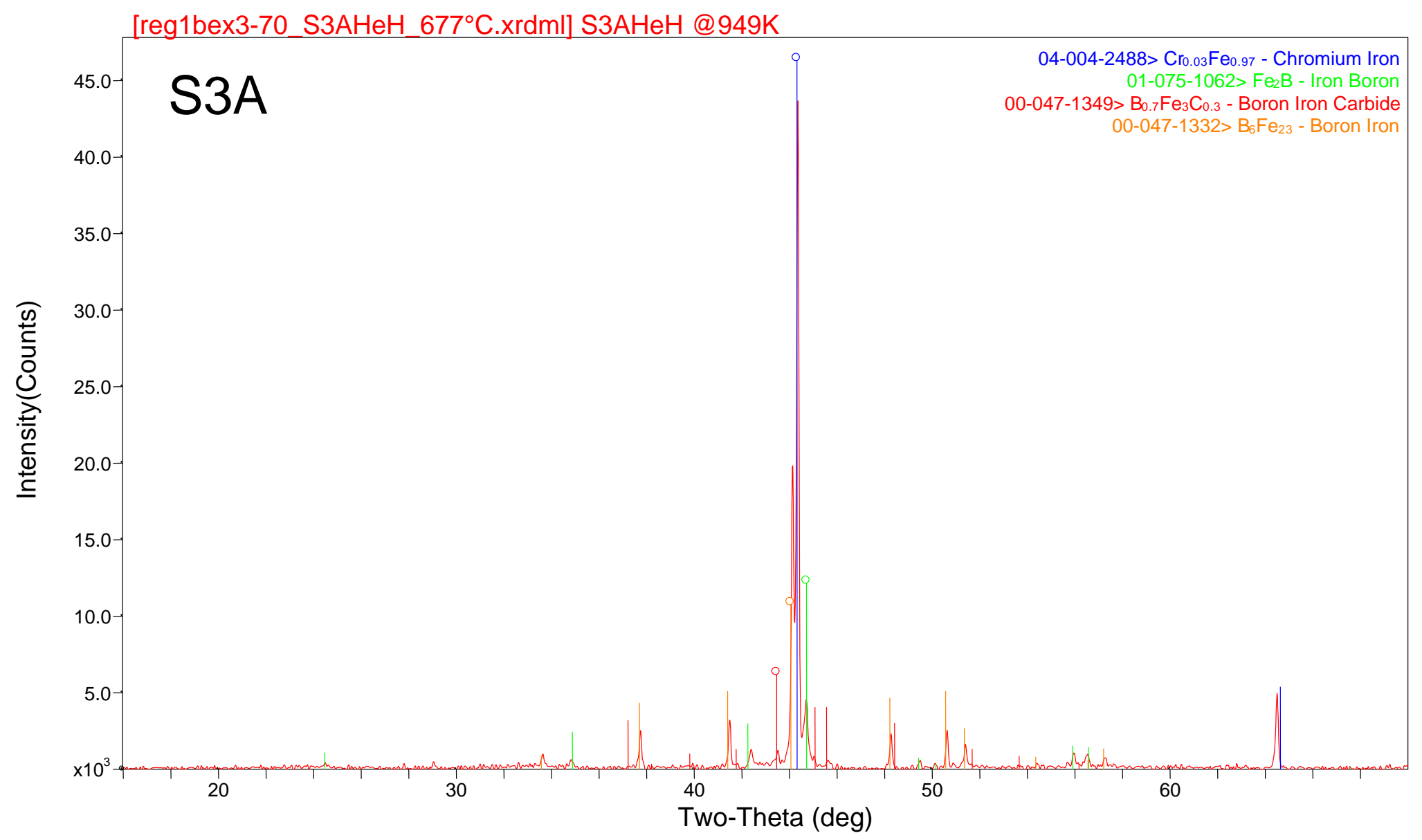

Figure 17. HTXRD scan of S3A at $650^{\circ} \mathrm{C}$ in $4 \%-\mathrm{H}_{2} / 96 \%-\mathrm{He}$. 


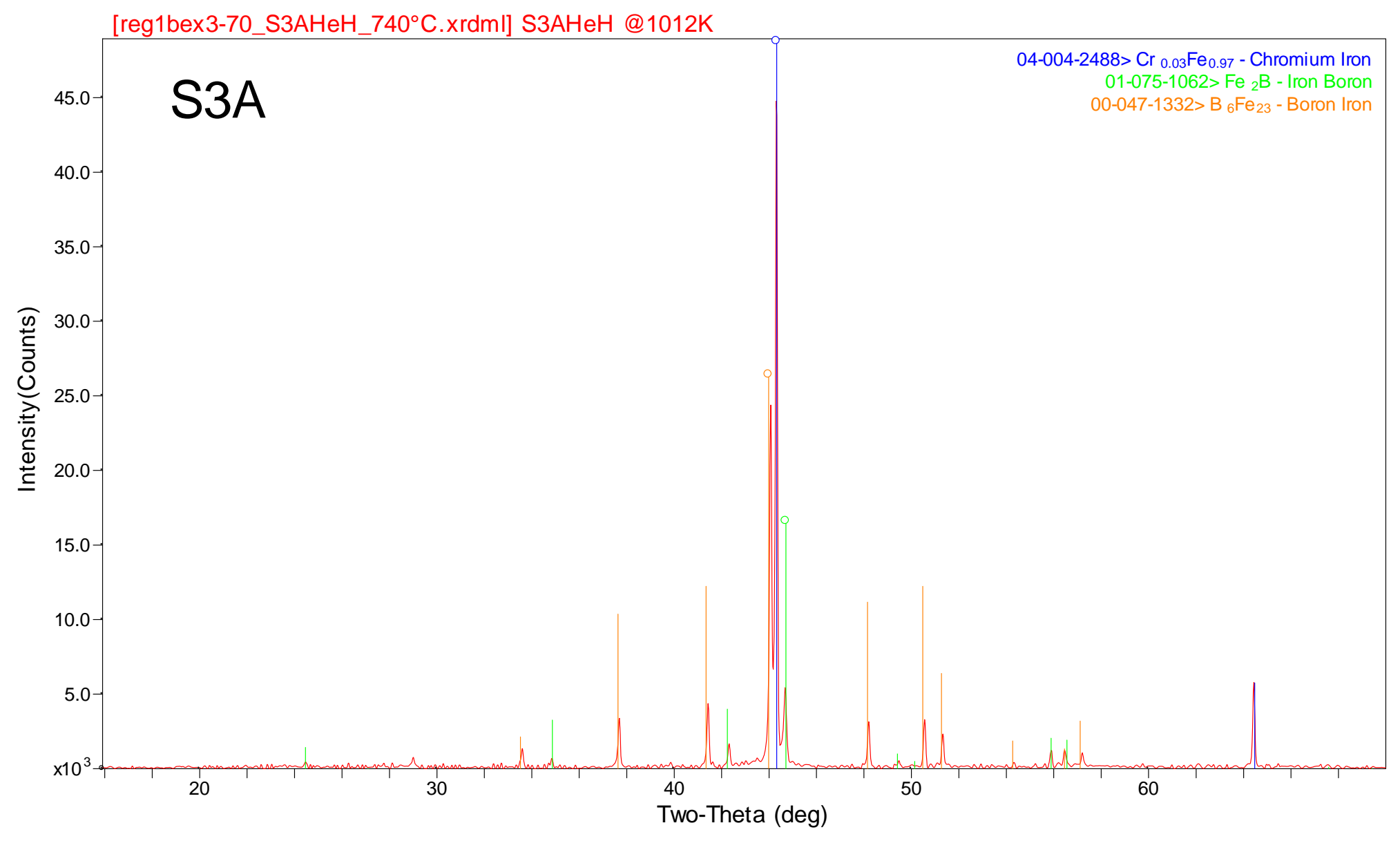

Figure 18. HTXRD scan of S3A at $710^{\circ} \mathrm{C}$ in $4 \%-\mathrm{H}_{2} / 96 \%-\mathrm{He}$. 


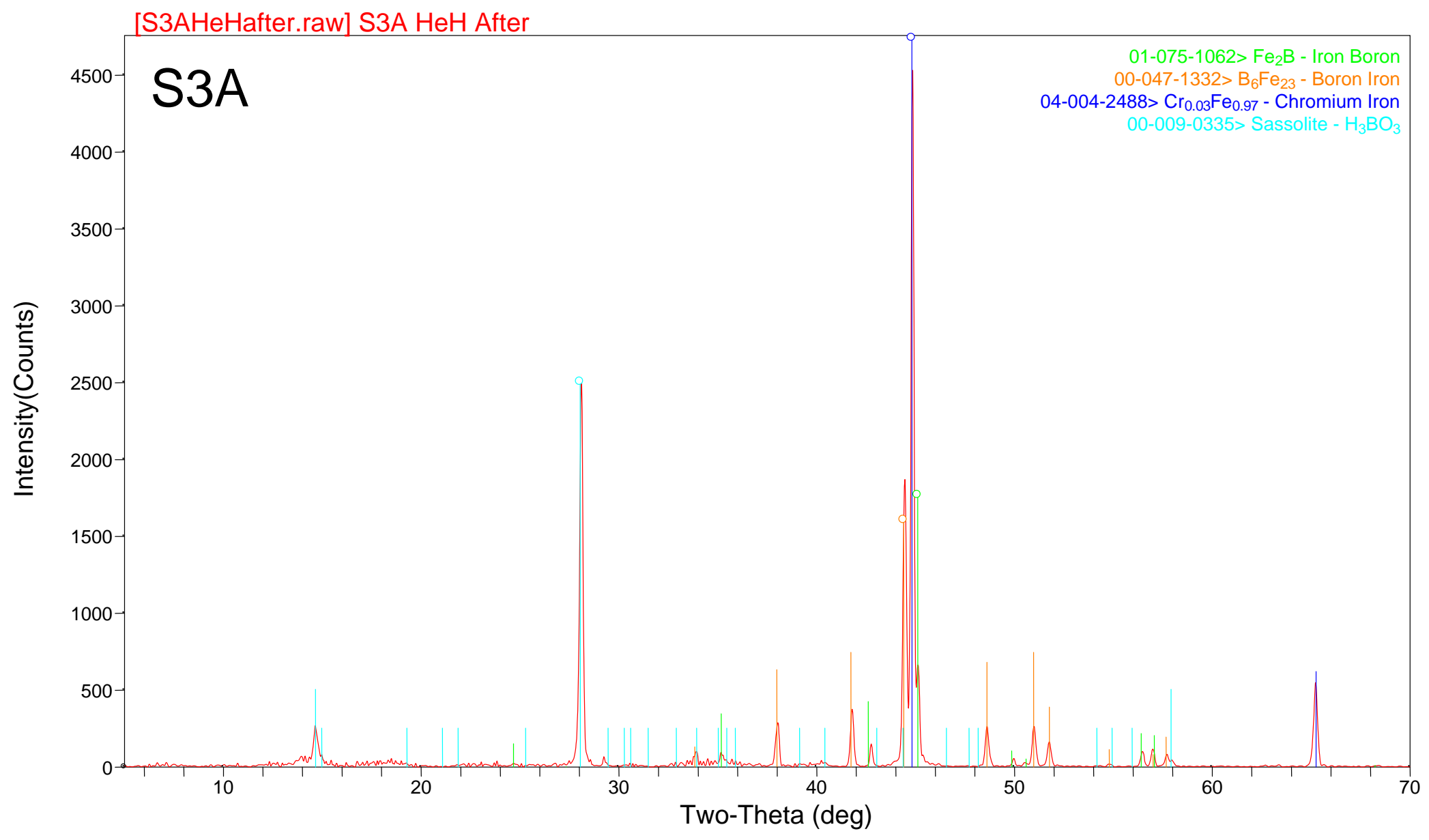

Figure 19. XRD scan of S3A HTXRD residue in $4 \%-\mathrm{H}_{2} / 96 \%-\mathrm{He}$. 


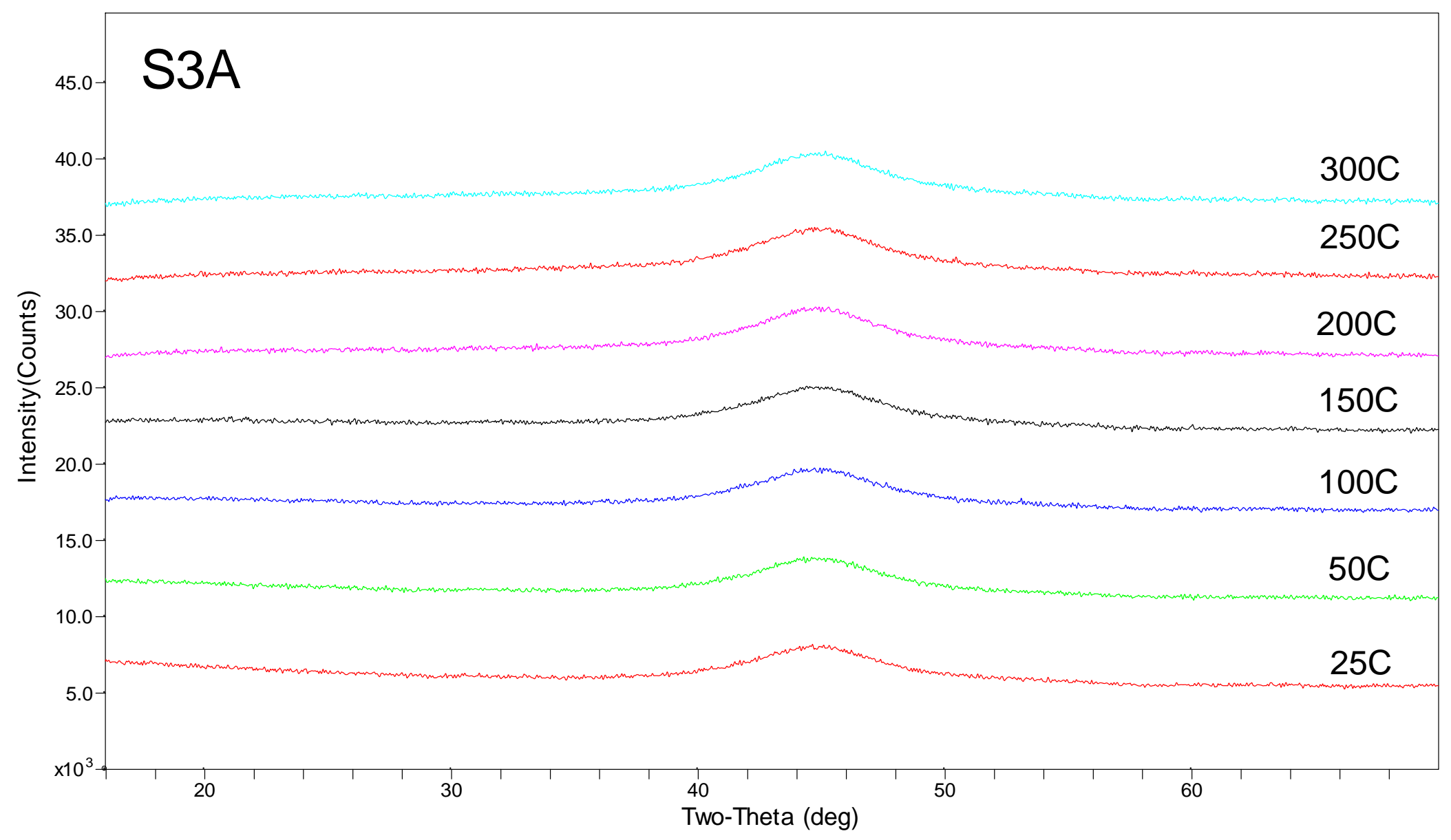

Figure 20. HTXRD scans of S3A from 25 to $300^{\circ} \mathrm{C}$ in air. 


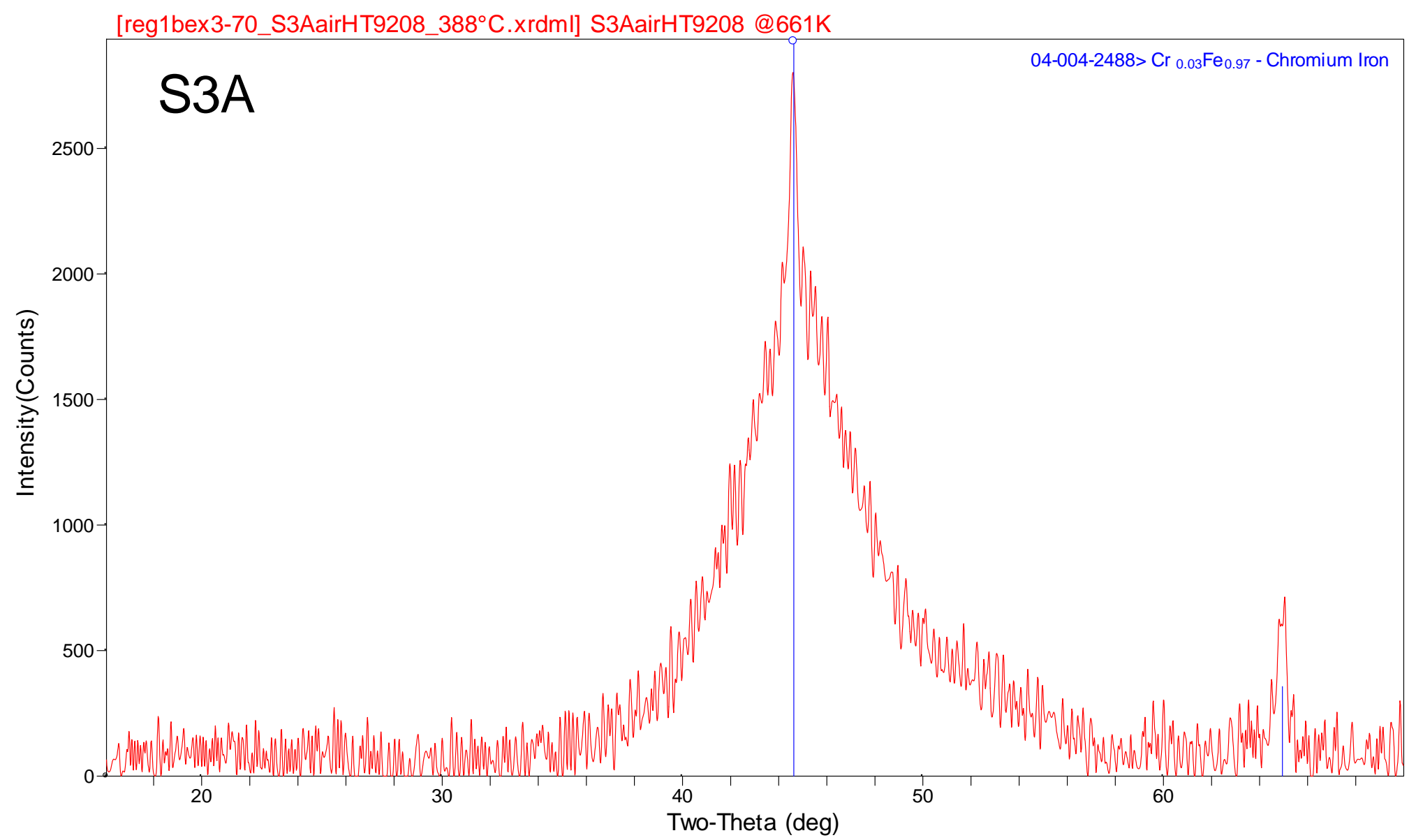

Figure 21. HTXRD scan of S3A at $350^{\circ} \mathrm{C}$ in air. 


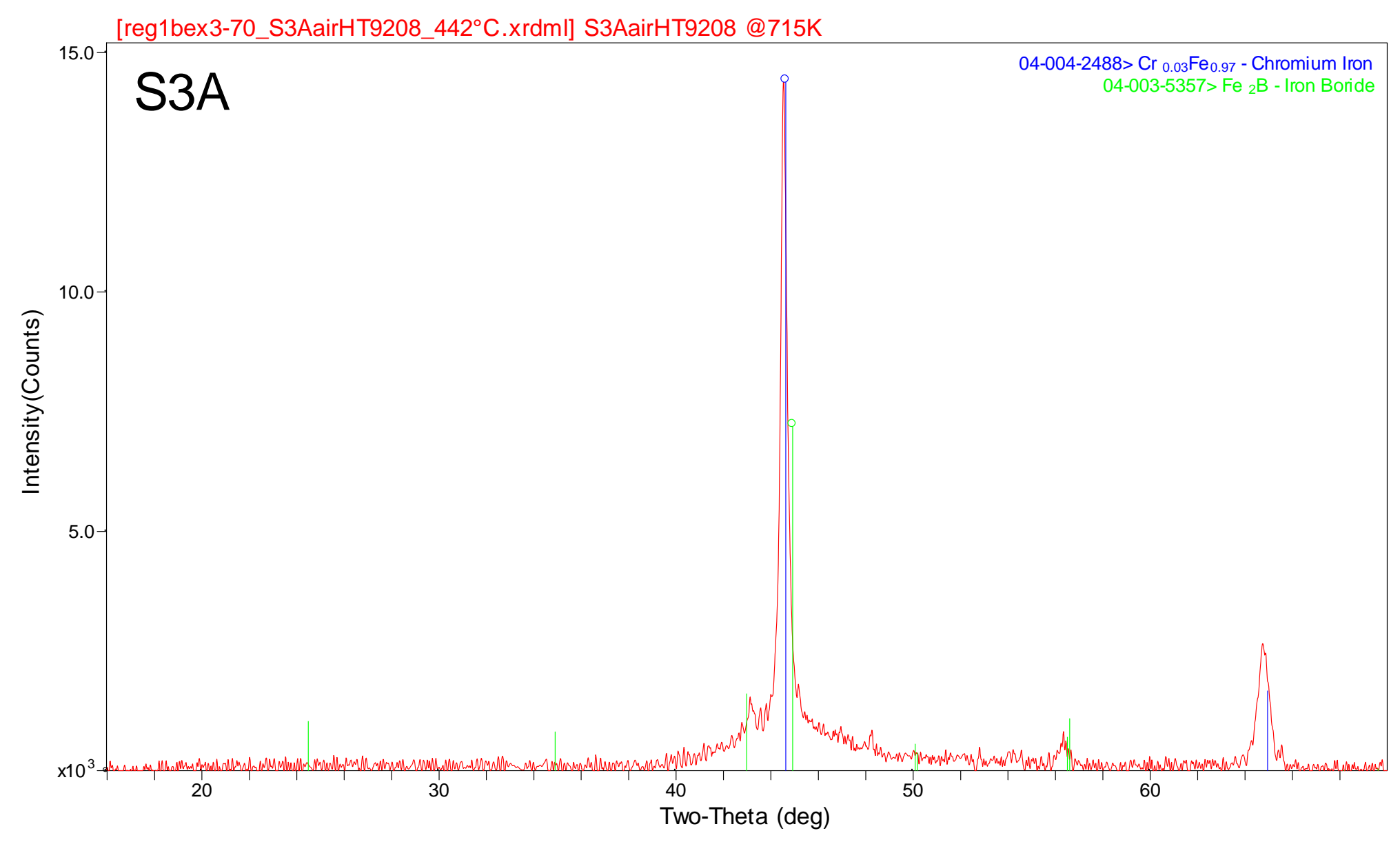

Figure 22. HTXRD scan of S3A at $400^{\circ} \mathrm{C}$ in air. 


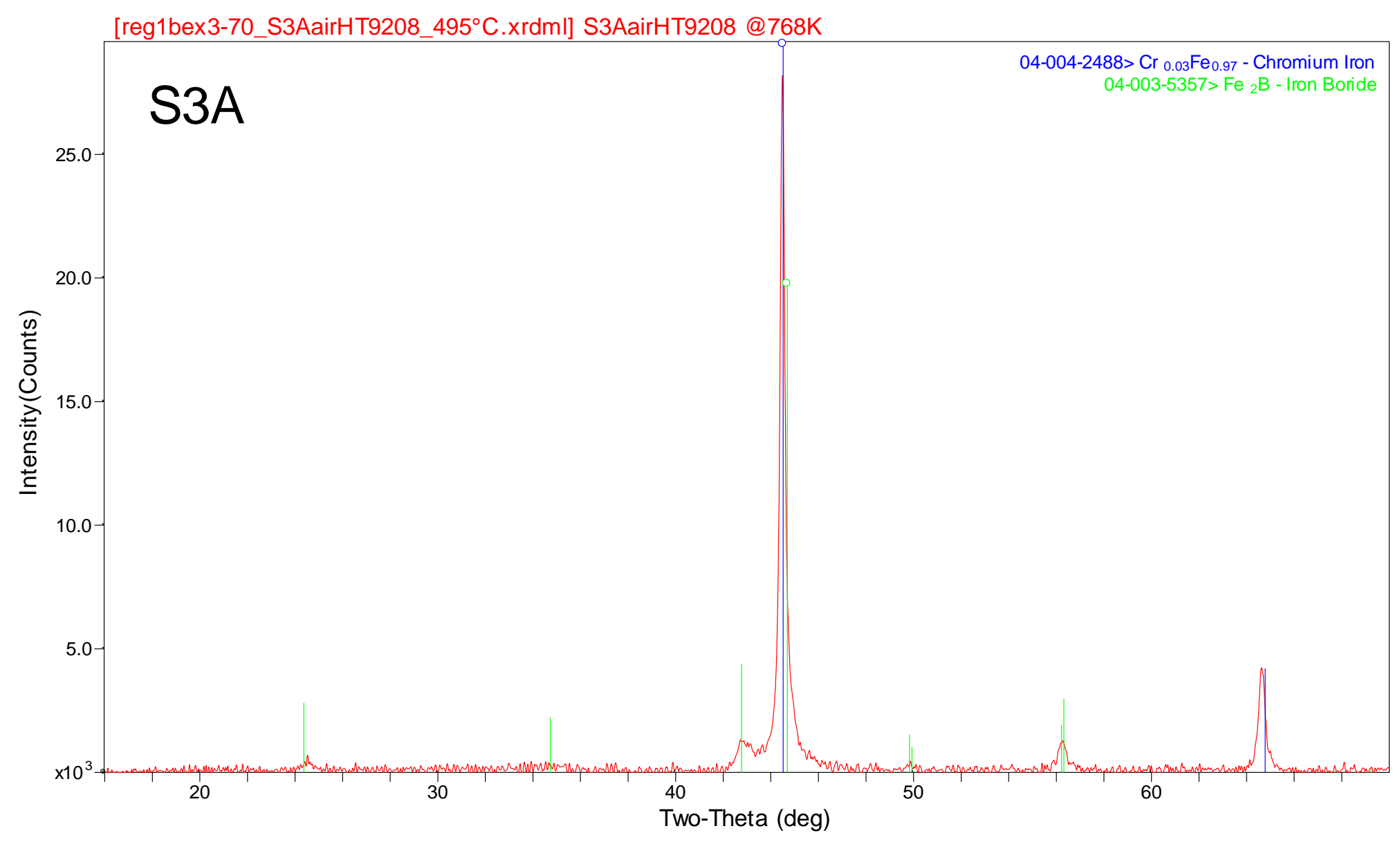

Figure 23. HTXRD scan of S3A at $450^{\circ} \mathrm{C}$ in air. 


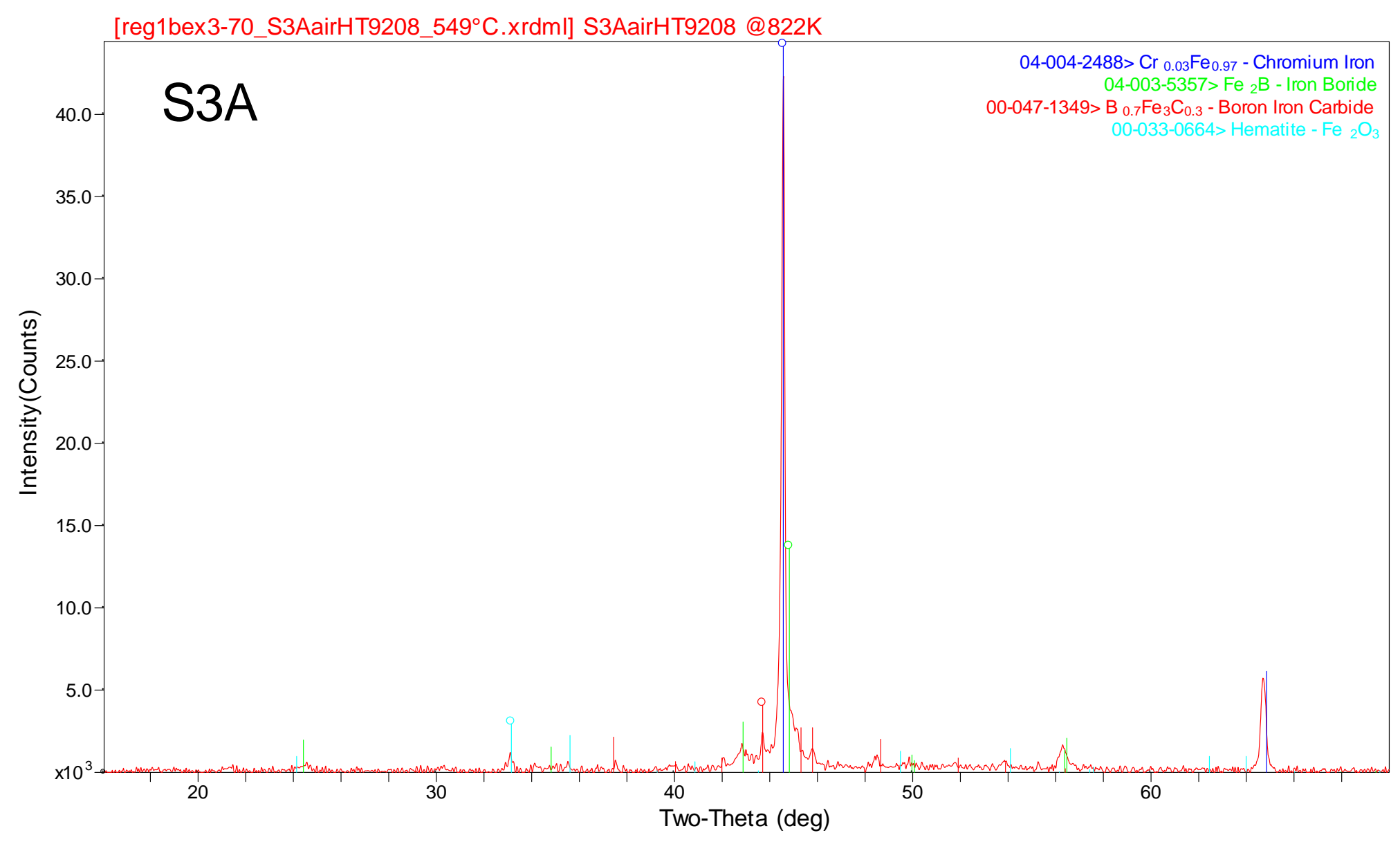

Figure 24. HTXRD scan of S3A at $500^{\circ} \mathrm{C}$ in air. 


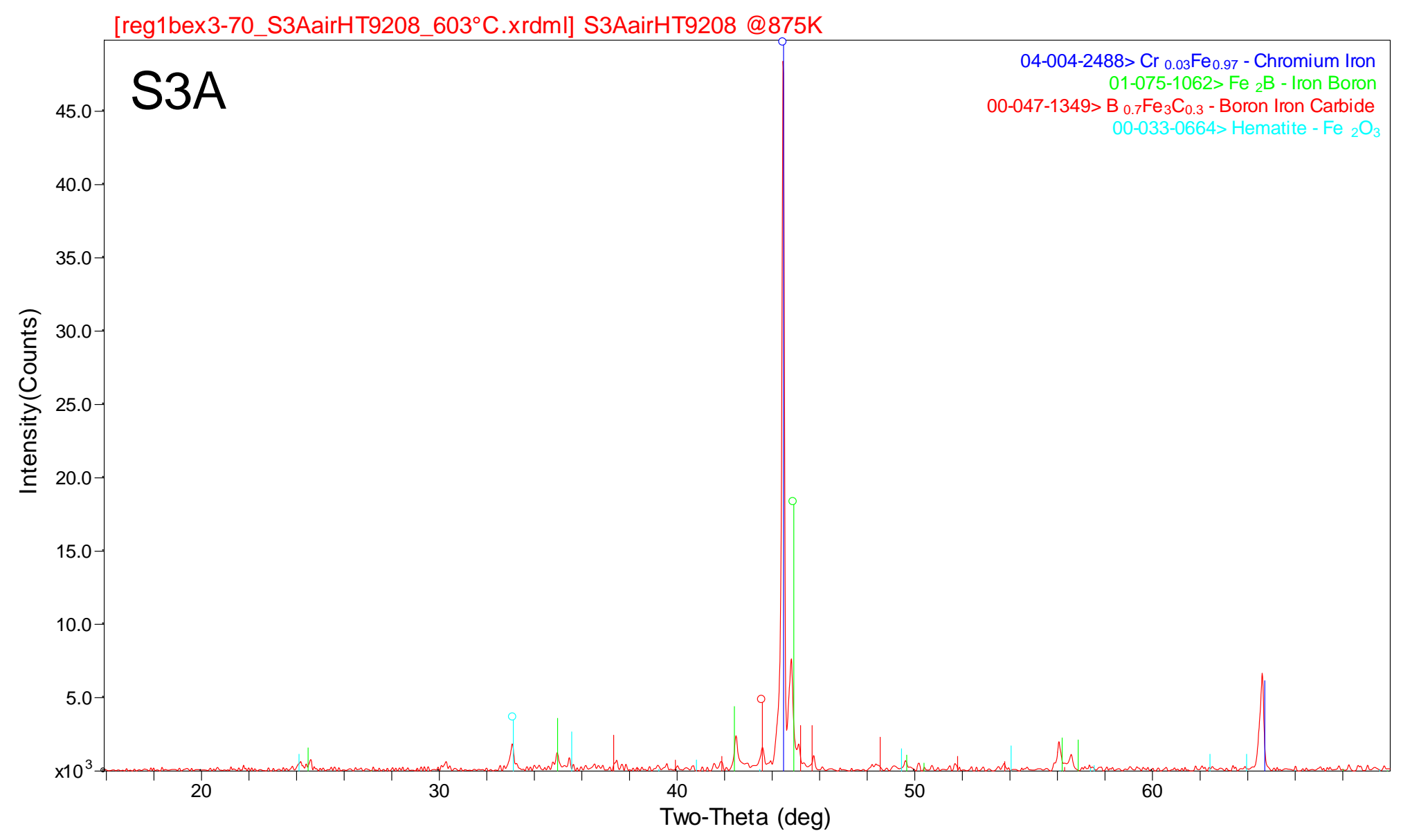

Figure 25. HTXRD scan of S3A at $550^{\circ} \mathrm{C}$ in air. 


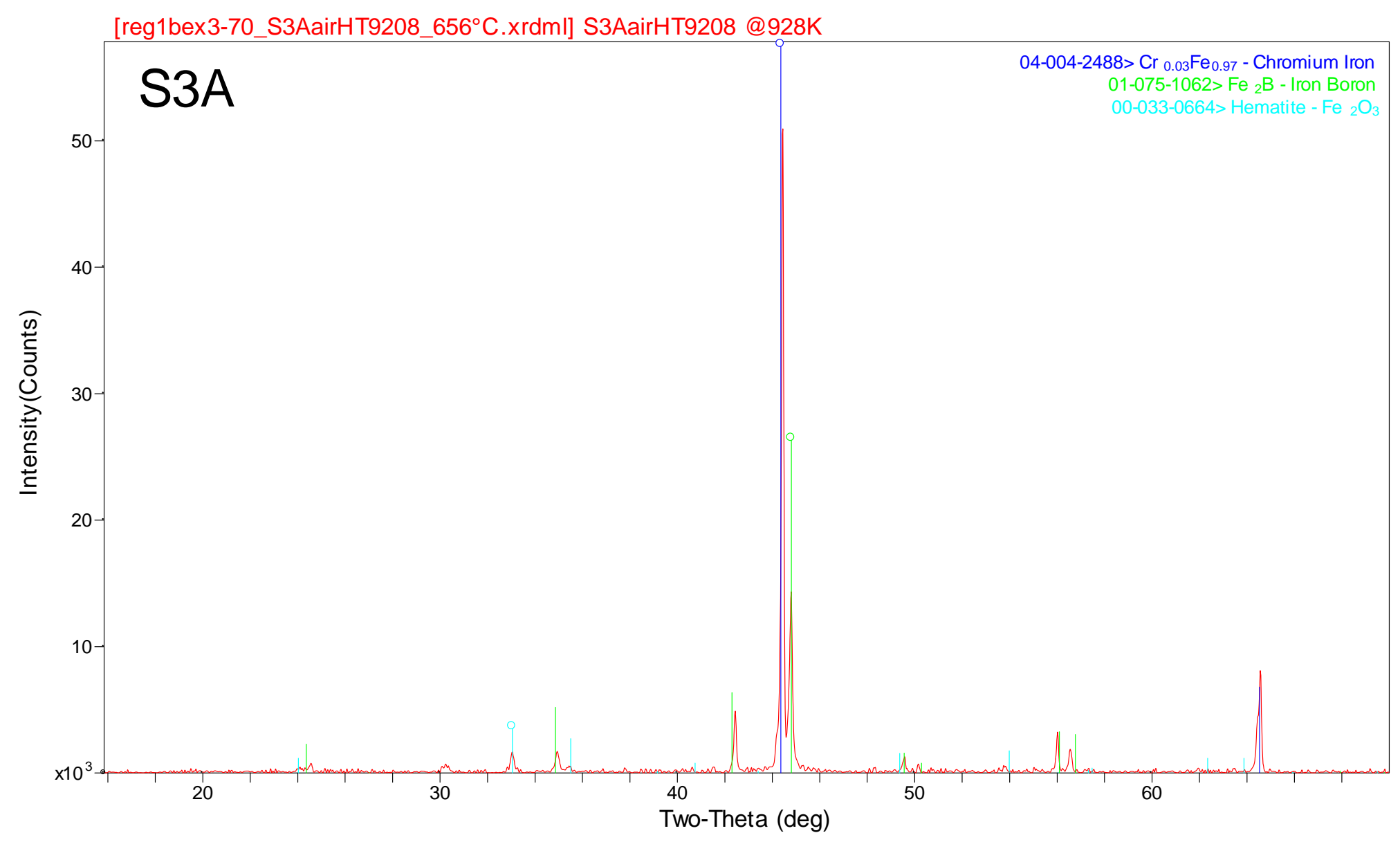

Figure 26. HTXRD scan of S3A at $600^{\circ} \mathrm{C}$ in air. 


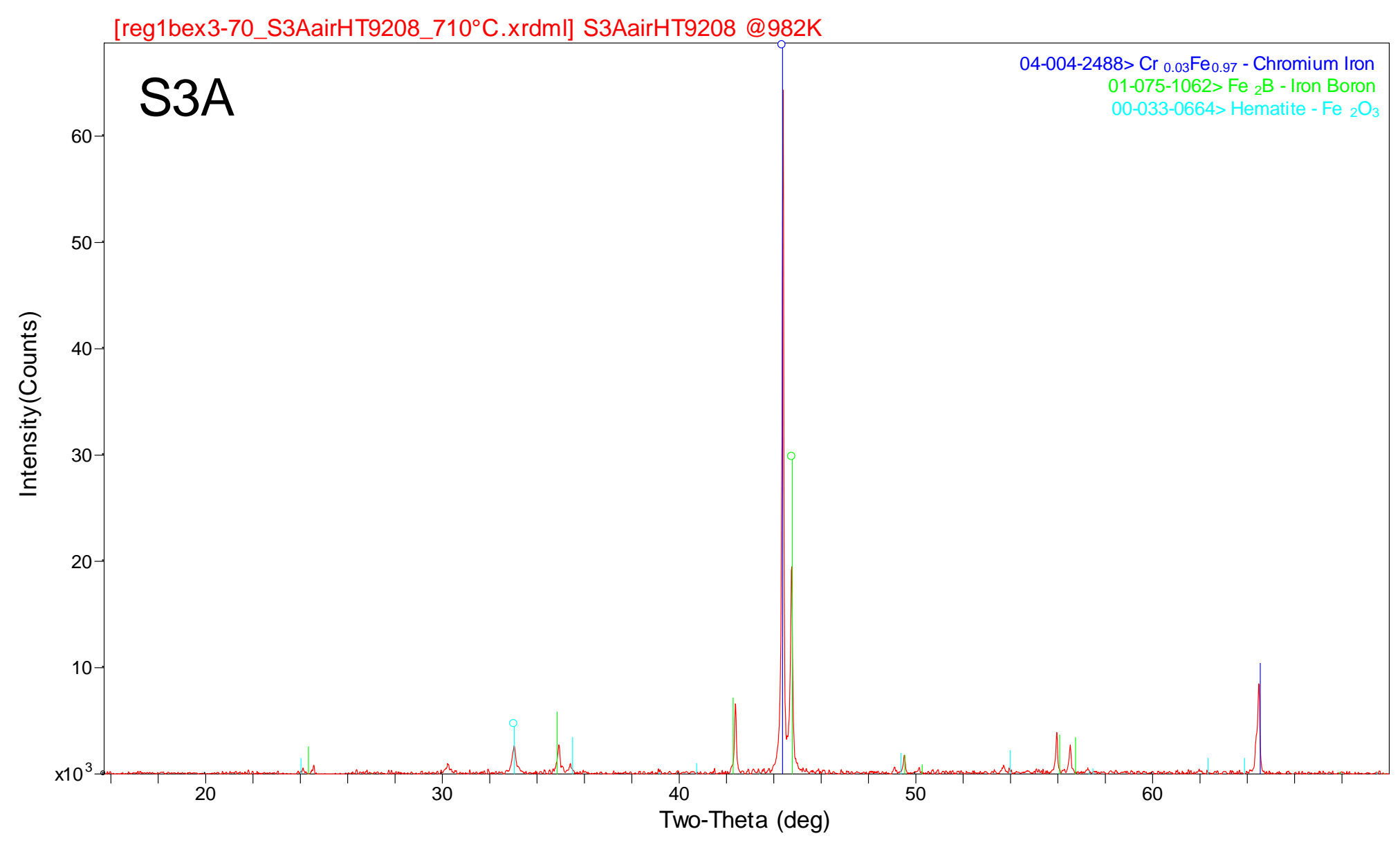

Figure 27. HTXRD scan of S3A at $650^{\circ} \mathrm{C}$ in air. 


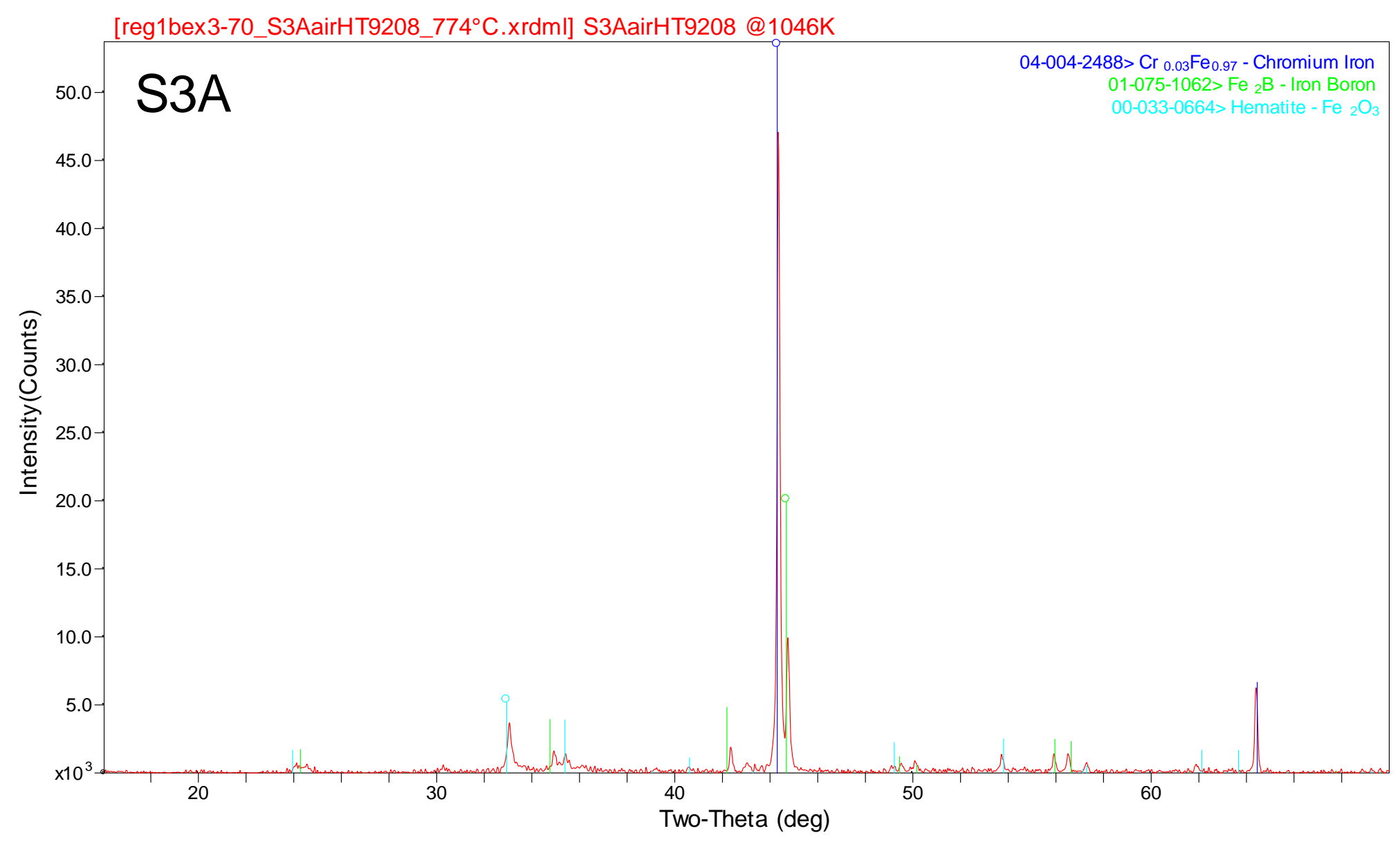

Figure 28. HTXRD scan of S3A at $710^{\circ} \mathrm{C}$ in air. 


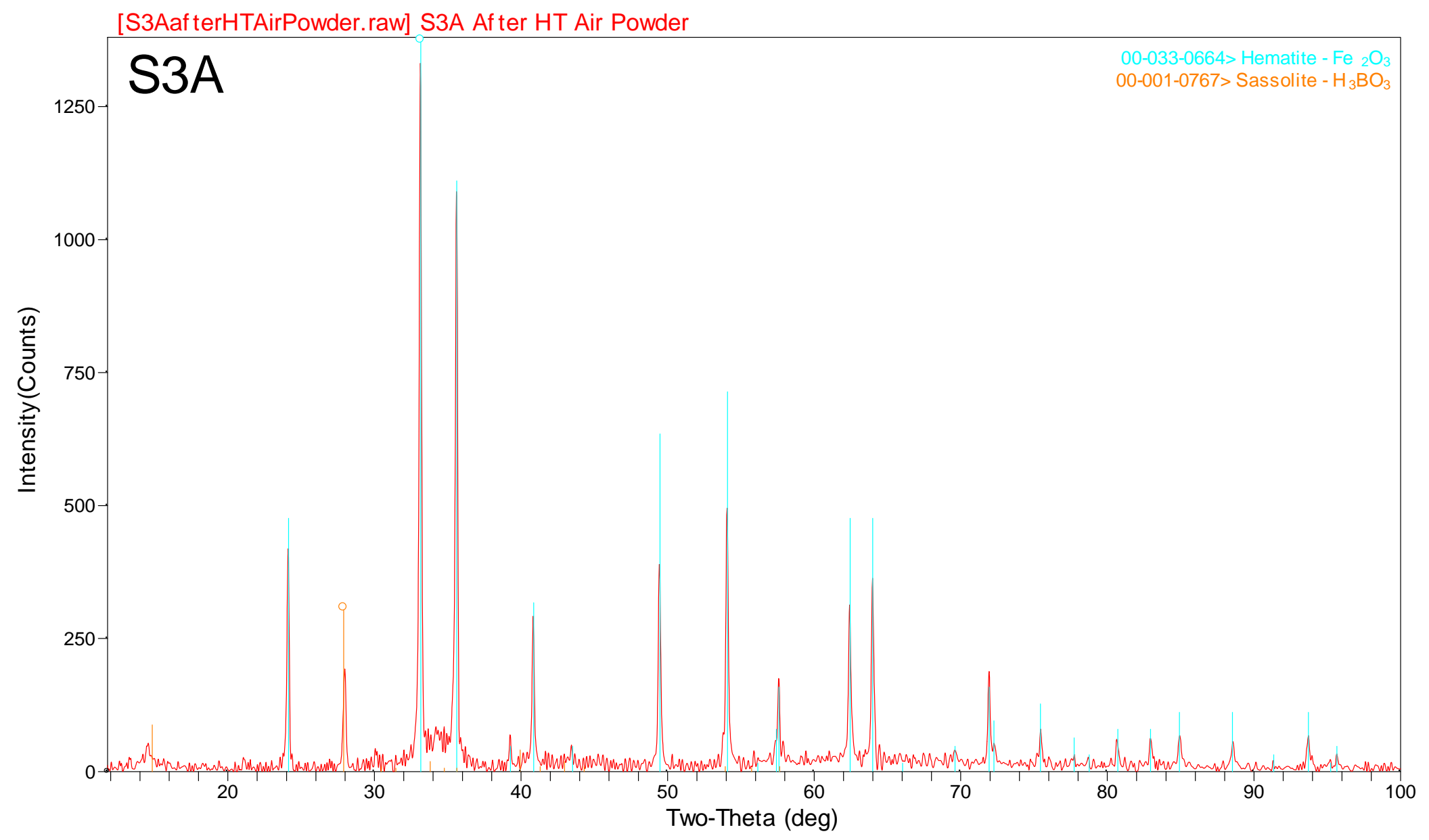

Figure 29. XRD scan of S3A HTXRD loose residue in air 
SRNS-STI-2008-00133

Revision 1

$\mathrm{X}$ 
SRNS-STI-2008-00133

Revision 1

Appendix B- XRD 2714 A Alloy 


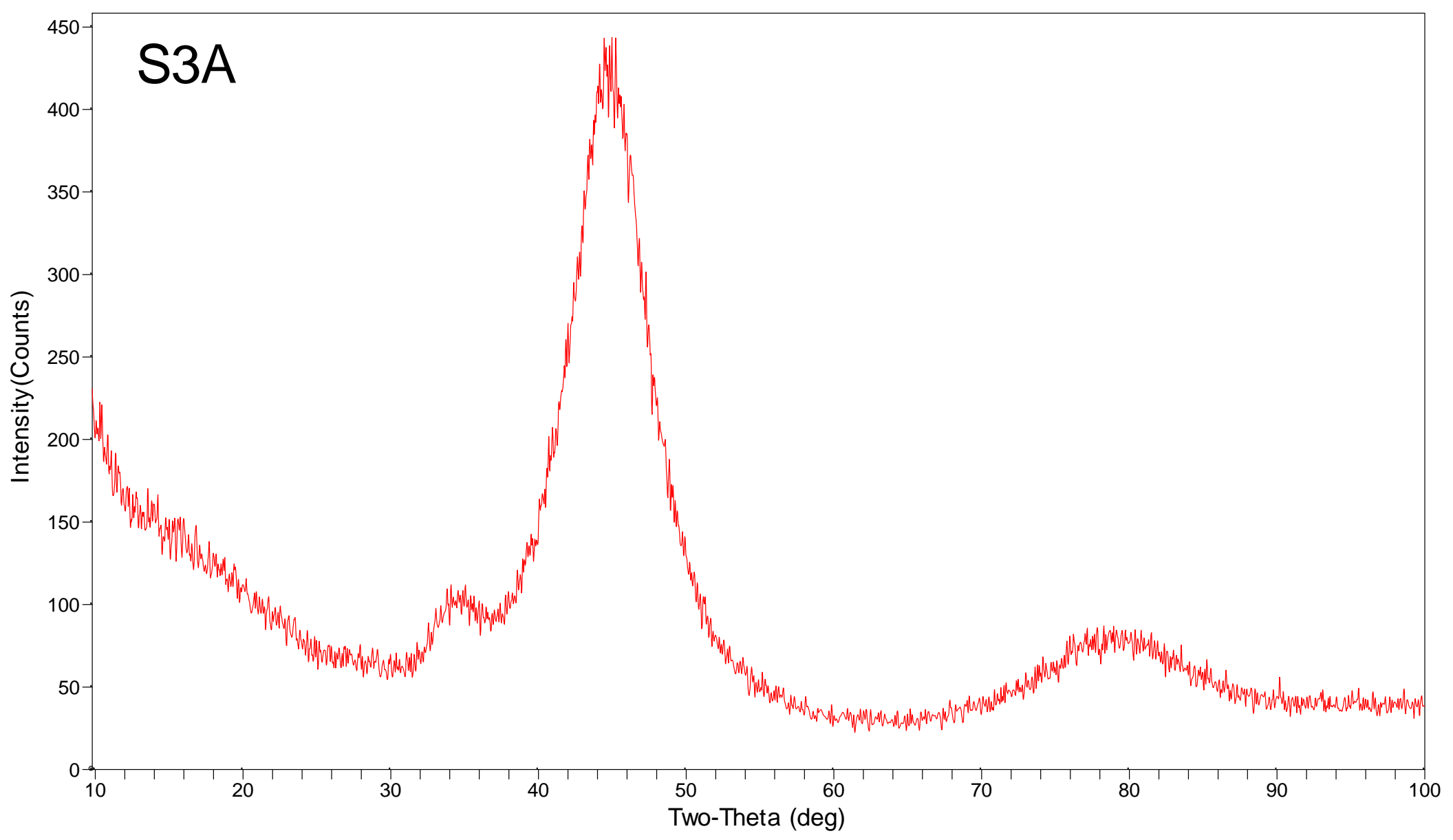

Figure 30. XRD scan of 2714 at $25^{\circ} \mathrm{C}$. 


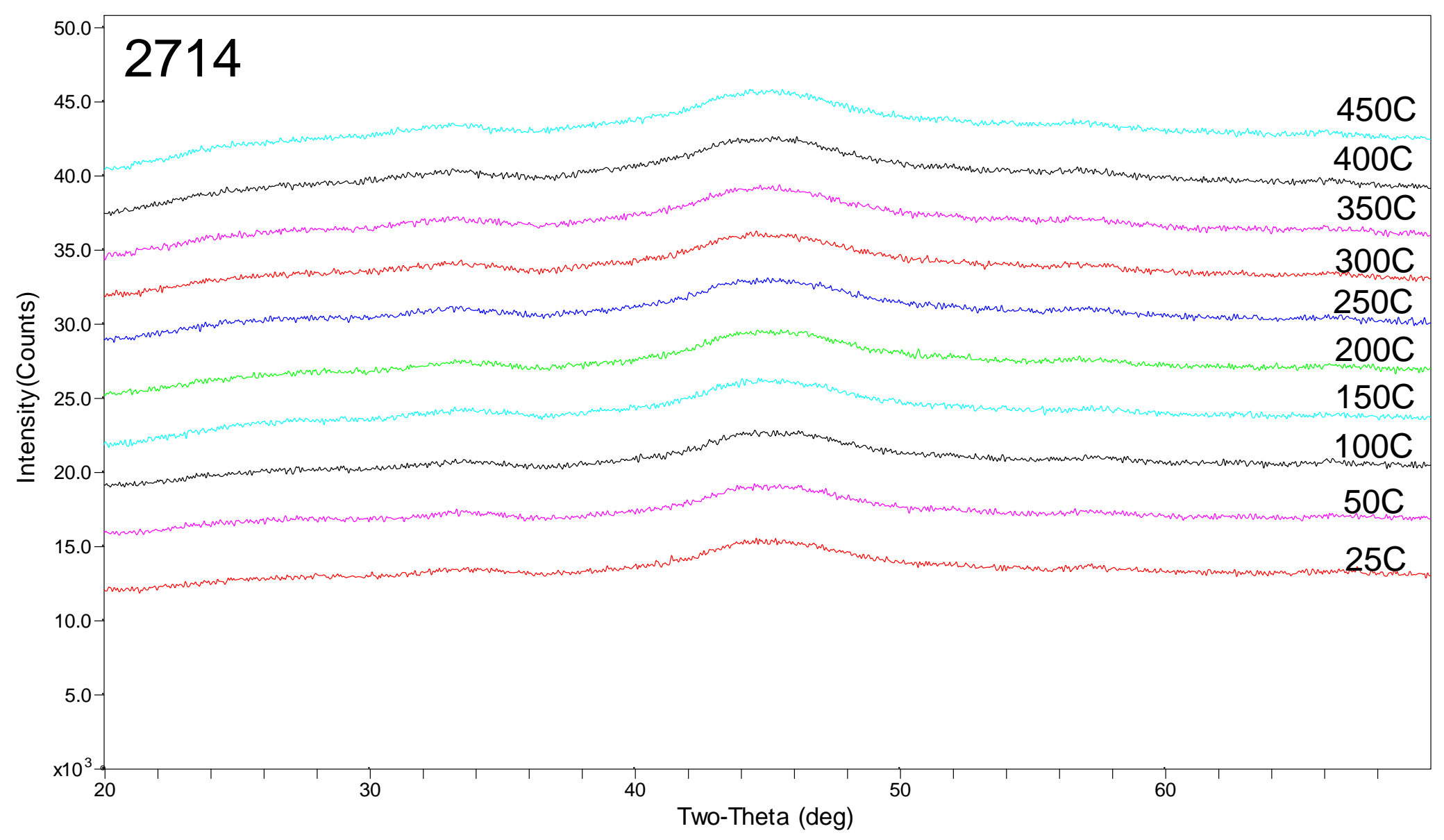

Figure 31. HTXRD scans of 2714 from $25^{\circ} \mathrm{C}$ to $450^{\circ} \mathrm{C}$ in $\mathrm{He}$. 


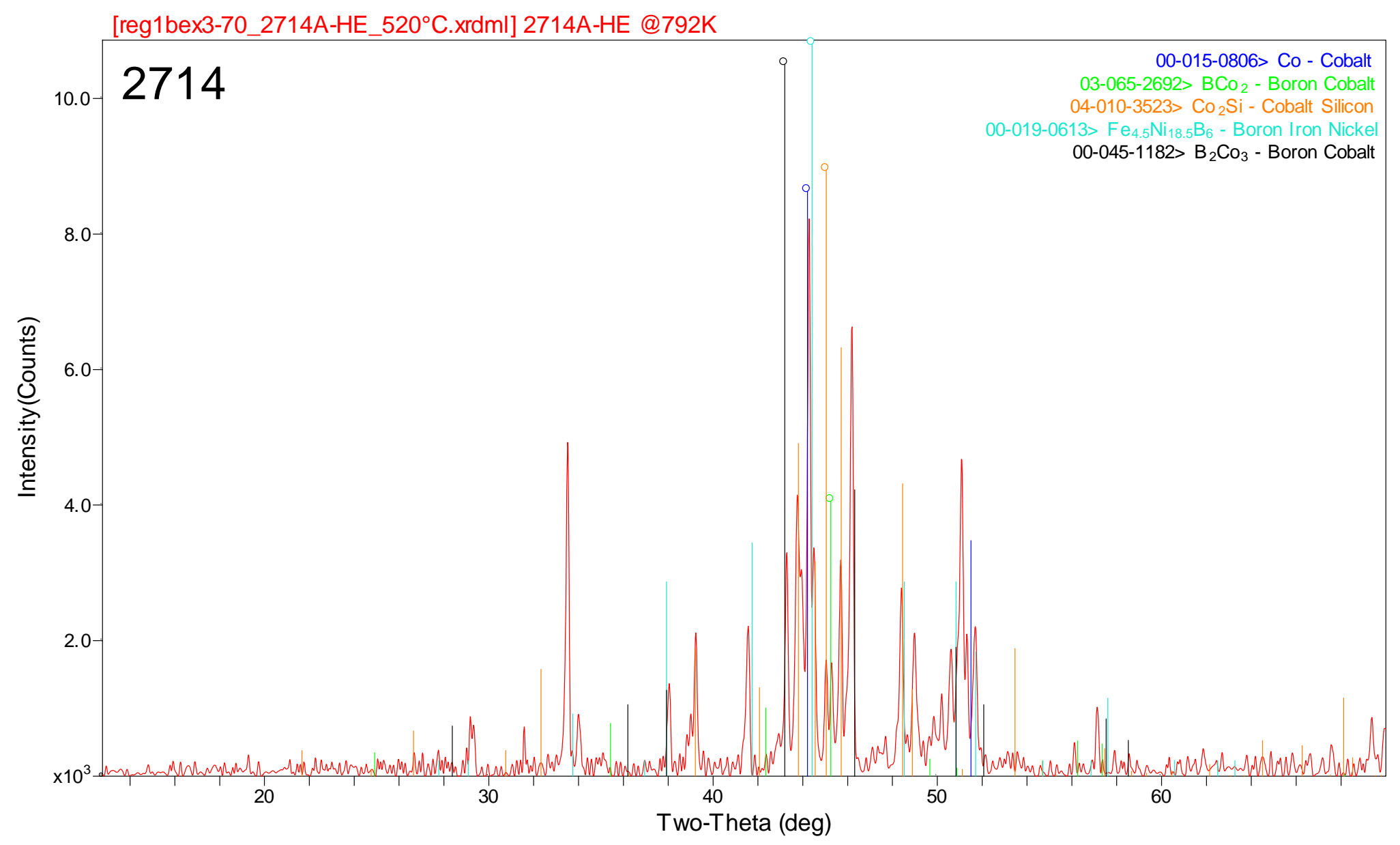

Figure 32. HTXRD scans of 2714 at $500^{\circ} \mathrm{C}$ in He. 


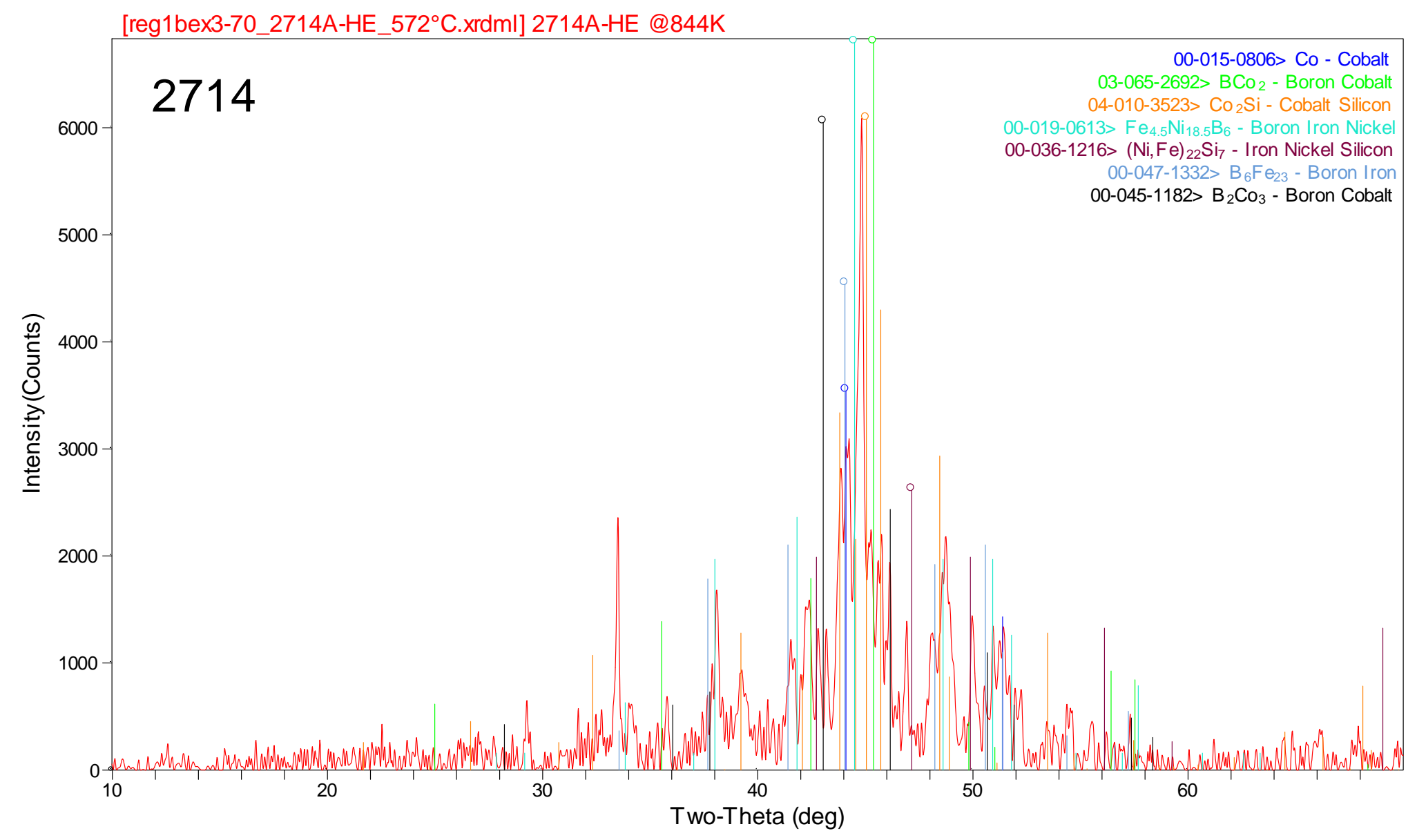

Figure 33. HTXRD scan of 2714 at $550^{\circ} \mathrm{C}$ in He. 


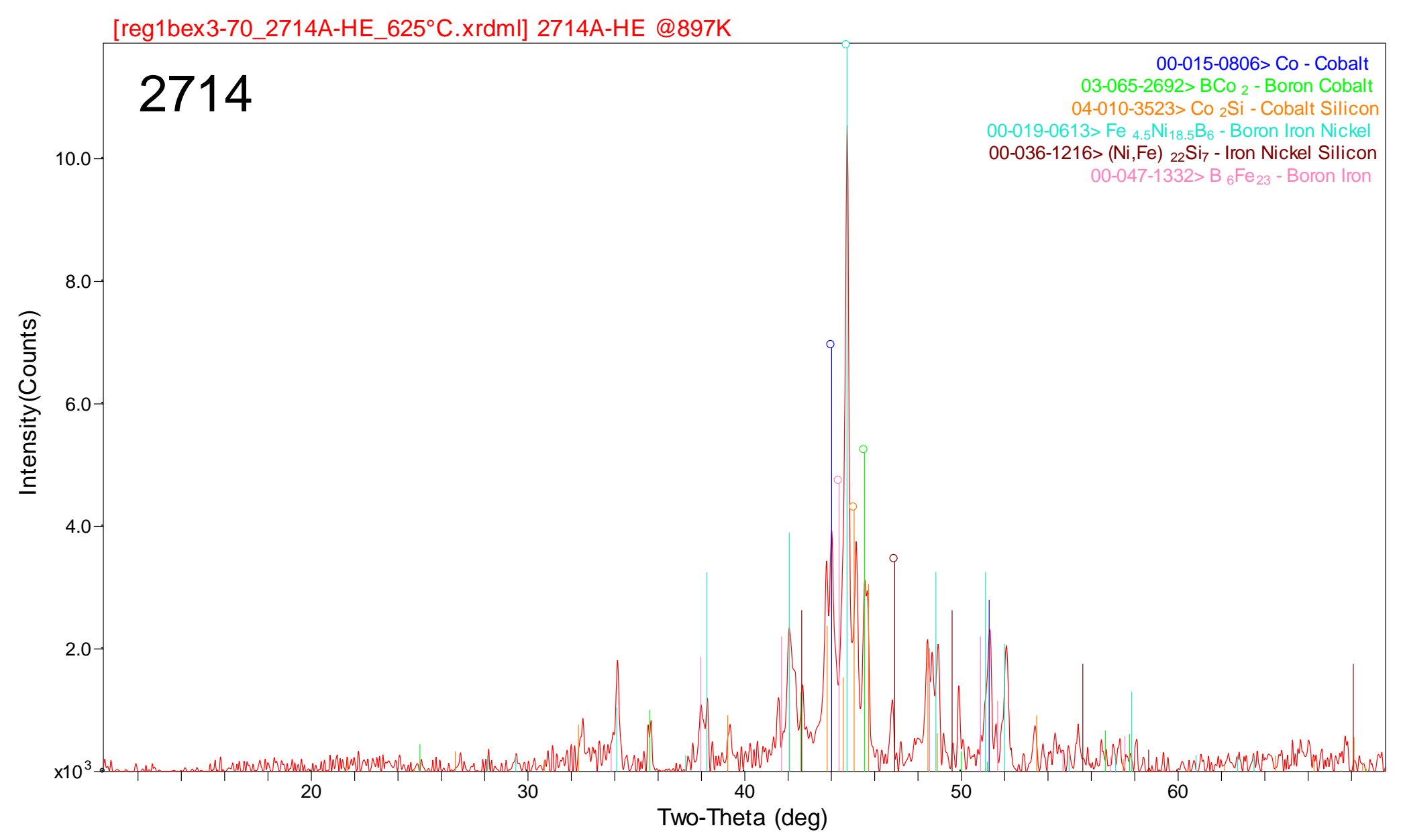

Figure 34. HTXRD scan of 2714 at $600^{\circ} \mathrm{C}$ in He. 


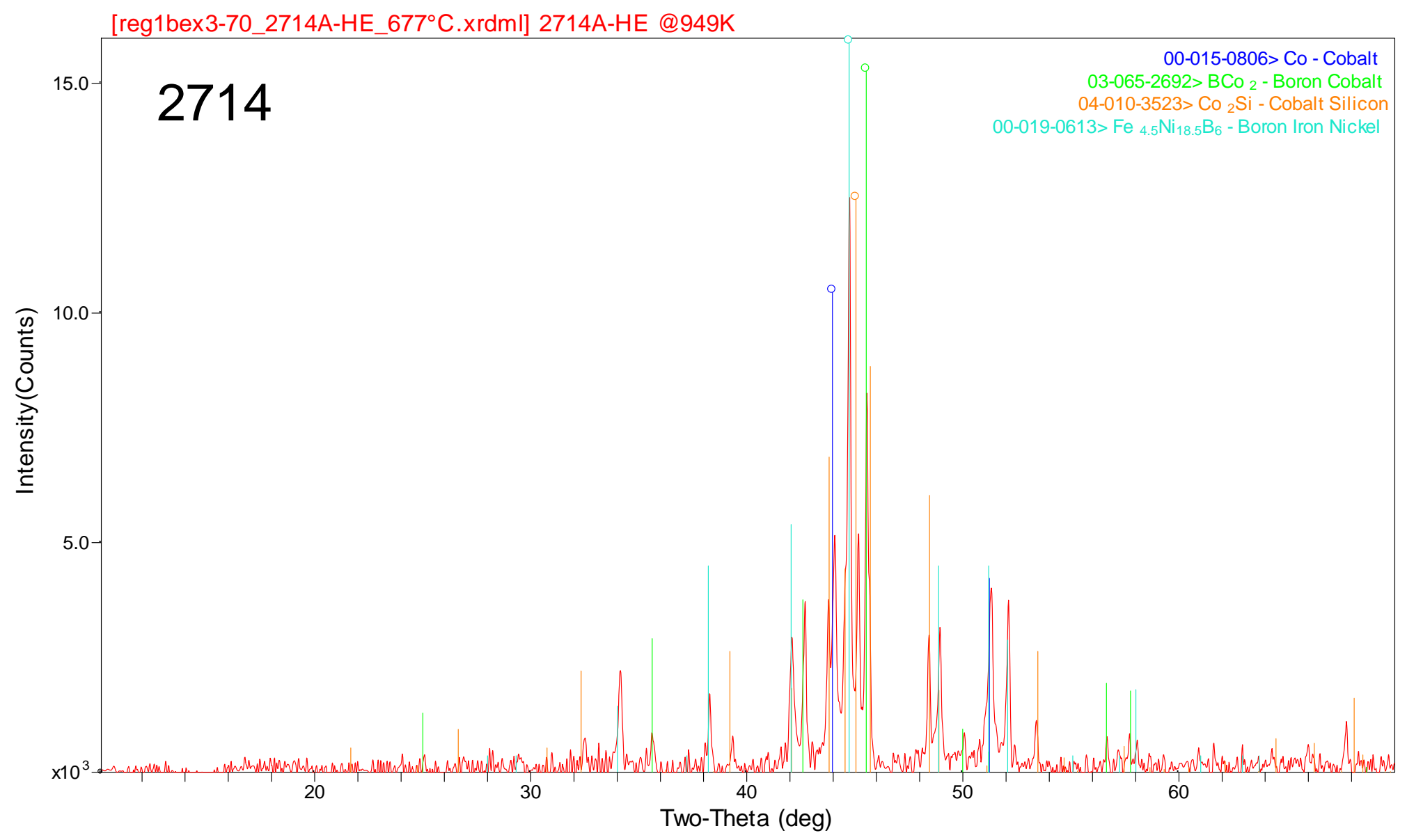

Figure 35. HTXRD scan of 2714 at $650^{\circ} \mathrm{C}$ in $\mathrm{He}$. 


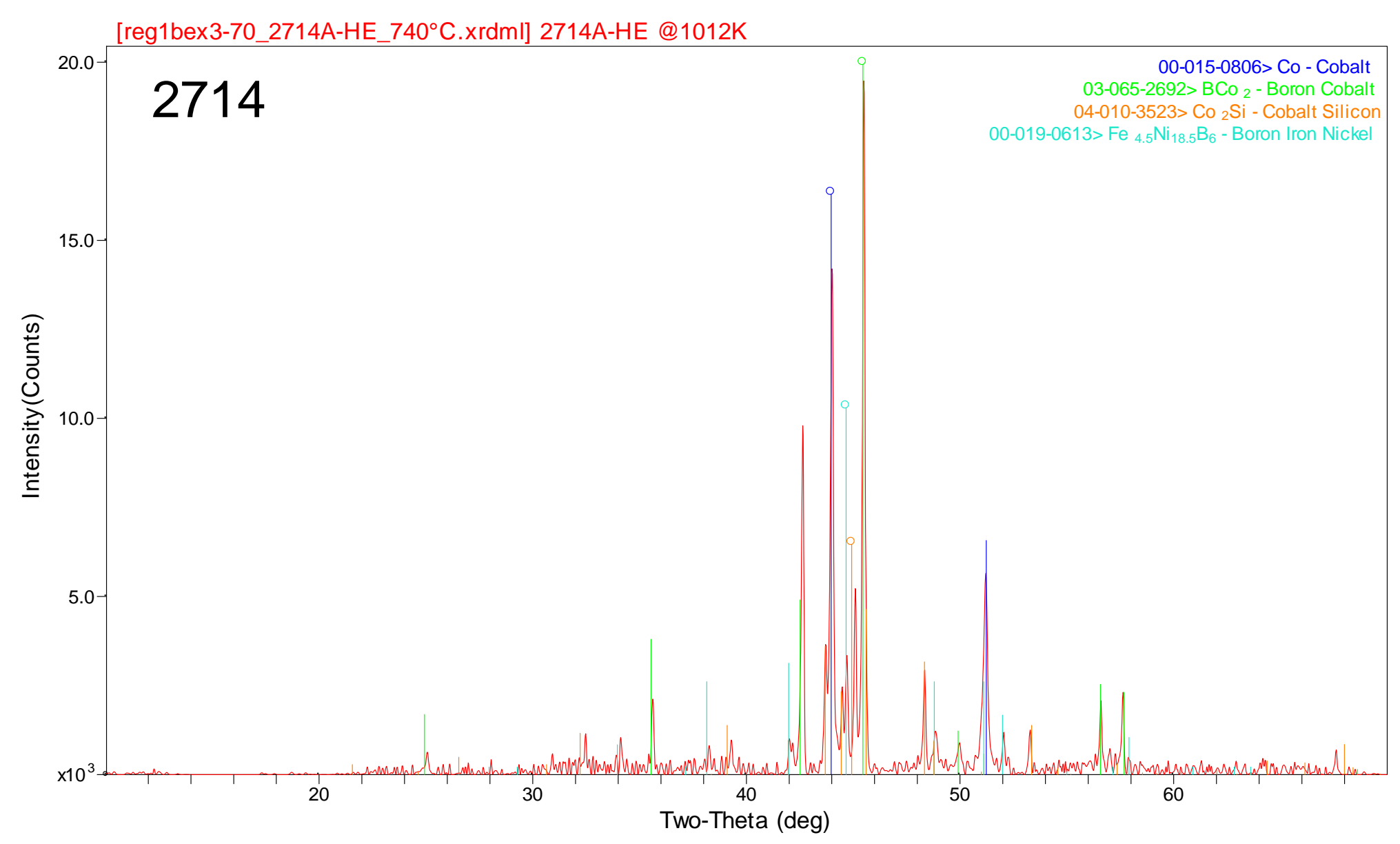

Figure 36. HTXRD scan of 2714 at $710^{\circ} \mathrm{C}$ in $\mathrm{He}$. 


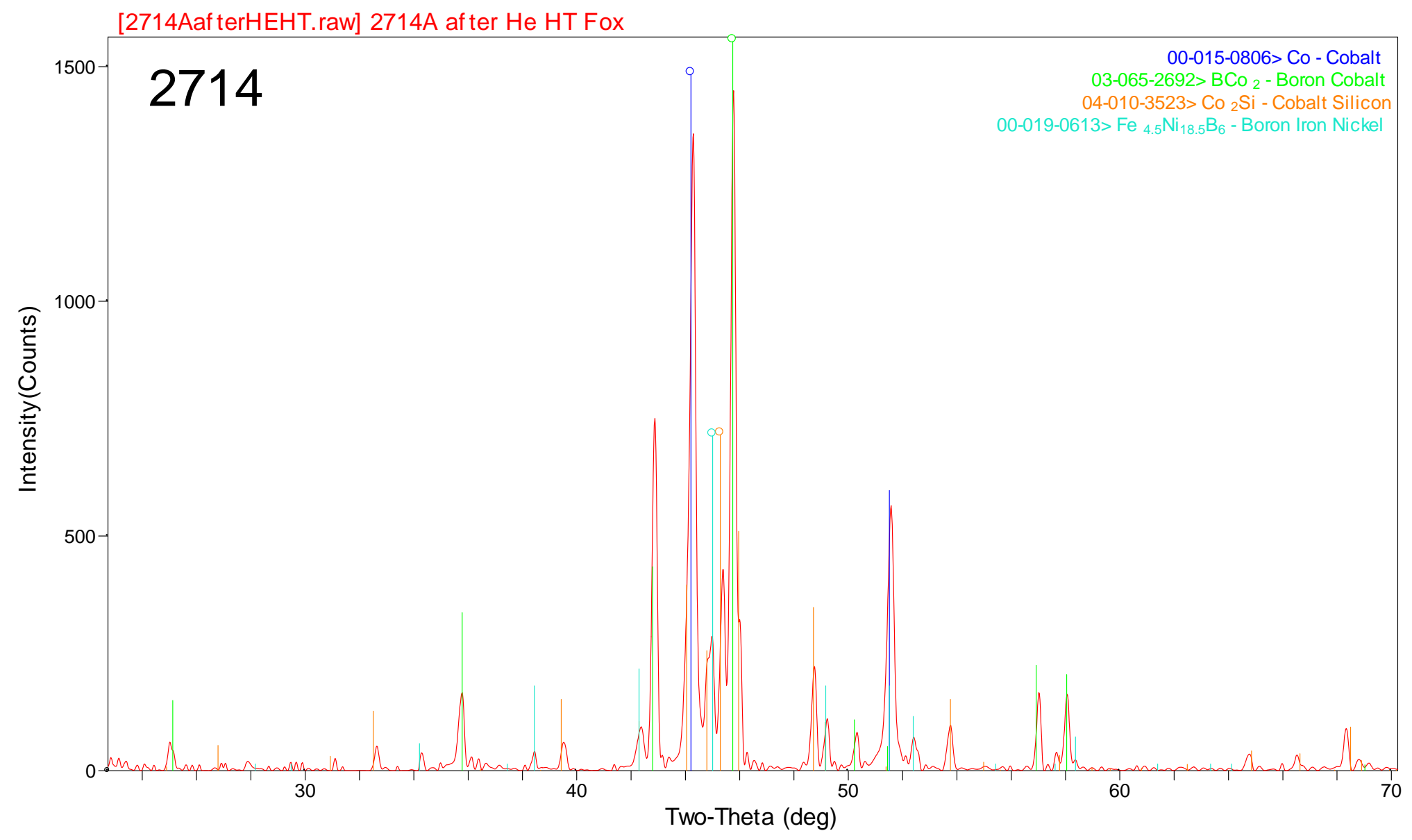

Figure 37. XRD scan of 2714 HTXRD residue in He. 


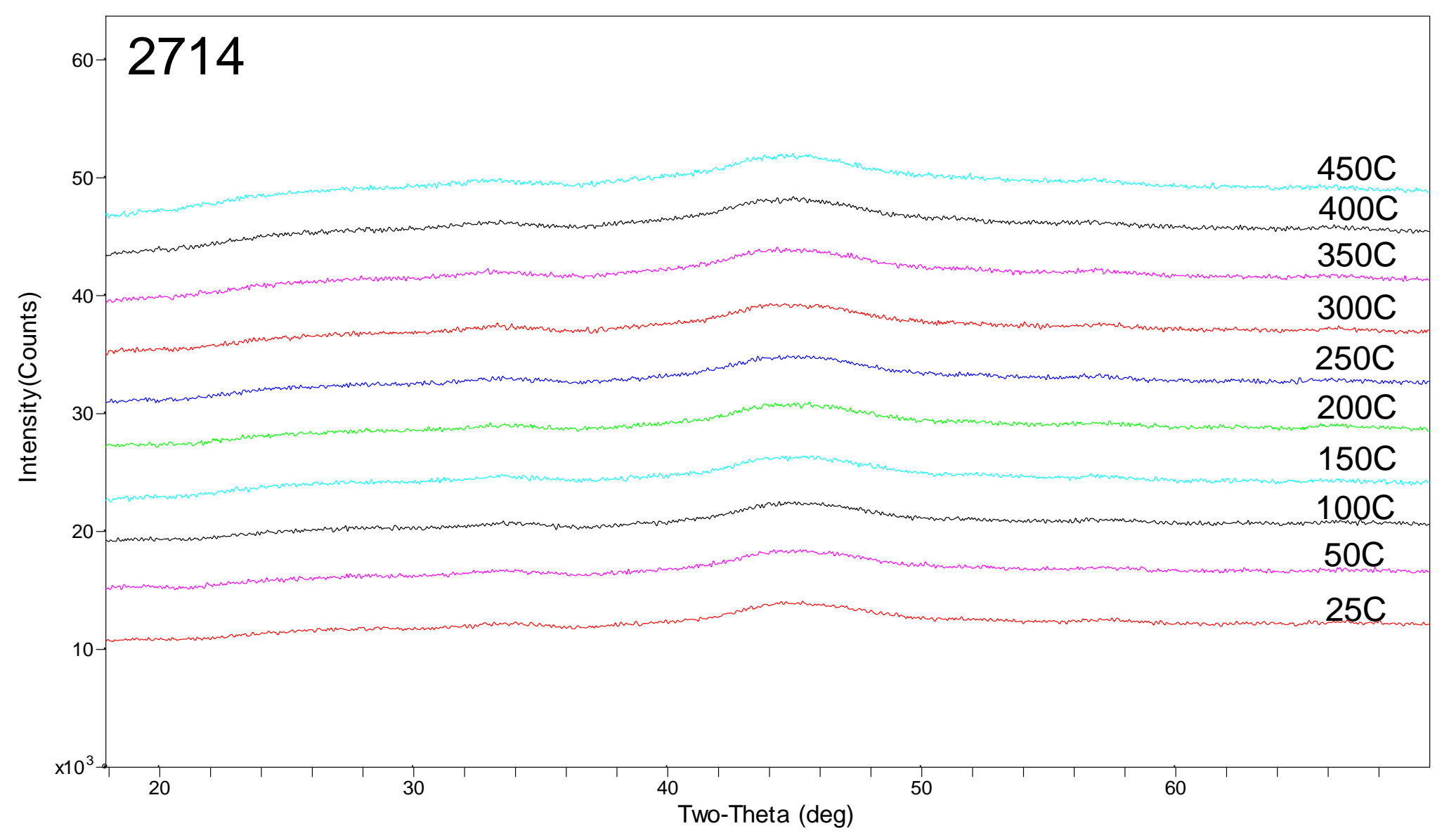

Figure 38. HTXRD scans of 2714 from 25 to $450^{\circ} \mathrm{C}$ in $4 \%-\mathrm{H}_{2} / 96 \%-\mathrm{He}$. 


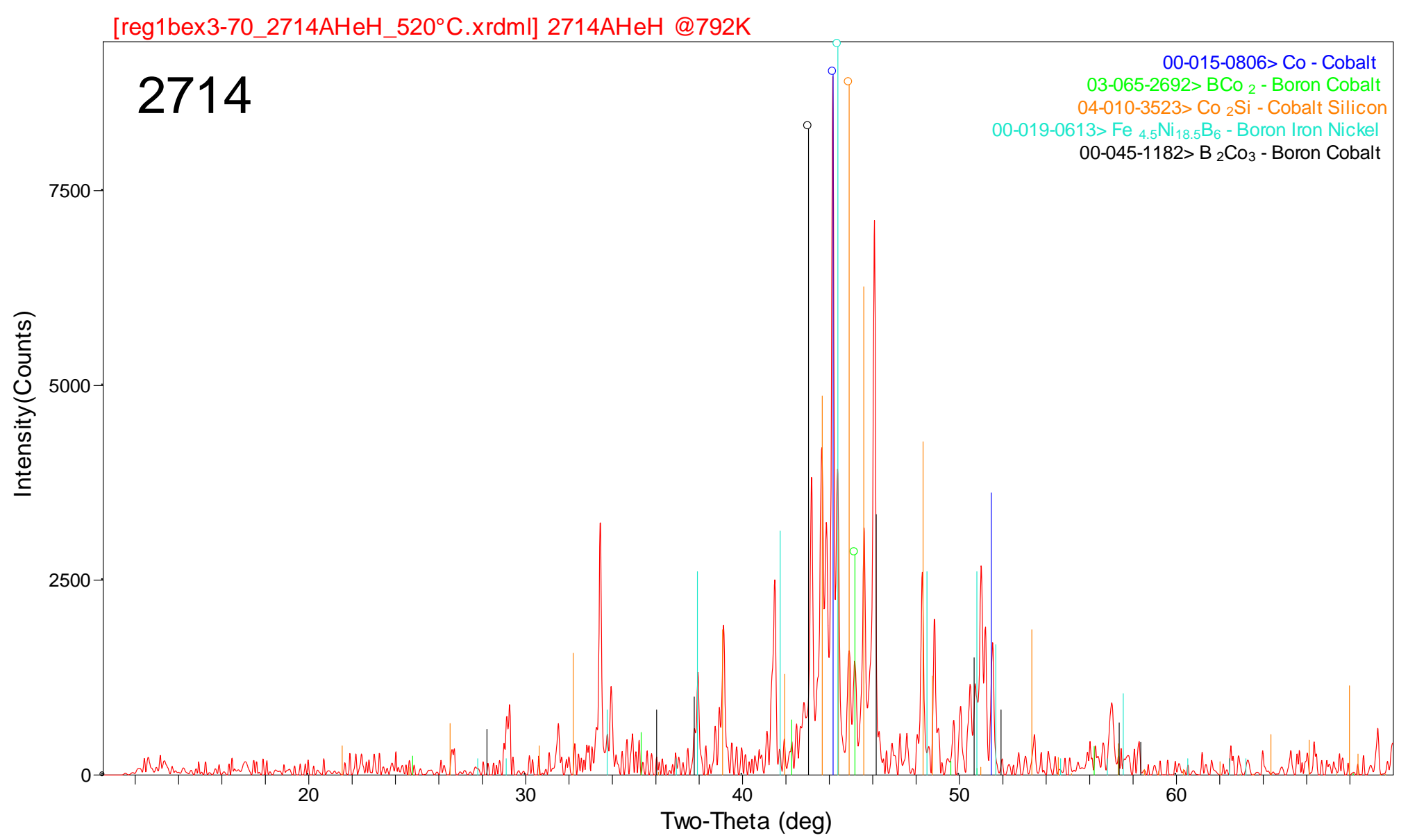

Figure 39. HTXRD scans of 2714 at $500^{\circ} \mathrm{C}$ in $4 \%-\mathrm{H}_{2} / 96 \%-\mathrm{He}$. 


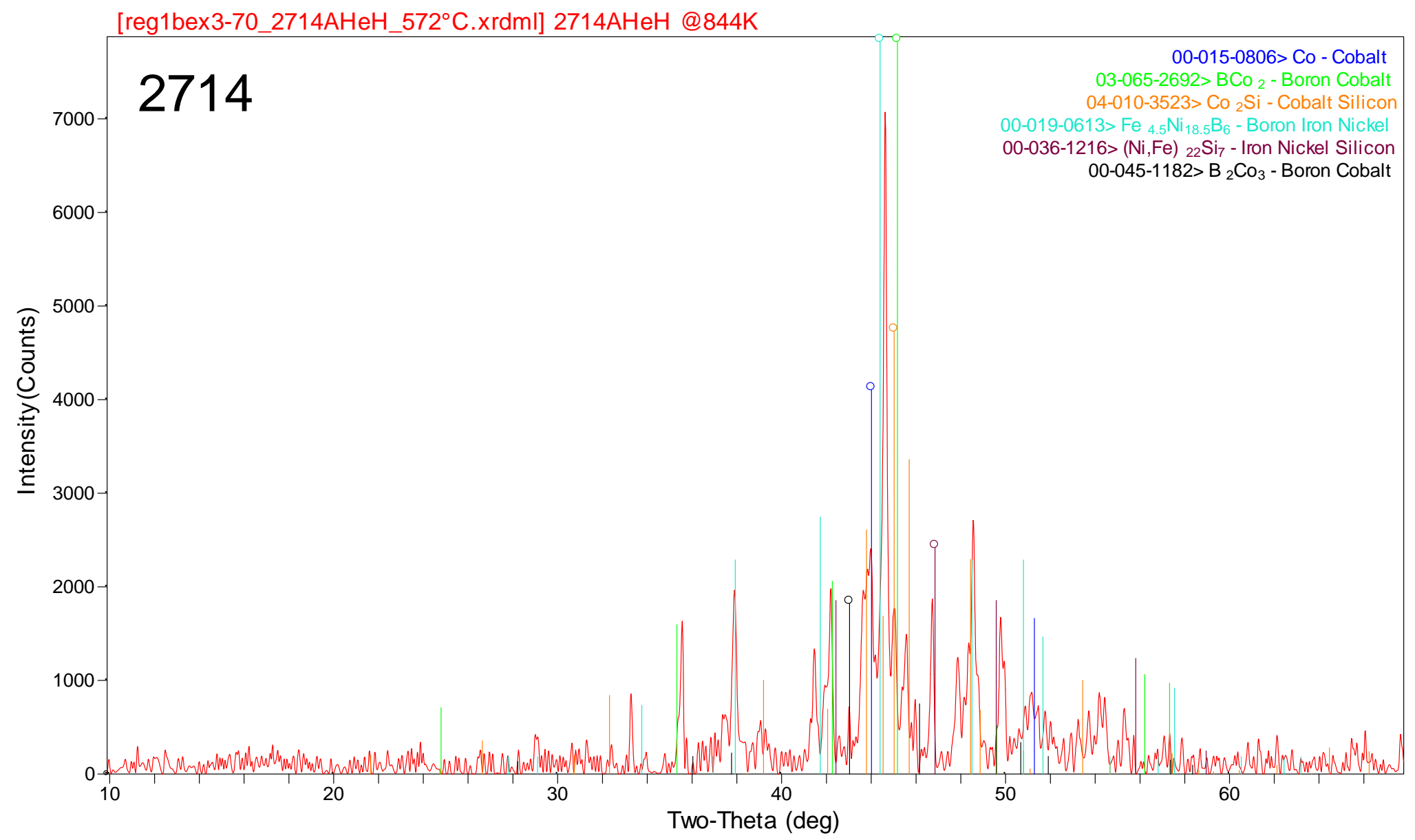

Figure 40. HTXRD scan of 2714 at $550^{\circ} \mathrm{C}$ in $4 \%-\mathrm{H}_{2} / 96 \%-\mathrm{He}$. 


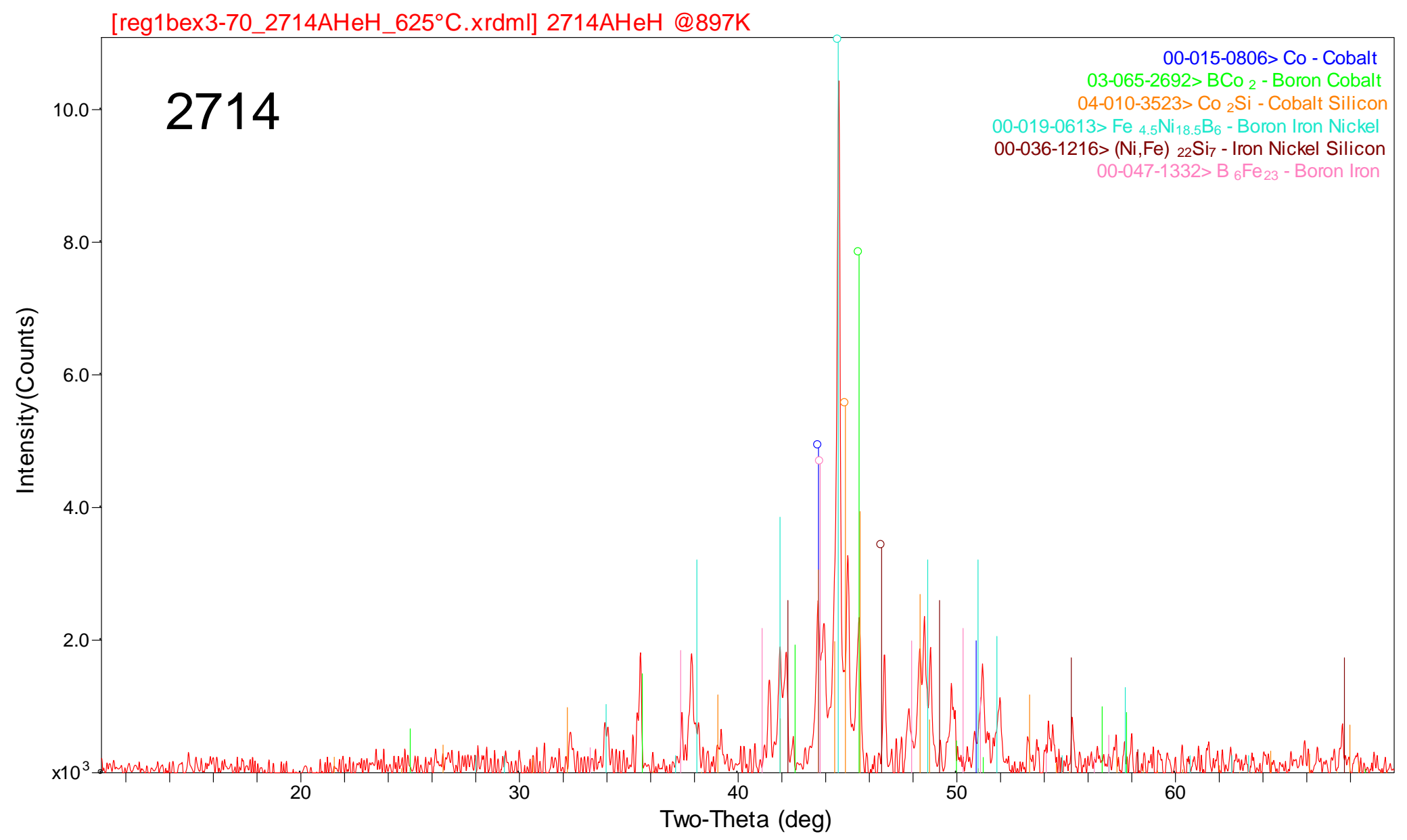

Figure 41. HTXRD scan of 2714 at $600^{\circ} \mathrm{C}$ in $4 \%-\mathrm{H}_{2} / 96 \%-\mathrm{He}$. 


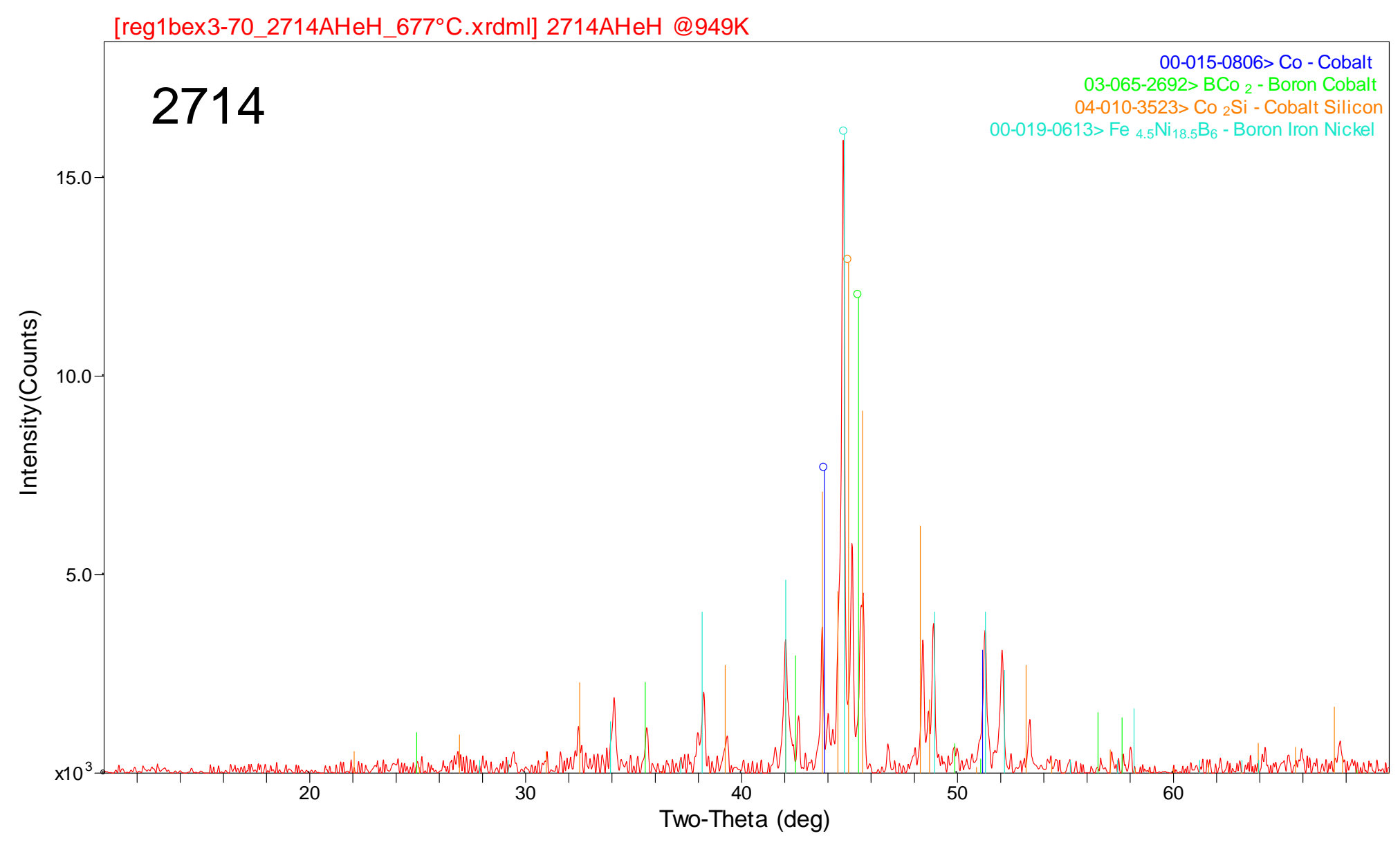

Figure 42. HTXRD scan of 2714 at $650^{\circ} \mathrm{C}$ in $4 \%-\mathrm{H}_{2} / 96 \%-\mathrm{He}$. 


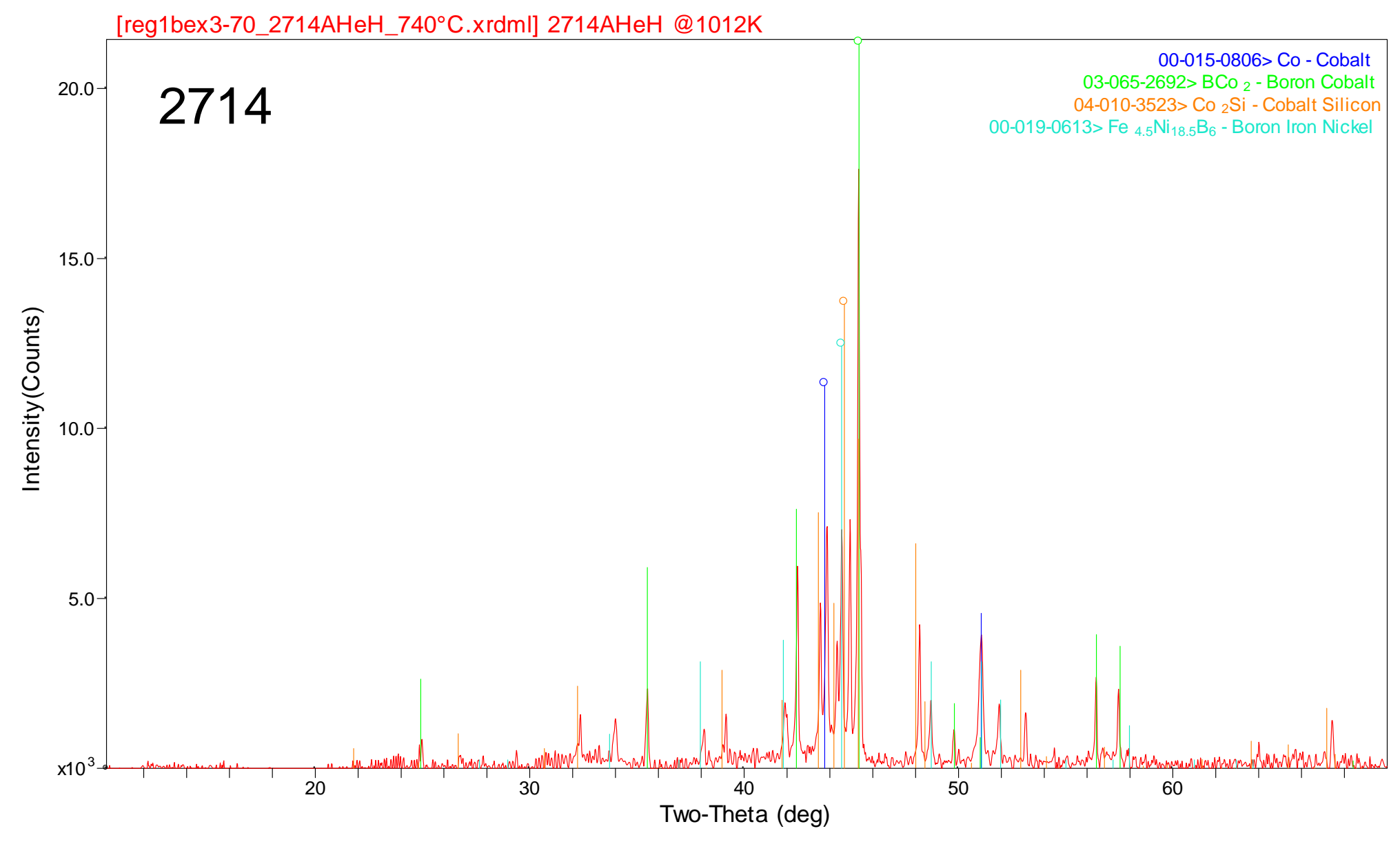

Figure 43. HTXRD scan of 2714 at $710^{\circ} \mathrm{C}$ in $4 \%-\mathrm{H}_{2} / 96 \%-\mathrm{He}$. 


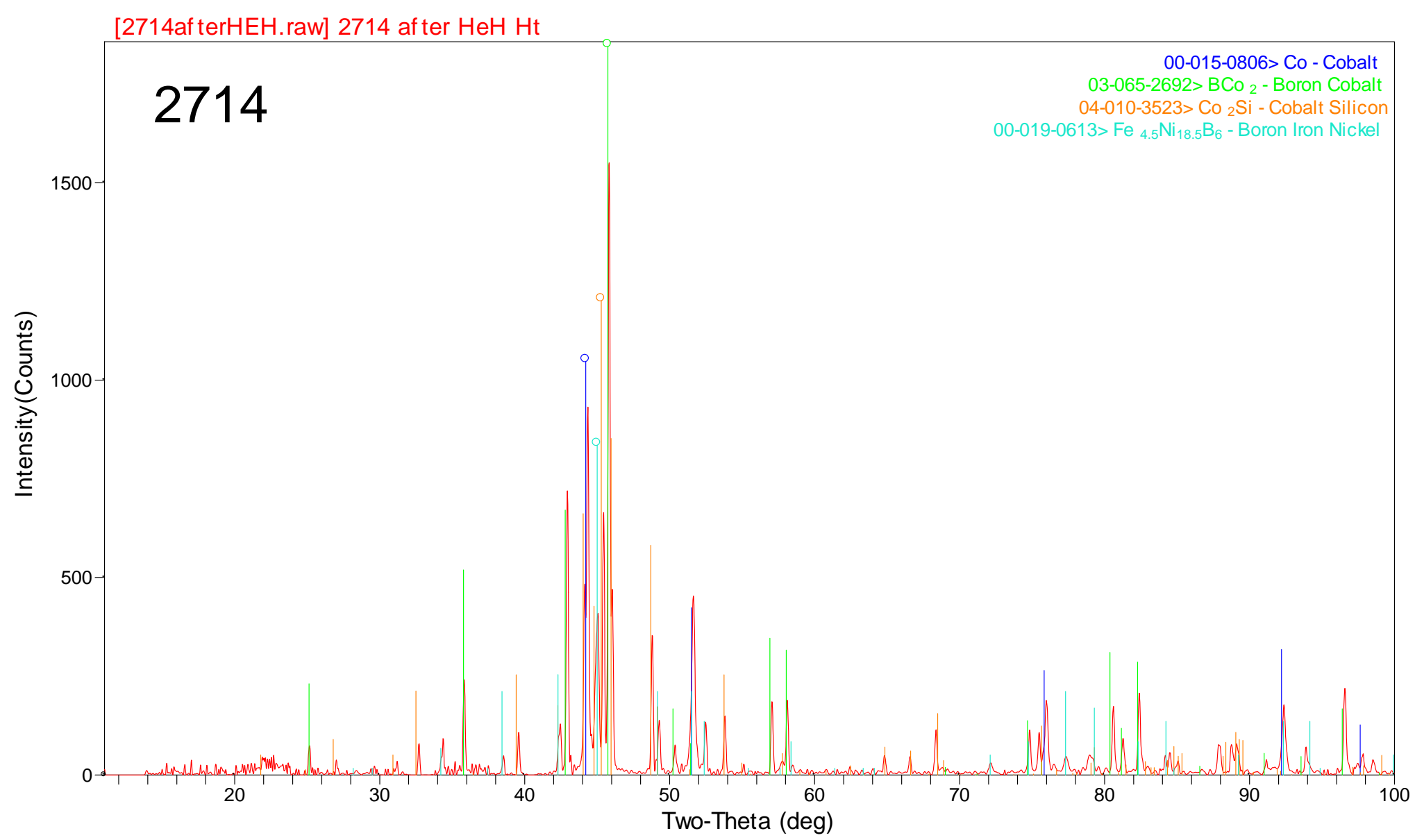

Figure 44. XRD scan of 2714 HTXRD residue in $4 \%-\mathrm{H}_{2} / 96 \%-H e$. 


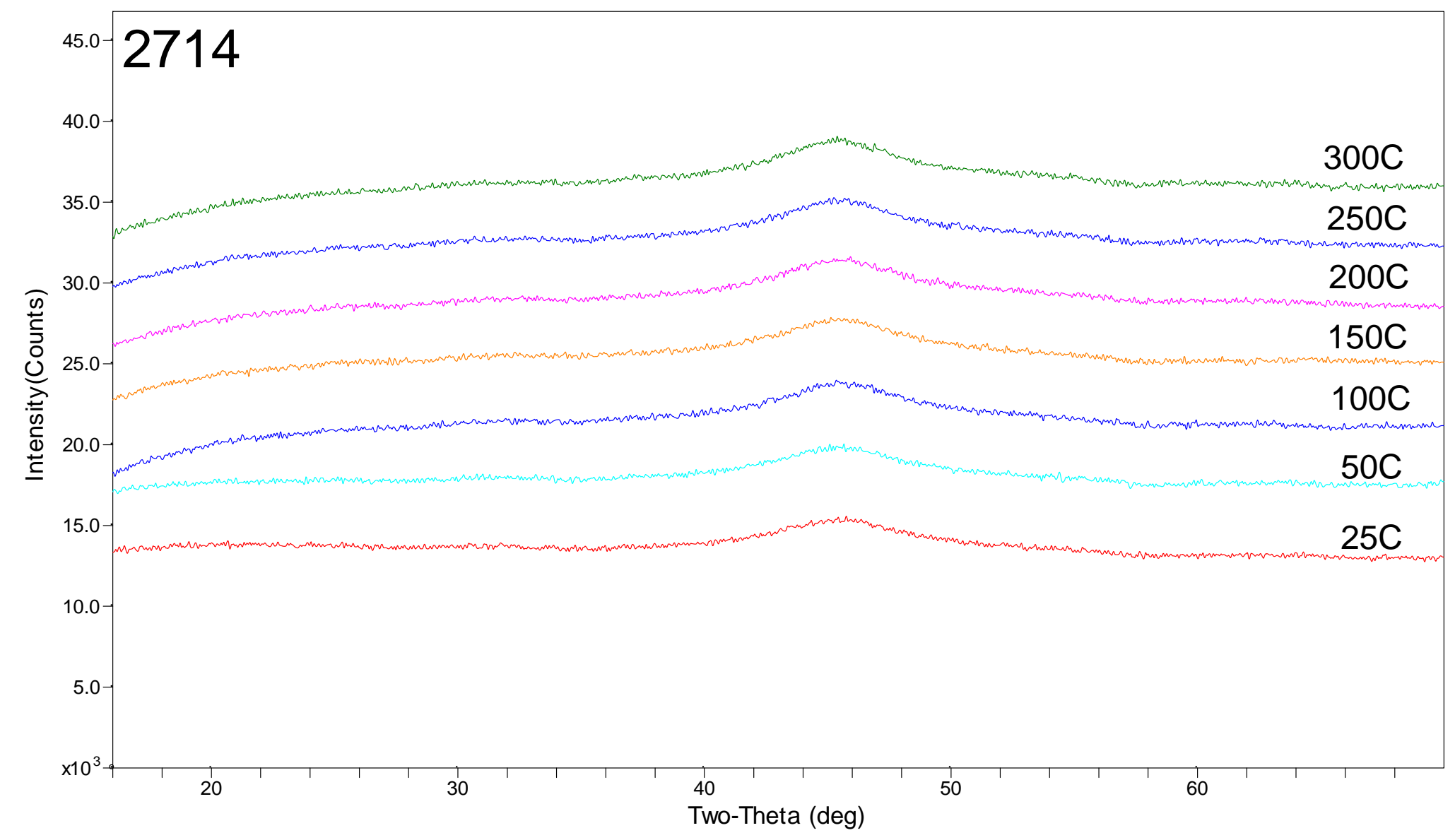

Figure 45. HTXRD scans of 2714 from 25 to $300^{\circ} \mathrm{C}$ in air. 


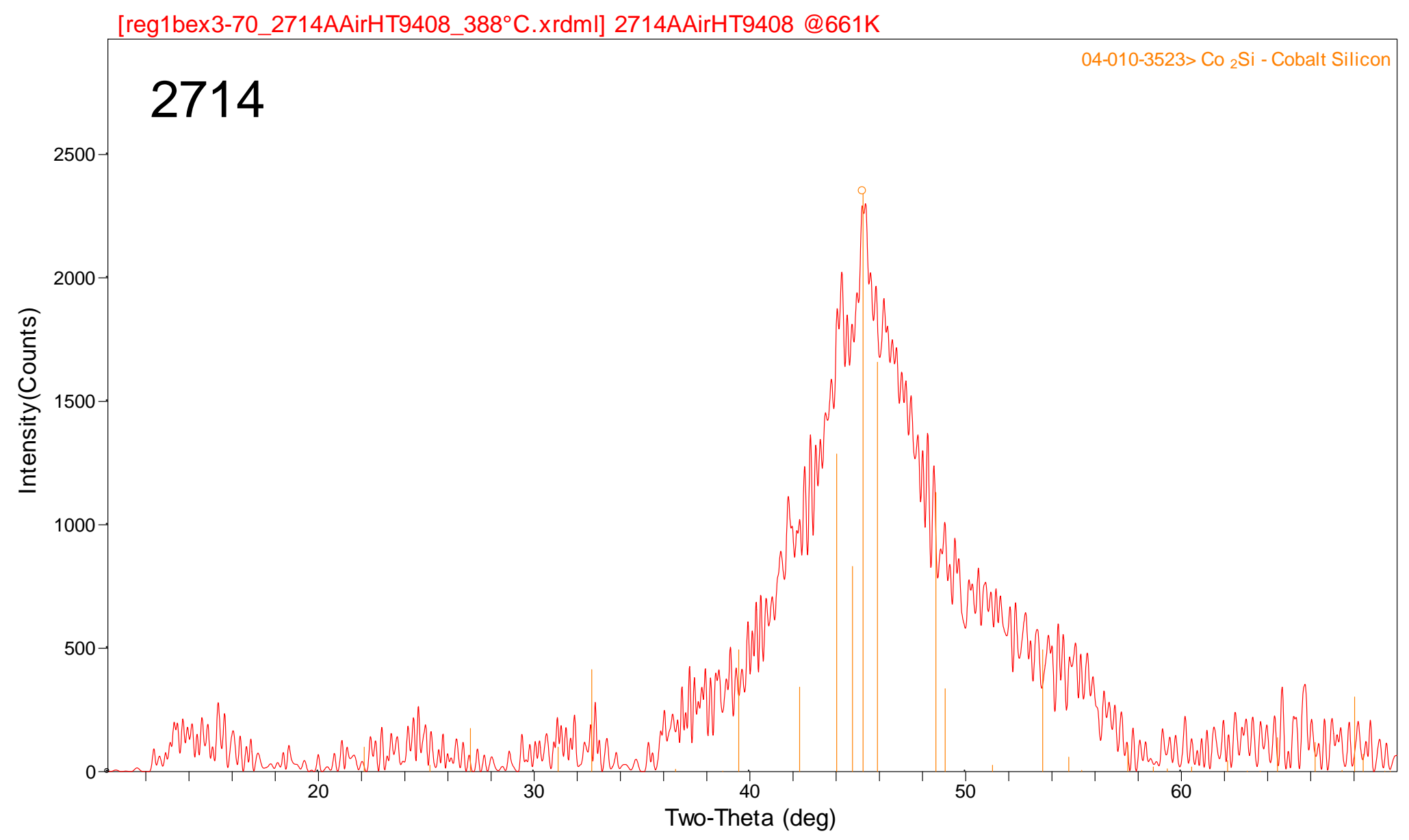

Figure 46. HTXRD scans of 2714 at $350^{\circ} \mathrm{C}$ in air. 


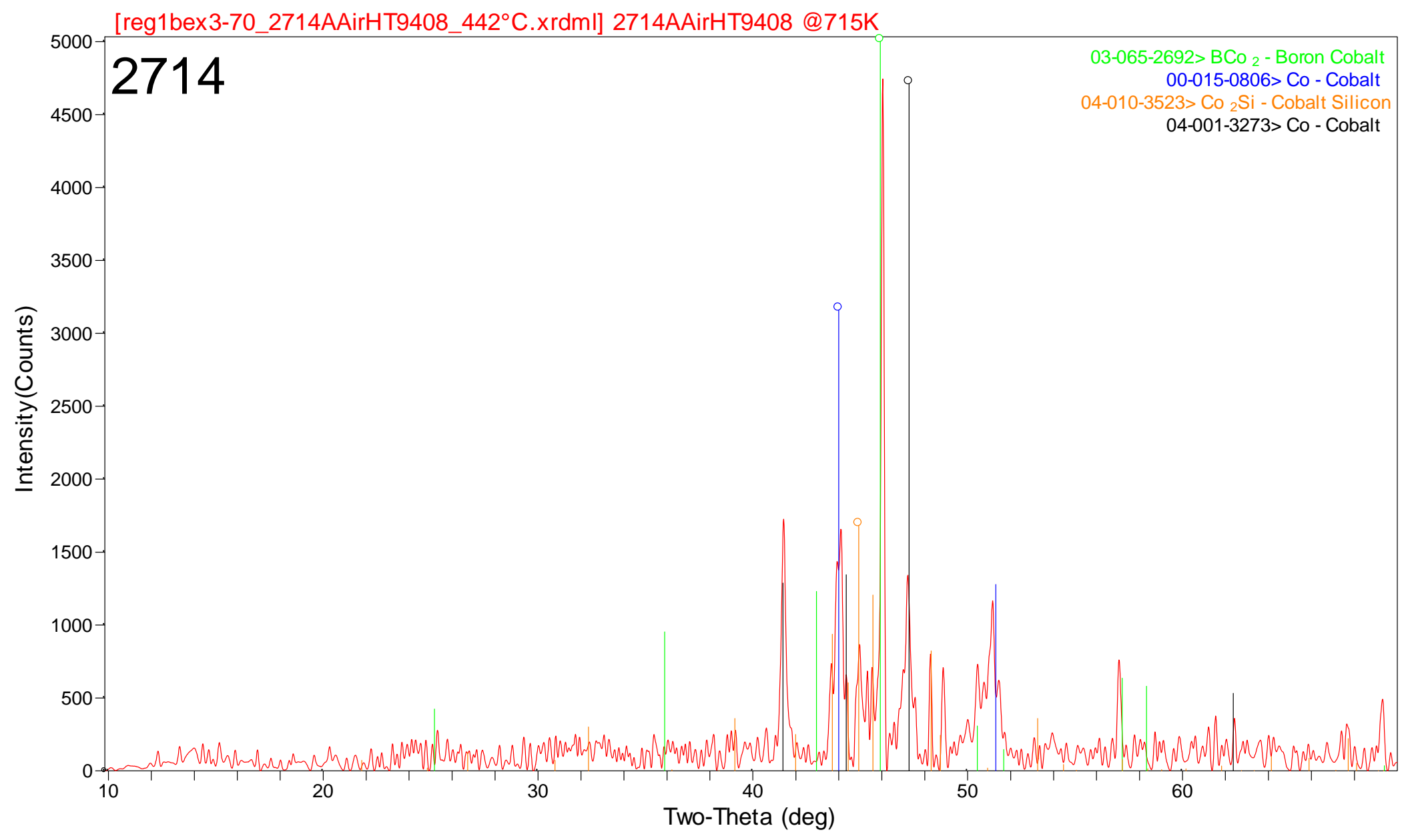

Figure 47. HTXRD scan of 2714 at $400^{\circ} \mathrm{C}$ in air. 


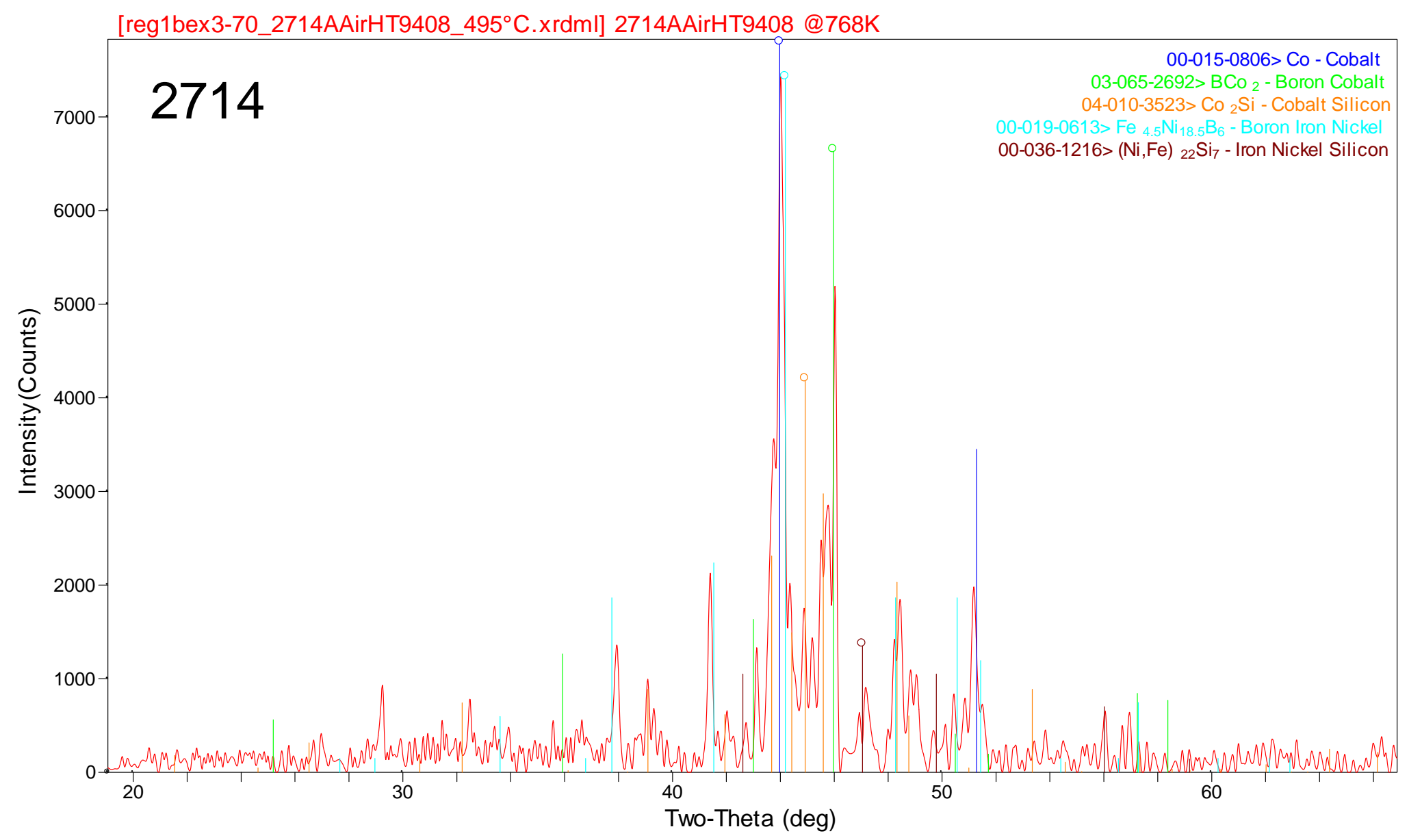

Figure 48. HTXRD scan of 2714 at $450^{\circ} \mathrm{C}$ in air. 


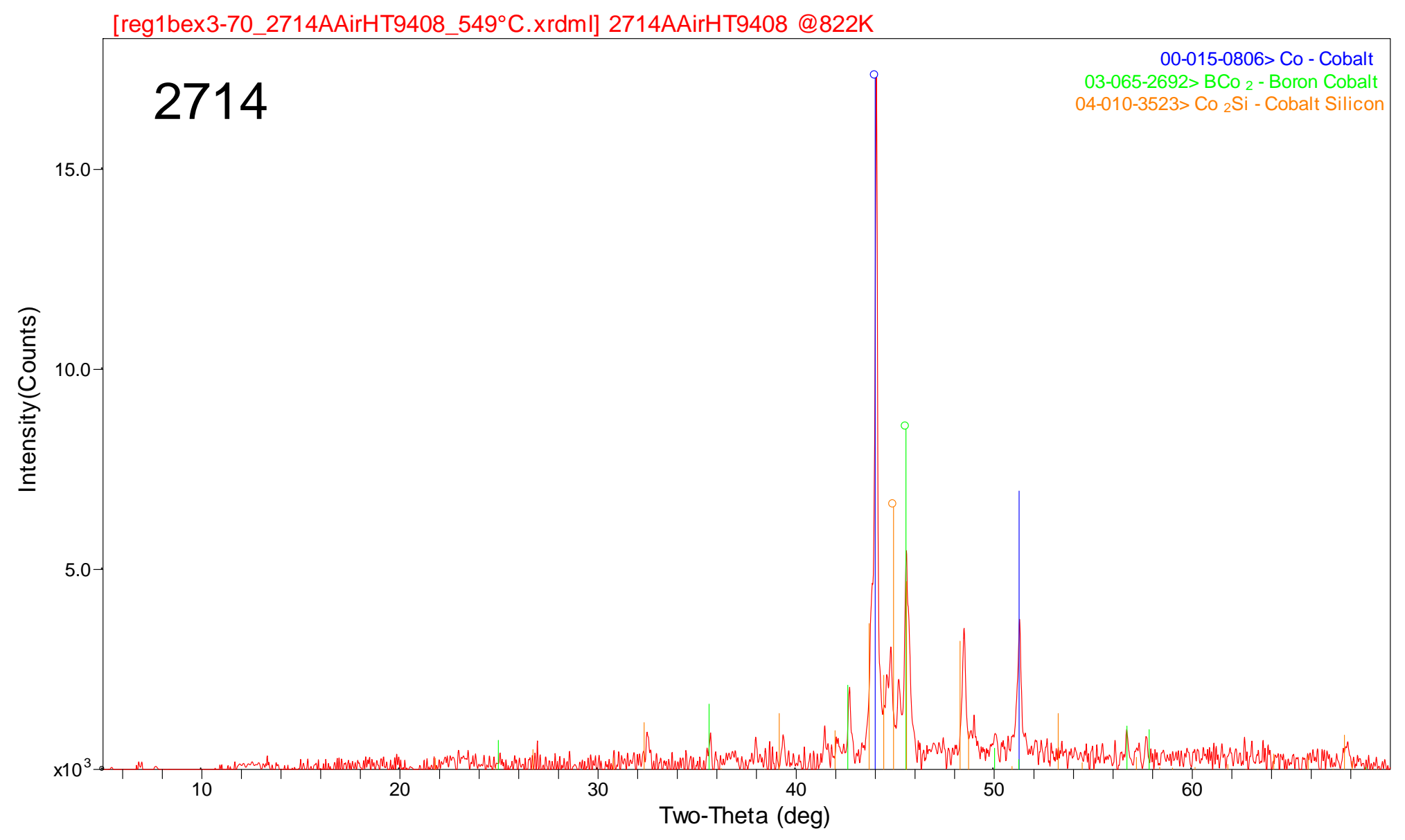

Figure 49. HTXRD scan of 2714 at $500^{\circ} \mathrm{C}$ in air. 


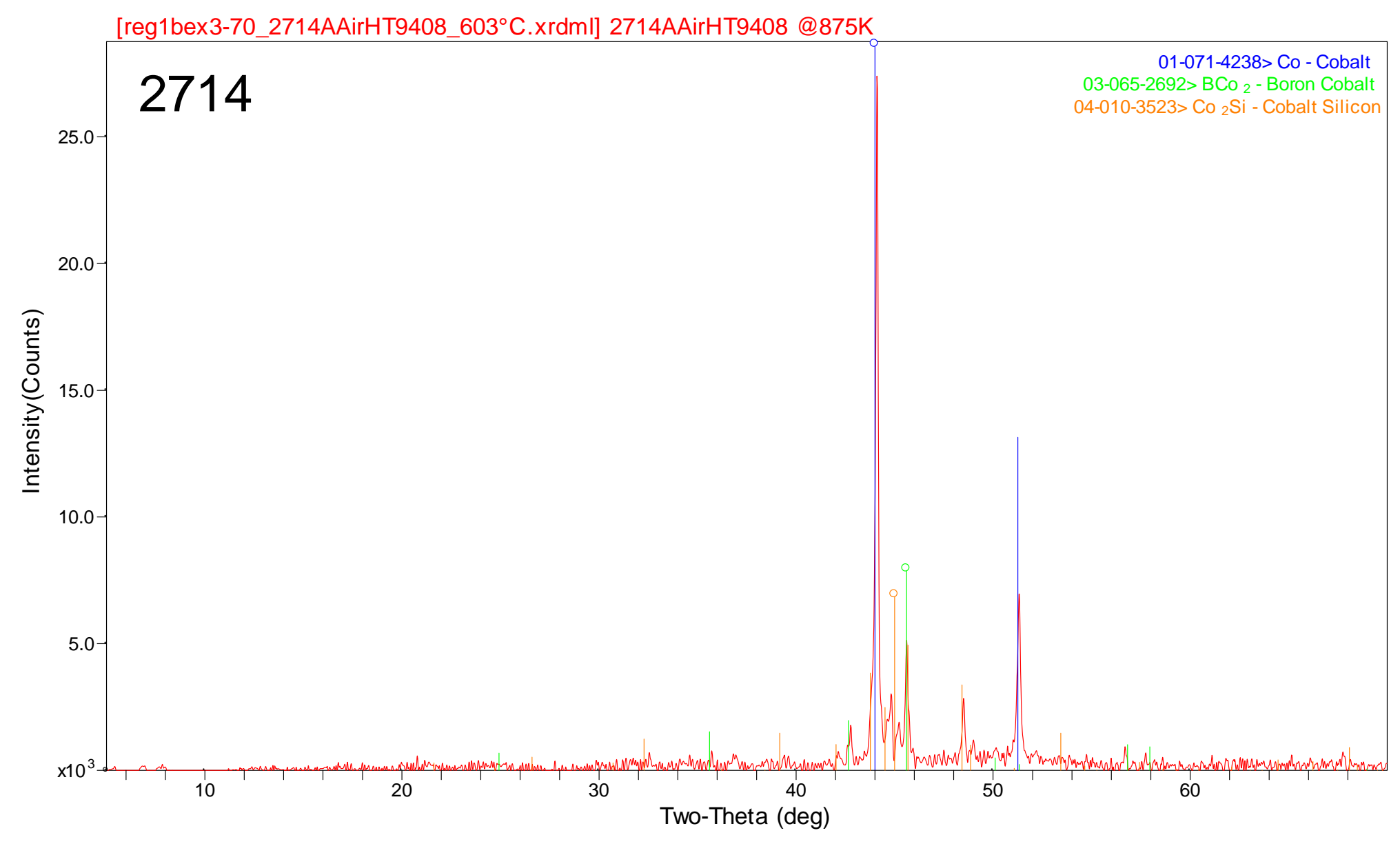

Figure 50. HTXRD scan of 2714 at $550^{\circ} \mathrm{C}$ in air. 


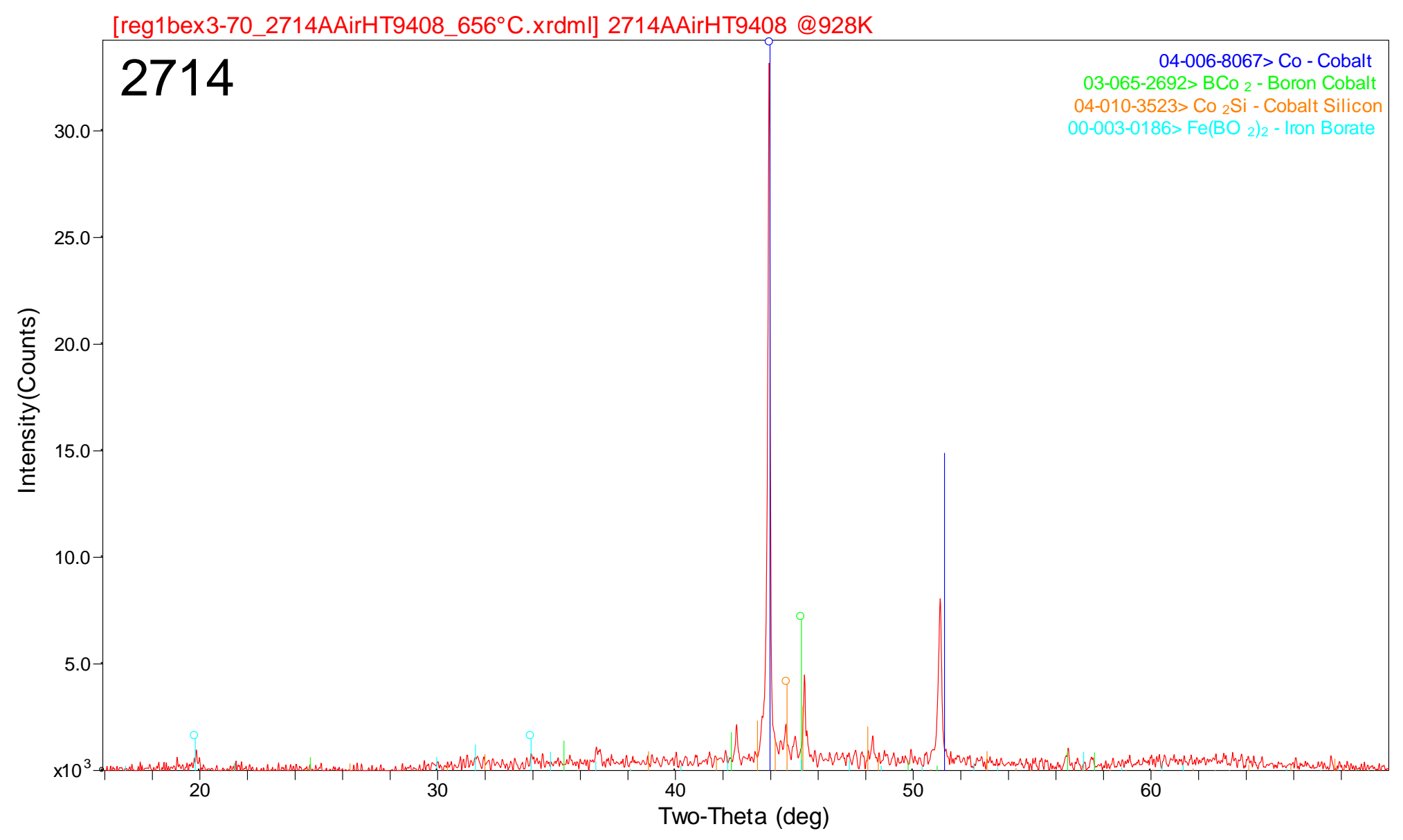

Figure 51. HTXRD scan of 2714 at $600^{\circ} \mathrm{C}$ in air. 


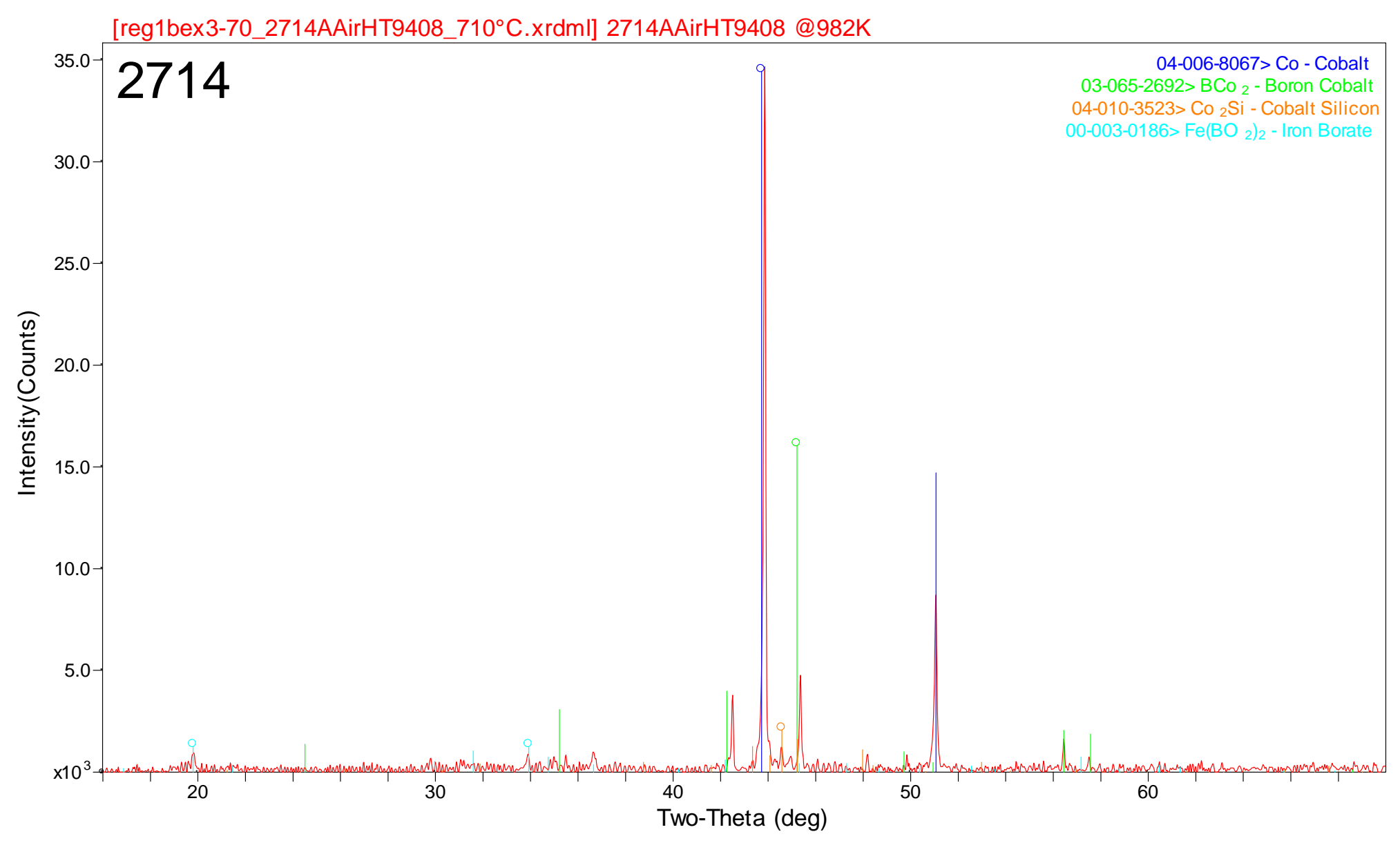

Figure 52. HTXRD scan of 2714 at $650^{\circ} \mathrm{C}$ in air. 


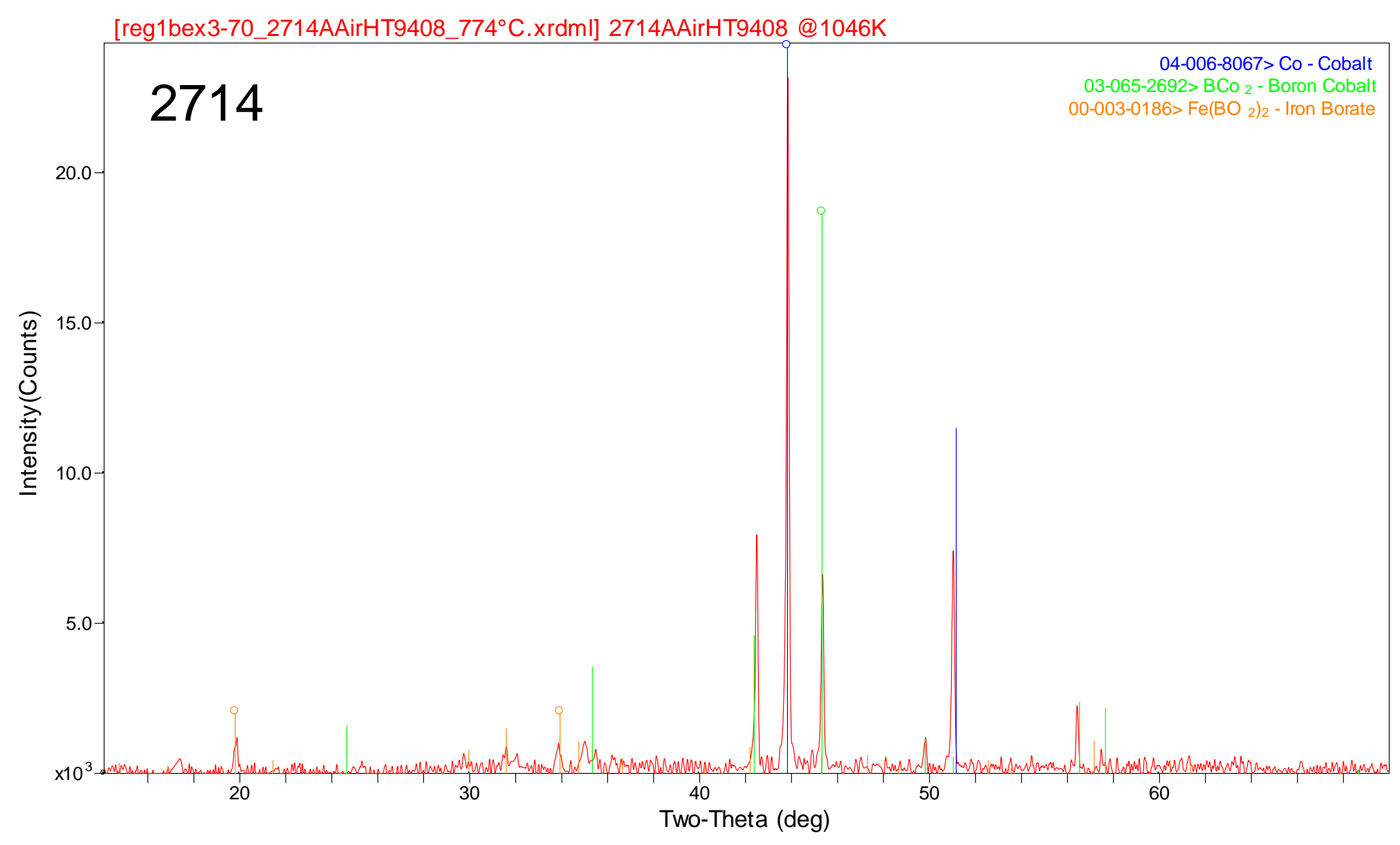

Figure 53. HTXRD scan of 2714 at $710^{\circ} \mathrm{C}$ in air. 


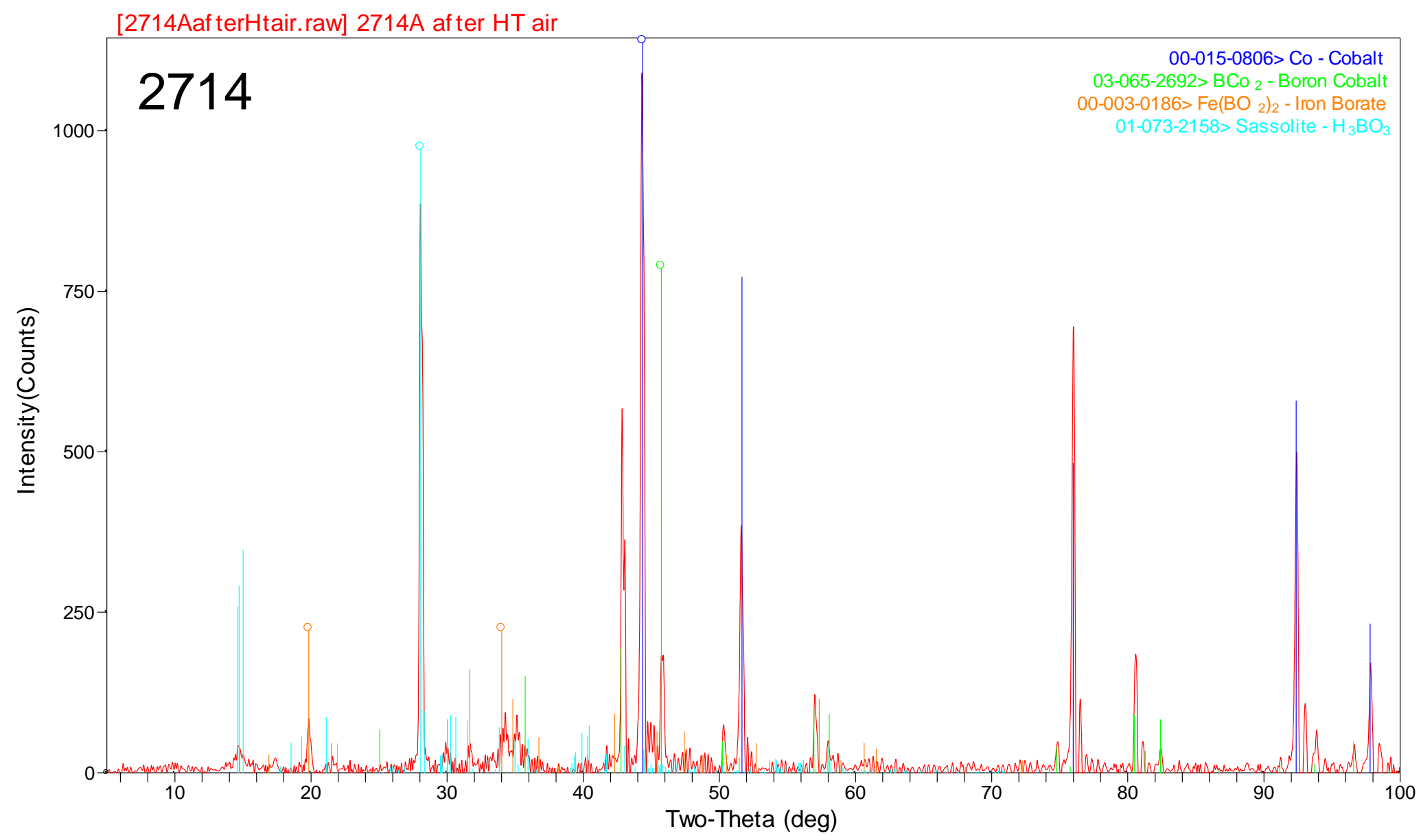

Figure 54. XRD scan of 2714 HTXRD residue in air. 
SRNS-STI-2008-00133

Revision 1

Appendix C-XRD 2826 Alloy 


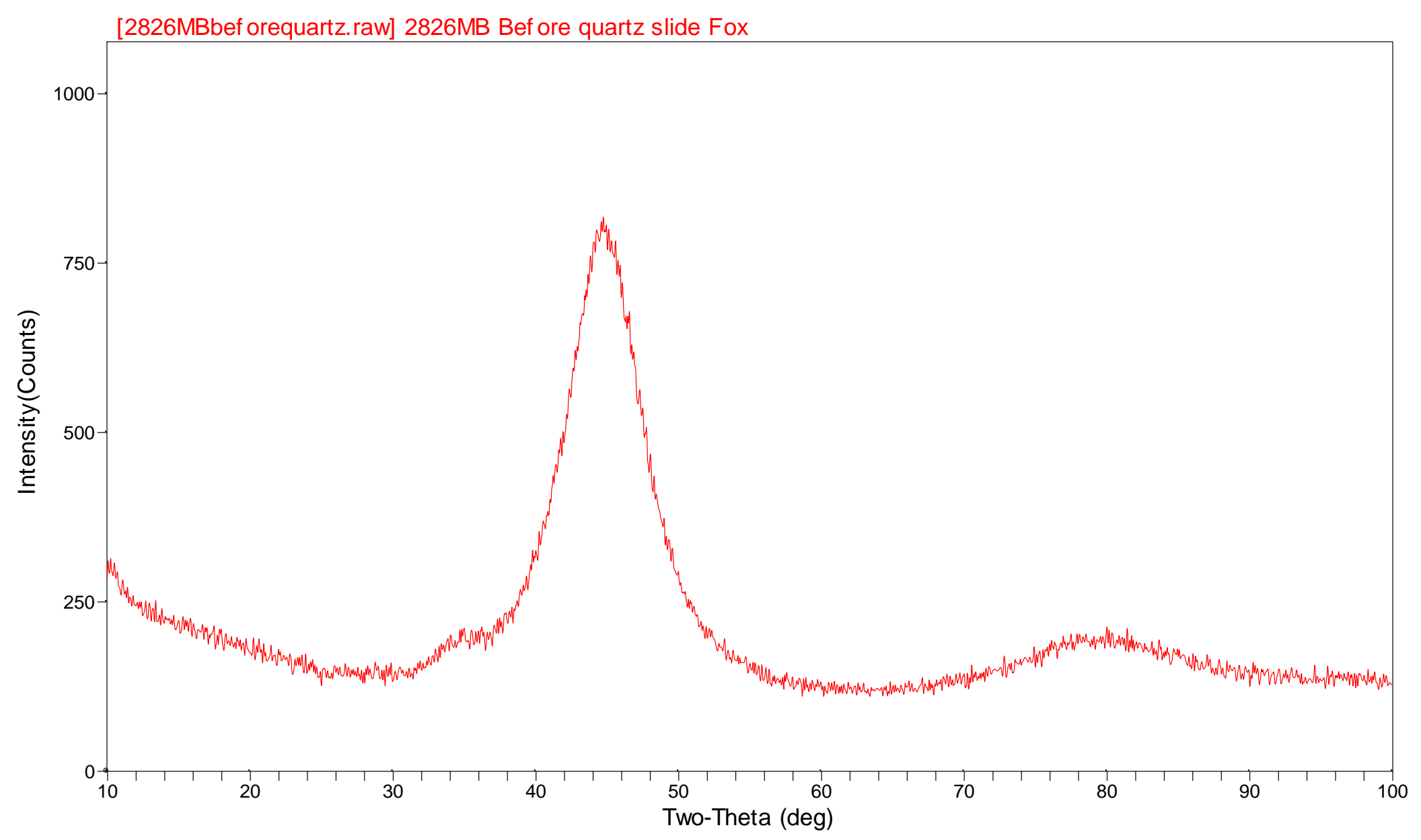

Figure 55. Conventional XRD scan of $2826 \mathrm{MB}$ at $25^{\circ} \mathrm{C}$. 


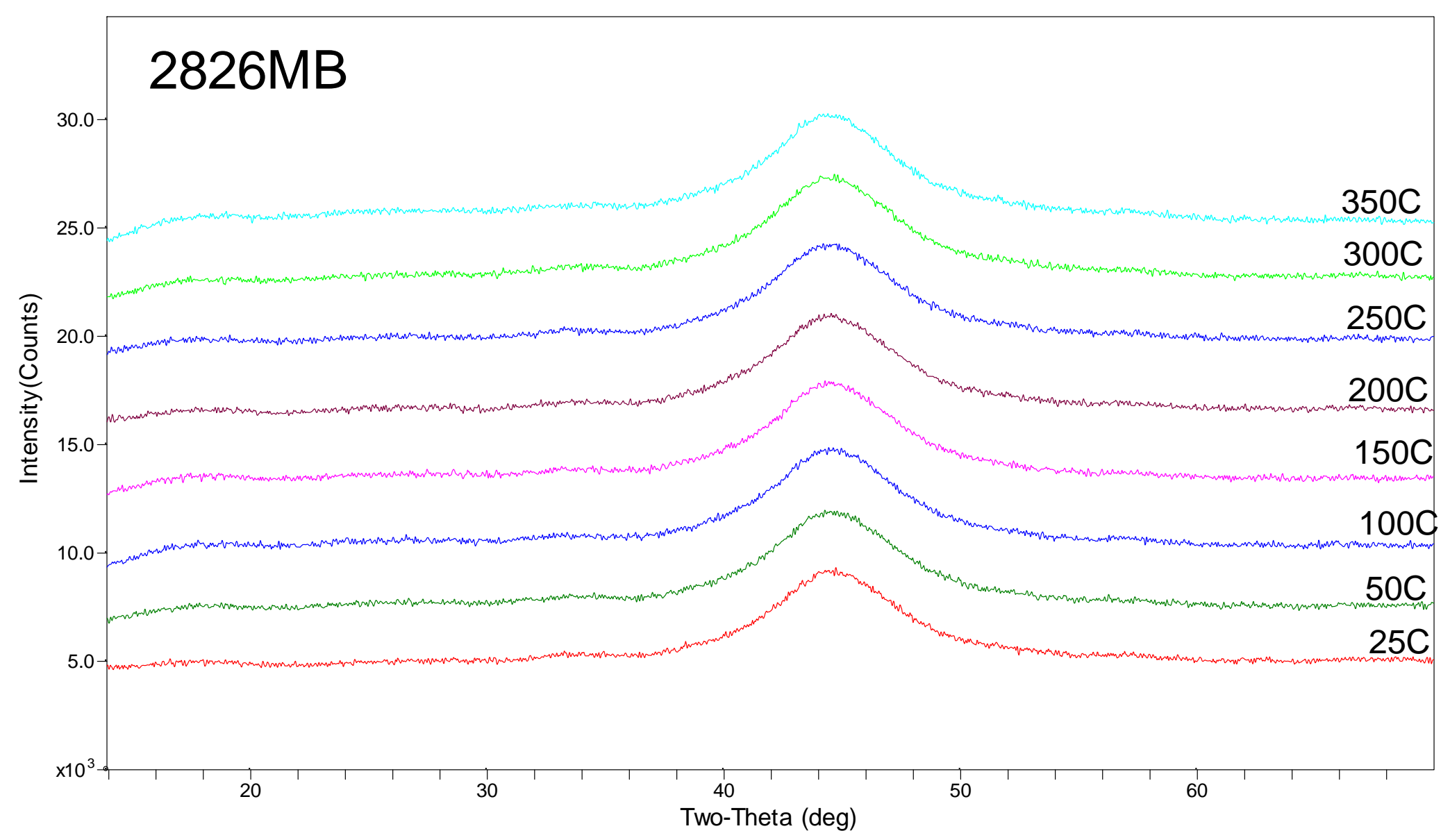

Figure 56. HTXRD scans of $2826 \mathrm{MB}$ from 25 to $350^{\circ} \mathrm{C}$ in $\mathrm{He}$. 


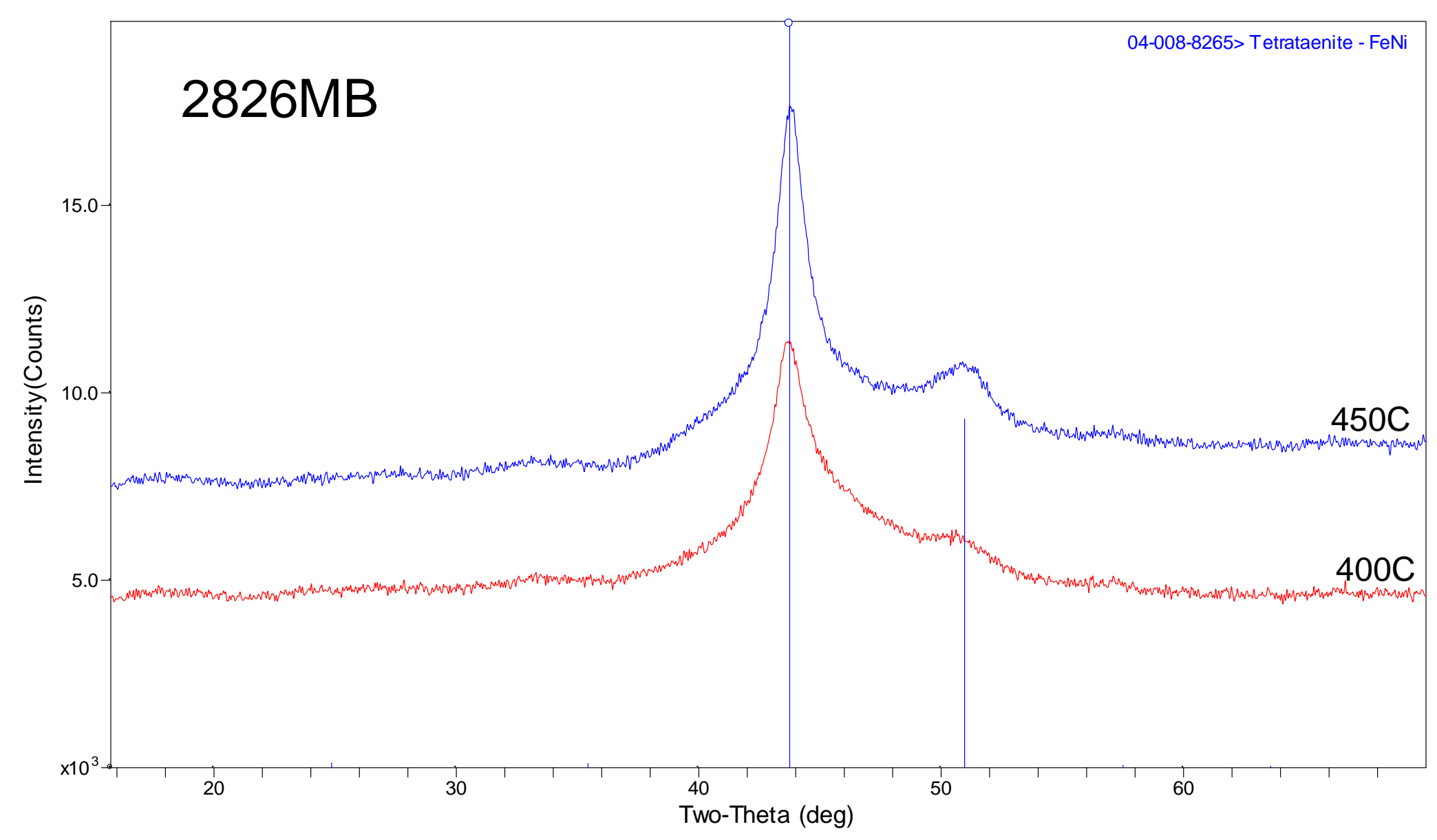

Figure 57. HTXRD scans of 2826MB at 400 and $450{ }^{\circ} \mathrm{C}$ in He. 


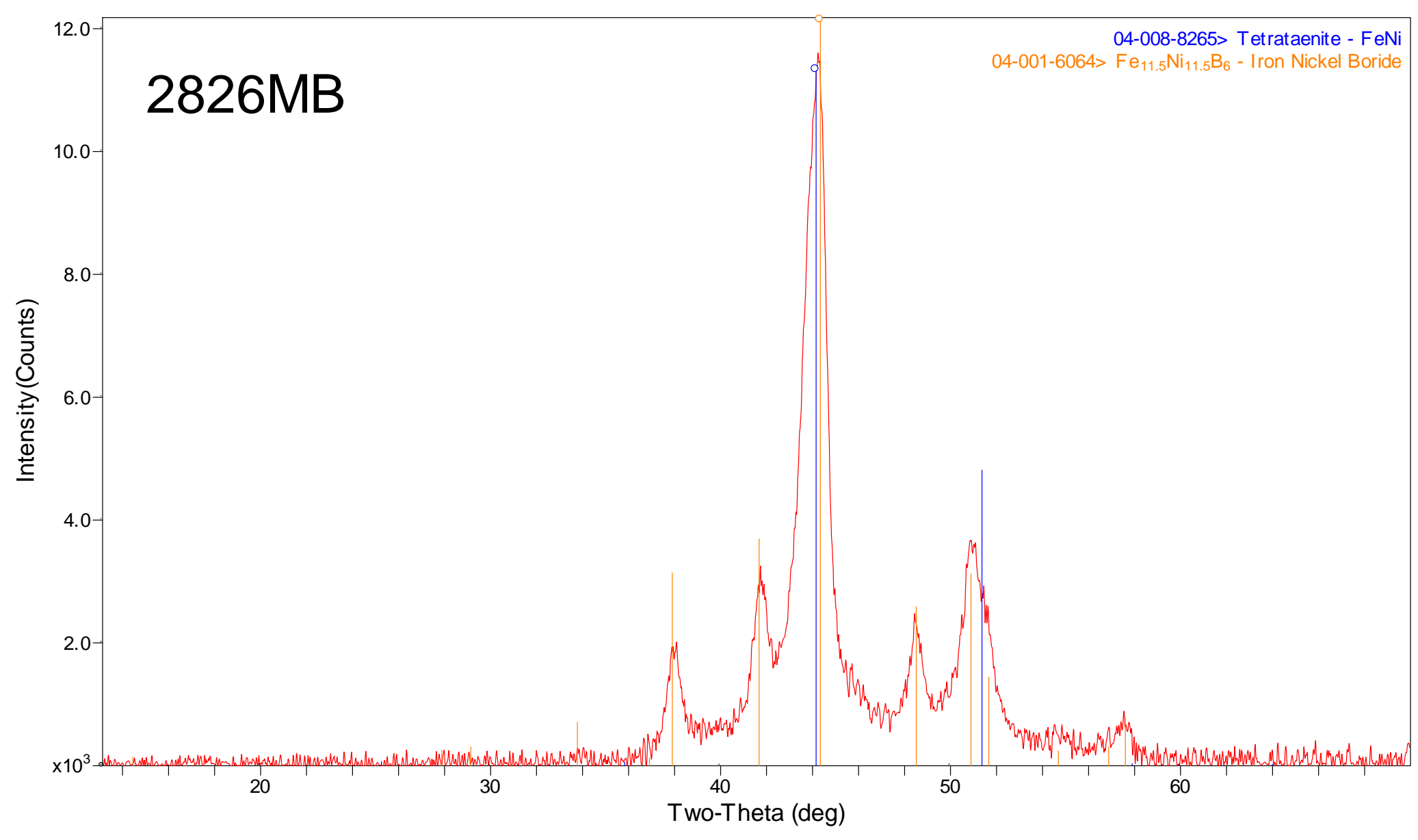

Figure 58. HTXRD scan of $2826 \mathrm{MB}$ at $500{ }^{\circ} \mathrm{C}$ in $\mathrm{He}$. 


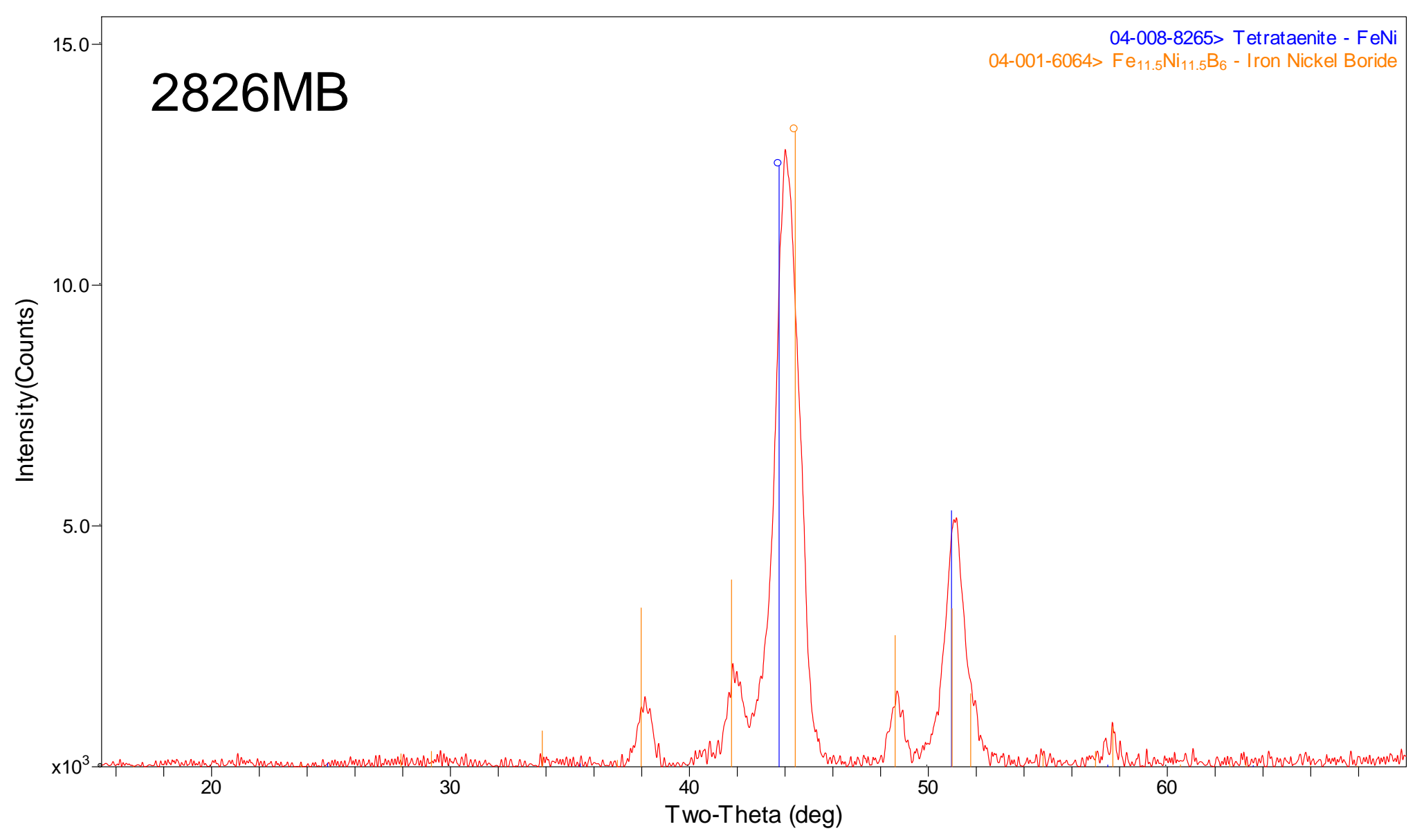

Figure 59. HTXRD scan of $2826 \mathrm{MB}$ at $550{ }^{\circ} \mathrm{C}$ in $\mathrm{He}$. 


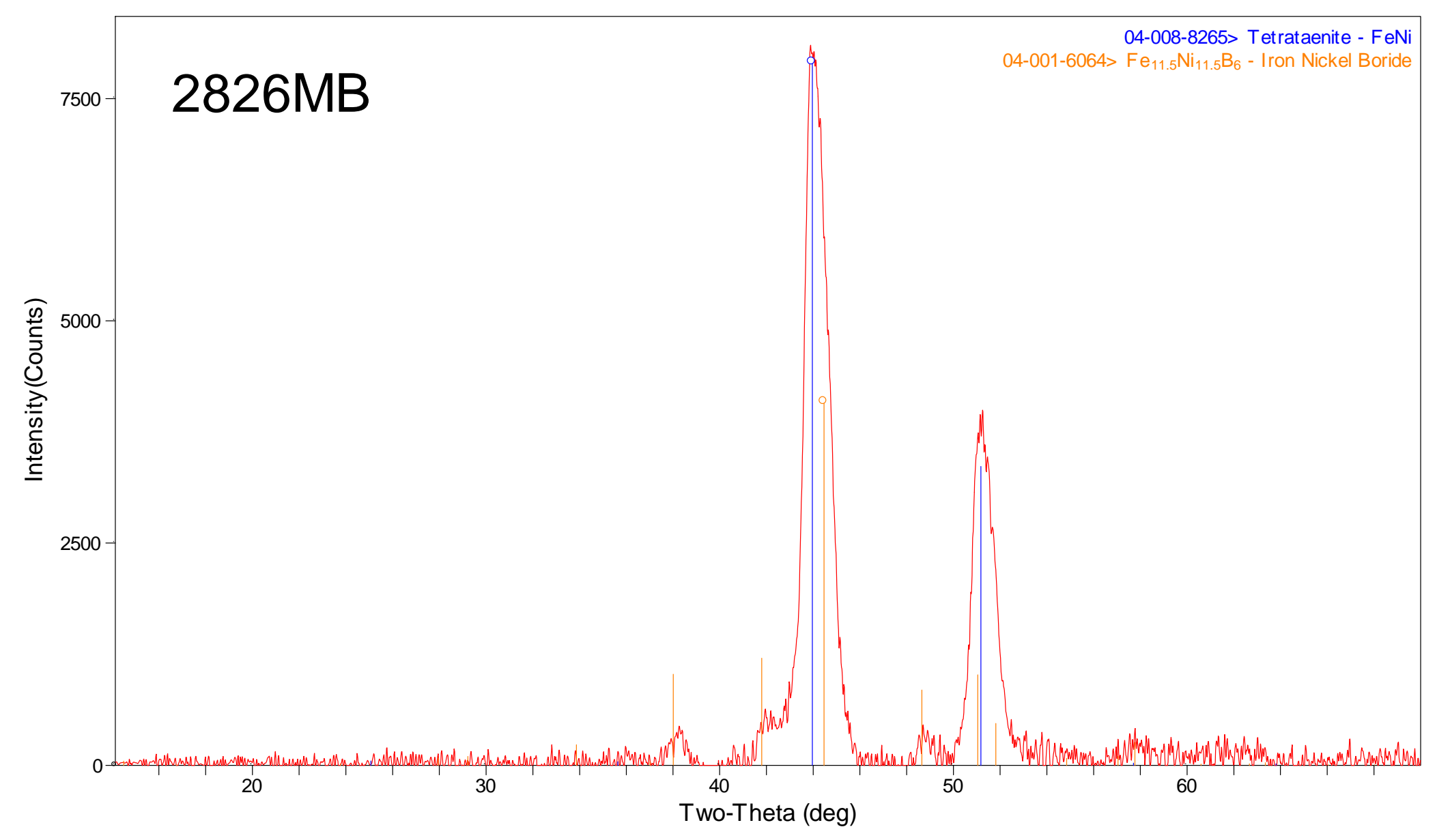

Figure 60. HTXRD scan of $2826 \mathrm{MB}$ at $600{ }^{\circ} \mathrm{C}$ in $\mathrm{He}$. 


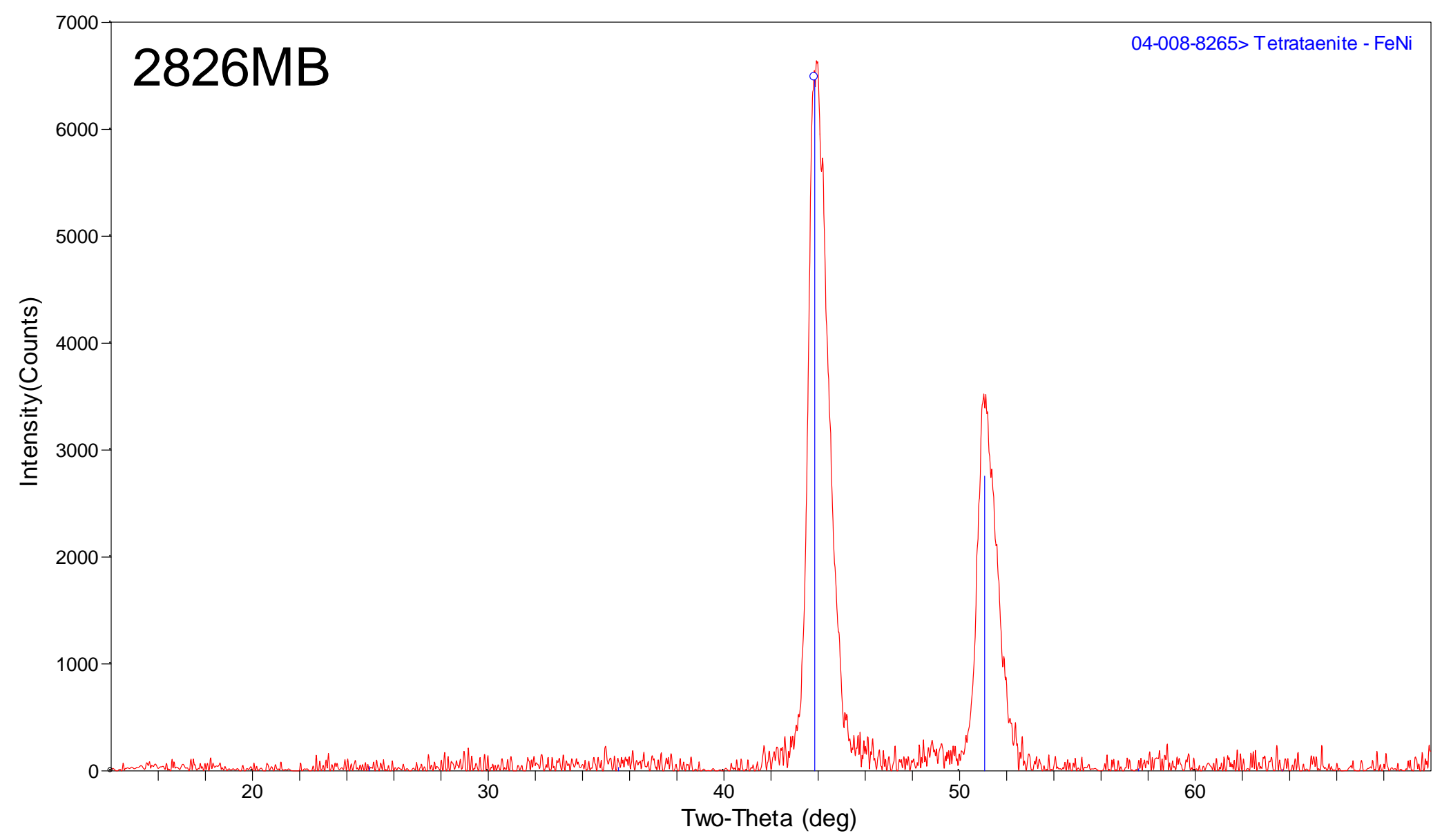

Figure 61. HTXRD scan of 2826MB at $650^{\circ} \mathrm{C}$ in He. 


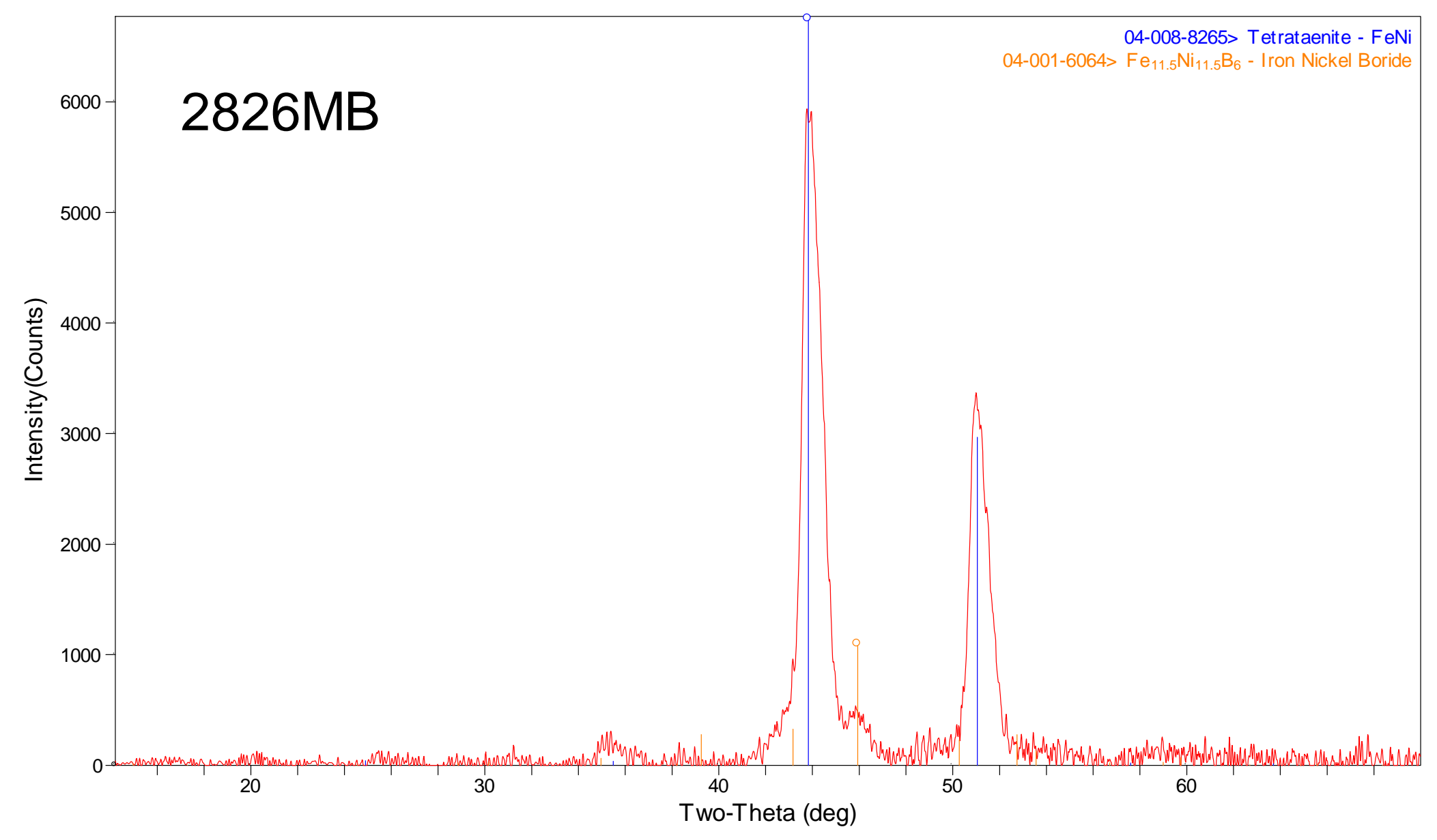

Figure 62. HTXRD scan of $2826 \mathrm{MB}$ at $710{ }^{\circ} \mathrm{C}$ in $\mathrm{He}$. 


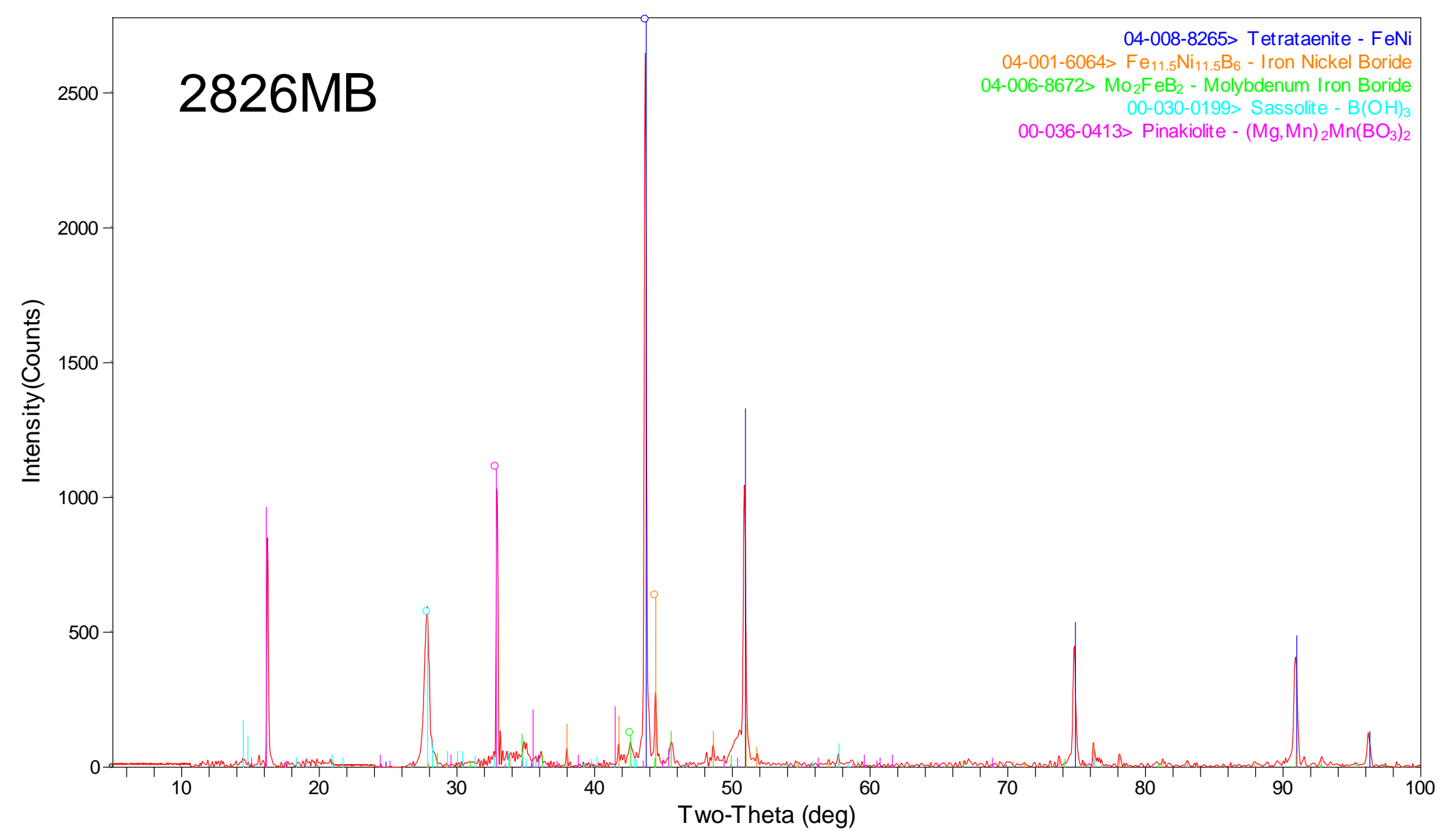

Figure 63. XRD scan of 2826MB HTXRD residue in He. 


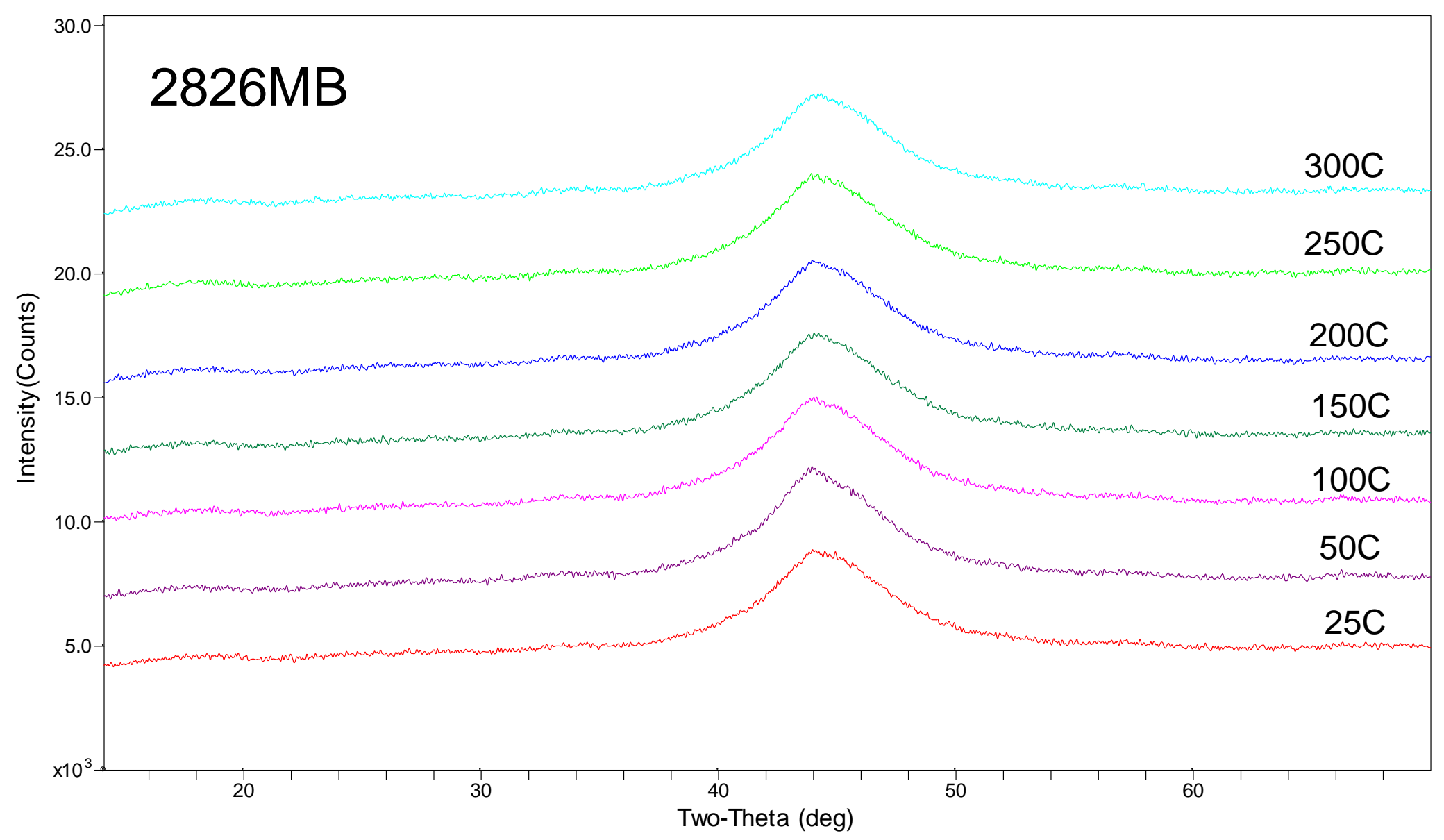

Figure 64. HTXRD scans of $2826 \mathrm{MB}$ from 25 to $300{ }^{\circ} \mathrm{C}$ in $4 \%-\mathrm{H}_{2} / 96 \%-\mathrm{He}$. 


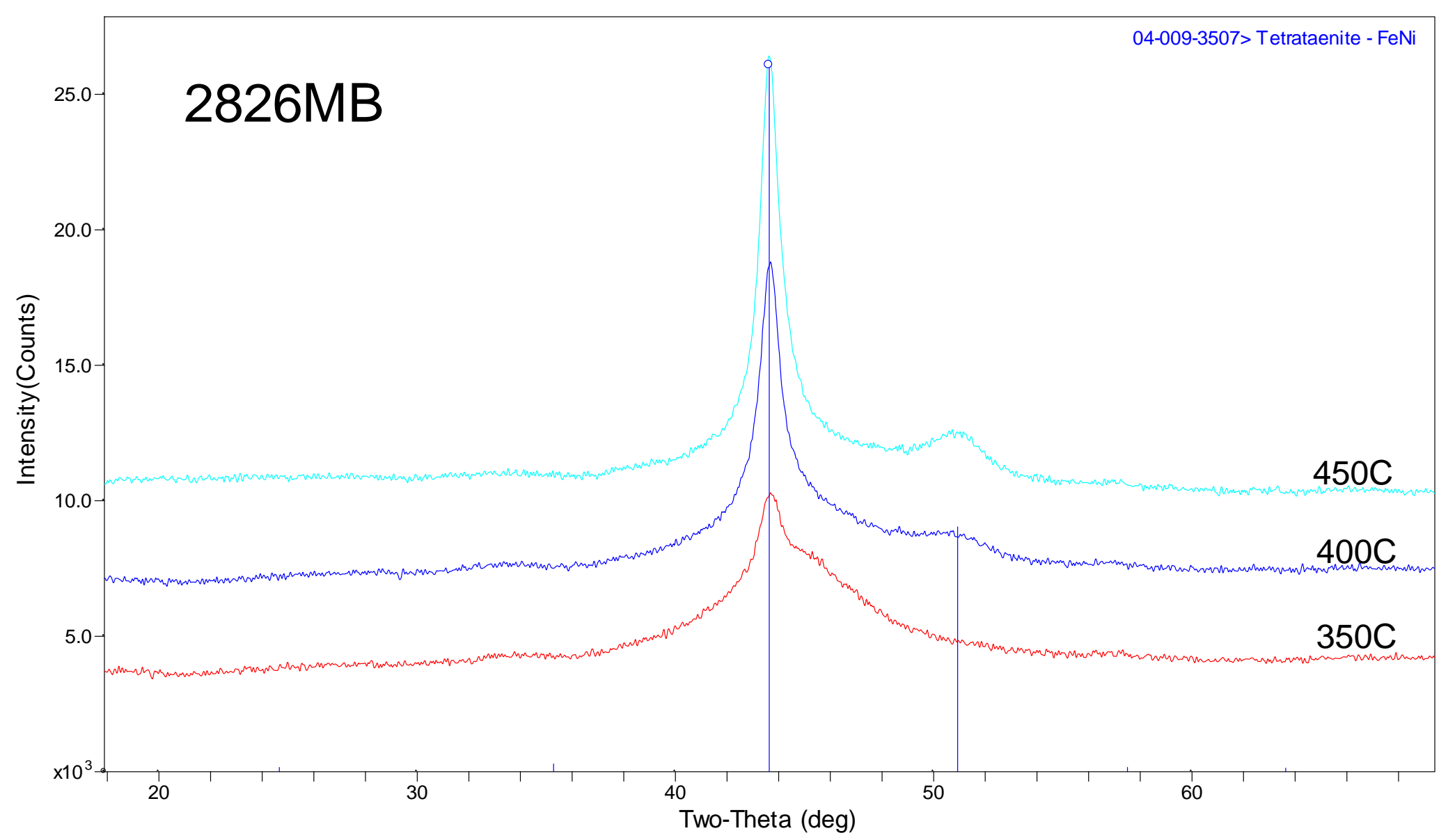

Figure 65. HTXRD scans of $2826 \mathrm{MB}$ from 350 to $450{ }^{\circ} \mathrm{C}$ in $4 \%-\mathrm{H}_{2} / 96 \%-\mathrm{He}$. 


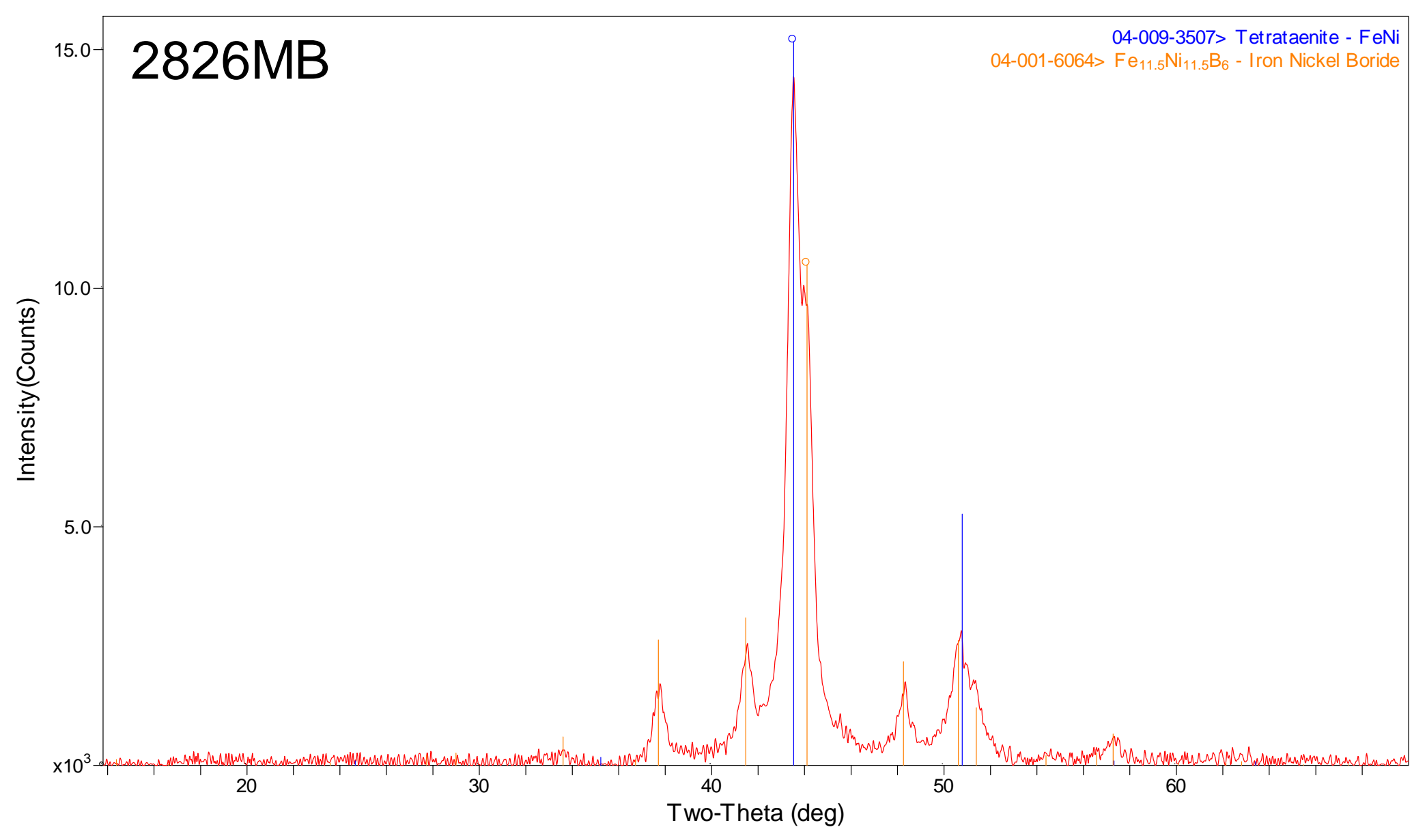

Figure 66. HTXRD scan of $2826 \mathrm{MB}$ at $500{ }^{\circ} \mathrm{C}$ in $4 \%-\mathrm{H}_{2} / 96 \%-\mathrm{He}$. 


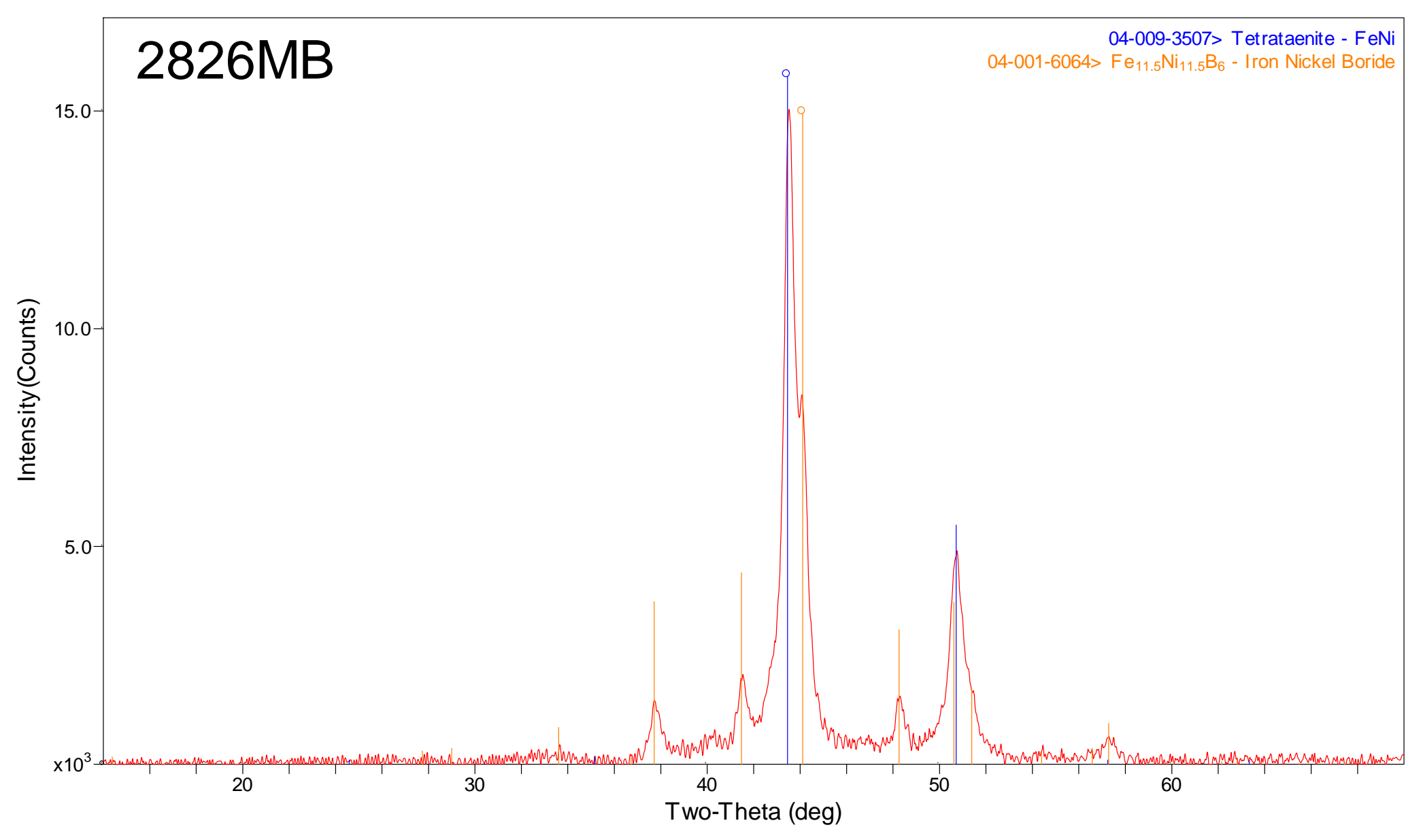

Figure 67. HTXRD scan of $2826 \mathrm{MB}$ at $550{ }^{\circ} \mathrm{C}$ in $4 \%-\mathrm{H}_{2} / 96 \%-\mathrm{He}$. 


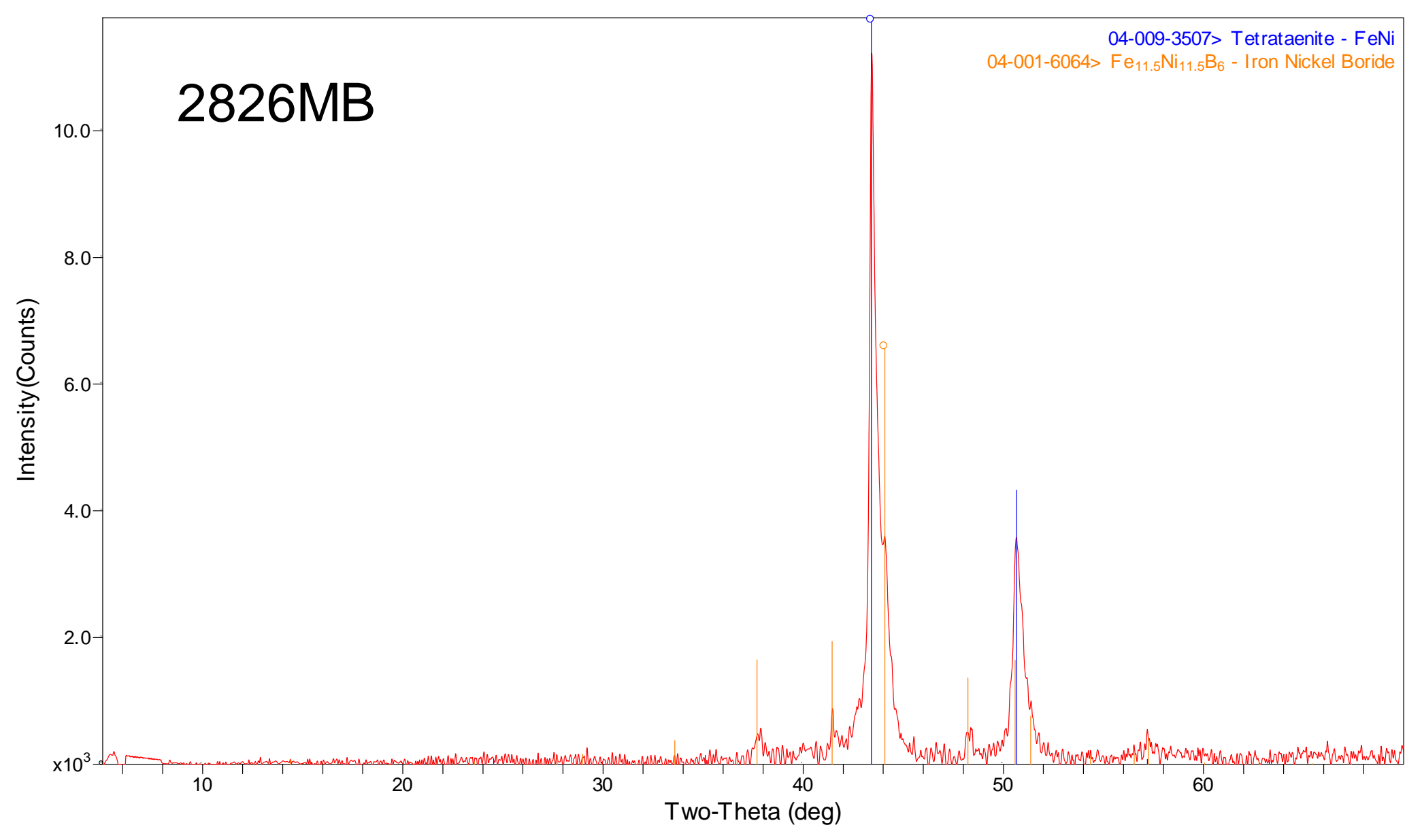

Figure 68. HTXRD scan of $2826 \mathrm{MB}$ at $600{ }^{\circ} \mathrm{C}$ in $4 \%-\mathrm{H}_{2} / 96 \%-\mathrm{He}$. 


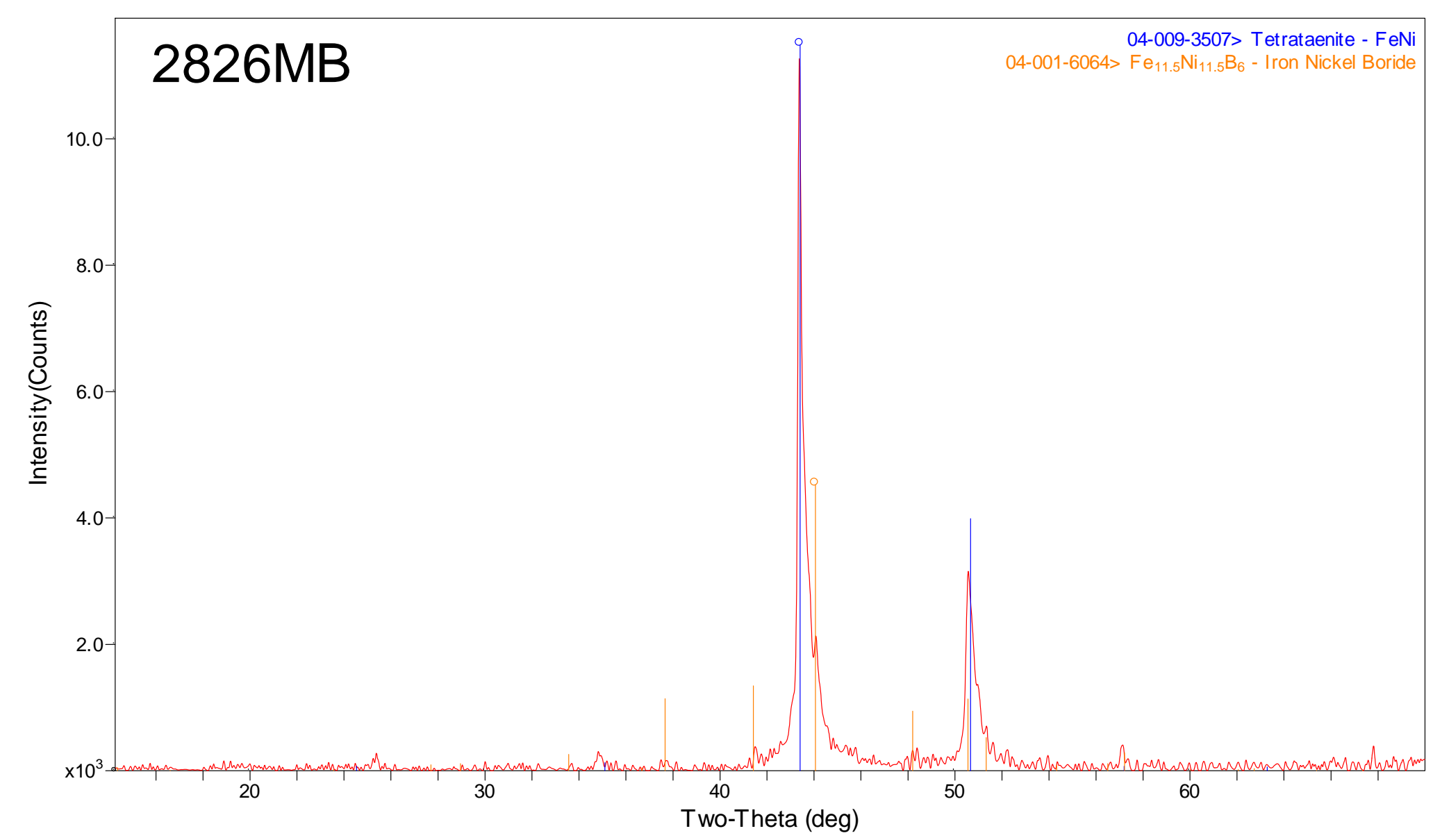

Figure 69. HTXRD scan of $2826 \mathrm{MB}$ at $650{ }^{\circ} \mathrm{C}$ in $4 \%-\mathrm{H}_{2} / 96 \%-\mathrm{He}$. 


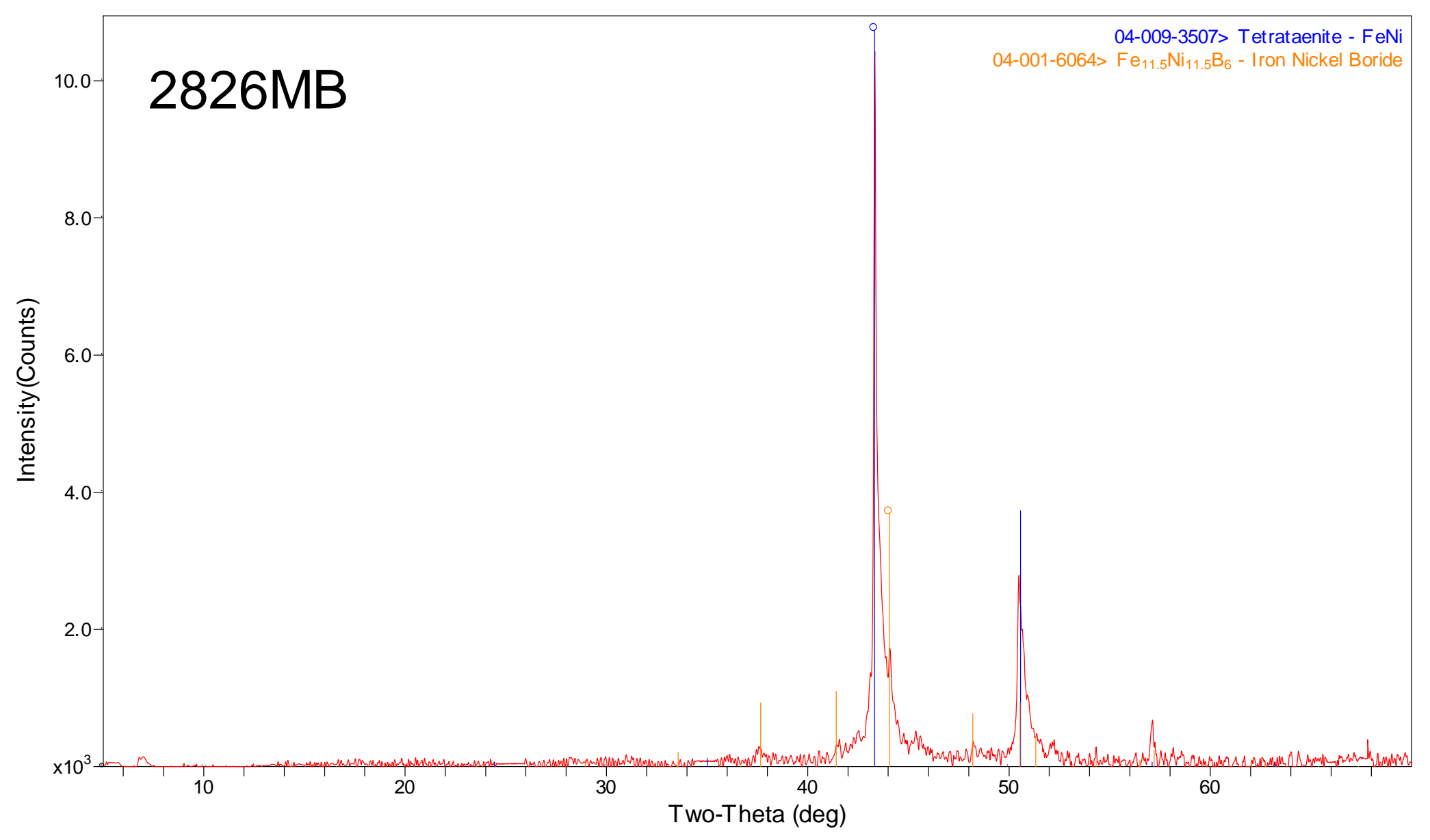

Figure 70. HTXRD scan of $2826 \mathrm{MB}$ at $710{ }^{\circ} \mathrm{C}$ in $4 \%-\mathrm{H}_{2} / 96 \%-\mathrm{He}$. 


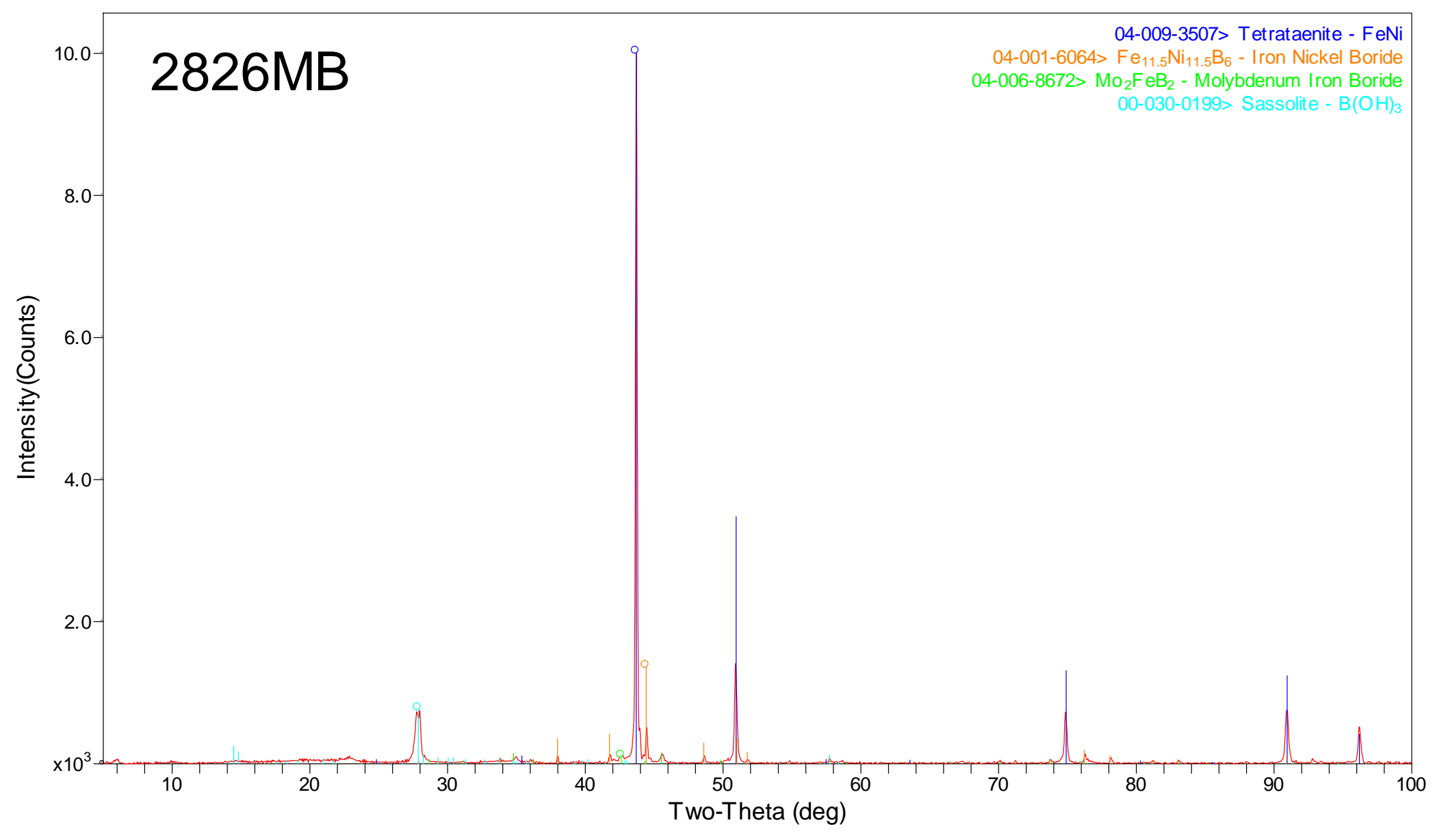

Figure 71. XRD scan of 2826MB HTXRD residue in $4 \%-\mathrm{H}_{2} / 96 \%-\mathrm{He}$. 


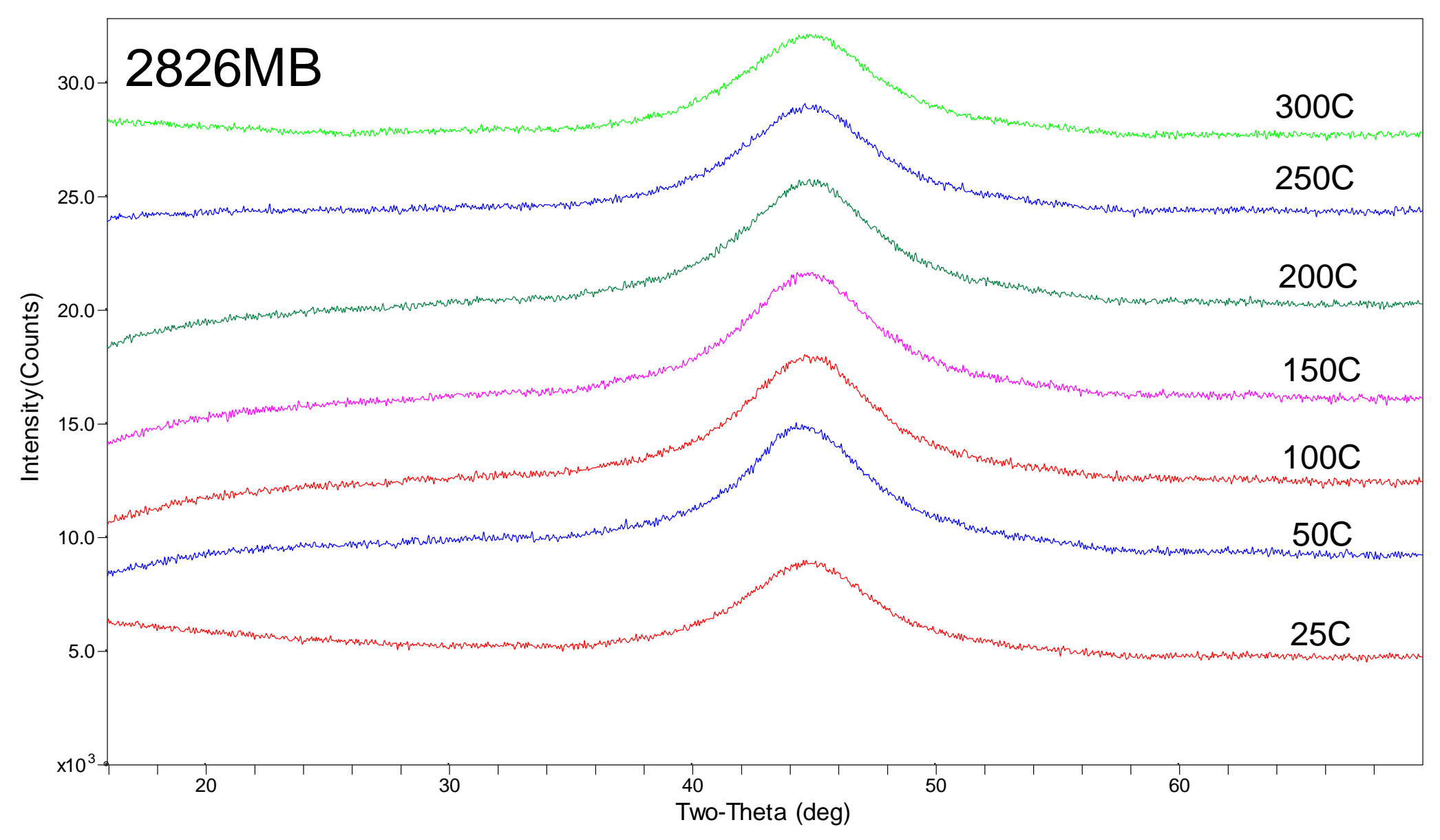

Figure 72. HTXRD scans of $2826 \mathrm{MB}$ from 25 to $300{ }^{\circ} \mathrm{C}$ in air. 


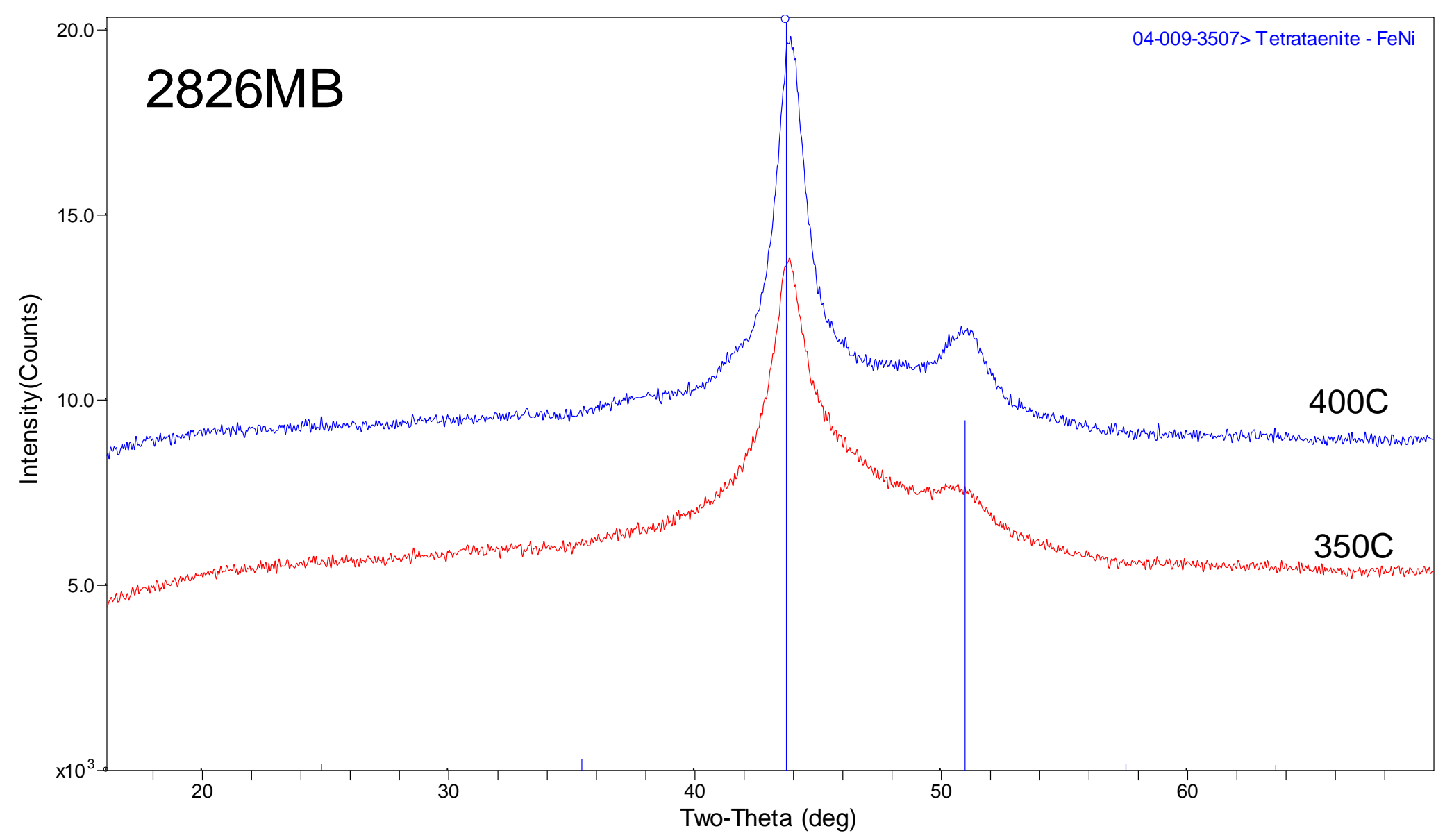

Figure 73. HTXRD scans of $2826 \mathrm{MB}$ at 350 and $400{ }^{\circ} \mathrm{C}$ in air. 


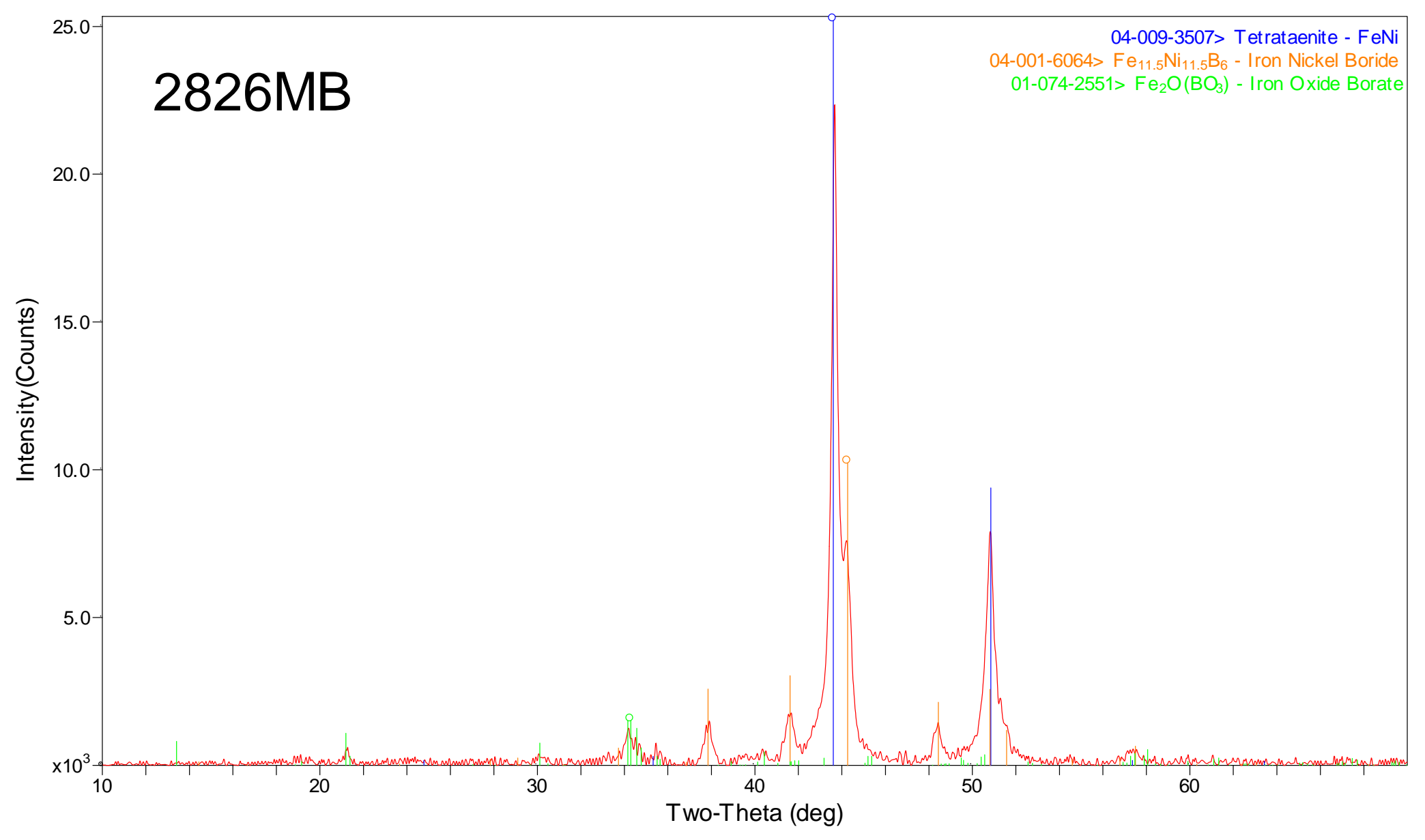

Figure 74. HTXRD scan of $2826 \mathrm{MB}$ at $450{ }^{\circ} \mathrm{C}$ in air. 


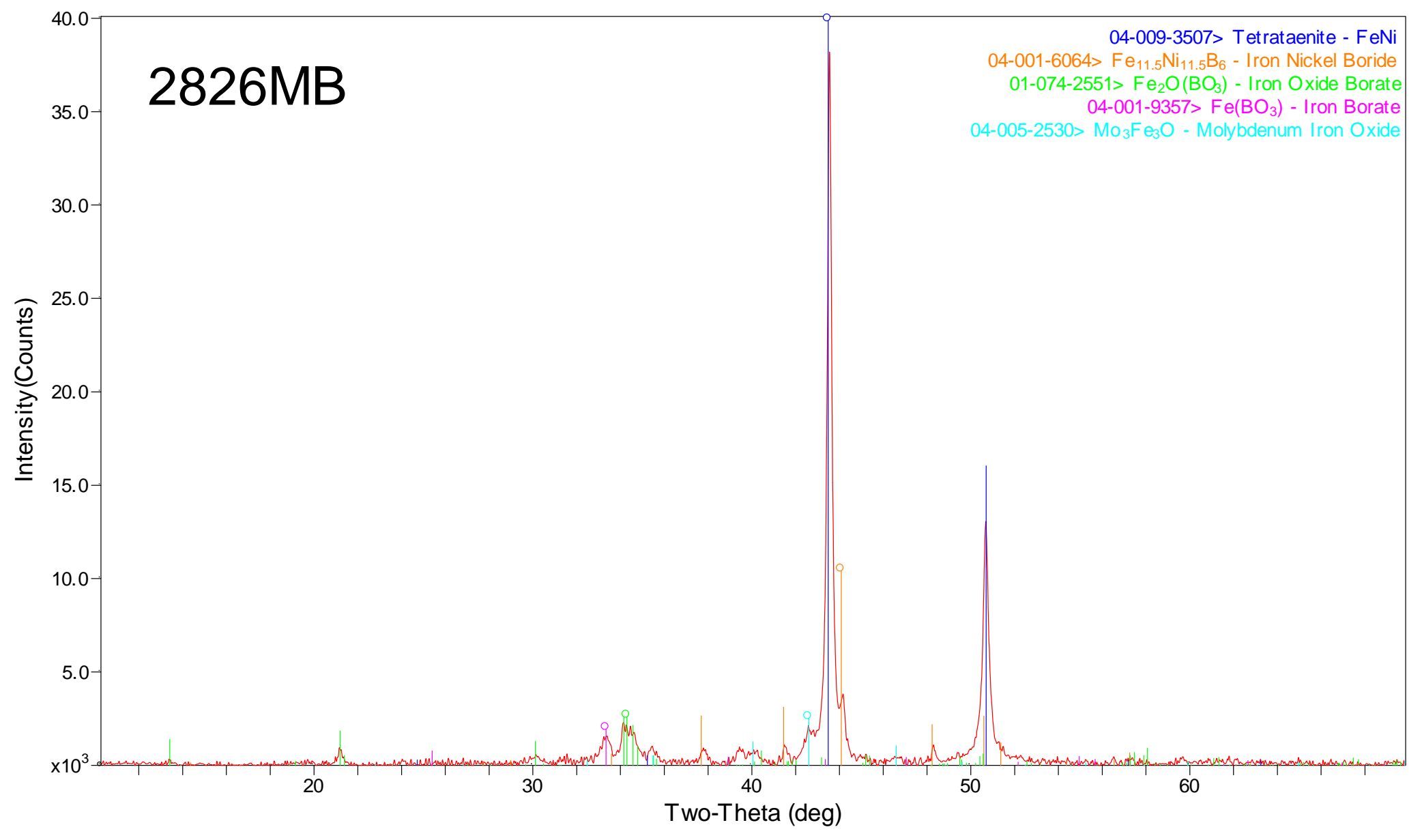

Figure 75. HTXRD scan of $2826 \mathrm{MB}$ at $500{ }^{\circ} \mathrm{C}$ in air. 


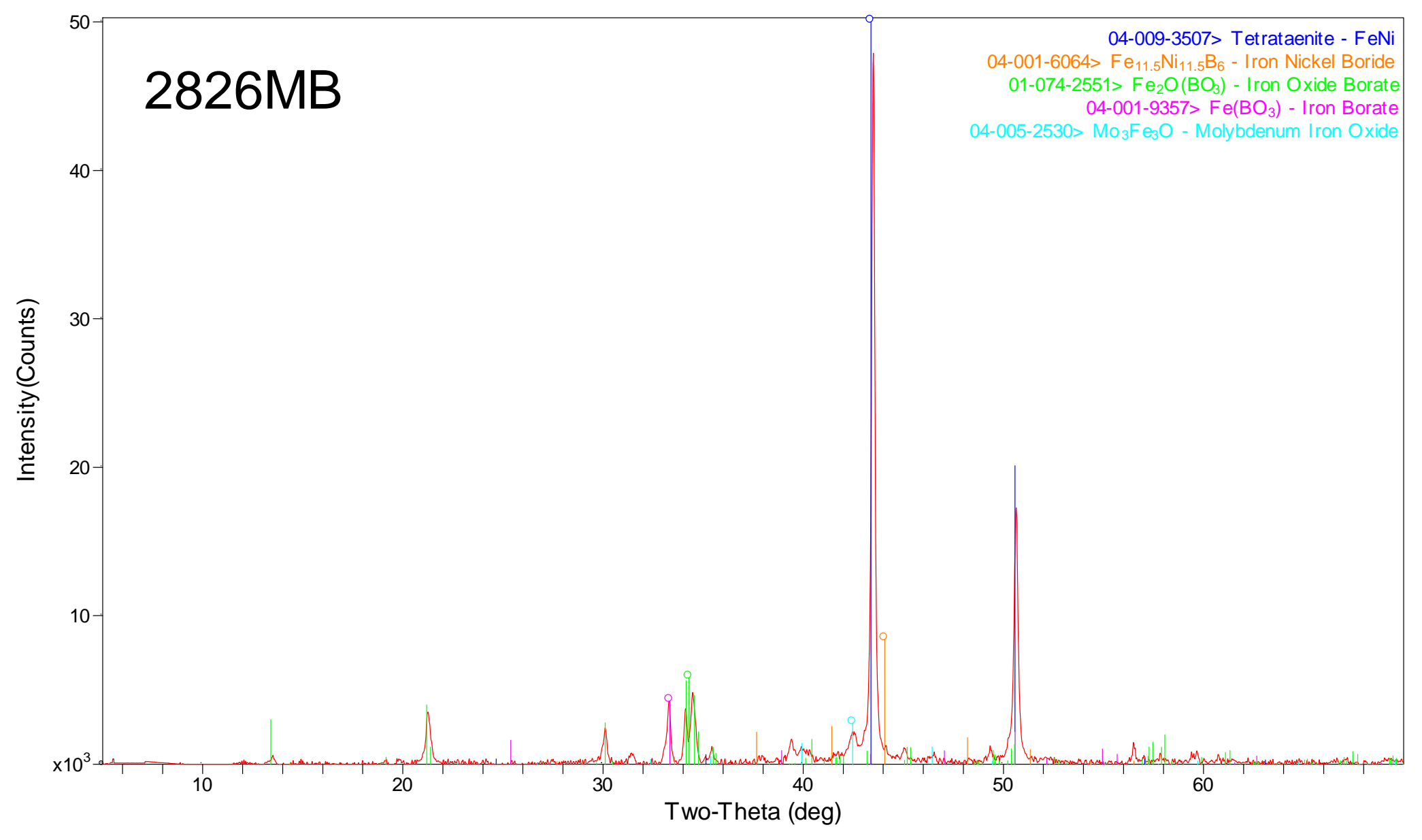

Figure 76. HTXRD scan of $2826 \mathrm{MB}$ at $550{ }^{\circ} \mathrm{C}$ in air. 


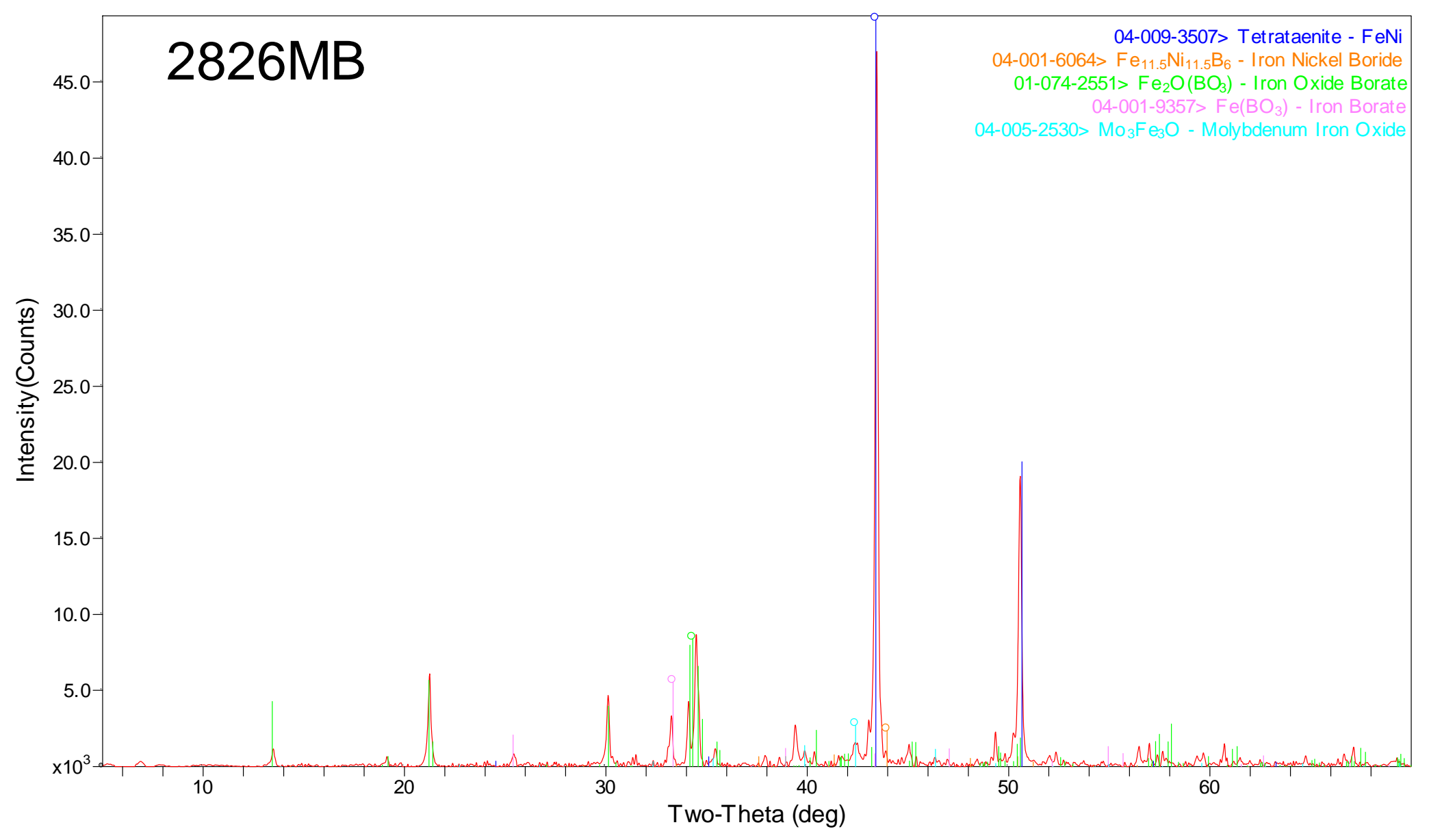

Figure 77. HTXRD scan of $2826 \mathrm{MB}$ at $600{ }^{\circ} \mathrm{C}$ in air. 


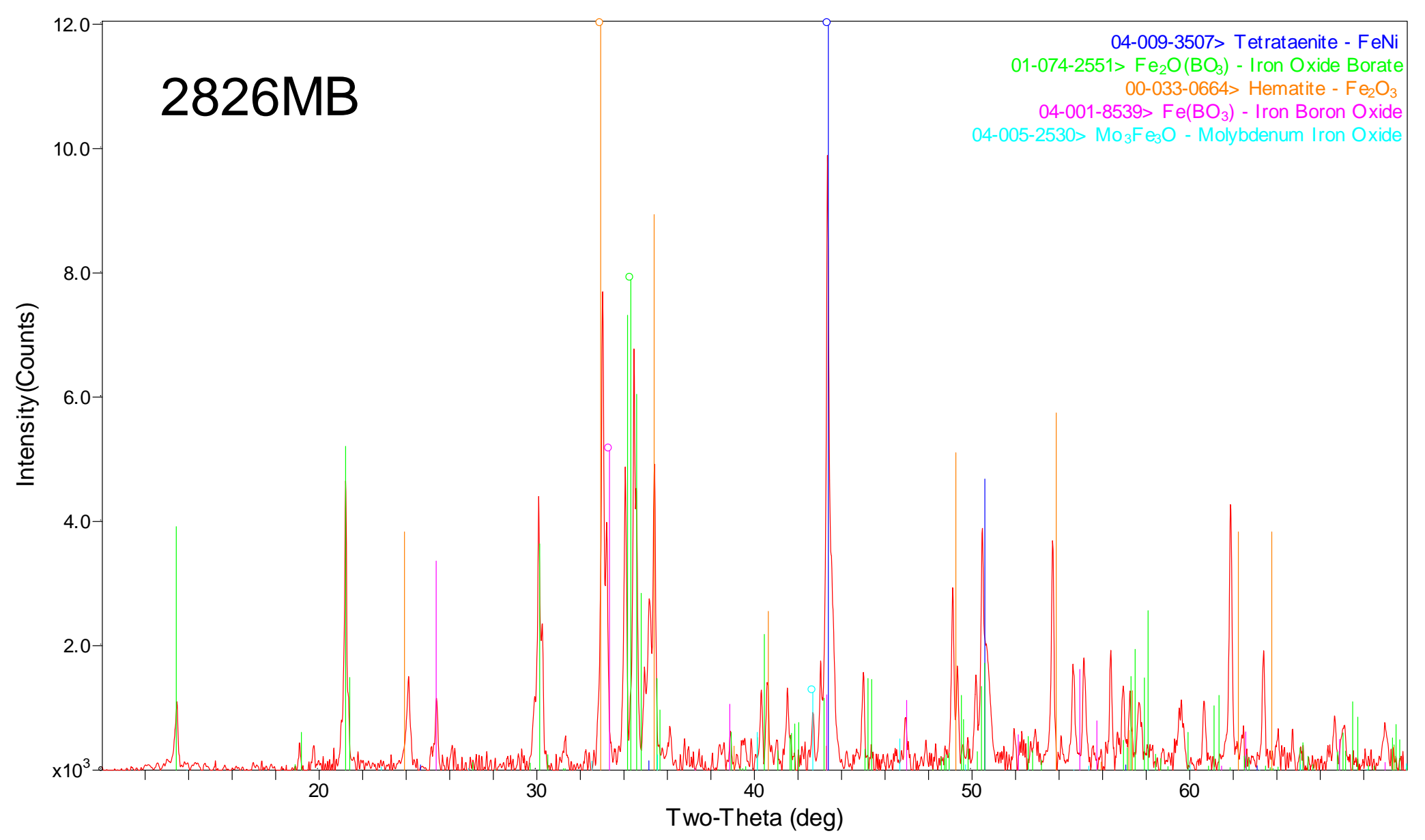

Figure 78. HTXRD scan of $2826 \mathrm{MB}$ at $650{ }^{\circ} \mathrm{C}$ in air. 


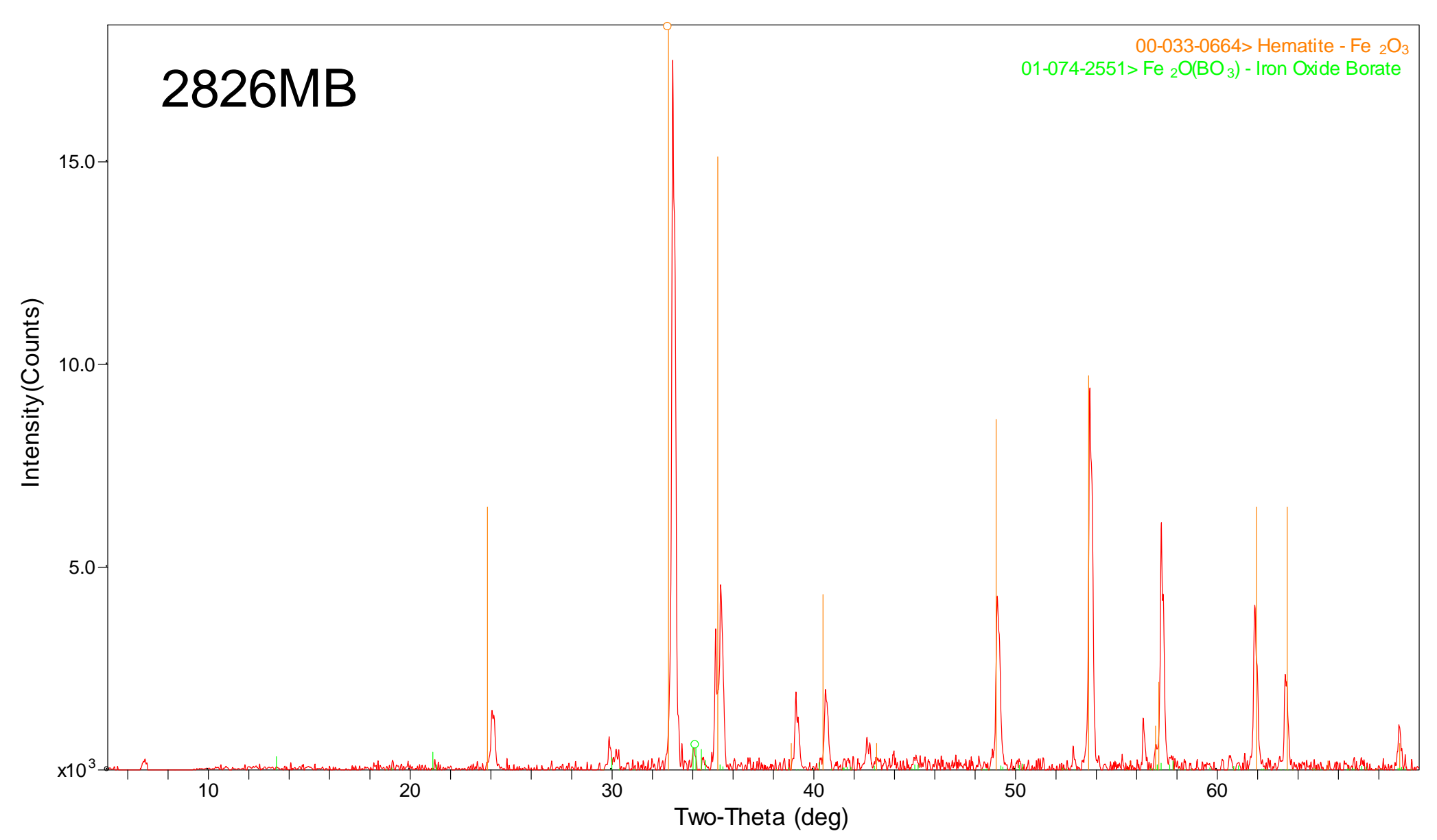

Figure 79. HTXRD scan of $2826 \mathrm{MB}$ at $710^{\circ} \mathrm{C}$ in air. 


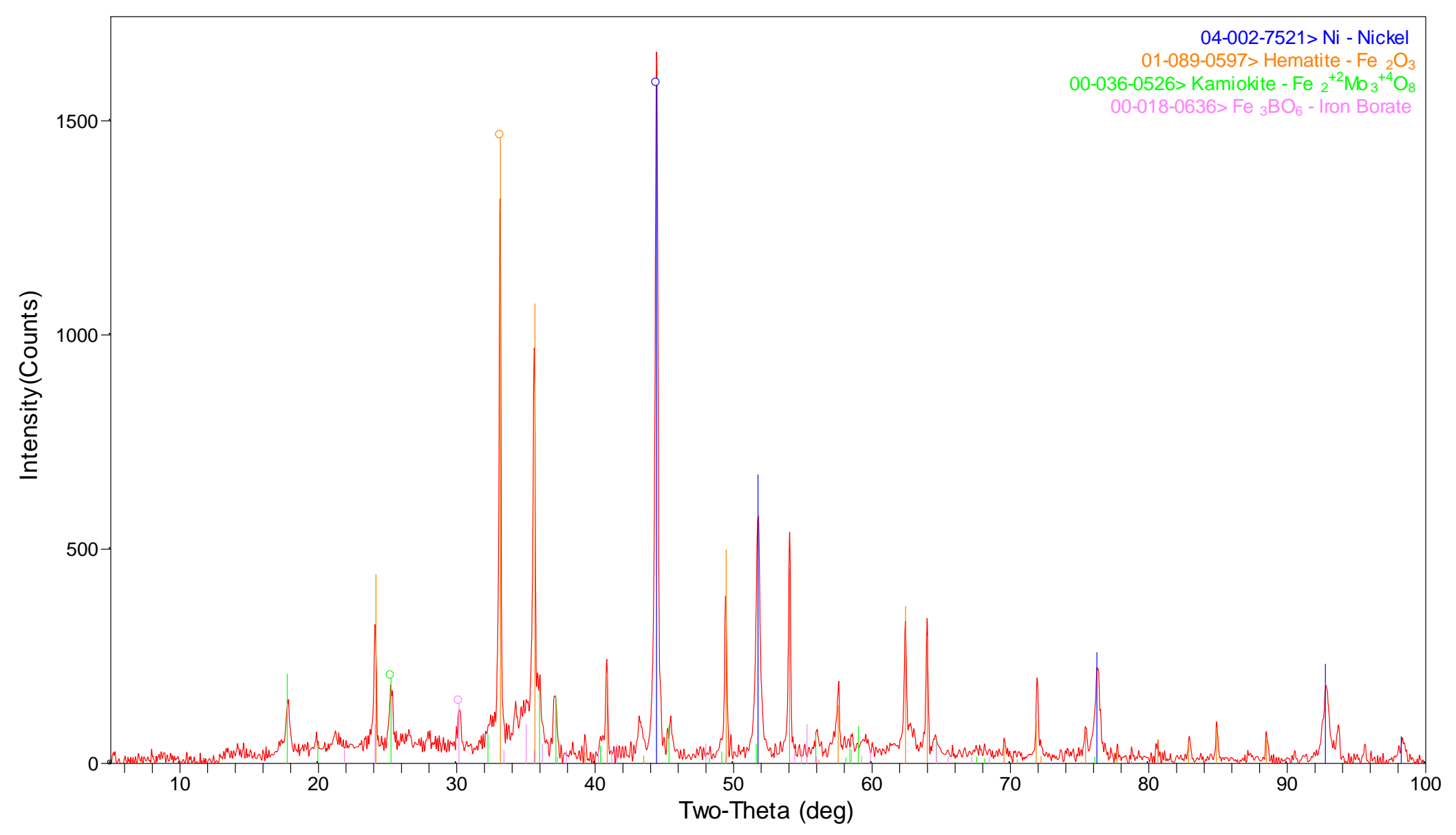

Figure 80. XRD scan of 2826MB HTXRD residue in air. 


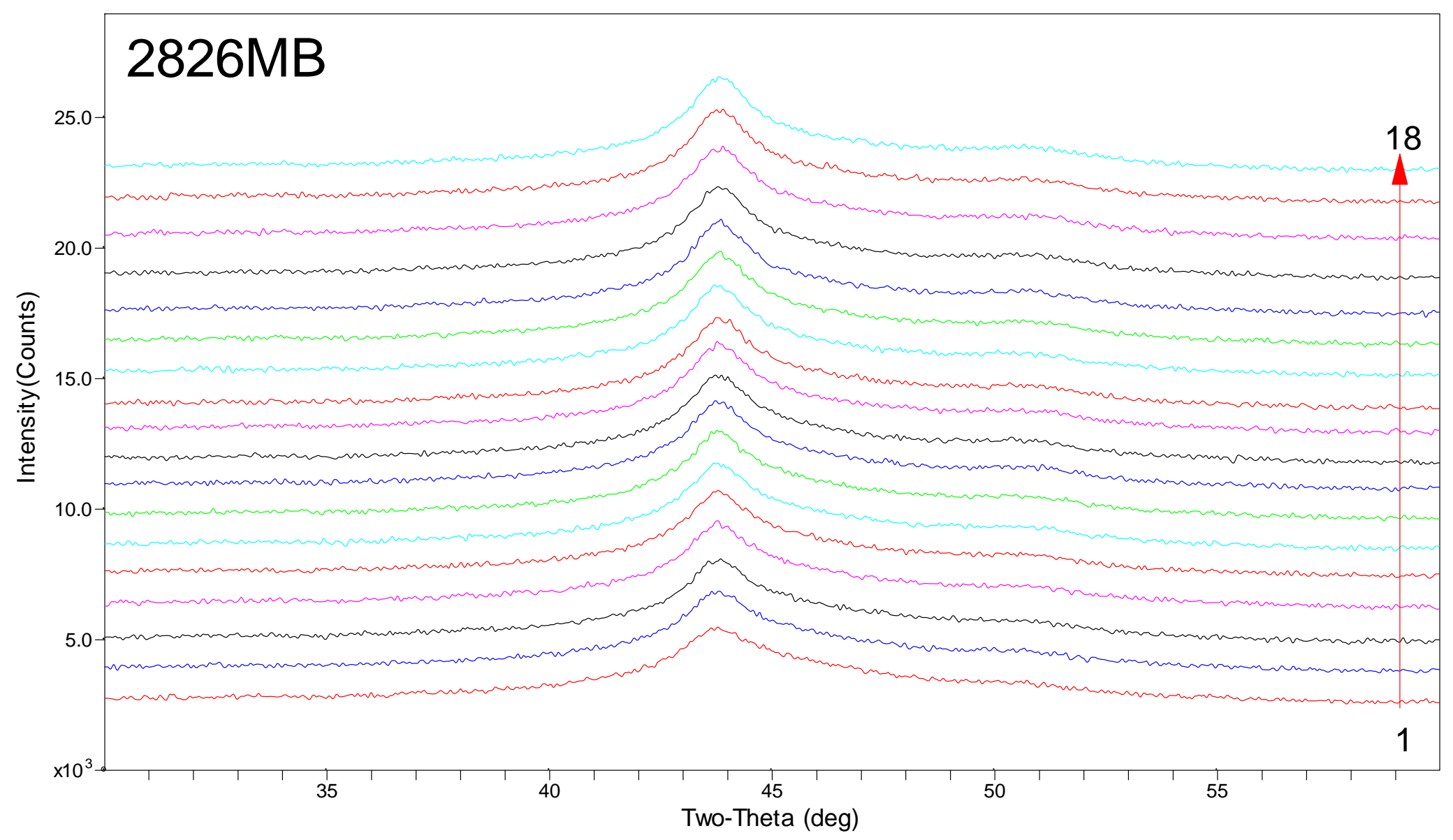

Figure 81. Isothermal XRD scans of $2826 \mathrm{MB}$ acquired over a $3 \mathrm{hr}$ period at $400{ }^{\circ} \mathrm{C}$ in $4 \%-\mathrm{H}_{2} / 96 \%-\mathrm{He}$. 


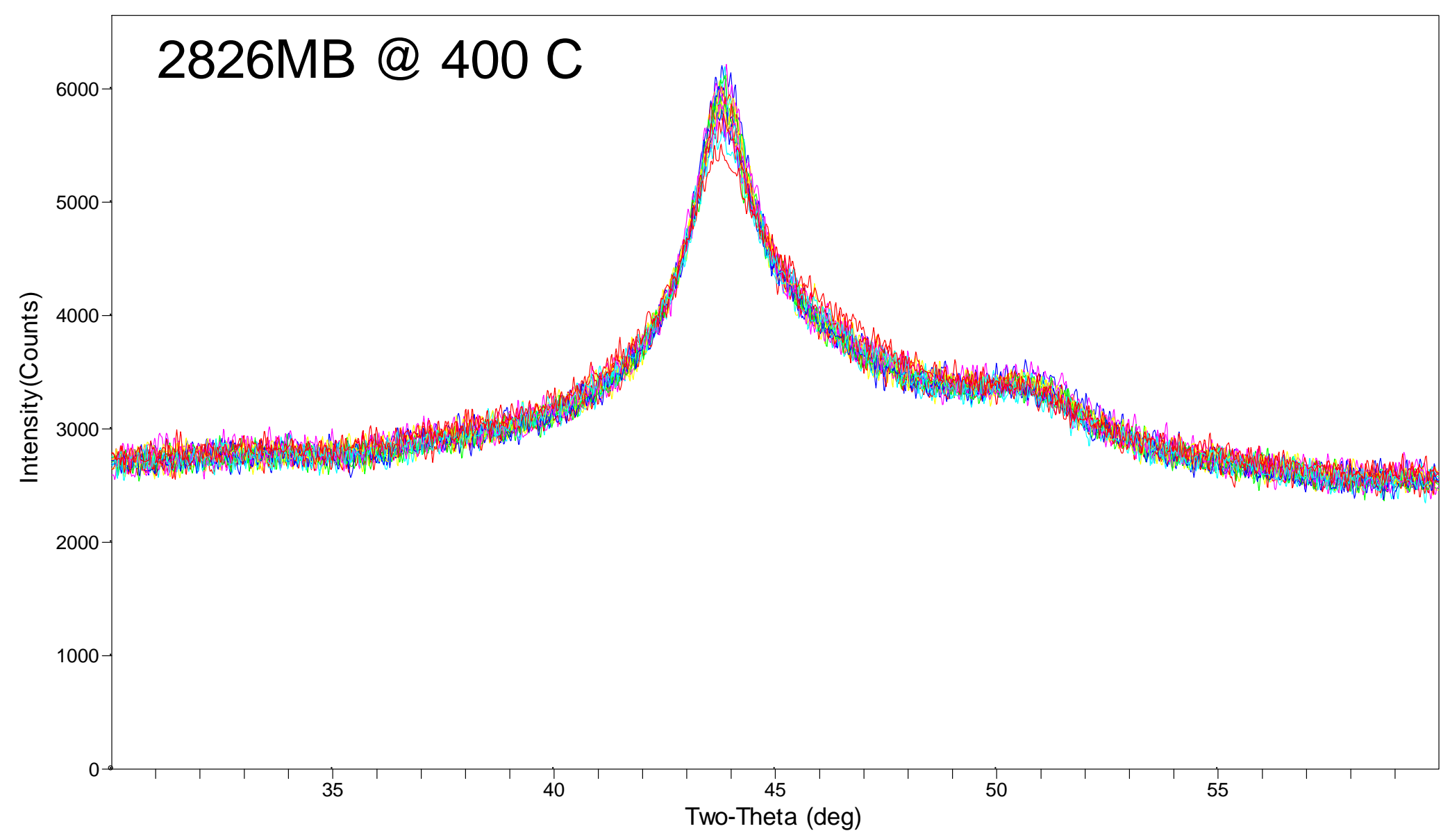

Figure 82. Isothermal XRD scans of $2826 \mathrm{MB}$ acquired over a 3 -hr period at $400{ }^{\circ} \mathrm{C}$ in $4 \%-\mathrm{H}_{2} / 96 \%$-He 
SRNS-STI-2008-00133

Revision 1

Appendix D- XRD 2605 SA1 Alloy 


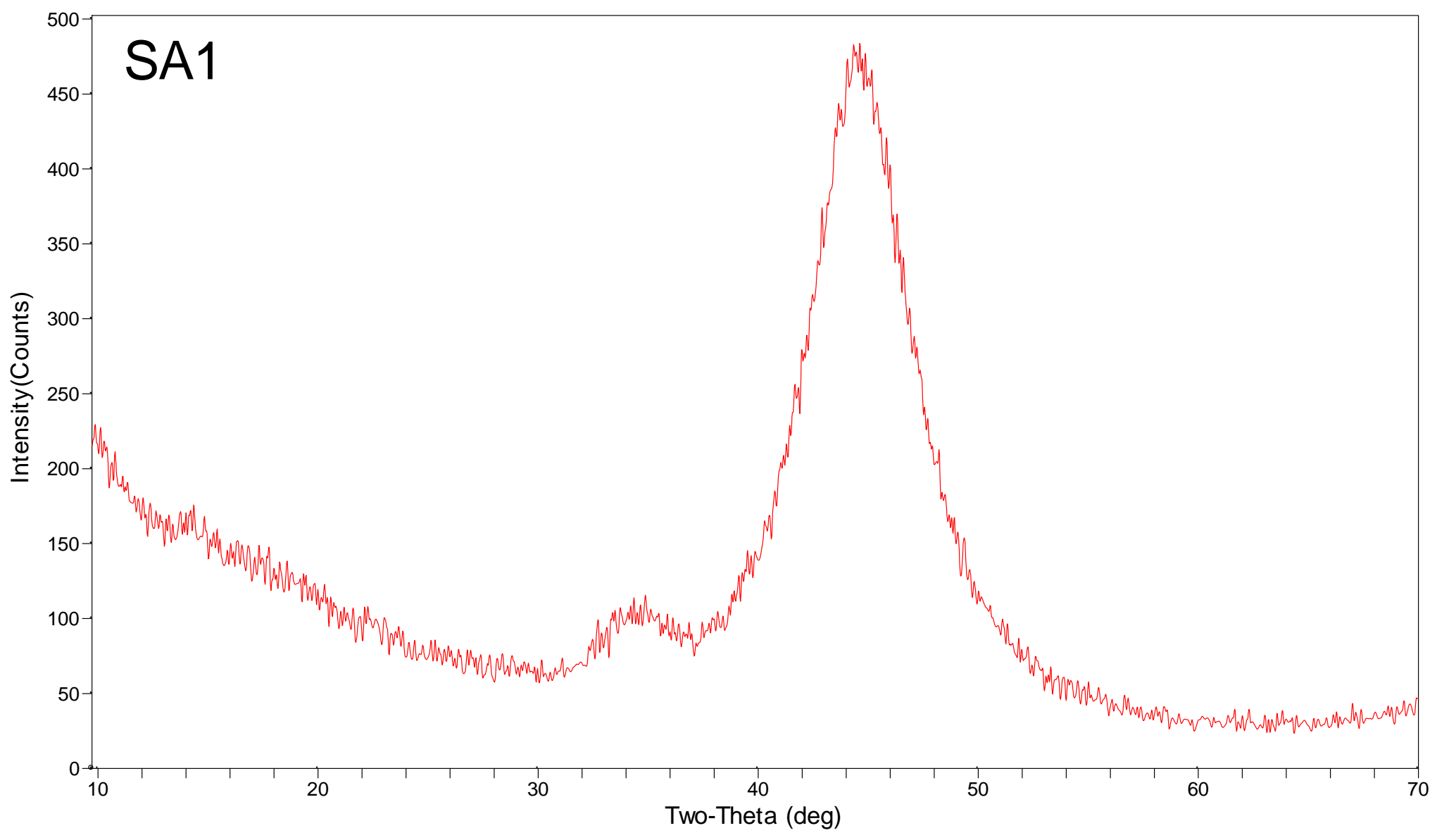

Figure 83. XRD scan of SA1 at $25^{\circ} \mathrm{C}$. 


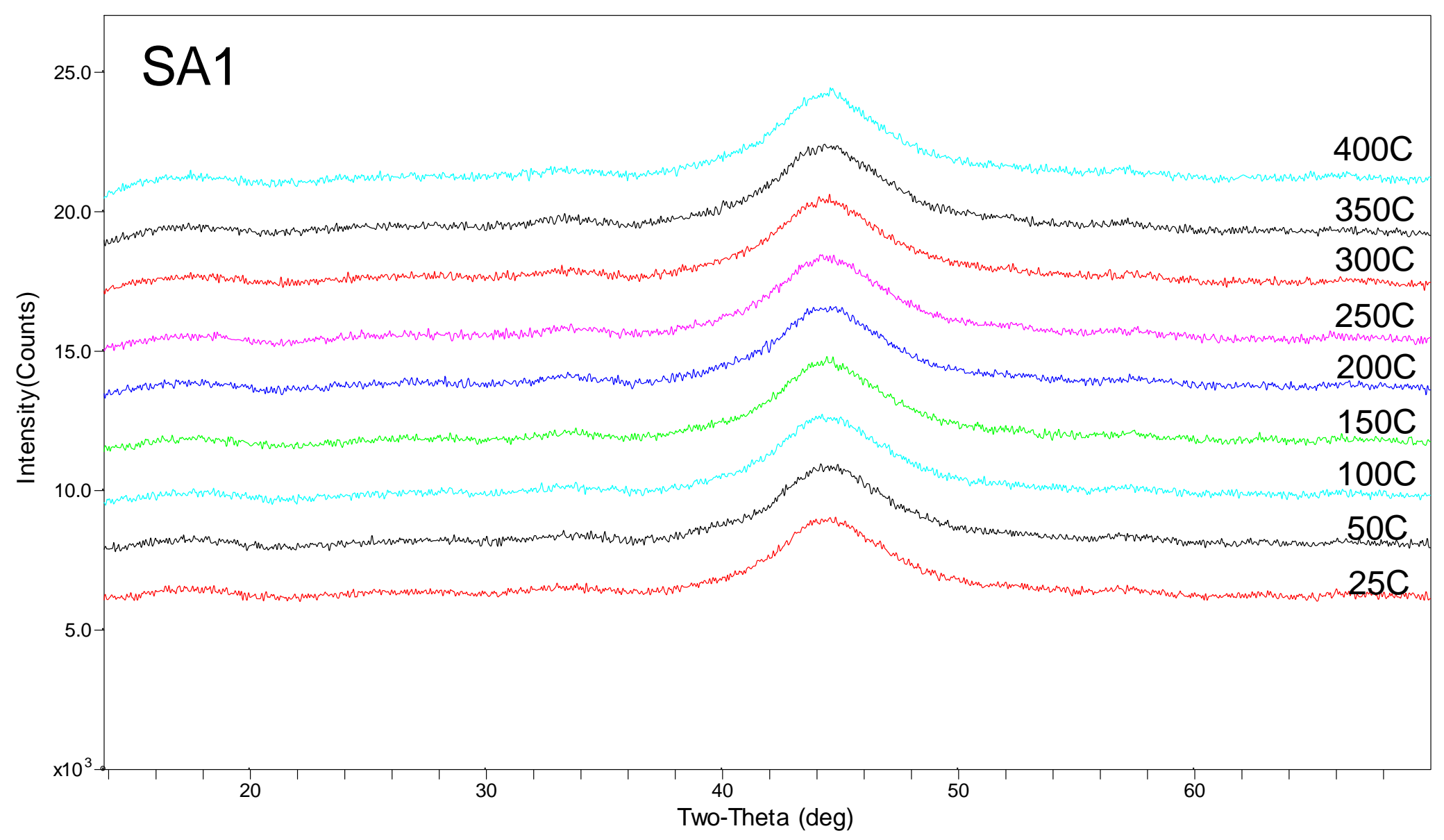

Figure 84. HTXRD scans of SA1 from $25^{\circ} \mathrm{C}$ to $400^{\circ} \mathrm{C}$ in He. 


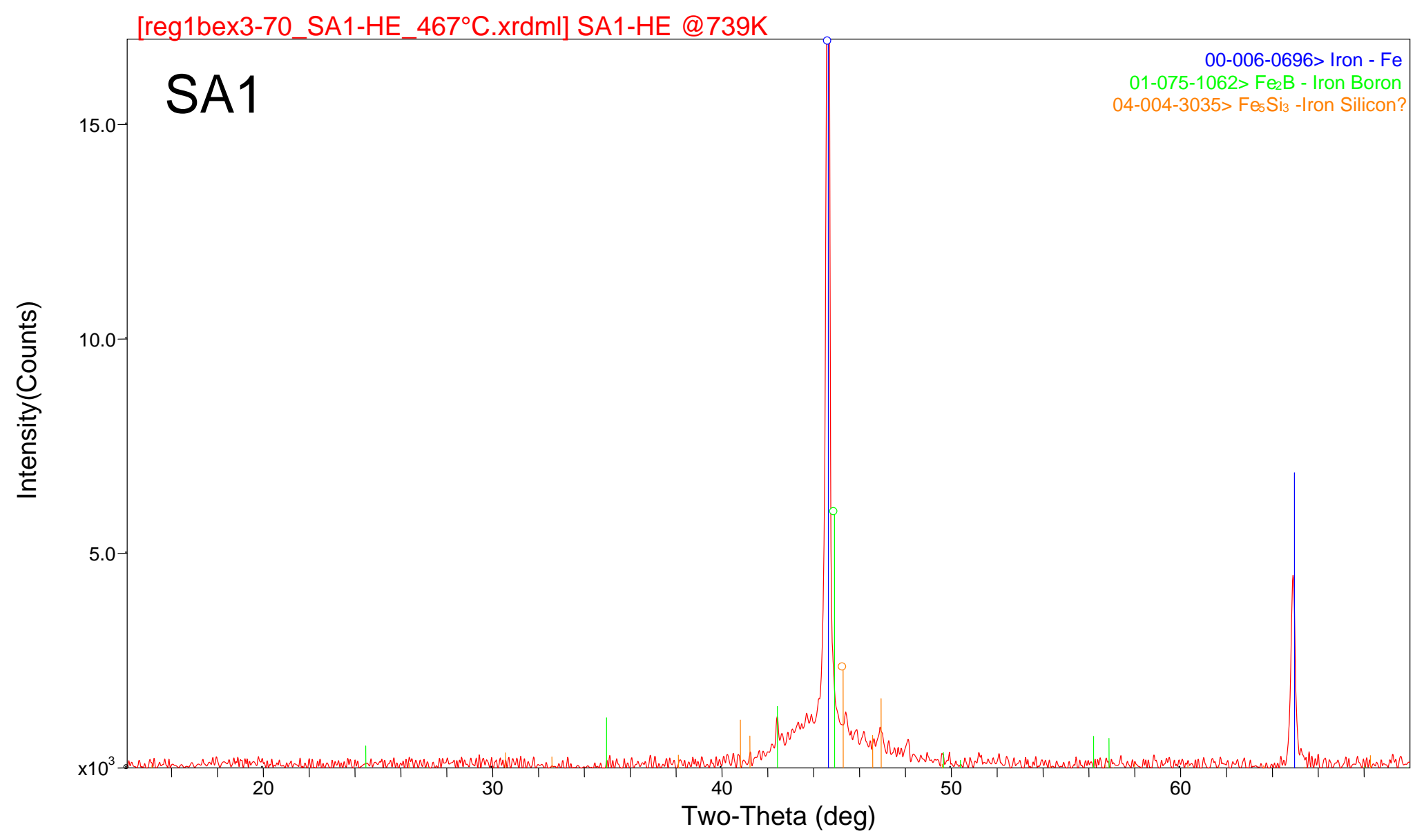

Figure 85. HTXRD scans of SA1 at $450^{\circ} \mathrm{C}$ in $\mathrm{He}$. 


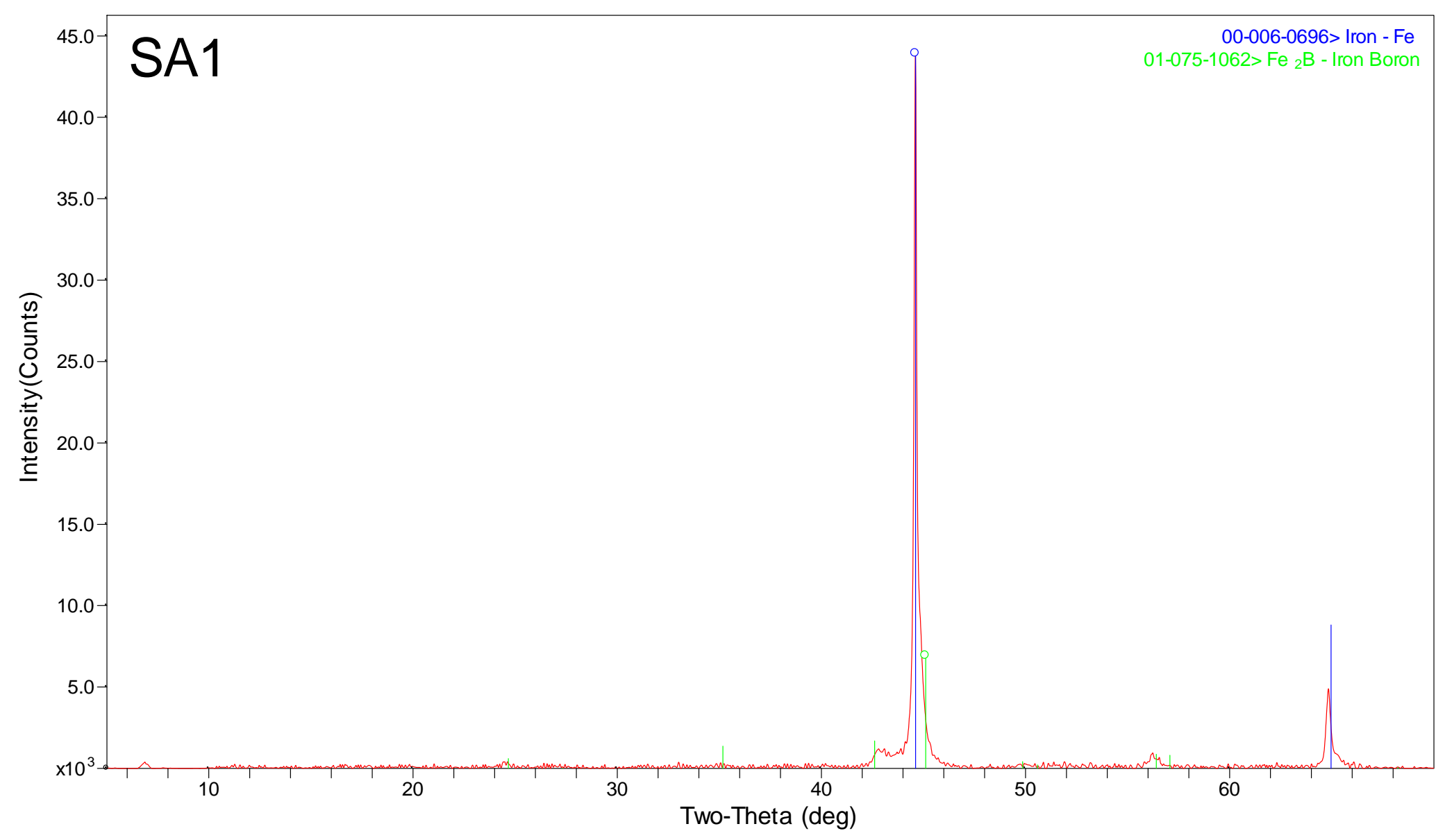

Figure 86. HTXRD scan of SA1 at $500^{\circ} \mathrm{C}$ in $\mathrm{He}$. 


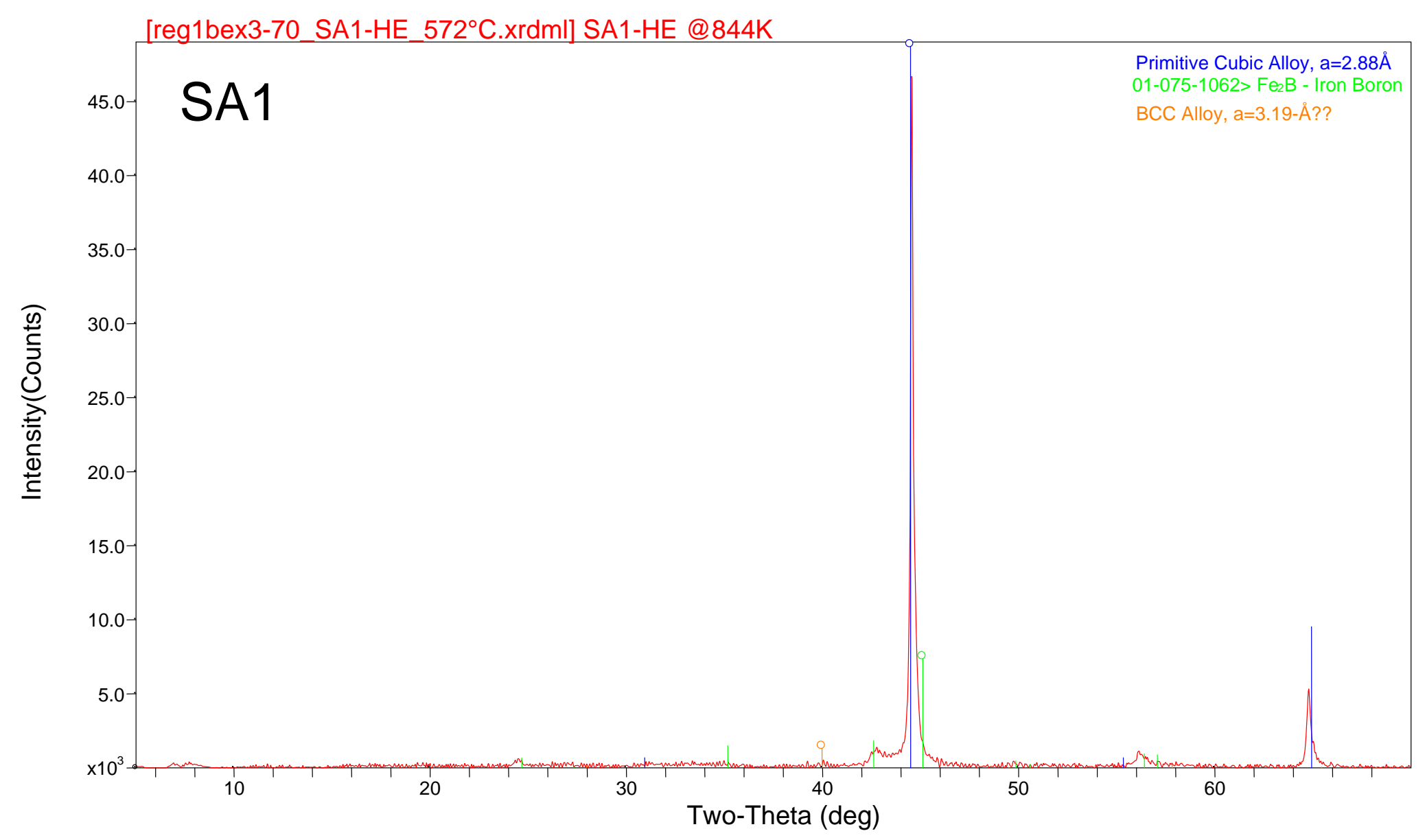

Figure 87. HTXRD scan of SA1 at $550^{\circ} \mathrm{C}$ in He. 


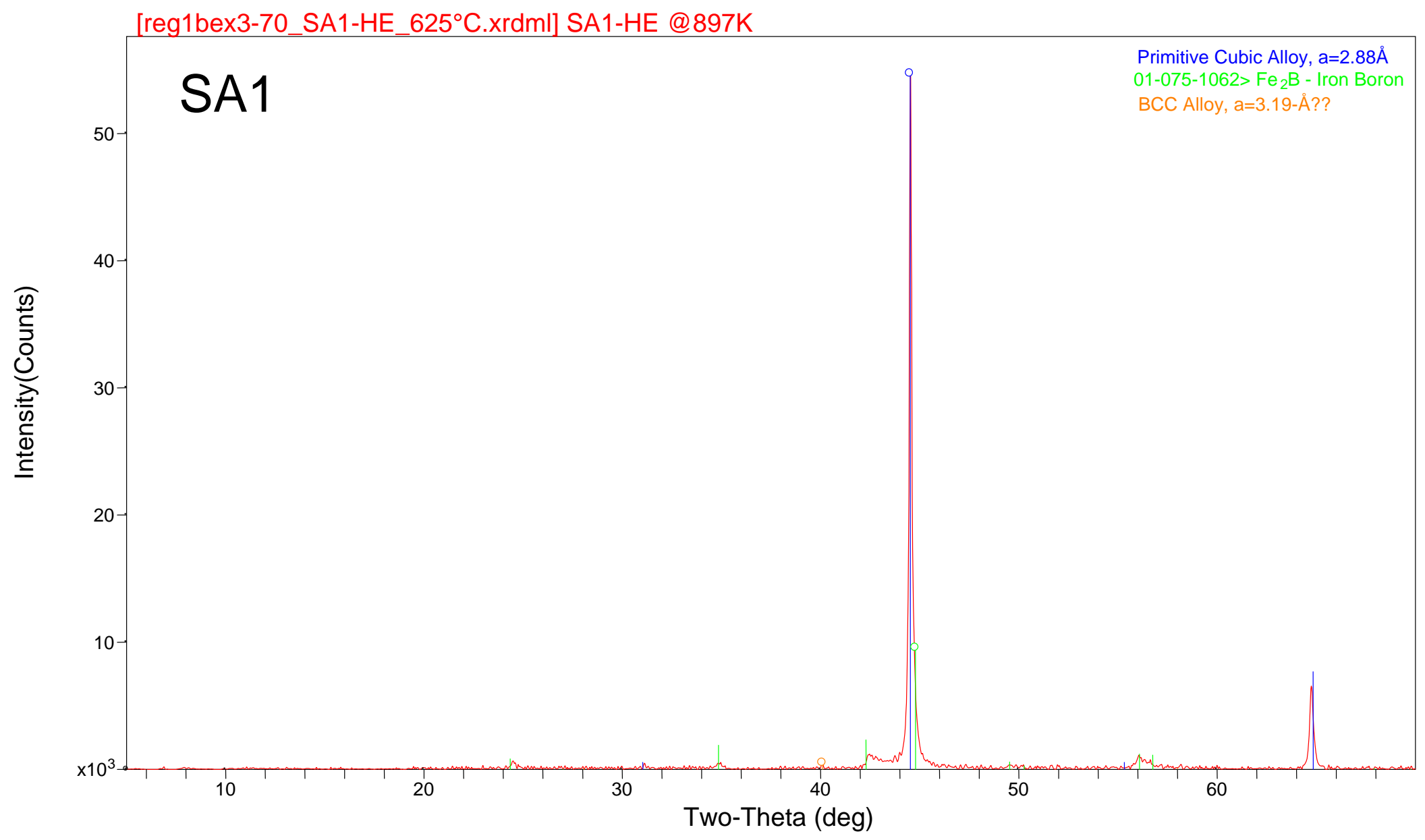

Figure 88. HTXRD scan of SA1 at $600^{\circ} \mathrm{C}$ in He. 


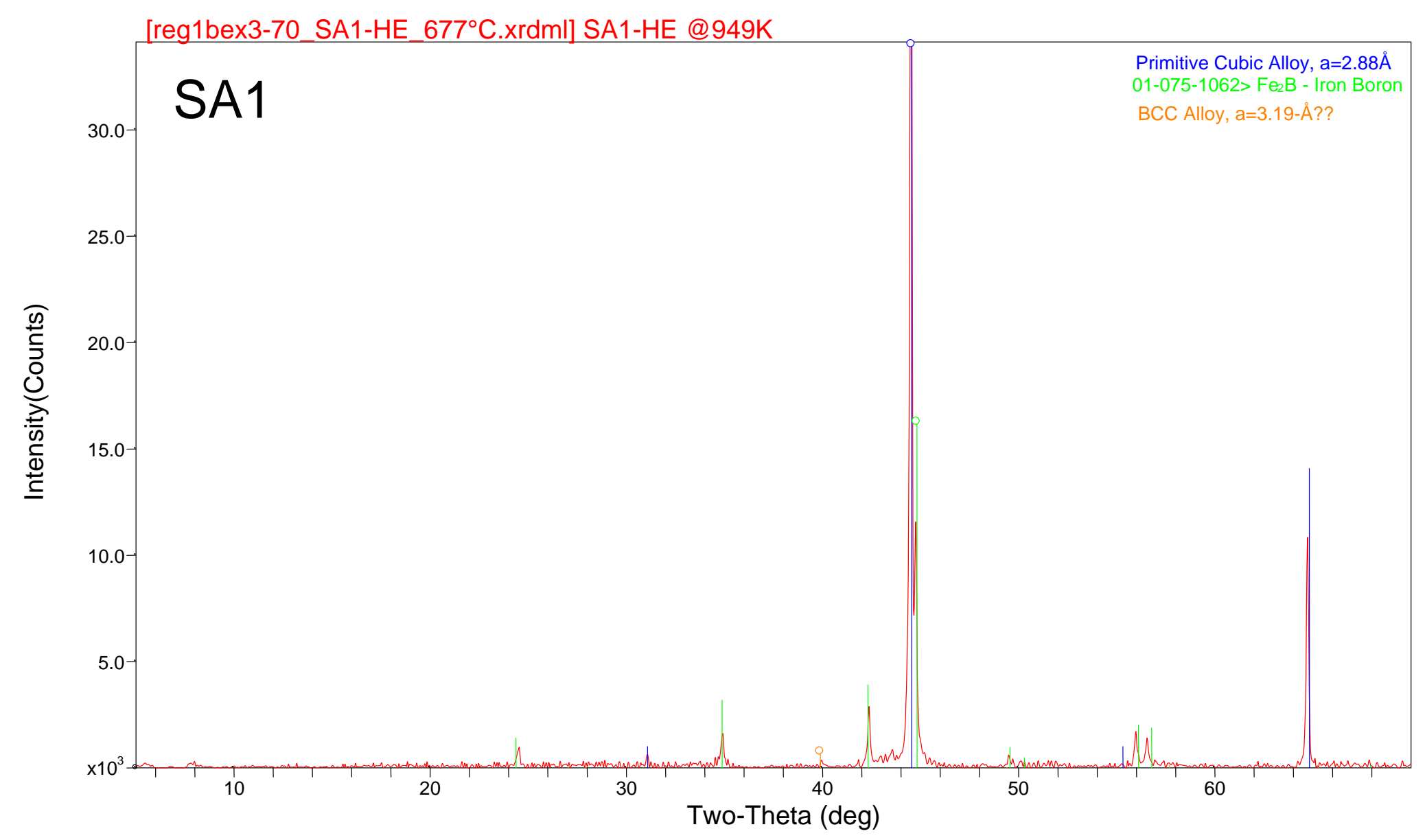

Figure 89. HTXRD scan of SA1 at $650^{\circ} \mathrm{C}$ in He. 


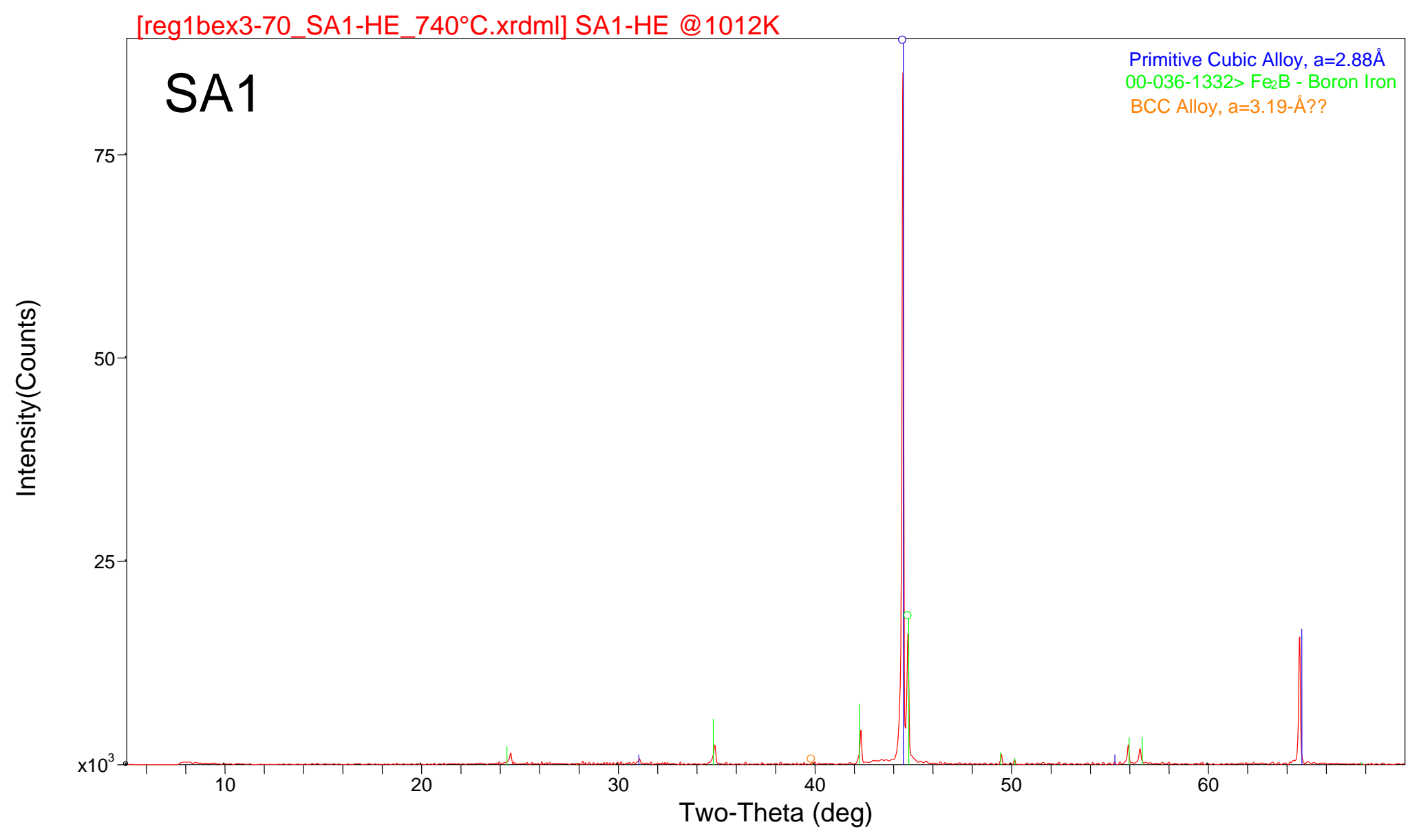

Figure 90. HTXRD scan of SA1 at $710^{\circ} \mathrm{C}$ in $\mathrm{He}$. 


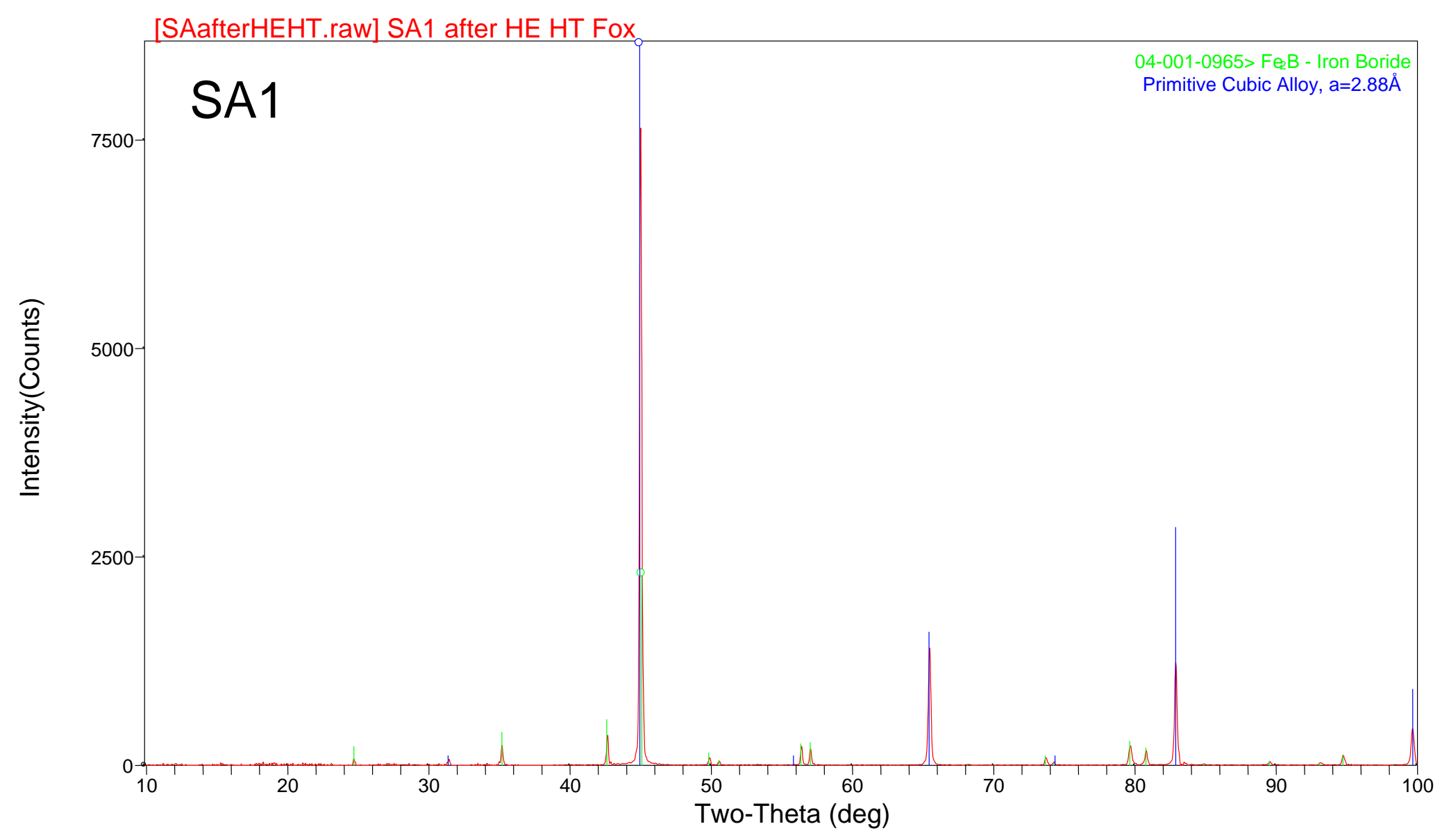

Figure 91. XRD scan of SA1 HTXRD residue in He. 


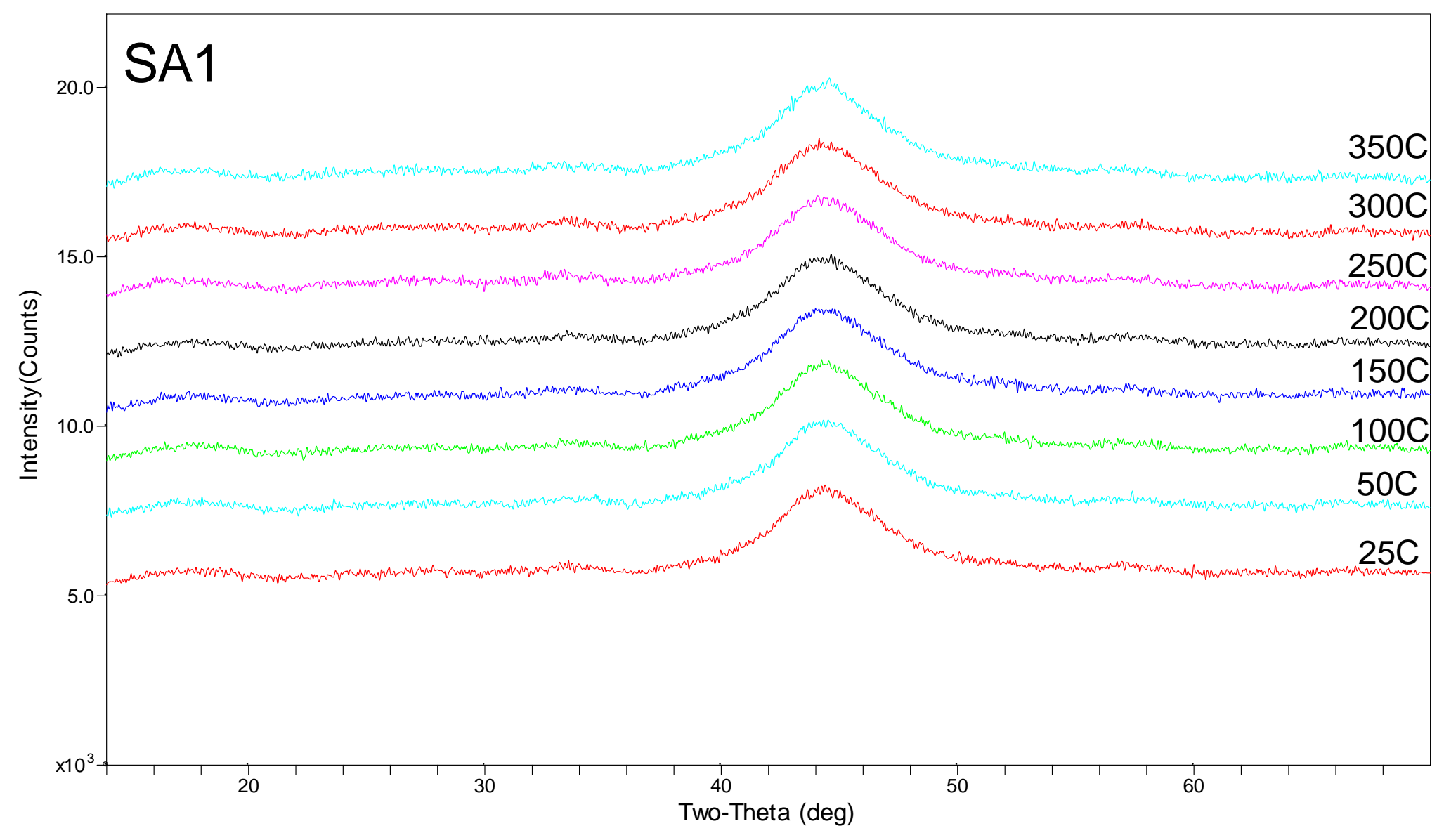

Figure 92. HTXRD scans of SA1 from 25 to $350^{\circ} \mathrm{C}$ in $4 \%-\mathrm{H}_{2} / 96 \%-\mathrm{He}$. 


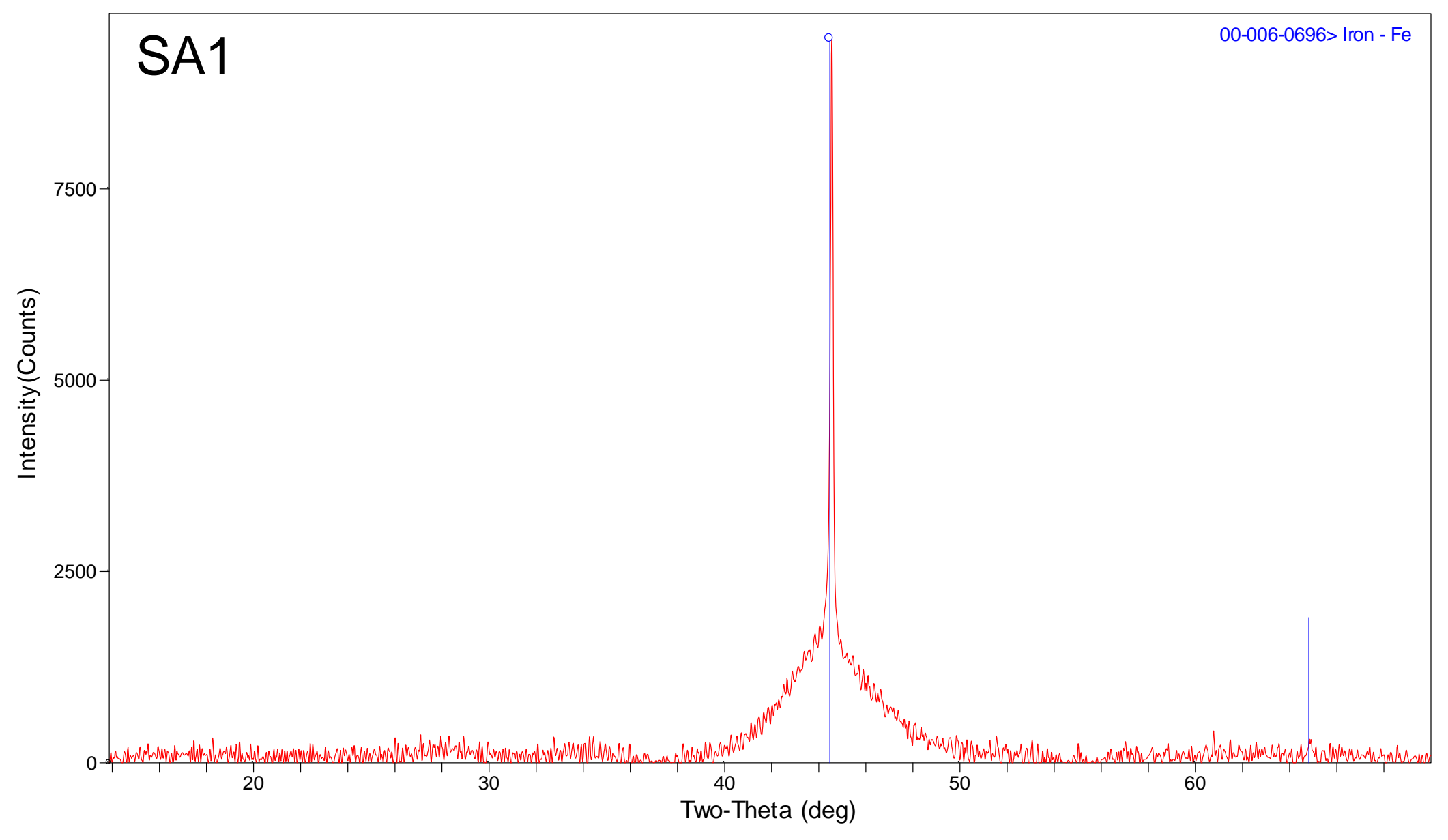

Figure 93. HTXRD scans of SA1 at $400^{\circ} \mathrm{C}$ in $4 \%-\mathrm{H}_{2} / 96 \%-\mathrm{He}$. 


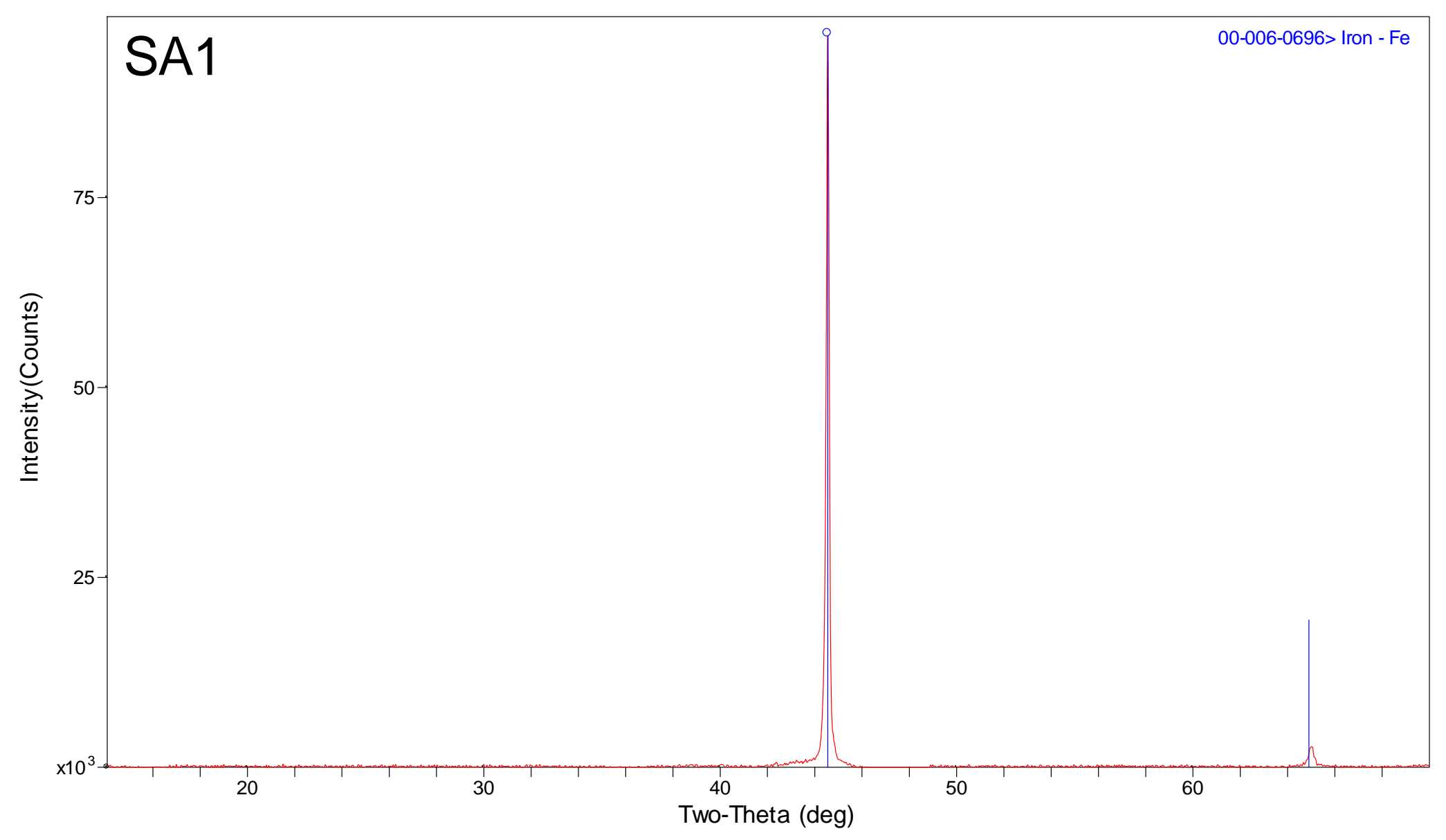

Figure 94. HTXRD scan of SA1 at $450^{\circ} \mathrm{C}$ in $4 \%-\mathrm{H}_{2} / 96 \%-\mathrm{He}$. 


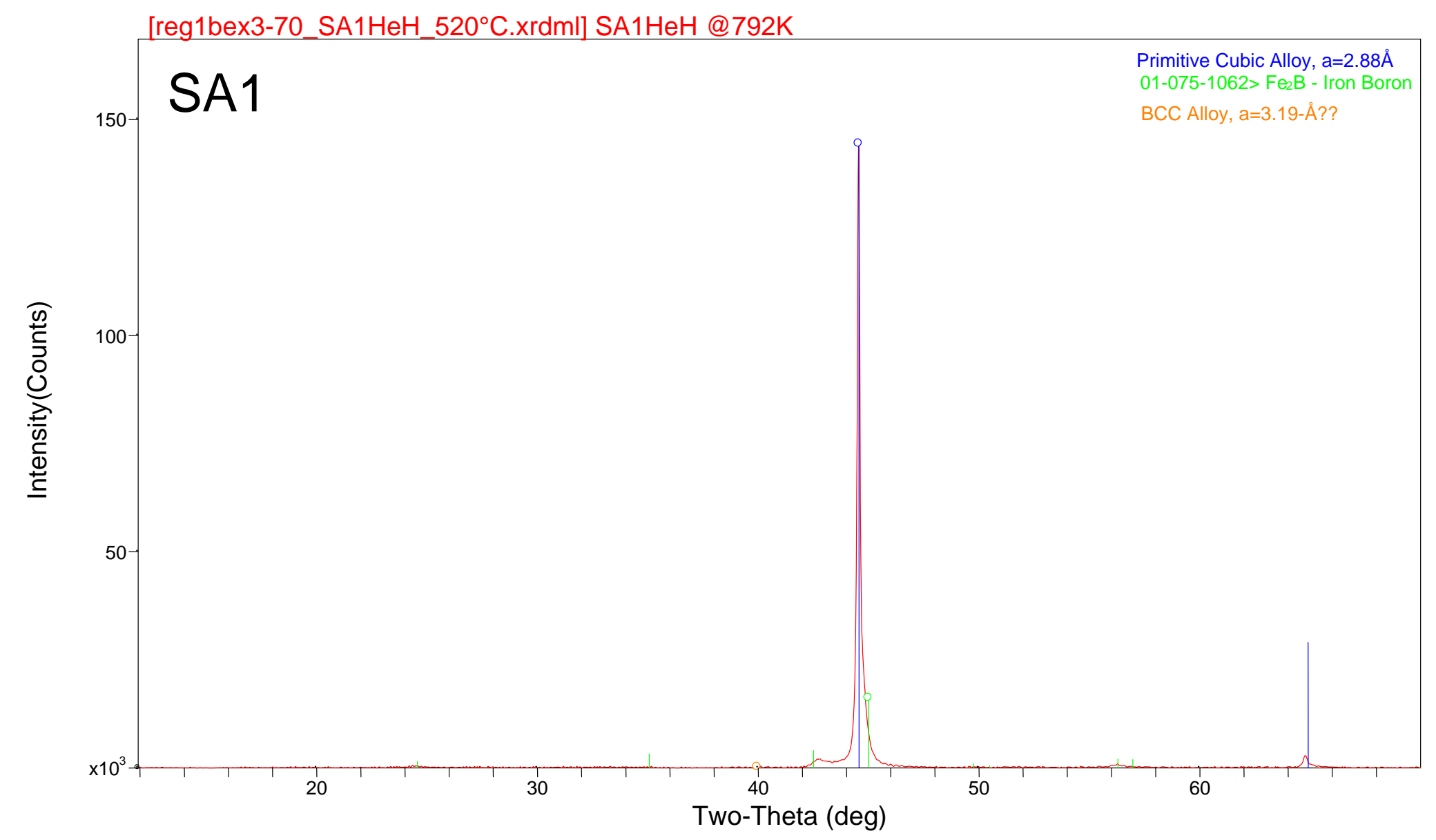

Figure 95. HTXRD scan of SA1 at $500^{\circ} \mathrm{C}$ in $4 \%-\mathrm{H}_{2} / 96 \%-\mathrm{He}$. 


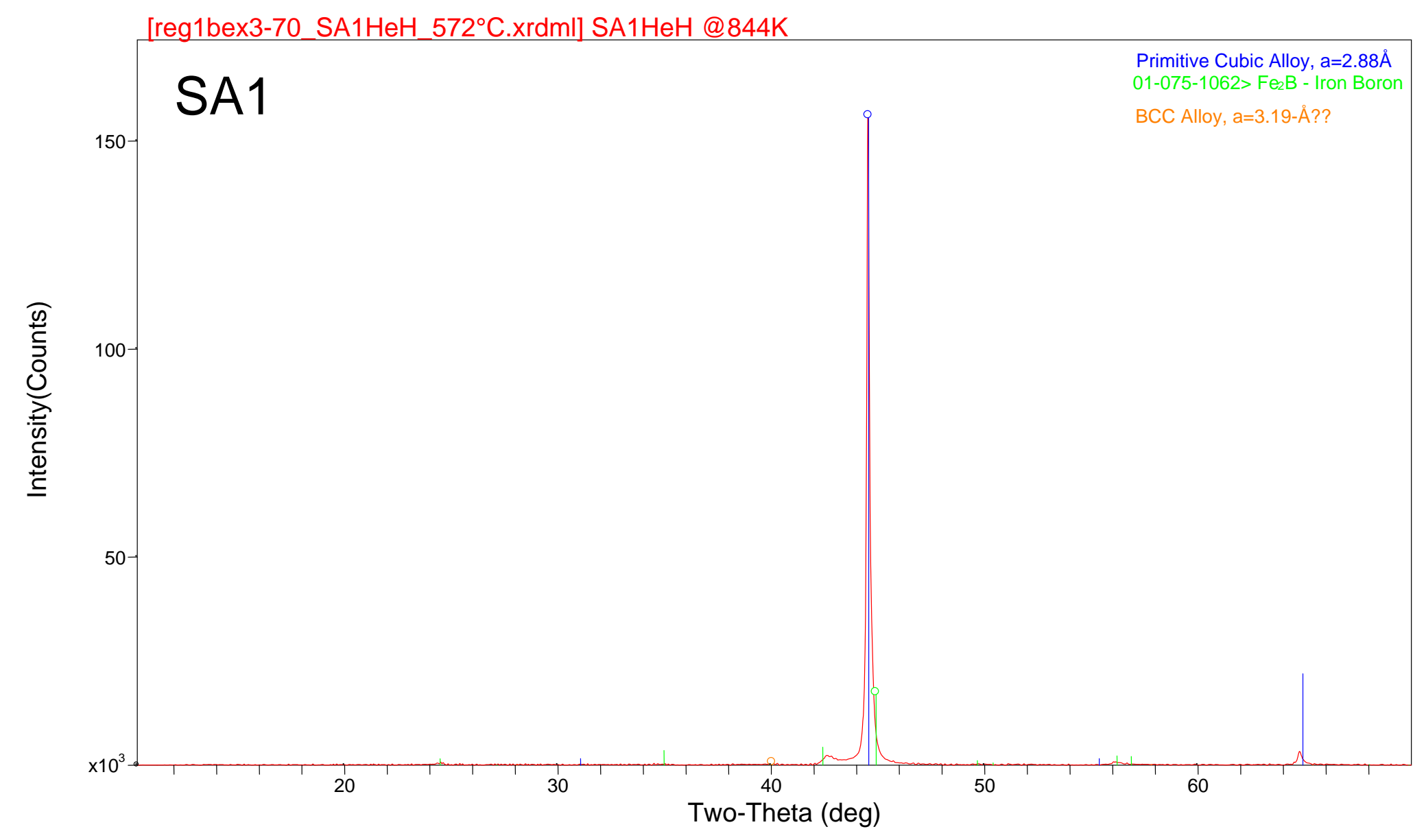

Figure 96. HTXRD scan of SA1 at $550^{\circ} \mathrm{C}$ in $4 \%-\mathrm{H}_{2} / 96 \%-\mathrm{He}$. 


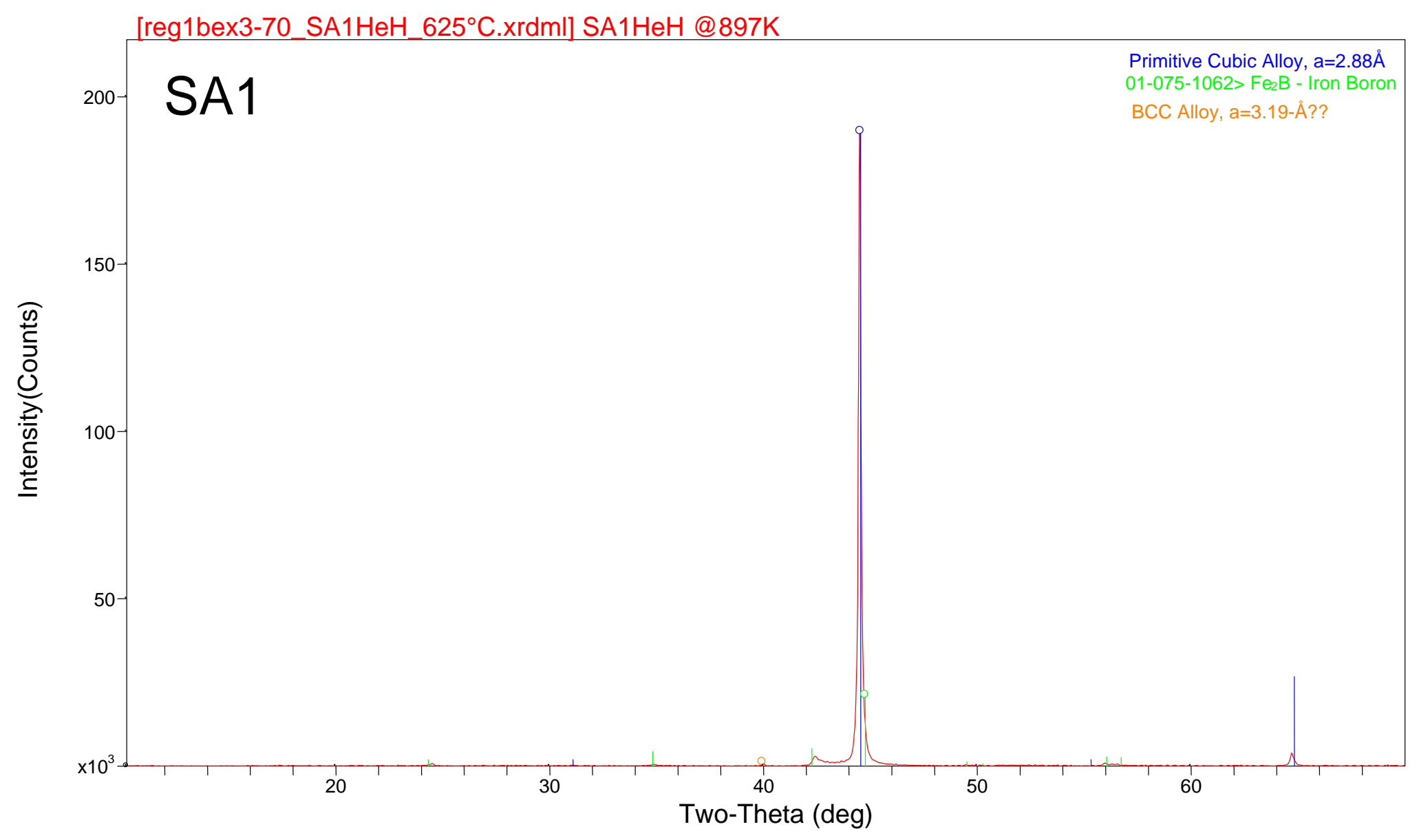

Figure 97. HTXRD scan of SA1 at $600^{\circ} \mathrm{C}$ in $4 \%-\mathrm{H}_{2} / 96 \%-\mathrm{He}$. 


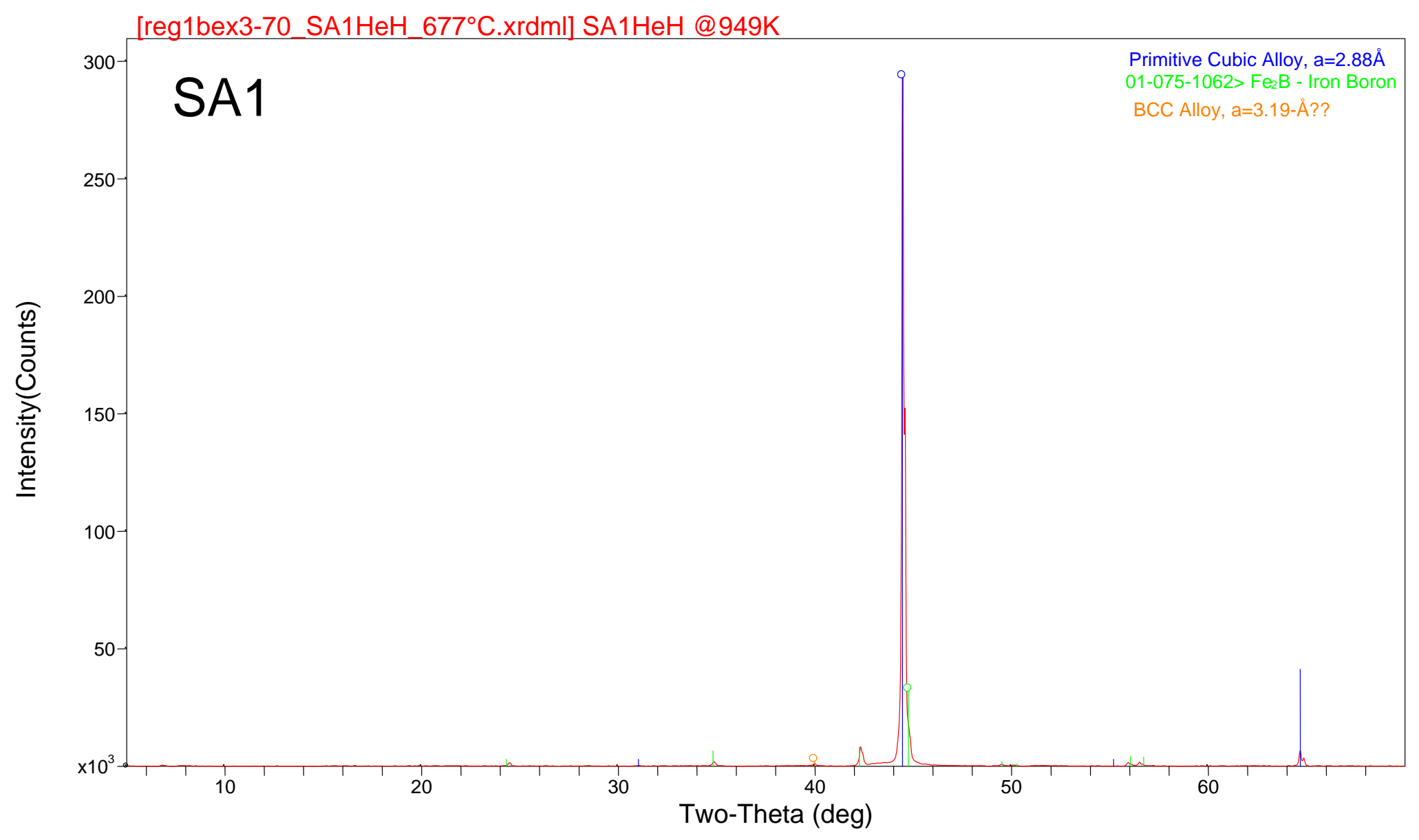

Figure 98. HTXRD scan of SA1 at $650^{\circ} \mathrm{C}$ in $4 \%-\mathrm{H}_{2} / 96 \%-\mathrm{He}$. 


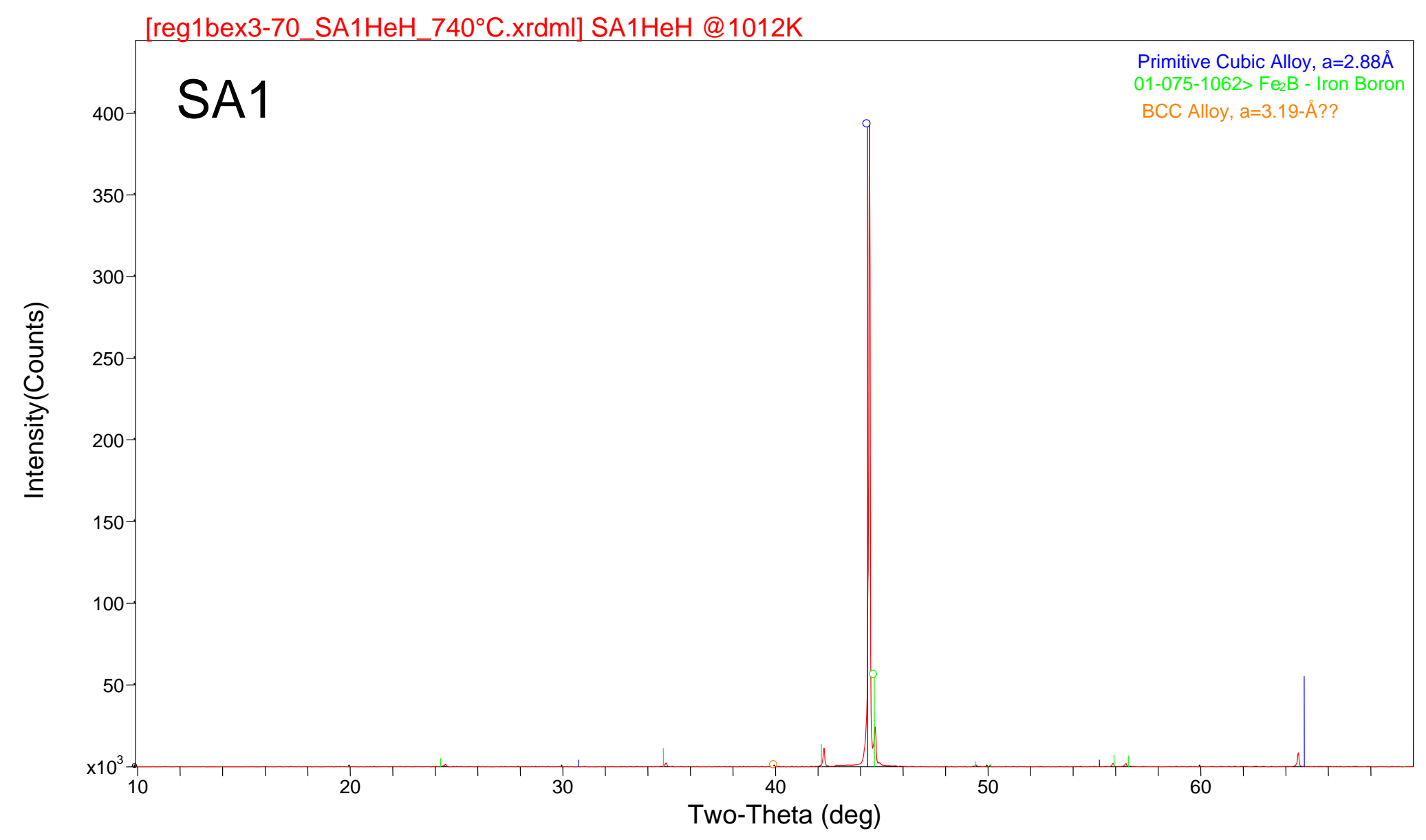

Figure 99. HTXRD scan of SA1 at $710^{\circ} \mathrm{C}$ in $4 \%-\mathrm{H}_{2} / 96 \%-\mathrm{He}$. 


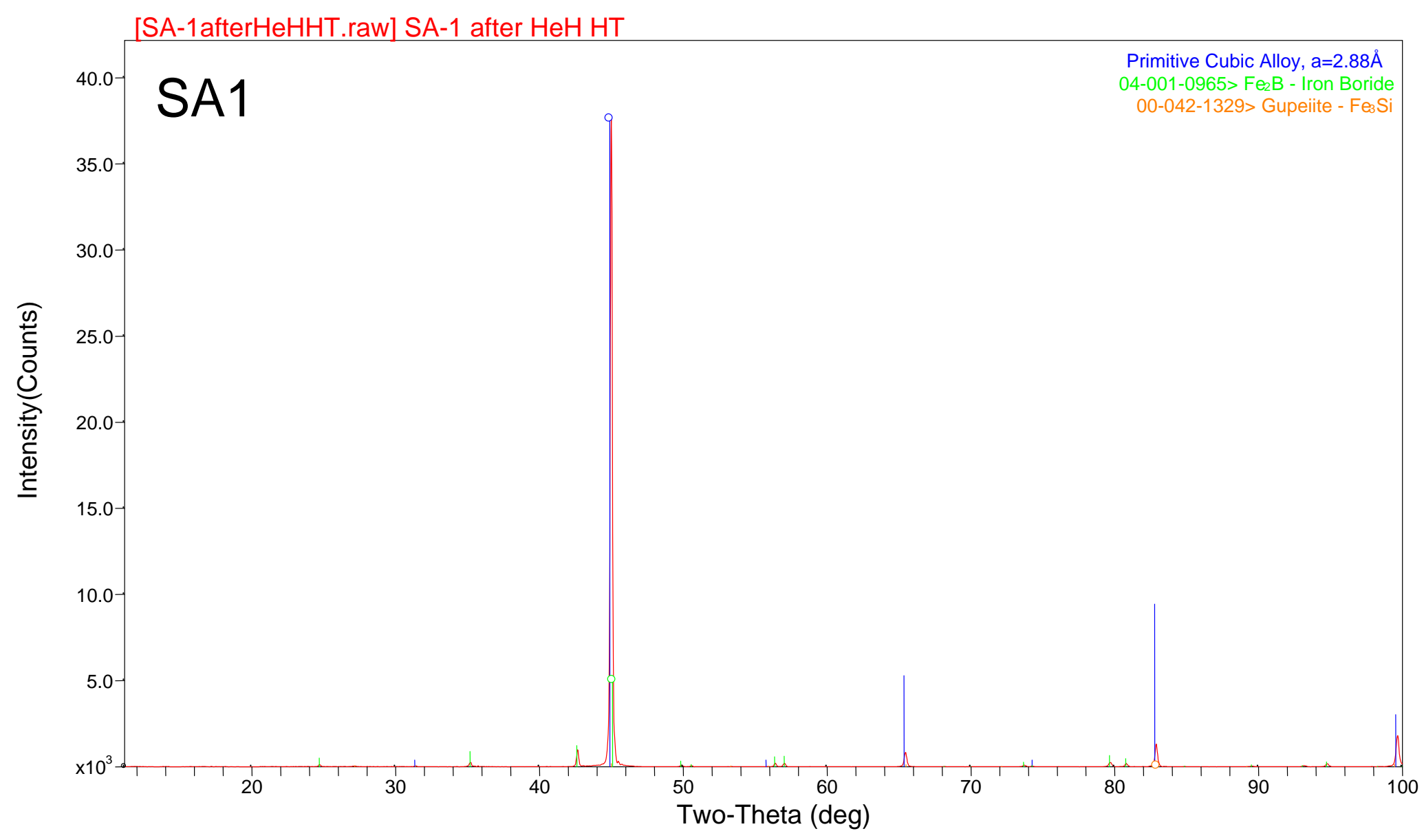

Figure 100. XRD scan of SA1 HTXRD residue in $4 \%-\mathrm{H}_{2} / 96 \%-\mathrm{He}$. 


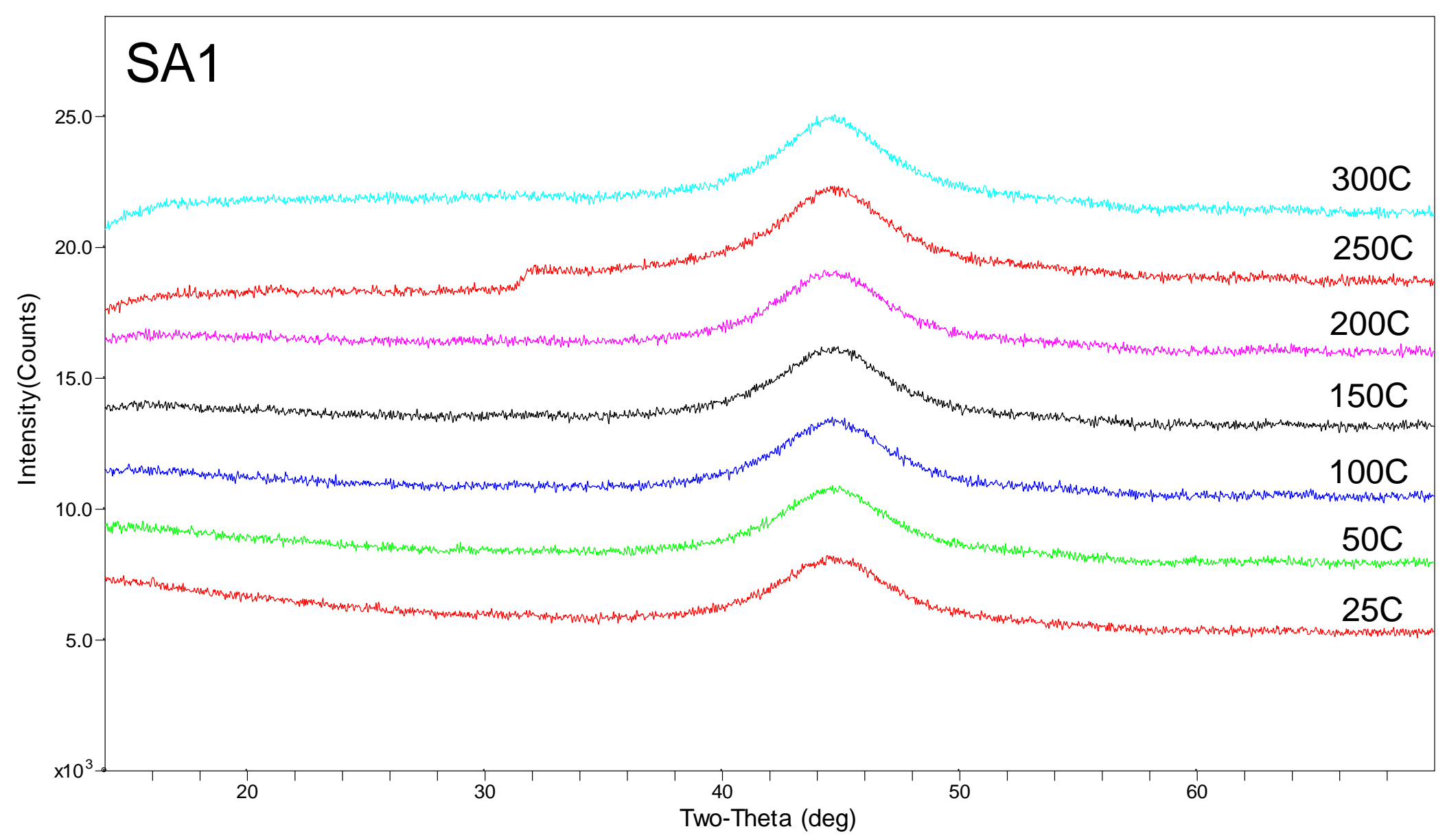

Figure 101. HTXRD scans of SA1 from 25 to $300^{\circ} \mathrm{C}$ in air. 


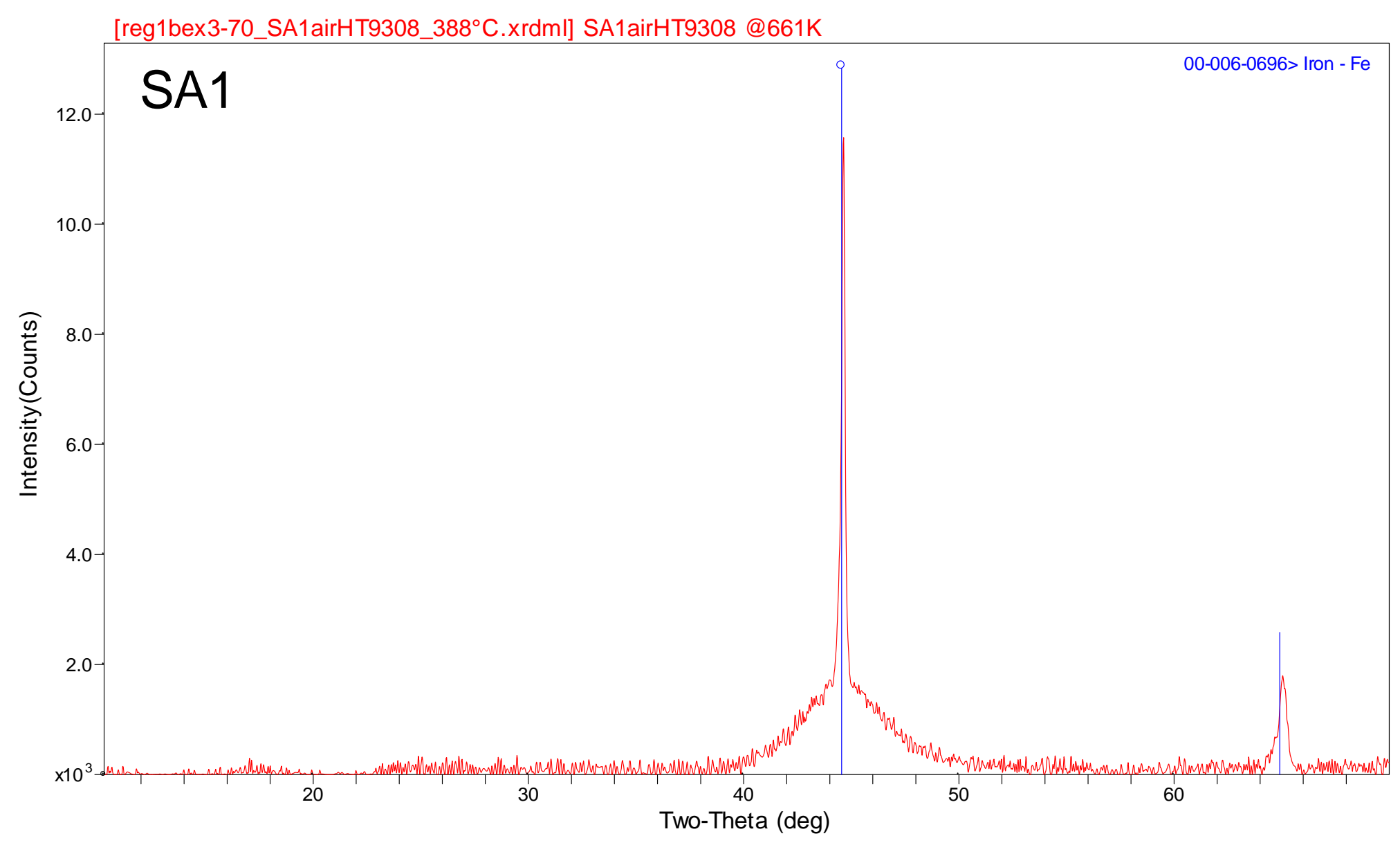

Figure 102. HTXRD scans of SA1 at $350^{\circ} \mathrm{C}$ in air. 


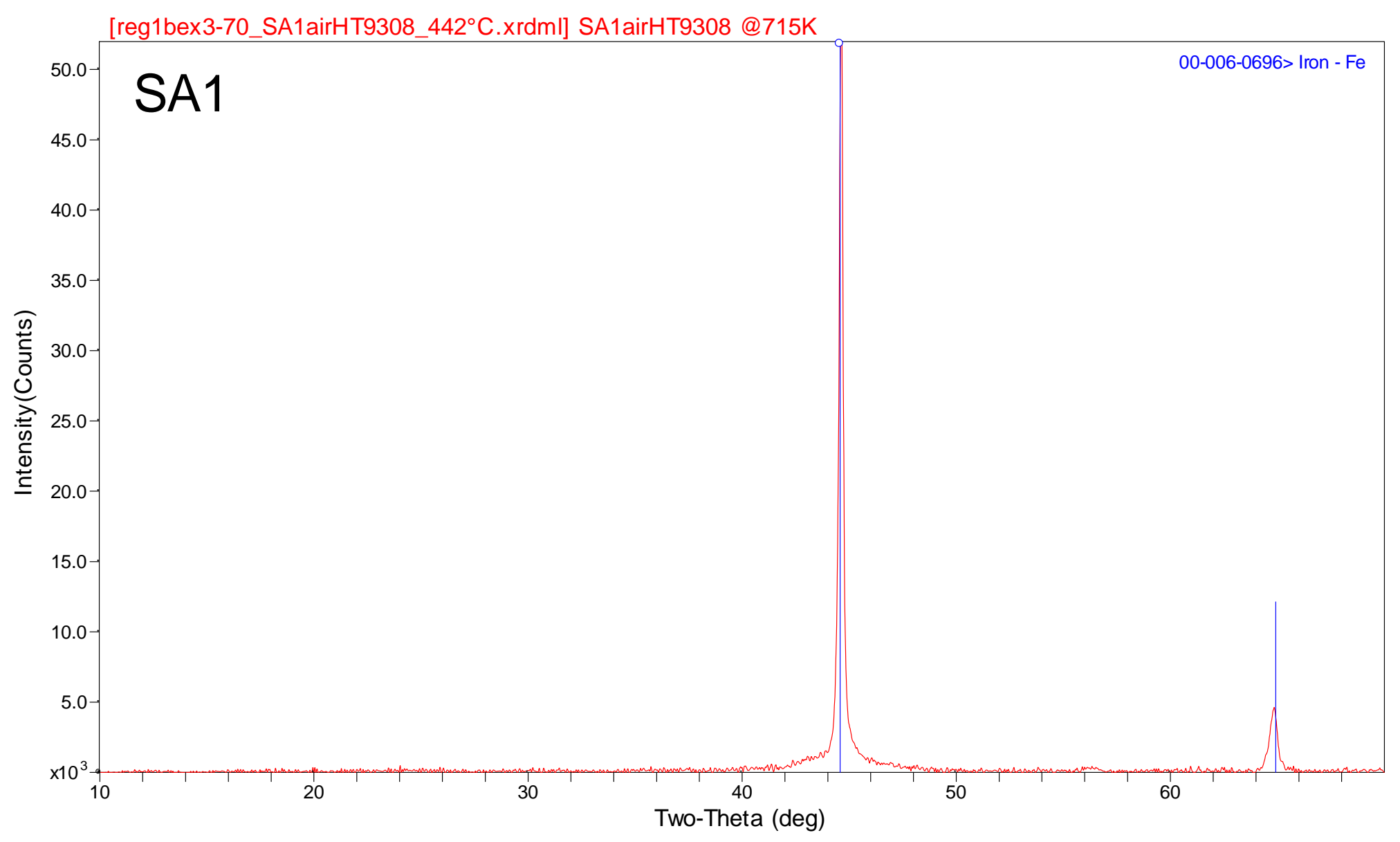

Figure 103. HTXRD scan of SA1 at $400^{\circ} \mathrm{C}$ in air. 


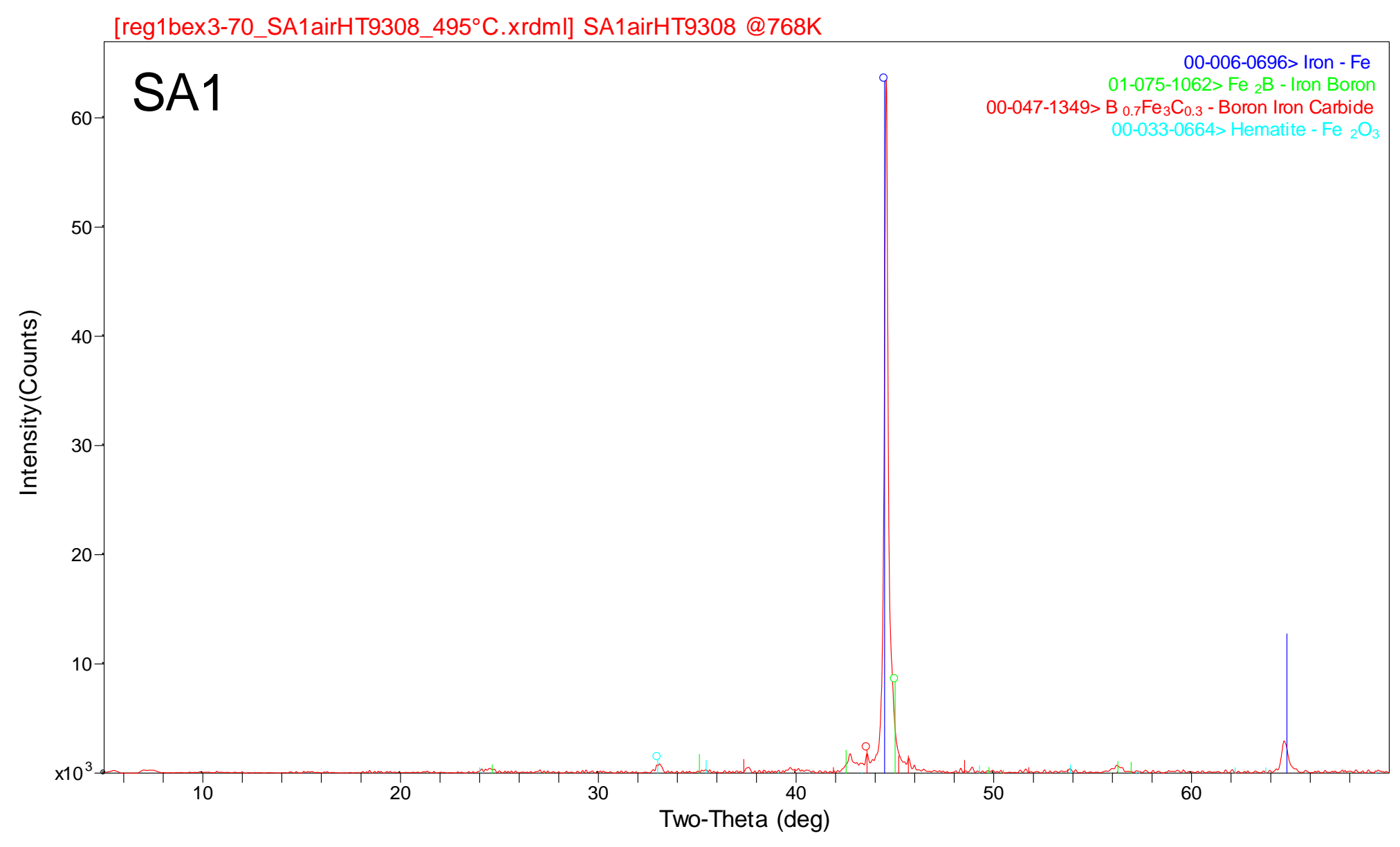

Figure 104. HTXRD scan of $\mathrm{SA1}$ at $450^{\circ} \mathrm{C}$ in air. 


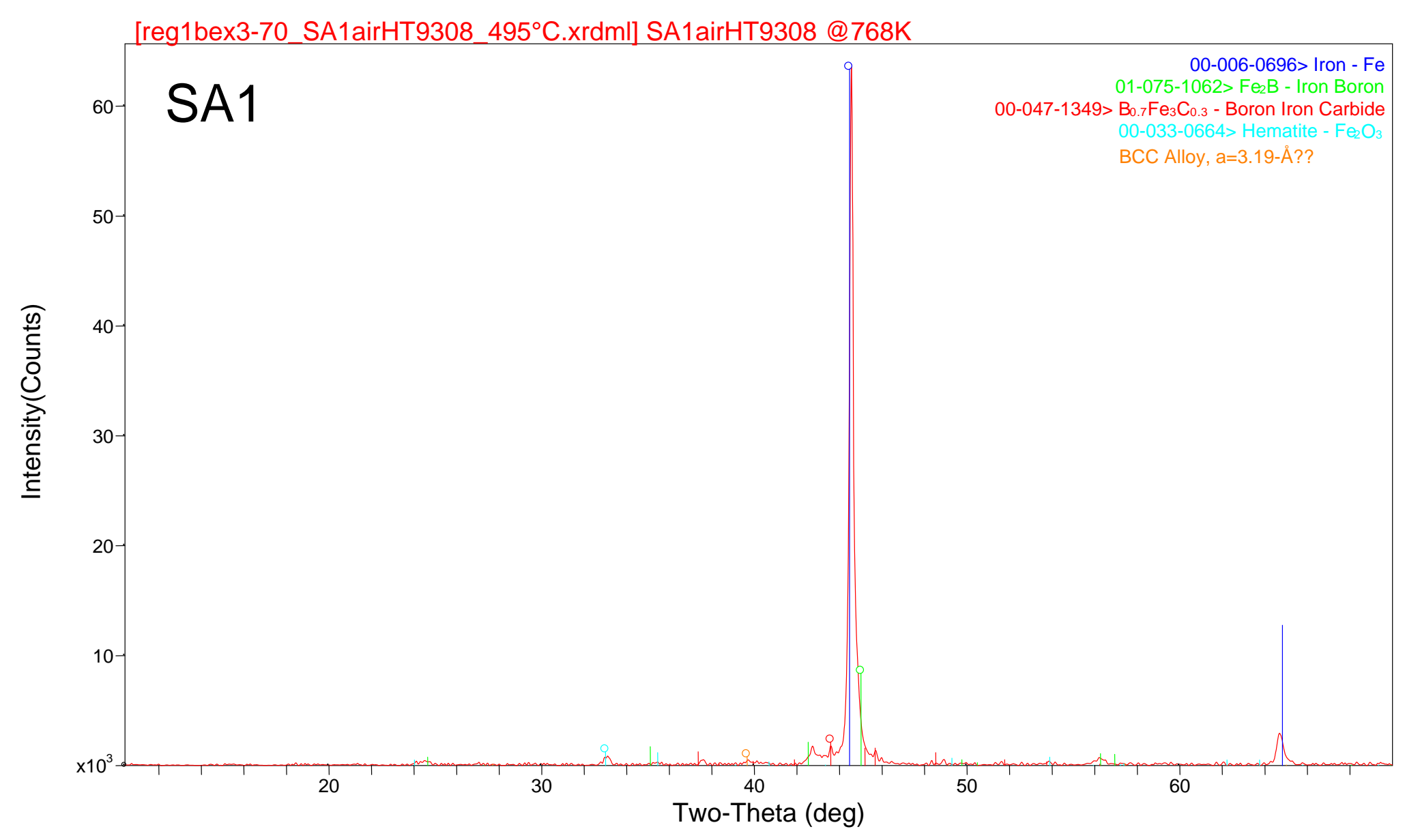

Figure 105. HTXRD scan of $\mathrm{SA1}$ at $500^{\circ} \mathrm{C}$ in air. 


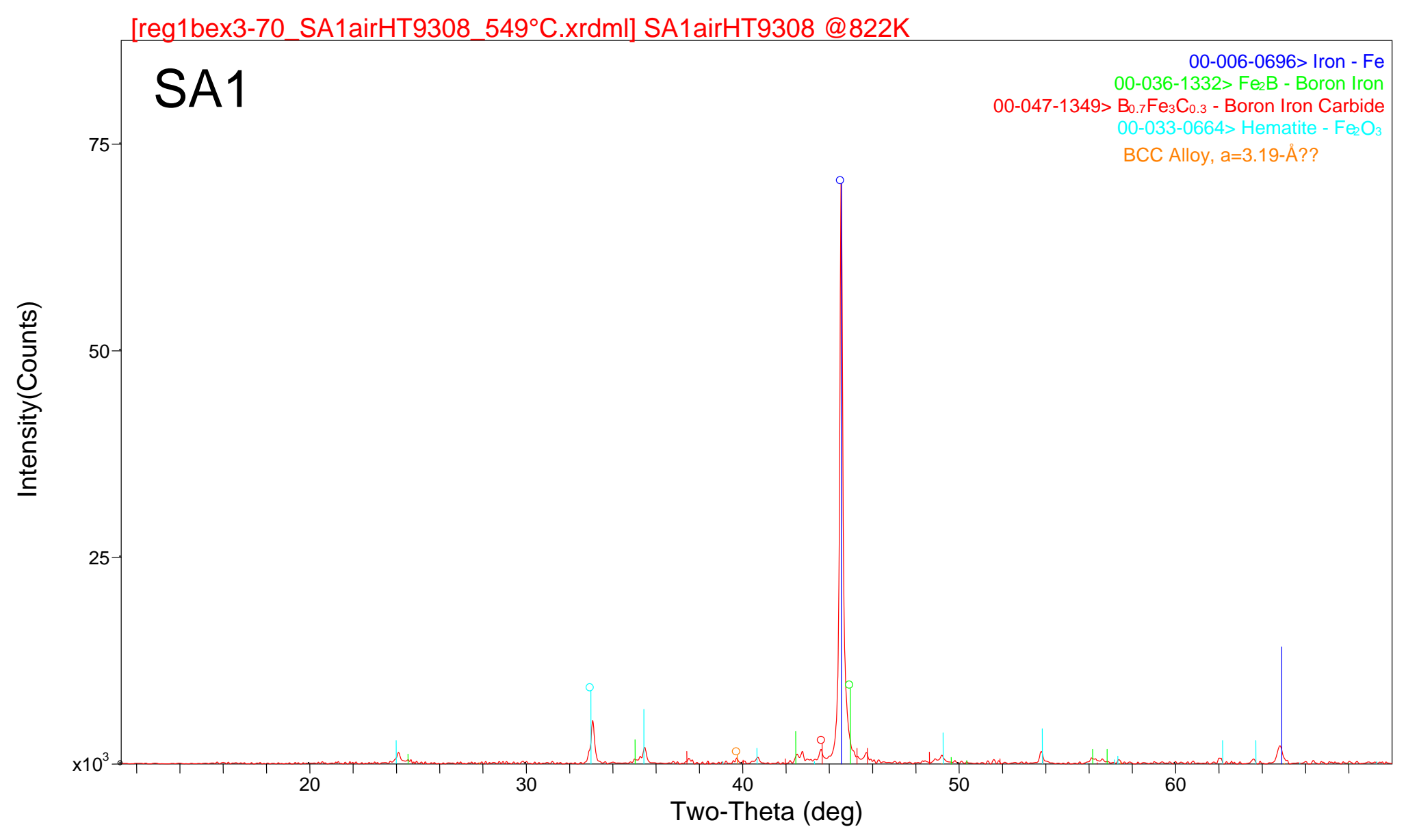

Figure 106. HTXRD scan of SA1 at $550^{\circ} \mathrm{C}$ in air. 


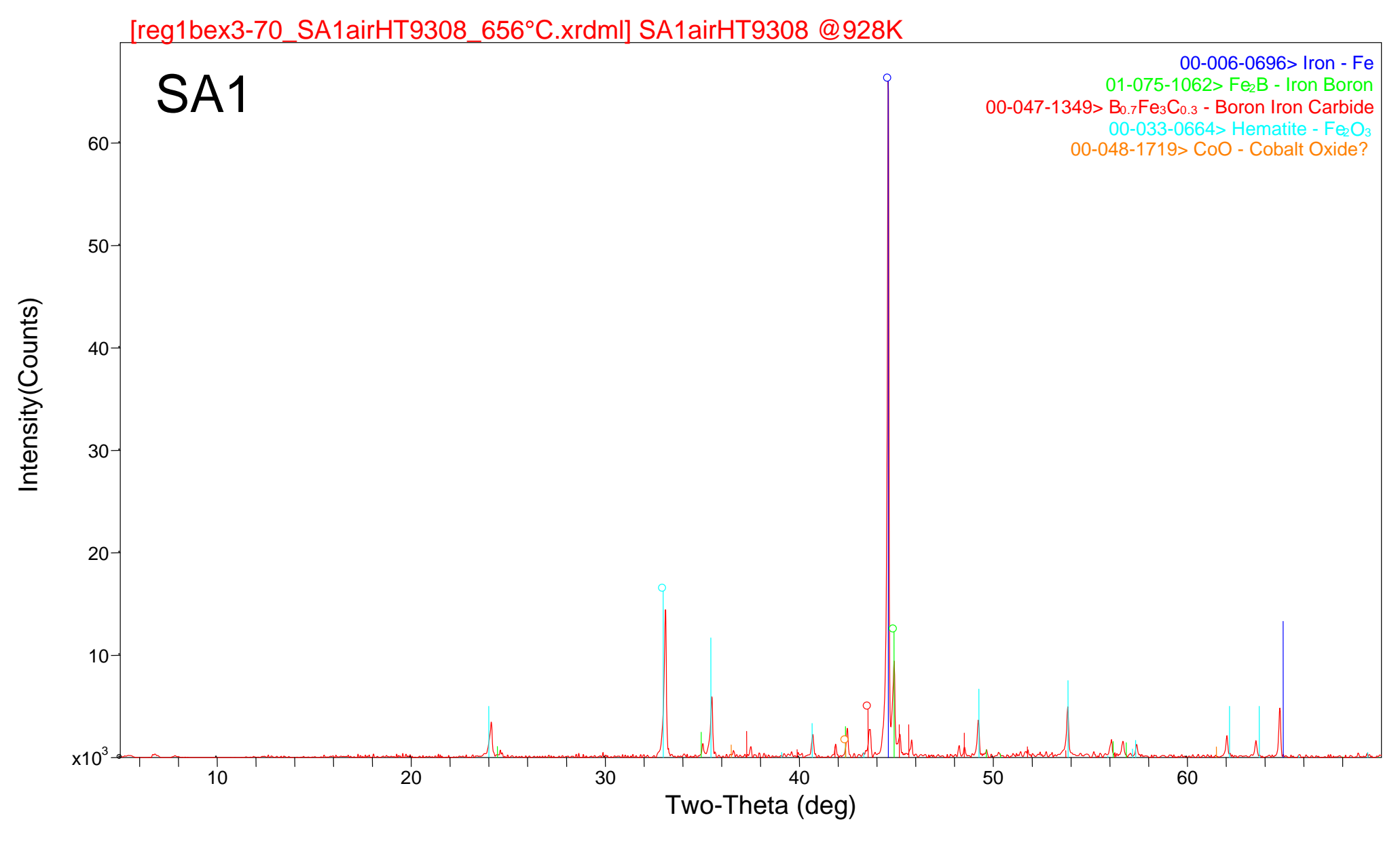

Figure 107. HTXRD scan of SA1 at $600^{\circ} \mathrm{C}$ in air. 


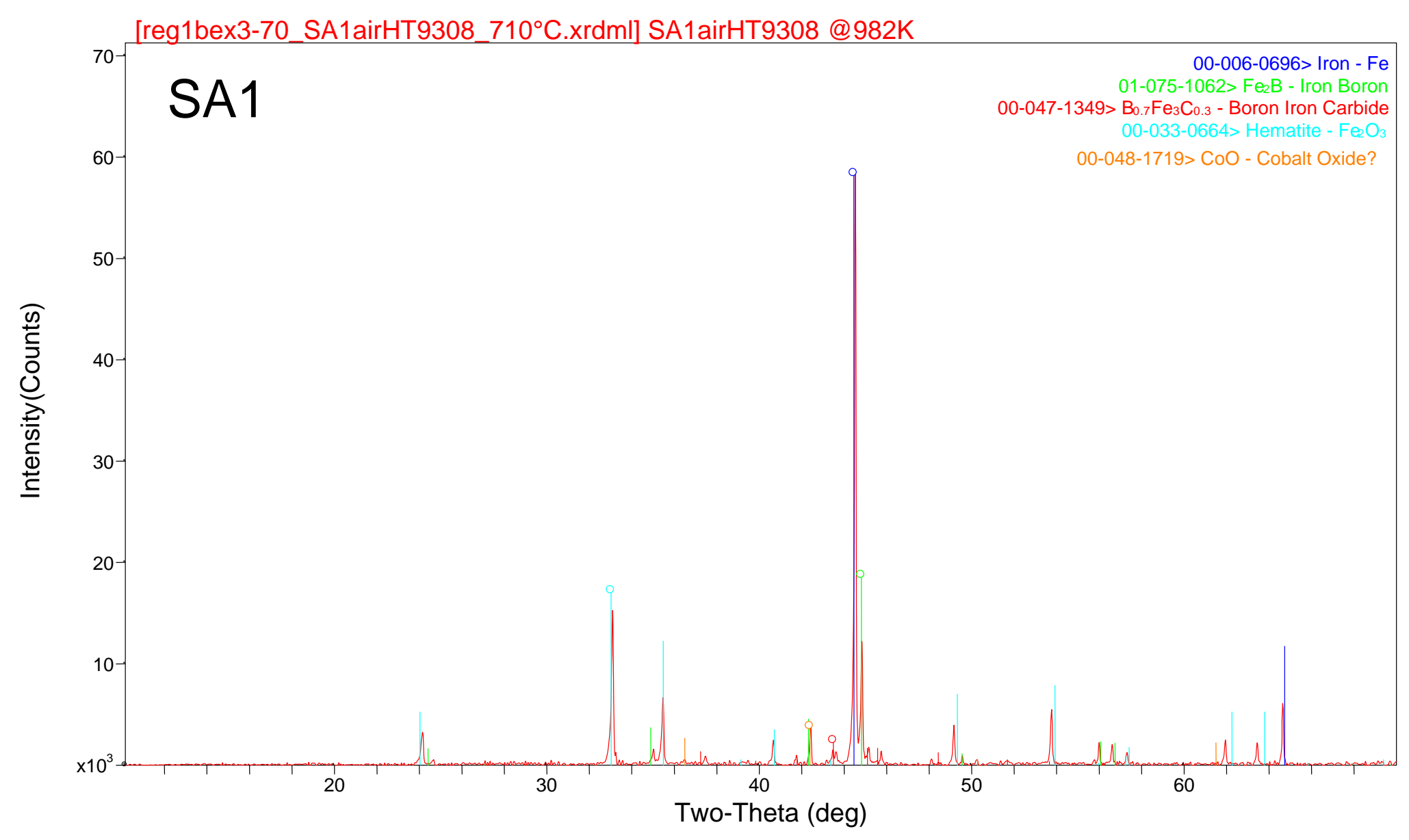

Figure 108. HTXRD scan of $\mathrm{SA1}$ at $650^{\circ} \mathrm{C}$ in air. 


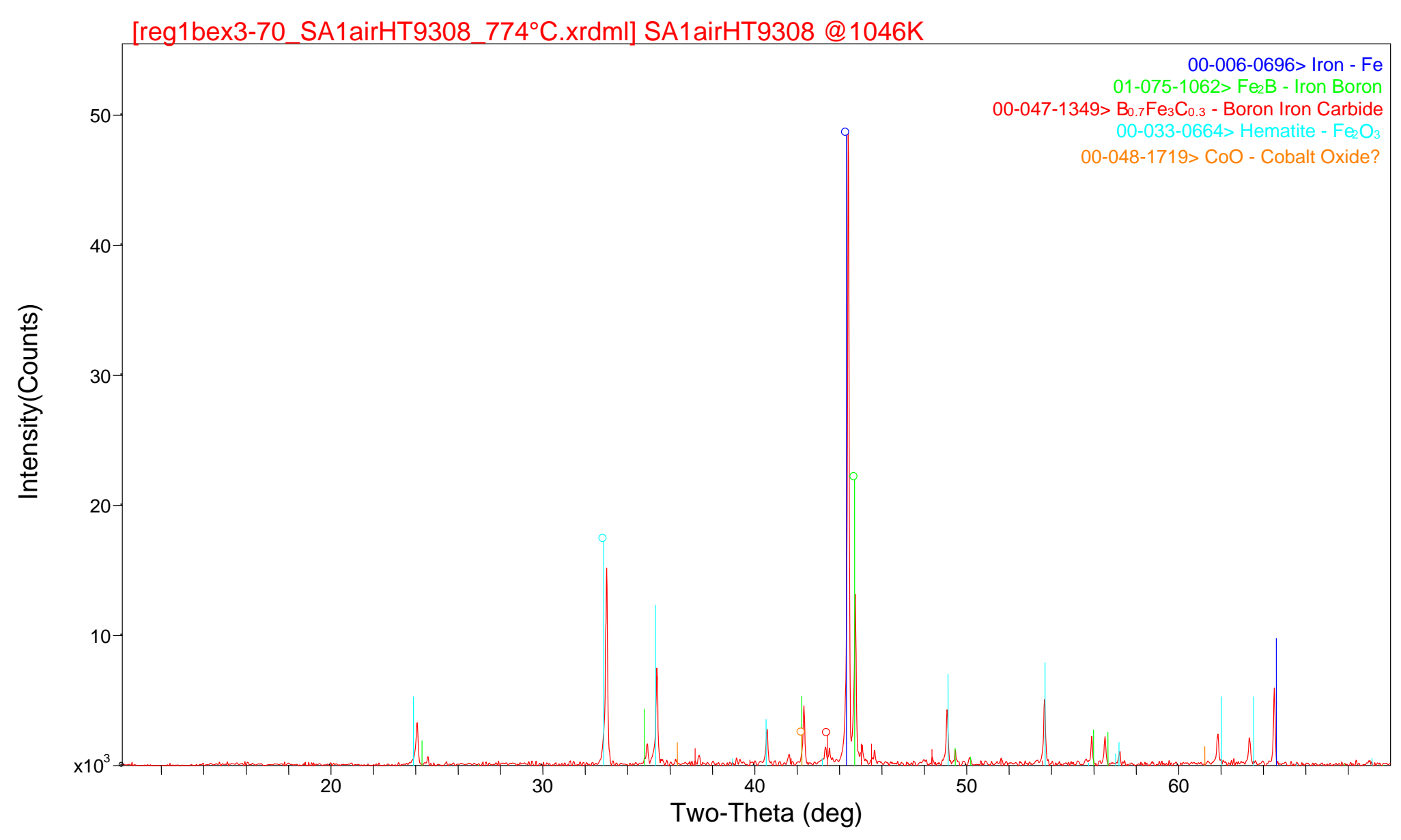

Figure 109. HTXRD scan of SA1 at $710^{\circ} \mathrm{C}$ in air. 


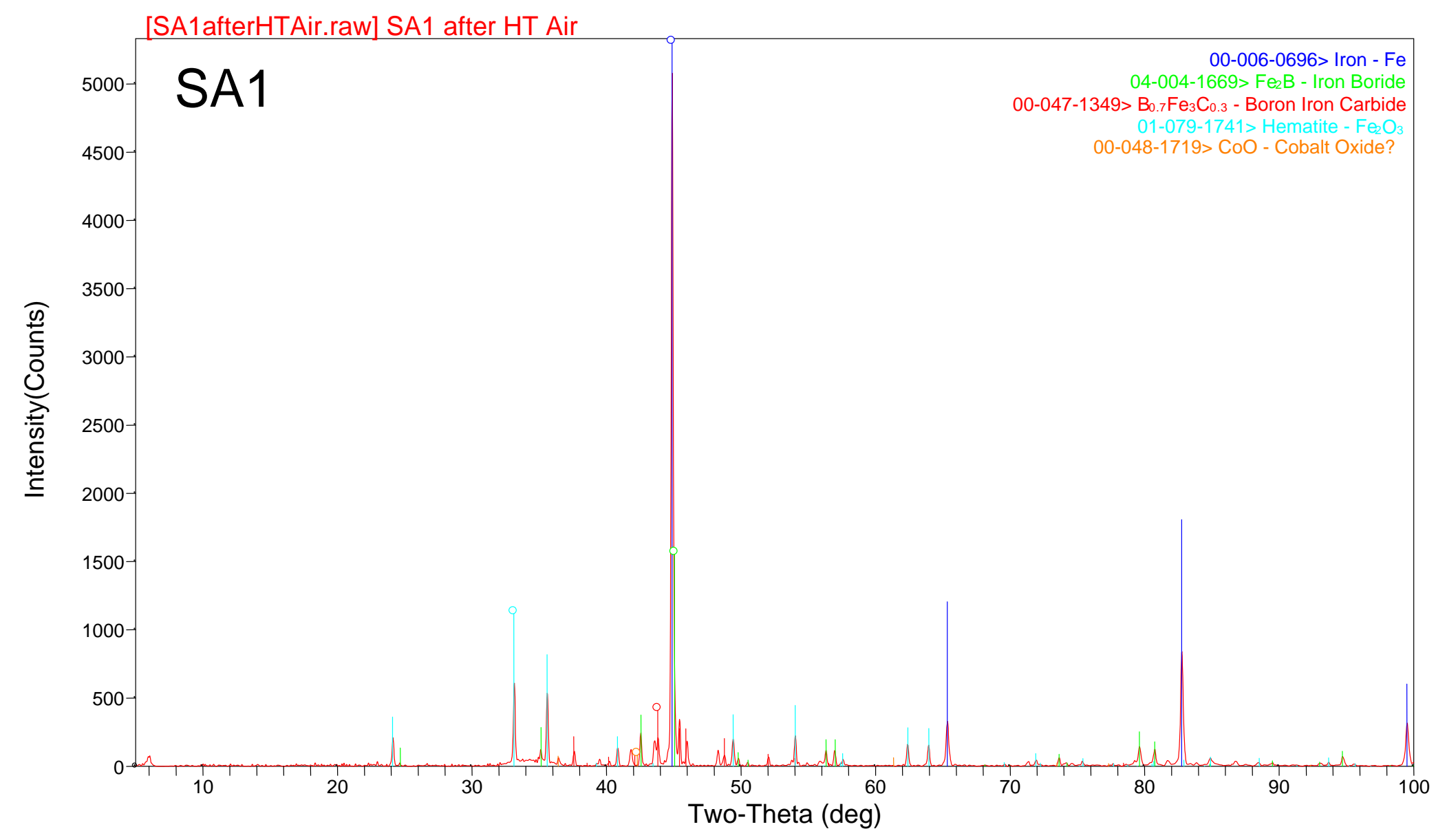

Figure 110. XRD scan of SA1 HTXRD residue in air. 
SRNS-STI-2008-00133

Revision 1 